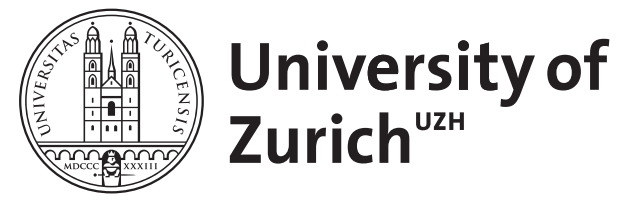

Zurich Open Repository and Archive

University of Zurich

University Library

Strickhofstrasse 39

CH-8057 Zurich

www.zora.uzh.ch

Year: 1980

\title{
Das Böcklein in der Milch seiner Mutter und Verwandtes: Im Lichte eines
} altorientalischen Bildmotivs

\author{
Keel, Othmar
}

Posted at the Zurich Open Repository and Archive, University of Zurich

ZORA URL: https://doi.org/10.5167/uzh-138423

Monograph

Published Version

Originally published at:

Keel, Othmar (1980). Das Böcklein in der Milch seiner Mutter und Verwandtes: Im Lichte eines altorientalischen Bildmotivs. Freiburg, Switzerland / Göttingen, Germany: Universitätsverlag / Vandenhoeck Ruprecht. 
KEEL · DAS BÖCKLEIN 


\section{ORBIS BIBLICUS ET ORIENTALIS}

Im Auftrag des Biblischen Institutes der Universität

Freiburg Schweiz

und des Seminars für biblische Zeitgeschichte

der Universität Münster

herausgegeben von

Othmar Keel, unter Mitarbeit von Bernard Trémel und Erich Zenger

Zu den Autoren:

Othmar Keel (1937) studierte Theologie in Freiburg/Schweiz und Rom, Bibelwissenschaft in Jerusalem und Zürich, altorientalische Kunstgeschichte in Zürich und Chicago und auf ausgedehnten Reisen durch den Nahen Osten. Er ist seit 1969 Professor für alttestamentliche Exegese an der Theol. Fakultät der Universität Freiburg/Schweiz. Othmar Keel ist verheiratet und Vater zweier Kinder. Von ihm sind nebst einer Reihe von Aufsätzen in Fachzeitschriften u. a. folgende Bücher erschienen: 1969 seine Dissertation «Feinde und Gottesleugner. Studien zum Image der Widersacher in den Individualpsalmen» (SBM 7, Stuttgart), 1972 «Die Welt der altorientalischen Bildsymbolik und das Alte Testament» (Zürich/Neukirchen, 3. Aufl. 1980), 1974 «Die Weisheit spielt vor Gott. Ein ikonographischer Beitrag zur Deutung von Sprüche 8,30f.» (Freiburg, Schweiz/Göttingen), 1974 «Wirkmächtige Siegeszeichen im Alten Testament» (OBO 5, Freiburg, Schweiz/Göttingen), 1977 «Jahwe-Visionen und Siegelkunst. Eine neue Deutung der Majestätsschilderungen in Jes 6, Ez 1 und 10 und Sach 4» (SBS 84/85, Stuttgart), 1977 «Vögel als Boten» (OBO 14, Freiburg, Schweiz/Göttingen), 1978 «Jahwes Entgegnung an Ijob. Eine Deutung von Ijob 38-41 vor dem Hintergrund der zeitgenössischen Bildkunst» (FRLANT 121, Göttingen). 


\section{ORBIS BIBLICUS ET ORIENTALIS 33}

\section{OTHMAR KEEL}

\section{DAS BÖCKLEIN IN \\ DER MILCH SEINER MUTTER UND VERWANDTES}

Im Lichte eines altorientalischen Bildmotivs

UNIVERSITÄTSVELAG FREIBURG SCHWEIZ VANDENHOECK \& RUPRECHT GÖTTINGEN 1980 
CIP-Kurztitelaufnabme der Deutschen Bibliothek

Keel, Othmar:

Das Böcklein in der Milch seiner Mutter und Verwandtes im Lichte eines altorientalischen Bildmotivs /

Othmar Keel.

Freiburg (Schweiz): Universitätsverlag

Göttingen: Vandenhoeck und Ruprecht, 1980.

(Orbis biblicus et orientalis; 33 )

ISBN 3-7278-0235-9 (Universitätsverlag)

ISBN 3-525-53340-3 (Vandenhoeck und Ruprecht)

Veröffentlicht mit der Unterstützung des Hochschulrates der Universität Freiburg Schweiz

(c) 1980 by Universitätsverlag Freiburg Schweiz Paulusdruckerei Freiburg Schweiz

Digitalisat erstellt durch Florian Lippke, Departement für Biblische Studien, Universität Freiburg Schweiz 
Für mein Patenkind LAURA-CHRIST INA und für seine Mutter 



\section{INHALTSVERZEICHNIS}

\section{Einführung}

Die einschlägigen Texte

1. Der Talmud und die Verbote, die Mutter- und Jungtier betreffen

2. Die Interpretation der Verbote durch das hellenistische Judentum und ihr Nachwirken bis in die Neuzeit

a. Das hellenistische Judentum

b. Welchem Missbrauch soll das "humanitär" verstandene Gebot begegnen ?

c. Die "humanitäre" Deutung im Mittelalter und in der Neuzeit

3. Die kultpolemische Deutung der Verbote

a. Zur Entstehung der kultpolemischen Deutung

b. Die kultpolemische Deutung im 20. Jahrhundert

4. Der literarische Kontext der biblischen Vorschriften und dessen Konsequenz für die Deutung

5. Der zeitgenössiche Horizont der biblischen Vorschriften

a. Der Sinn für das besondere Verhältnis zwischen Muttertier und Jungem im Alten Orient

b. Das säugende Muttertier als Symbol des Segens und der sorgenden Liebe der Gottheit

Zusammenfassung

Tafeln

Quellen zu den Abbildungen 

EINFUEHRUNG

Das Verbot, ein Böcklein in der Milch seiner Mutter zu kochen, hat für die rituell reine (koschere) jüdische küche weit mehr Konsequenzen gehabt als das viel bekanntere Verbot, Schweinefleisch zu essen. Sein extensives Verständnis hat zur Fcrderung geführt, die Fleisch- und Michküche zu trennen (verschiedene Pfannen etc.) und Gerichte mit Fleisch, bezw. Milch, nicht im Rahmen e $i \mathrm{n}$ e $r$ Mahlzeit zu servieren. Viele Israel-Reisende haben mit diesen Konsequenzen - oft kopfschüttelnd - Bekanntschaft gemacht, ohne ihre biblische Wurzel zu ahnen. $\mathrm{zu}$ einer eingehenderen Beschäftigung mit dieser haben mich aber nicht so sehr ihre einschneidenden Konsequenzen, sondern die Beschäftigung mit der altisraelitischen Glyptik geführt.

Die Bedeutung der säugenden Capride für die ältere israelitische Siegelkunst liess in mir Zweifel am heute vorherrschenden Verständnis der Verbote als Abwehrmassnahmen gegen kanaanäische Kultbräuche aufkommen. Diese Zweifel wurden durch die neuere Erkenntnis verstärkt, dass der für einen solchen Kultbrauch angeführte Beleg aus dem ugaritischen Text "Schachar und Schalim" offensichtlich keiner ist.

Einladungen $\mathrm{zu}$ Gastvorlesungen in Graz und Innsbruck durch Prof. Johannes MARBOCK und Prof Arnold GAMPER gaben mir Gelegenheit, die mühsame Arbeit am Führer für ein paar Wochen loszuwerden und mich dem Thema etwas eingehender zu widmen. Wichtige Literaturhinweise verdanke ich Frau Dr. Elisabeth STAEHELIN, Basel, meinen Kollegen Dominique BARTHELEMY und Georges SCHELBERT und meinem Assistenten Urs WINTER. Das exegetische Material hat zu einem guten Teil Rolf WIDMER im Rahmen einer Zwischenexamens-Arbeit zusammengetragen. Mit wohltuender Selbstverständlichkeit und 
mit allmählich erstaunlicher Effizienz haben meine Frau Hildi KEEL-LEU die Zeichnungen und die Institutssekretärin Frau Bernadette SCHACHER die Offsetvorlagen angefertigt.

Was mich an dieser Arbeit faszinierte, ist einmal mehr die Feststellung : Die Traditionen Israels bedeuten nicht nur Absonderung von seiner Umwelt, nicht nur Segen, der von ihm zu den völkern ausstrahlt. Israel hat seinerseits viel Licht aus dieser Umwelt aufgenommen. Es hat wie eine Linse verstreute Strahlen zu einem einzigen wirksamen strahl gebündelt. Und in diesen Strahl ist - auf dem Umweg eigentümlicher Brechungen - auch etwas vom Erbarmen (רזמים) der grossen altorientalischen Muttergottheiten eingegangen.

Ebenso unbedacht und dogmatisch, wie früher das Glück der Mutter-Kind-Beziehung idealisiert wurde, wird es heute problematisiert. Die kleine Arbeit ist meinem jüngsten Patenkind LAURA-CHRISTINA und seiner Mutter gewidmet, die an diesem Trend vorbei ihre Mutter-Kind-Beziehung unbekümmert geniessen und eine zeitlos lebenslustige Vision einmal mehr Wirklichkeit sein lassen.

Fribourg, Mai 1980 
DIE EINSCHLAEGIGEN TEXTE

Ex 22,28b.29 (Bundesbuch)

בכור בניך תתן-לי: כן-תעשה לשרך לצאנך שבעת ימים יהוה עם-אמו

בירם השמיניני תתנר-ליריורי

"Den Erstgeborenen unter deinen söhnen sollst du mir geben. Ebenso sollst du verfahren bei deinen Rindern, bei deinem Kleinvieh; sieben Tage lang soll es (das Erstgeborene) bei seiner Mutter bleiben, am achten Tage sollst du es mir geben."

Lev 22,27 (Heiligkeitsgesetz)

שרר אר-כשב אר-עז כי ירלי ליד רהיה שבעת ימים תחת אמר רמירם השמיני

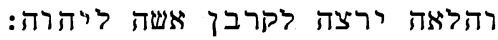

"Wenn ein Rind oder ein Schaf oder eine Ziege geboren wird, so soll das Tier sieben Tage lang unter seiner Mutter bleiben; vom achten Tage an und weiterhin findet es als Feueropferdarbringung für Jahwe Wohlgefallen."

$\underline{\text { Ex 23,19b (Bundesbuch) }}$

לא-תבשל גדי בחלב אמר:

"Du sollst nicht das Zicklein in der Milch seiner Mutter kochen!"

Ex 34,26b (Privilegrecht Jahwes)

לא-תבשל גדי בחלב אמר:

"Du sollst nicht das Zicklein in der Milch seiner Mutter kochen !"

Dtn 14,21c (Deuteronomisches Gesetz)

לא-תבשל גדי בחלב אמר:

"Du sollst nicht das Zicklein in der Milch seiner Mutter kochen !" 
Lev 22,28 (Heiiigkeitsgesetz)

רשרר אר-שה אתר ראת-בנר לא תשחטר בירם אחד:

"Ein Rind oder ein Stück Kleinvieh dürft ihr nicht an ein und demselben Tage zusammen mit seinem Jungen schlachten !"

\section{Dtn 22,6f (Deuteronomisches Gesetz)}

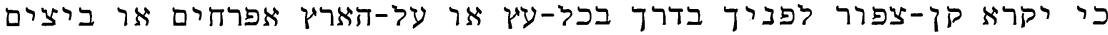

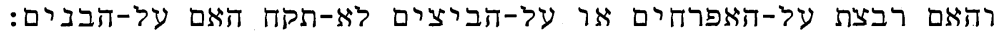

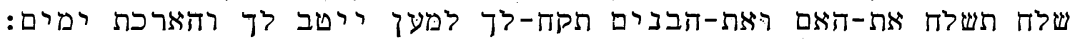

"Wenn dir unterwegs zufällig auf irgendeinem Baum oder auf dem Boden ein Vogelnest zu Gesicht kommt mit Jungen oder Eiern, und die Mutter sitzt auf den Jungen oder Eiern, so darfst du nicht die Mutter über den Jungen fangen. Lass die Mutter fliegen; die Jungen magst du fangen; dass es dir wohlergehe und deine Lebenstage lange währen."

(Uebersetzungen nach M.NOTH und G.von RAD im ATD) 
1. Der Talmud und die Verbote, die Mutter- und Jungtier betreffen

MOSCHE BEN MAIMON (1135-1204 n.Chr.) unterscheidet in seinem "Führer der Unschlüssigen" zwischen denen, denen der blosse Wille Gottes als Grundlage des Gesetzes genügt und Leuten wie ihm selber, die einen Zusammenhang zwischen der umfassenden Weisheit Gottes und den einzelnen Vorschriften des Gesetzes suchen $^{1}$. Die Rabbinen, die sich mit unseren Geboten befassten und in der Mischna und der Gemara, d.h. im Talmud, zu Worte kommen, gehören zur ersten Gruppe. Sie haben die Gültigkeit und Reichweite unserer Gebote, nicht aber deren Sinn zu bestimmen versucht.

Zum Verbot, ein Böcklein in der Milch seiner Mutter zu kochen (Ex 23,19 Par.) statuiert Mischna Chullin VIII,4 : "Fleisch von einem reinen Vieh (zusammen) mit Milch von einem reinen Vieh zu kochen oder zu geniessen, ist verboten". Die Gemara (fol. 113b; vgl. auch fol. 114a) begründet das damit, dass unter "Böckchen" (גדי) nur dort, wo es - wie in Gen 38,20 - ausdrücklich als Ziegenböckchen qualifiziert wird, ein solches zu verstehen sei. Ueberall sonst sei auch das Junge von Kuh und Schaf darunter $\mathrm{zu}$ verstehen ${ }^{2}$.

M. HARAN gibt zwar zu, dass גדי "Ziegenböckchen" heisse. Da es aber die üblichste Fleischnahrung dargestellt hätte, würde es in Ex 23,19 Par. tatsächlich paradigmatisch für alle geschlachteten Jungtiere stehen ${ }^{3}$. Die Gemara versucht denn auch im ein-

1 III 48; ed. MUNK III 400; vgl. auch III 26 und 31; ed. MUNK III 203-210, $247 \mathrm{f}$.

2 GOLDSCHMIDT, Der babylonische Talmud VIII 1165f; vgl. weiter ebd. $1168 f$.

3 JJS 30 (1979) 31-33. 
zelnen mit der ganzen Kunst rabbinischer Exegese das sehr weit gefasste Verbot zu begründen. So wird etwa die Frage aufgeworfen, warum man das Junge (der ziege) nicht in der Milch seiner grösseren Schwester (gemeint ist die Kuh) kochen dürfe; es werde doch nur die Milch seiner Mutter verboten. Antwort : "Dies ist (durch einen Schluss) vom Leichteren auf das Schwerere $\mathrm{zu}$ folgern : wenn mit der (Milch) der Mutter, init der es zusammen zur Verzehntung (Lev 27,32 ) in den stall kommt, das Kochen verboten ist, um wieviel mehr ist mit der einer (grösseren) Schwester, mit der es nicht zusammen zur Verzehntung in den stall kommt, das Kochen verboten" 4 . Die Logik dieser und ähnlicher Argumentationen ist wohl nur von dem $\mathrm{zu}$ erreichenden $\mathrm{ziel}$ her $\mathrm{zu}$ verstehen, das extensive Verständnis des Verbots zu legitimieren. D. DAUBE vermutet zwar, das Verbot, ein Böcklein in der Milch seiner Mutter zu kochen, sei ursprünglich umfassender gewesen, es wäre sonst schwierig zu verstehen, wie die Vorschrift des AT in solchem Masse hätte ausgeweitet werden können ${ }^{5}$. Aber wie es dann vom allgemeinen Verbot, Fleisch in Milch zu kochen, zum präzisen Verbot, ein Böcklein in der Milch seiner Mutter zu kochen, gekommen wäre, kann DAUBE nicht erklären und ist wohl auch nicht zu erklären. Hingegen ist die Tendenz, das ursprünglich eng gefasste Verbot auszuweiten, auch in nachtalmudischer zeit noch wirksam gewesen, insofern es auch auf das Fleisch von Geflügel ausgedehnt wurde ${ }^{6}$.

Nebst dem Gültigkeitsbereich diskutiert der Talmud auch die Sanktionen, die den Uebertreter des Verbots treffen sollen. Es wird diskutiert, ob nur der, der Fleisch in Milch kocht, oder auch der, der das so gekochte Fleisch isst, Geisselhiebe bekommen soll (fol. 114a) ${ }^{7}$.

4 bChullin fol. 114a; GOLDSCHMIDT, Der babylonische Talmud VIII 1168.

5 JThS 37 (1936) $290 f$.

6 Ebd. 290.

7 GOLDSCHMIDT, Der babylonische Talmud VIII $1167 f$. 
So ausführlich sich der Talmud mit dem Gebot beschäftigt ${ }^{8}$, so gibt es bei den Rabbinen, soweit ich sehe, doch keinerlei Diskussion über den Sinn des Verbots. Das Verbot, Fleisch in Milch zu kochen, wird vielmehr geradezu als Paradebeispiel für ein Verbot genannt, dessen Bedeutung unbekannt ist und dessen Gründe zu erfahren zu den Freuden der künftigen Welt gehört. "Und Gott wird dasitzen und ihnen die Gründe der Tora (טעמי התורה) enthüllen, weshalb er uns das Schwein und Blut und Fett und Fleisch in Milch usw. verboten hat" ${ }^{9}$.

Aehnlich wie Ex 23,19 Par. werden auch die Verbote behandelt, ein Muttertier und sein Junges am gleichen Tag $\mathrm{zu}$ schlachten (Lev 22, 28) ${ }^{10}$, ein Neugeborenes vor dem 8. Tag von seiner Mutter zu trennen (Ex 22,29; Lev 22,27$)^{11}$ oder einen Vogel und seine Brut gleichzeitig $z u$ behändigen (Dtn $22,6 f)^{12}$. Auf dieses letzte Verbot bezieht sich eine Bemerkung im Mischnatraktat Berakot : "Wer (beim Gebet) sagt : 'Auf ein Vogelnest reicht dein Erbarmen'..., den heisst man schweigen"13. Zur Begründung dieser Verordnung sagt Rabbi JOSE BEN ZEBIDA (um 350 n.Chr.) : "Weil er (der so betet) die Gebote (מדרתיר) des Heiligen, gepriesen sei er, zu Barmherzigkeiten (רחמים) macht, während sie ja Verordnungen (גזרות) sind"14. Der Tora sollte als Gesetz souveräner göttlicher Entscheidungen und nicht aus (vermeintlicher?) Einsicht in ihr Wesen gehorcht werden. Das objekt des göttlichen Willens

8 Ebd. 1165-1178.

9 STRACK/BILLERBECK, Kommentar zum Neuen Testament I 660; IV $1153 f$.

10 bChullin 77b-83b; GOLDSCHMIDT, Der babylonische Talmud VIII 1051-1069.

11 bChullin fol.81a; GOLDSCHMIDT, Der babylonische Talmud VIII 1061.

12 bChullin 138b-142; GOLDSCHMIDT, Der babylonische Talmud VIII 1258-1276.

13 Mischna Berakot V 3a; bBerakot fol. 33b; GOLDSCHMIDT, Der babylonische Talmud I 126.

14 Ebd. 
sollte genau bestimmt und die Durchsetzung dieses Willens urgiert, nicht aber sein Sinn erforscht werden. Der bekämpfte Satz "auf ein Vogelnest reicht dein Erbarmen" zeigt aber, dass der Gedanke vom Erbarmen Gottes, der sich in diesen Geboten ausdrücke, im nicht-offiziellen palästinensischen Judentum nicht unbekannt war. Für Jesus und seine Zuhörer ist es offensichtlich eine anerkannte Wahrheit, dass der Vater im Himmel auch für die vögel sorgt (Mt 6,26=Lk 12,24; vgl. Ps 104,21; 147,9; Ijob 38,39-41) und kein Spatz ohne sein Wissen zu Boden fällt (Mt 10,29=Lk 12,6 ). Dem Städter und Rabbinenschüler Paulus erscheint es hingegen ganz unwahrscheinlich, dass Gott sich um Rinder kümmern solle (1 Kor 9,9).

2. Die Interpretation der Verbote durch das hellenistische Judentum und ihr Nachwirken bis in die Neuzeit

Während das palästinisch-rabbinische Judentum die Orthopraxie raffinierte und die fides quaerens intellectum gelegentlich geradezu grundsätzlich zurückwies ${ }^{15}$, hat das hellenistische Judentum sich nicht mit dieser reinen Gehorsamshaltung begnügt.

\section{a. Das hellenistische Judentum}

Unter dem Ansturm der Fragen und Kritiken aus der heidnischen Umwelt und von missionarischem Eifer erfüllt, versuchte das hellenistische Judentum die einzelnen Gesetze allgemein menschlich verständlich und einsichtig $\mathrm{zu}$ machen. In dieser Perspektive hat PHILO VON ALEXANDRIEN (ca. $20 \mathrm{v}$. $-45 \mathrm{n} . \mathrm{Chr}$ ) unsere Verbote in seinem Traktat "De virtutibus" (\$\$125-144) in einen grösseren Zusammenhang gestellt und ausführlich begründet.

15 Vgl. dazu STRACK/BILLERBECK, Kommentar zum Neuen Testament I $660,861,1153 f$. 
Nachdem PHILO das hohe Niveau der Gesetze, die das zwischenmenschliche Leben betreffen, dargelegt hat, fährt er fort : "Aber er (scl. Mose als Gesetzgeber) dehnt das Masshalten und

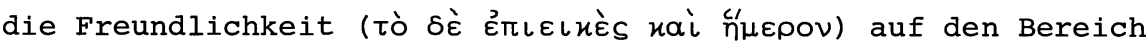
der unvernünftigen Lebewesen aus und sichert auch ihnen einen Nutzen (vom Gesetz) wie von einer wohltuenden Quelle. Er gebietet tatsächlich im Hinblick auf die Haustiere, die Schafe, die Ziegen und die Rinder, sich davon zurückzuhalten, unmittelbar nach ihrer Geburt aus ihnen Nutzen zu ziehen, sei es, dass man sie als Speise verwendet, sei es, dass man sie unter dem Vorwand, sie zu opfern, wegnimmt"16. PHILO bezieht sich hier auf Ex 22,29 und Lev 22,27 und deutet diese Vorschrift wie folgt : "Er (scl. Mose) sieht darin den Ausdruck einer grausamen Seele, (nämlich) auf der Lauer zu liegen, um die Neugeborenen sofort von ihrer Mutter zu trennen, nur um den Bauch zu befriedigen; ja noch mehr : (er sieht darin) den schändlichen Ausdruck einer abnormen und verkommenen Seele (Ex 22,29; Lev 22 , 27)" 17 . PHILO fährt dann fort, während einer Hungersnot wäre ein solches Verhalten verzeihlich. Aber in normalen Zeiten dürfe man sich keine solchen perversen Gedanken gestatten ${ }^{18}$. "Und was gäbe es Brutaleres als den Geburtsschmerzen von aussen her noch zusätzliche Schmerzen hinzuzufügen, indem man die Jungen sofort von den Muttertieren trennt. Denn wenn man sie ihnen wegnimmt, müssen sie in grosse Trauer geraten, aufgrund der natürlichen mütterlichen Instinkte, die unmittelbar nach dem Werfen besonders stark sind"19. Man könnte auf den ersten Blick PHILOS Verständnis für die Mutterliebe der Tiere für bloss sentimental halten. Aber das ist nicht der Fall. Sie beruht auf

16 De virtutibus $\$ 125 f$; ed. WENDLAND V 303.

17 Ebd. \$127; ed. WENDLAND V $303 f$.

18 Ebd.

19 Ebd. $\$ 128$; ed. WENDLAND V 304. 
einer soliden Kenntnis des Verhaltens der Tiere und bestimmter biologischer Gegebenheiten. Denn er fährt fort : "Zu diesem Zeitpunkt sind die Euter eine wirkliche Quelle, aber es hat (wenn man sie wegnimmt) keine Jungen um zu saugen. Da die Milch keinen Ausgang mehr findet, werden die Zitzen hart und beschwert; durch das Gewicht der im Innern geronnenen Milch beginnen sie (die Mutter) zu schmerzen"20. "'Lass der Mutter ihr Junges', sagt er (scl. der Gesetzgeber), ' wenn nicht für immer, dann wenigstens für die ersten sieben Tage, damit sie es mit ihrer Milch nähre und die Quellen nicht unnütz mache, die die Natur ( $(\hat{n}$ yúoıs) in den Eutern fliessen liess, indem man die zweite der Wohltaten unterdrückt, die durch die tiefe Vorsehung vorbereitet wurden, durch die sie mit ewiger und vollkommener Weisheit auf die ferne Folge der Ereignisse blickt; die erste dieser Wohltaten ist die Gabe des Lebens, durch die das, was nicht existierte, ins Dasein gebracht wird, die zweite ist das Fliessen der Milch'"2l. PHILO singt dann einen Hymnus auf die Milch ${ }^{22}$. Interessant ist, wie das Gebot von Ex 22,29 Par. mit dem Respekt vor einem Lebensablauf begründet wird, der früher oder später zwar doch durchschnitten werden darf, aber nicht in diesem entscheidenden Moment, wo der zusammenhang besonders deutlich ist. Nach einem kurzen, aber heftigen Ausfall gegen das weitverbreitete Aussetzen und Töten der neugeborenen Kinder, das angesichts des Schutzes, den der Gesetzgeber den neugeborenen Tieren angedeihen lässt, als besonders verwerflich erscheint ${ }^{23}$, kehrt er zu den Tieren zurück.

"Im Bestreben, unter allen möglichen Formen die Samen der Freundlichkeit und des Masshaltens (

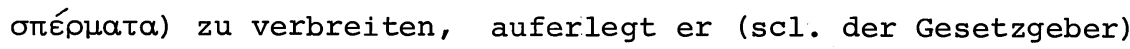

20 Ebd.

21 Ebd. §129f; ed. WENDLAND V $304 f$.

22 Ebd. §130; ed. WENDLAND V $304 \mathrm{f}$.

23 Ebd. \$131-133; ed. WENDLAND V 305f. 
eine andere Vorschrift, die den vorausgehenden nahesteht, indem er untersagt, am gleichen Tag das Muttertier und sein Junges zu opfern (Lev 22,28); denn wenn man sie opfern muss, dann soll es wenigstens $\mathrm{zu}$ verschiedenen Zeiten geschehen; es ist der Gipfel der Barbarei, am gleichen Tag jenes, das das Leben gegeben und jenes, das es empfangen hat, zu töten" ${ }^{24}$. Nachdem er ein solches Vorgehen mit den schärfsten Worten verurteilt hat, fährt PHILO fort : "Beachte aber auch, dass das Gesetz alle trächtigen Tiere vom heiligen Bereich fern hält und nicht gestattet, dass sie geopfert werden, bis sie geworfen haben" ${ }^{25}$. Ein solches Gesetz ist weder im AT noch - soweit ich sehe - in der rabbinischen Literatur überliefert. Im AT wird nur das Aufschlitzen von Schwangeren als Greueltat einer verrohten Soldateska mit besonderer Heftigkeit angeprangert ${ }^{26}$. Ist es denkbar, dass PHILO diese Vorschrift einfach erfunden hat ? Es scheint zunächst nicht sehr wahrscheinlich. Die Art, wie er sie zum Ruhm der jüdischen Gesetze benützt, könnte dies aber doch als nicht ganz abwegig erscheinen lassen. Er verweist auf ein in der antiken Welt vielfach bezeugtes Gesetz, nämlich das Verbot, schwangere Frauen hinzurichten, bevor sie geboren hatten 27 . "Diese ihre Verordnungen", so sagt er, "gelten für menschliche Wesen, aber Mose erhob sich zu weiterer Höhe, indem er die Pflicht $z u$ anständiger Behandlung sogar auf unvernünftige Tiere ausdehnte..."28. Damit sollte dann aber doch

24 Ebd. $\$ 134$; ed. WENDLAND V $306 \mathrm{f}$.

25 Ebd. \$137; ed. WENDLAND V $307 f$.

26 Vgl. 2 Kön 8,12; 15,16; Hos 13,16; Am 1,13; vgl. dazu auch Ilias VI, 57f, ed. ALLEN/MONRO I 6.57f; SCHMOEKEL, Ur, Assur und Babylon 114 .

27 DIODOR SICULUS (I 77; ed. VOGEL I 130-132) bezeichnet es als ägyptisches Gesetz; AELIAN (Varia Historia V 18; ed. HERCHER I 76) als ein athenisches; und PLUTARCH (De sera numinis vindicta 7; BERNARDAKIS, Moralia III $428 \mathrm{ff}$ ) als ein ägyptisches, das die Griechen kopiert hätten.

28 PHILO, De virtutibus $\S 140$; ed. WENDLAND V 309. 
wieder insinuiert werden, wieviel rücksichtsvoller man erst Menschen gegenüber $\mathrm{zu}$ sein habe; die Vorwürfe der Misanthropie an die Adresse der Juden seien deshalb völlig haltlos. Dann kehrt er zu seinem eigentlichen Thema zurück : "Mose hat verboten, ein Lamm oder Böcklein oder eine ähnliche Art von Tieren von seiner Mutter wegzunehmen, bevor es entwöhnt ist. Er hat verboten, ein Muttertier und sein Junges am gleichen Tag zu töten. Er geht noch weiter, wenn er sagt : 'Du sollst ein Böcklein nicht in der Milch seiner Mutter kochen'"29. Wenn die Natur, um das Ueberleben der Art besorgt, die Milch fliessen lässt, dann ist es abnorm, wenn die Unmässigkeit der Menschen soweit geht, dass sie sich der Quelle des Lebens genau dazu bedient, den körper zu zerstören, der überleben sollte. "Wenn einer wirklich Fleisch in Milch kochen will, dann soll er es ohne Grausamkeit machen und indem er alle Gottlosigkeit vermeidet. Ueberall sind Herden von unzählbaren Tieren, die jeden Tag gemolken werden..., und da Milch so reichlich vorhanden ist, verrät derjenige, der das Fleisch eines Lammes, eines Böckleins oder sonst irgendeines Jungtiers in der Milch seiner Mutter kocht, sich als ein grausam brutaler Charakter, dem das wesentlichste Gefühl, das der Vernunft am nächsten steht, fehlt, nämlich das Mitleid (to

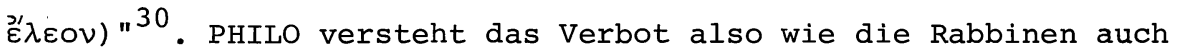
im Hinblick auf alle Jungtiere, nicht nur auf die (Ziegen-) Böcklein. Im Gegensatz zu den Rabbinen versteht er es aber nicht als Verbot, Fleisch in irgendwelcher Milch zu kochen, oder gar Milch- und Fleischspeisen gleichzeitig zu geniessen.

PHILOS Argumentation ist recht komplex und mit dem Stichwort "humanitär" nicht zureichend charakterisiert. Mindestens drei Aspekte sind zu beachten. Einmal sieht er den Sinn der Gebote im Respekt vor der vollkommenen Weisheit der Natur bei ihrer Sorge um die Weitergabe des Lebens ${ }^{31}$. Dann fasst er die Tiere

29 Ebd. \$142; ed. WENDLAND V 309f.

30 Ebd. $\$ 144$; ed. WENDLAND V 310.

31 Besonders \$129f; ed. WENDLAND V $304 \mathrm{f}$. 
um ihrer selbst willen ins Auge, ihre Instinkte, ihre Schmerzen, die willkürlich $\mathrm{zu}$ verletzen verabscheuenswerte Grausamkeit verrät ${ }^{32}$. Und endlich soll, was PHILO besonders betont, der zweite Aspekt die Grundlage vermehrter Menschenfreundlichkeit sein, denn wenn der Gesetzgeber schon den vernunftlosen Tieren gegenüber solche Rücksichtnahme verlangt, wieviel mehr dann gegenüber den Mitmenschen. Einzig dieser dritte Aspekt scheint mir mit Recht als "humanitär" bezeichnet werden zu können.

PHILO steht mit seiner Betrachtungsweise im hellenistischen Judentum nicht isoliert da. FLAVIUS JOSEPHUS erwähnt in seiner $\mathrm{Zu}-$ sammenfassung der jüdischen Gesetze (Gesetzesepitome) in der apologetischen Schrift "Contra Apionem" (um 95 n.Chr.) die von PHILO aufgeführten Gebote zwar nicht. Aber auch er vertritt die Ansicht : "So vollkommen lehrte er (scl. der Gesetzgeber Mose)

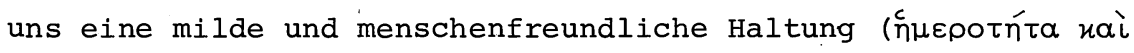
$\varphi \iota \lambda \alpha \nu \vartheta \rho \omega \pi(\alpha \nu)$, dass er nicht einmal die vernunftlosen Tiere vernachlässigte" ${ }^{33}$. Neben anderen Beispielen führt er an : "Er schrieb vor, den Jungvögeln die Eltern nicht wegzunehmen" ${ }^{34}$. In der von EUSEBIUS überlieferten Gesetzesepitome des PHILO, in den Hypothetika, erwähnt schon dieser unter den kleinen Dingen, mit denen sich der Gesetzgeber beschäftigt habe, die Vogelbrut, die im Nest zu zerstören er verboten habe ${ }^{35}$.

Auch PSEUDOPHOKYLIDES, der wohl noch später anzusetzen ist als JOSEPHUS, hat dieses Verbot in seine Sentenzensammlung aufgenommen : "Nimm nicht aus einem Nest die vögel insgesamt"36. Daneben stellt er die Sentenz, die sich ähnlich bei JOSEPHUS fin-

32 Besonders $\$ 128$; ed. WENDLAND V 304. PHILO bewegt sich damit auf gut atl Grund; vgl. dazu unten S. $51 f$.

33 II $\$ 213$; ed. NIESE V 86.

34 Ebd.

35 Hypothetika 7,9; in : EUSEBIUS, Praeparatio ev. (ed. MRAS) I 431 .

$36 \mathrm{Z} .84$; ed. YOUNG 102; Uebersetzung : RIESSLER, Altjüdisches Schrifttum 865; vgl. KUECHLER, Weisheitstraditionen 215,225. 
det : "Verschon die Mutter :"37, und begründet dieses Gebot über JOSEPHUS hinaus mit dem Satz : "Damit sie dir aufs neue Junge schenke !"38

Der in diesen Sentenzen geforderte Schutz der Vogelbrut bzw. der Vogelmutter beruht, falls nicht ausserbiblisches Brauchtum eingewirkt hat, auf Dtn 22,6f. (Vgl. den Text S. 12 ).

b. Welchem Misstand soll das "humanitär" verstandene Gebot begegnen ?

In der ausführlichen Darstellung der Gebotsgruppe stellt schon PHILO im Zusammenhang mit der Tötung eines Muttertiers und seines Jungen am gleichen Tag die Frage : "Warum tut dies jemand ? Es muss entweder unter dem Vorwand der Opfer geschehen, oder um den Bauch zufrieden zu stellen" ${ }^{39}$. Letzteres bezeichnet er im folgenden als "Bedürfnisse monströser Fressucht" ( $\tau \tilde{n} s$ Ú

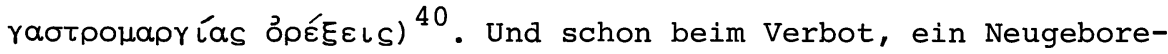
nes vor dem achten Lebenstag seiner Mutter wegzunehmen, bezeichnet er die Lust des Bauches als Movens $\mathrm{zu}$ solch ruchlosem Tun

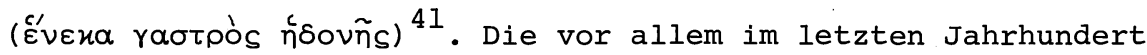
noch ziemlich zahlreichen Interpreten, die ähnlich wie PHILO dem Verbot, ein Böcklein in der Milch seiner Mutter zu kochen, eine "humanitäre" Absicht zugrundelegten, versuchten in der Regel zu demonstrieren, dass es einen weit verbreiteten orientalischen Brauch gegeben habe, Zicklein in Sauermilch zu kochen ${ }^{42}$. Tatsächlich berichten Reisende des 19. und 20. Jhs. oft von Gerichten, in denen das Fleisch junger Ziegen in Sauermilch gekocht wurde.

37 Ebd. Z.85a; ed. YOUNG 102 .

$38 \mathrm{Ebd}$. Z.85b.

39 De virtutibus 135; ed. WENDLAND V 307.

40 Ebd. \$136; ed. WENDLAND V 307.

41 Ebd. \$126; ed. WENDLAND V 303.

42 In frischer Milch kann Fleisch nicht gekocht werden, da diese bekanntlich übersiedet; vgl. dazu HARAN, JJS 30 (1979) $30 f$. 
Nicht selten erinnern sie sich dabei auch an das Verbot, ein Böcklein in der Milch seiner Mutter zu kochen ${ }^{43}$.

Der jüdische Gelehrte ISAAK ABRABANEL (1437-1508 n.Chr.) will diesen Brauch im 15.Jh. auch in Spanien beobachtet haben, besonders bei den jährlichen Zusammenkünften der Hirten, und selbst in England soll Fleisch in Milch gekocht worden sein ${ }^{44}$. Als ältester Beleg für diese Sitte wird in der exegetischen Literatur ein Hinweis bei ABRAHAM BEN MEIR IBN ESRA (1092-1167 n.Chr.) angeführt ${ }^{45}$. IBN ESRA sagt in seinem Kommentar zu Ex 23,19 (kurze Fassung) : "Heute ist es Brauch bei den Ischmaelitern, das Böcklein in Milch zu kochen, und sie sagen, dass dies ein bekömmliches Gericht sei. Verboten ist es als eine Grausamkeit des Herzens, also aus dem gleichen Grund wie es und sein Junges (Hinweis auf Lev 22,28 )" 46 . In der längeren Fassung seines Kommentars versucht IBN ESRA den Brauch der Ischmaeliter (d.h. der Araber) zusätzlich zu erklären : "Kein Mensch isst Fleisch in Milch, denn das ist keine bekömmliche Speise. Zudem braucht das Fleisch viel Zeit zum Kochen, und bei der Milch ist das nicht so. Deshalb ist es bis heute im Lande Ischmaels nicht Brauch, dass jemand Lamm in Milch gekocht isst, denn im Lamm gibt es ja viel Flüssigkeit und ebenso in der Milch, und siehe, das ist schädlich, weswegen man es nicht isst. Und weil im Fleisch des Böckleins keine Flüssigkeit ist..., deshalb kocht man das Böcklein in Milch"47. Sehr präzise sind die Vorstellungen IBN ESRAS nicht, aber immerhin scheint er von diesem Brauch gehört zu haben, und er versucht, ihn kulinarisch-hygienisch $\mathrm{zu}$ verstehen.

43 HARAN, a.a.O. $31 f$ Anm.24, nennt J.L.BURCKHARDT, G.JACOB, L.BAUER, N.GLUECK. Vgl. auch FISCHER, Milk 98, bes. Anm.12.

44 Ed. anonyma, Jerusalem 1964, $217 f$.

45 Z.B. KEIL, Genesis und Exodus 485.

46 Ed. REGGIO, Prag 1940, 68

47 Ed. WEISER, Jerusalem 1977, 161. 
M. HARAN sieht schon in Gen 18,8 einen Hinweis auf dieses Rezept, wo erzählt wird, Abraham hätte seinen Gästen ein Kalb zusammen mit Frisch- und Sauermilch serviert ${ }^{48}$. Aber wenn Abraham hier auch dem rabbinischen Verständnis zuwiderhandelt und Fleisch und Milch zusammen aufträgt, so wird doch nicht gesagt, das Fleisch sei in Milch gekocht worden. Es gibt aber einen sogar noch gut tausend Jahre älteren Hinweis darauf, dass in Milch gekochtes Fleisch eine syrisch-palästinische Spezialität war. In der aus dem 20. Jh.v.Chr. stammenden ägyptischen Sinuhe-Geschichte erzählt der nach Palästina geflohene ägyptische Held, er sei dort sehr ehrenvoll aufgenommen und üppig verpflegt worden. Als Höhepunkt - und wahrscheinlich als typisch für die kanaanäische im Gegensatz zur ägyptischen Küche - nennt er den Umstand : "Milch war in allem, was gekocht wurde (irtt $m p(f) s t n b t) " 49$. Wenn hier auch nicht ausdrücklich Fleisch erwähnt wird, so ist dieses doch wohl in "allem" eingeschlossen, zumal vorher hauptsächlich von Fleisch die Rede war. In Milch gekochtes Fleisch scheint bis heute im Gegensatz zur ägyptischen für die syrisch-palästinensische küche typisch zu sein ${ }^{50}$. In diesem Brauch hat das verbot, ein Böcklien (als beliebteste Fleischart) nicht in der Milch seiner Mutter zu kochen, einen Rahmen, einen Verstehenshorizont, wenn auch noch keinen bestimmten Sinn.

Der Sinn wird von PHILO und seinen Gefolgsleuten bis heute darin gesehen, dass innerhalb dieses Rahmens des Essens und Geniessens Grenzen gesetzt werden, die vor allem die direkte Beziehung zwischen dem Muttertier und seinem Jungen schützen (das Junge nicht vor dem achten Tag töten, Muttertier und Junges nicht am gleichen Tag töten; Zicklein nicht in der Milch seiner Mutter kochen; Vogelmutter und ihre Brut nicht zusammen verspeisen). Darin sieht man den Willen des Gesetzgebers ausgedrückt, das Zartgefühl, das

\footnotetext{
48 JJS 30 (1979) $28 f$.

49 B 91/92; vgl. FISCHER, Milk 97-99.

50 Ebd.
} 
Mitleid als echt menschliche Haltung zu fördern, zumal ja eine solche Schonung der Tiere - aufgrund eines Schlusses de minore ad majus - eine noch viel radikalere Schonung des Menschen postuliert ${ }^{51}$. S.BOCHARTIUS sieht denn in unseren Gesetzen, ähnlich wie Paulus im Verbot, dem dreschenden Rinde das Maul zu verbinden ( 1 Kor 9,9f), auch hauptsächlich einen typologischen Sinn : "Sed illae leges... propter nos lalae sunt... nempe ut is doceremur, quam humani et aequi esse debeamus erga homines, qui nobis similes sunt, et ad imaiginem Dei facti. Quando quidem in bruta etiam lex ea vetat admitte..." 52 . Der Mensch soll den Menschen mit Zartgefühl und Mitleid behandeln. Solches Mitleid ist, wie PHILO sagt, das dem Verstand nächststehende und not-

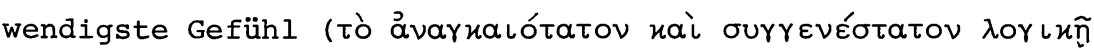

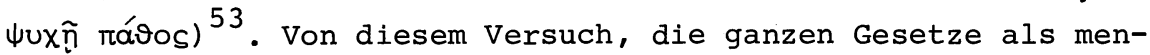
schengemäss und vernünftig $z u$ erweisen, ist es dann nur noch ein kleiner Schritt zur utilitaristischen Begründung des Verbots, sich der Vogelmutter und ihrer Brut zu bemächtigen (Dtn 22,6f), die PSEUDOPHOKYLIDES anführt : "Verschone die Mutter, damit sie dir aufs neue Junge schenke :"54. Ebenso anthropozentrisch, und zwar in einem utilitaristisch-rationalistischen Sinn, ist die Begründung, die MAIMONIDES für das Verbot bringt, ein Böcklein in der Milch seiner Mutter zu kochen : Dies wäre eine zu fette Speise, die das Blut verdicke 55 .

51 Vgl. PHILO, De virtutibus $\S \S 131 \mathrm{ff}, 139 \mathrm{f}$; ed. WENDLAND V $305 f, 308 f$.

52 Hierozoicon I 635.

53 De virtutibus $\$ 144$; ed. WENDLAND V 310.

54 PSEUDOPHOKYLIDES $\mathrm{Z} .85$; ed. YOUNG 102.

55 More nebukim (Führer der Unschlüssigen) III, 48; ed. MUNK III 398. 
c. Die "humanitäre" Deutung im Mittelalter und in der Neuzeit

Wie schon bei PHILO hat sich dieser Traditionsstrom aber auch im folgenden nicht mit diesem humanitär-anthropozentrisch-rationalen Gesichtspunkt begnügt. Der Gesichtspunkt, das eine und andere oder alle diese Gebote schützten eine von Weisheit und Liebe geprägte Schöpfungsordnung, fand besonders im 19. Jh. wieder seine Vertreter. So meint C.F.KEIL, die Vorschrift von Ex 23,19 Par. verbiete das Kochen eines Böckleins in Milch "als eine das von Gott zwischen Alten und Jungen geordnete und geheiligte Verhältnis missachtende Umkehrung der göttlichen Weltordnung" 56 , und nach H.J.CRELIER soll das Verbot "un acte de dureté qui blesse le sentiment de la nature" verhindern ${ }^{57}$. Noch K.ELLIGER redet im Zusammenhang mit dem Verbot, Muttertier und Junges am gleichen Tag zu schlachten, "von uralten Anschauungen über Lebens- und Seelenzusammenhänge" ${ }^{58}$. Ob man das Verhältnis, das sich in der Beziehung zwischen Mutter und Neugeborenem manifestiert, wie PHILO 59 oder H.J.CRELIER als "Natur", wie C.F. KEIL als "göttliche Weltordnung" oder wie K.ELLIGER als "Lebensund Seelenzusammenhänge" bezeichnet, in jedem Fall werden diese Gebote so als Schutz eines Lebensprozesses verstanden, an dem der Mensch, die Haustiere und die Vogelmutter in gleicher Weise Anteil haben, und von dessen Schutz sie in gleicher Weise profitieren. Ob dieser Schutz bzw. diese Tabuisierung als Respekt vor dem Geheimnis des Lebens oder als Magie und Aberglaube zu qualifizieren sind, hängt von der Einsicht der Subjekte ab, die diese Vorschriften tradiert bekommen.

Nebst der humanitär-anthropozentrischen und der magisch-religiösen finden wir wie schon bei PHILO auch in der Folgezeit immer

56 Genesis und Exodus 485.

57 L'Exode 195.

58 Leviticus 301.

59 De virtutibus $\$ 129$; ed. WENDLAND V 304. 
wieder ein Verständnis dieser Gebote, das sich an den objektiven Bedürfnissen der Tiere orientiert. Besonders ausgeprägt ist dieser Zug bei MAIMONIDES. Er erklärt das Verbot, ein Muttertier und sein Junges am gleichen Tag zu töten (Lev 22,28), mit der Sorge, das Junge nicht vor den Augen seiner Mutter zu schlachten $^{60}$. Und MAIMONIDEs fährt fort : "Denn das Tier würde in diesem Falle einen zu grossen Schmerz erleiden. In Wirklichkeit gibt es in dieser Beziehung keinen Unterschied zwischen dem Schmerz, den ein Mensch, und dem, den ein anderes Lebewesen erleidet; denn die Liebe und zärtlichkeit einer Mutter zu ihrem Kind hängen nicht von der Vernunft $a b$, sondern von der Tätigkeit der Vorstellungskraft, die die Mehrzahl der Lebewesen in ebenso hohem Mass besitzen wie der Mensch. Wenn diese Vorschrift im besonderen im Hinblick auf die Rinder und Schafe erlassen wurde, so geschah das, weil dies die Haustiere sind, die wir essen dürfen und die man in der Regel isst, und das sind auch die Arten, bei denen man die Mutter und ihr Junges unterscheiden kann. Die Vorschrift, die Mutter vom Vogelnest zu entlassen, hat einen ähnlichen Grund. Tatsächlich sind die bereits bebrüteten Eier und die jungen vögel, die die Mutter noch brauchen, nicht gut zu essen; wenn man also die Mutter entlassen muss, so dass sie davon fliegt, so wird sie nicht nur den Schmerz nicht haben, sehen zu müssen, dass man ihre Jungen wegnimmt, sondern häufig wird das sogar der Anlass sein, alles bleiben zu lassen, denn das, was zu nehmen erlaubt wäre, ist in der Regel nicht gut zu essen"61.

MAIMONIDES legt hier beide Verbote als solche aus, die dem Schutz der Tiere dienen. Dabei ist allerdings nicht $\mathrm{zu}$ übersehen, dass er den Geboten einen Sinn beilegen muss, der nicht gerade selbstverständlich in ihrer Perspektive liegt. Lev 22,28 redet nicht davon, dass man das Junge nicht vor den Augen des Muttertiers

60 Vgl. dazu die Söhne Zidkijas, die vor seinen Augen abgeschlachtet $(2$ Kön 25,7 ; Jer 39,$6 ; 52,10)$ und die 7 makkabäischen Brüder, die vor den Augen ihrer Mutter zu Tode gequält werden ( 2 Makk 7 passim).

61 More nebukim III 48; ed. MUNK III $399 \mathrm{f}$. 
schlachten dürfe. Und noch weniger überzeugt die Deutung von Dtn 22,6f, denn Eier zu speisezwecken einzusammeln, war im Alten Orient durchaus gebräuchlich (vgl. Jes 10,14). Das Verbot ist, wie bei Lev 22,28, gegen die gleichzeitige Vernichtung von Muttertier und Jungem gerichtet (Lev 22,28 : בירם אחד; Dtn 22,6 : האם על-הבנים (ה)

3. Die kultpolemische Deutung der Verbote

B.BAENTSCH bemerkt zu Ex 23,19: "Um milde Schonung der Natur handelt es sich hier nicht; die alten Gesetzgeber waren nicht sentimental"62. Es waren die im 19. und 20. Jh. neu erworbenen Kenntnisse des Alten Orients und der Ethnologie, die an der Interpretation PHILOS und seiner Gefolgsleuten Zweifel aufkommen liessen. Diese Kenntnisse legten nahe, vertrauten Erklärungen zu misstrauen und einer Deutung umso mehr zu trauen, je fremder sie war und je ferner sie den eigenen gewohnten Gedankengängen stand. So hat der berühmte Ethnologe J.G.FRAZER eingewandt : "Die Annahme..., die in alter und neuer Zeit Anerkennung gefunden hat, dem Verbot liege eine verfeinerte Humanität zugrunde, steht zum Gesamttenor der Gesetzessammlung (scl. dem Bundesbuch) im Widerspruch, in dem es gefunden wird"63. Noch radikaler formuliert M.RADIN : "Wenn es wahr ist, wie schon festgestellt wurde, dass sich selbst in den Lehren Jesu, soweit sie erhalten sind, kein Wort des Mitleids mit den leidenden Tieren findet, dürfen wir kaum erwarten, ein solches Mitleid bei einem Volk zu finden, das gewohnt war, ein Ritual mit blutigen Opfern als eine der betontesten göttlichen Einrichtungen $z u$ betrachten. Tatsächlich finden wir in der Mittelmeerwelt nirgends mehr als

62 Exodus - Leviticus - Numeri 209.

63 Folk-lore III 117. 
eine Spur von irgendetwas, das in dieser Hinsicht modernem Fühlen nahe käme..." 64 .

\section{a. Zur Entstehung der kultpolemischen Deutung}

Die Kritiker der humanitären Interpretation nehmen als Grund für das Verbot, ein Böcklein in der Milch seiner Mutter zu kochen, meist die Abwehr eines heidnischen Brauches an. Soweit ich sehe, findet sich dieser Gedanke erstmals bei MOSCHE BEN MAIMON (1135-1204 n.Chr.) in seinem schon mehrmals zitierten "Führer der Unschlüssigen" (More nebukim) 65 , wo er von den Speisegeboten handelt. Er sagt : "Was das Verbot betrifft, in Milch gekochtes Fleisch zu essen, so ist es nicht unwahrscheinlich, dass - abgesehen davon, dass es eine sehr fette Speise ist, die zu Uebersättigung führt, - der Götzendienst damit etwas zu tun hat. Man hat dies vielleicht bei einem bestimmten götzendienerischen Kult gegessen, der an einem der Feste der Heiden begangen wurde. Was mich in diesem letzteren Gedanken bestärkt, ist der Umstand, dass das Gesetz, wo es die beiden ersten Male den Genuss von in Milch gekochtem Fleisch verbietet, im zusammenhang mit dem Wallfahrtsgebot davon spricht : 'Dreimal im Jahr...' (Ex 23,17-19; 34,25-26). Es ist, als ob es sagen würde : 'Während einer Wallfahrt, wenn ihr in den Tempel des Ewigen, eures Gottes, eintretet, werdet ihr dort nichts auf die genannte Weise kochen, wie die Götzendiener es hielten.' Das ist, glaube ich, der einsichtige Grund für dieses Verbot; aber ich habe zu diesem Punkt keine einzige Stelle in den Büchern der Sabier gefunden, die ich gelesen habe" 66 . Unter "Sabiern" versteht MAIMONIDES ganz einfach Heiden ${ }^{67}$. MAIMONIDES saugt sich diese Erklärung also aus den Fingern. Es handelt sich um eine reine Spekulation.

64 AJSL $40(1923 / 24) 210$.

65 III 48; ed. MUNK III 398.

66 Ebd.

67 CHWOLSON, Ssabier und Ssabismus I $692 f$. 
MAIMONIDES ist dazu wohl durch den vorangehenden Abschnitt seines Traktates angeregt worden. Er lautet : "Das Verbot, ein Glied eines lebenden Tieres zu essen ${ }^{68}$, hat als Grund, die Gewöhnung an Grausamkeit ( $\mathrm{u} u$ vermeiden). Die Könige der Heiden handelten damals so, und es war auch ein götzendienerischer Brauch, einem Vierfüssler ein bestimmtes Glied abzuschneiden und $z u$ essen"69. Woher MAIMONIDES diese Auskunft hat, wissen wir nicht. Immerhin wird im ägyptischen Totenkult mindestens der Brauch dargestellt (und ist zeitweilig wahrscheinlich auch praktiziert worden), einem lebenden Kalb das eine Vorderbein abzuschneiden und dem Toten zu opfern ${ }^{70}$. Ein Relief aus der 19. Dyn. (ca. 13001200 v.Chr.) zeigt, wie der rechte Vorderfuss des Kalbes abgeschnitten wird, während das Kalb und die Kuh Zeichen höchster Erregung erkennen lassen (Abb.1). "Die Illustrationen des Papyrus Ani (aus der gleichen Zeit) geben die Szenen mit grosser Anschaulichkeit wieder (Abb.2 bietet einen Ausschnitt). Vor der Fassade des Grabes mit der aufgesetzten kleinen Pyramide ist auf einer Matte die Mumie des Ani aufgerichtet, die ein Priester mit der Maske des Anubis schützend von hinten umfängt, vor ihr kniet klagend die Frau des Toten, während neben oder hinter ihr ein Priester mit umgehängtem Pantherfell über einem grossen Aufbau von Opferspeisen räuchert und der Vorlesepriester Sprüche aus einem Papyrus rezitiert. Auf diese Gruppe eilt ein nur mit einem Schurz bekleideter Mann $z u$, der ein Vorderbein herbeibringt. Hinter ihm sind zwei Holzgestelle mit Speisen aufgestellt worden. Diese szene nimmt nur die Hälfte des Bildraums der übrigen ein, so dass darüber die Kuh mit dem ihr gegenüberstehenden Kälbchen auf einer eigenen Bodenlinie dargestellt werden konnte. Auf ihre Erregung deutet der erhobene, leicht nach hinten geneigte Kopf, so dass eines der Hörner über die Begrenzungslinie hinaus-

68 Die Rabbinen fanden dieses Verbot in Gen 9,4 und Dtn 12,23; siehe bSanhedrin 57a = GOLDSCHMIDT, Der babylonische Talmud VII 242f; bChullin 10lb = GOLDSCHMIDT, a.a.O. VIII $1130 f$.

69 More nebukim III 48 ; ed. MUNK III 398.

70 EGGEBRECHT, Schlachtungsbräuche 55-61. 


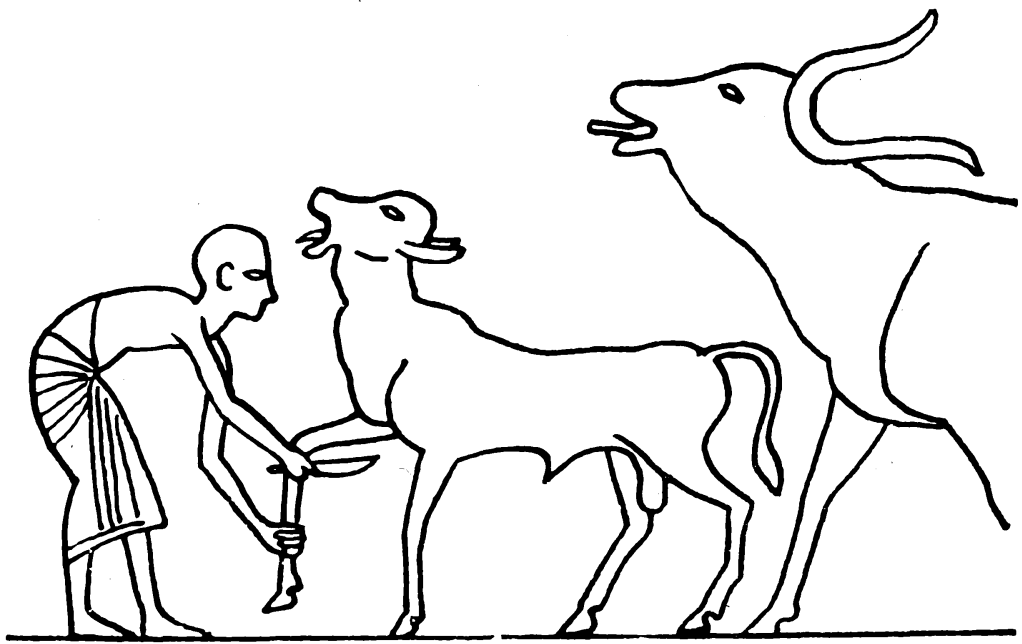

Abb.1 Relief aus dem Grab eines Ptahmose, Museum Kairo Nr.396, 19.Dyn.; WEIGALL, JEA 2 (1915) 10.

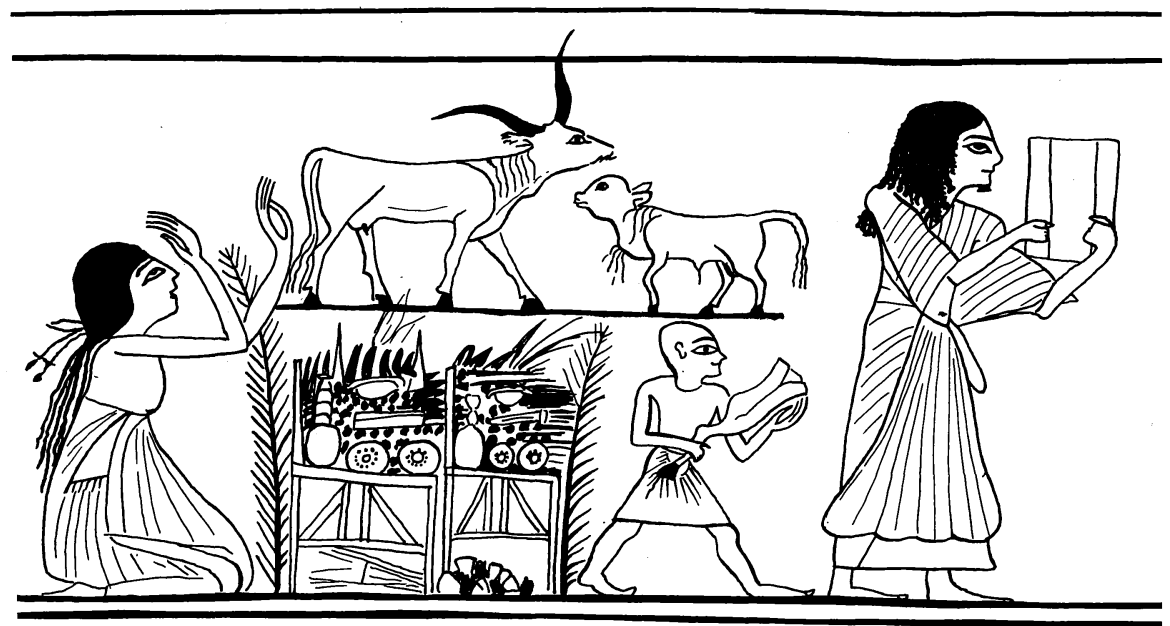

Abb.2 Malerei vom Papyrus des Ani, Britisches Museum 10470, 19.Dyn.; DONDELINGER, Papyrus d'Ani Pl.6. (Ausschnitt!) 
greift. Unmittelbar dahinter gibt eine Gruppe von Klagefrauen in heftigen Gebärden nach allen Seiten ihrem Schmerz Ausdruck, während Diener mit der Grabausstattung darauf zuschreiten" ${ }^{71}$.

Der genaue Sinn der Zeremonie ist schwer $\mathrm{zu}$ bestimmen und schwer zu verstehen ist, wie das Wissen um einen solchen Brauch aus dem 13.Jh. v. Chr. zu MAIMONIDES gelangt sein soll. Doch ist ein einmal bezeugter Brauch in der Regel nicht einmalig. Das Verzehren von lebendig zerrissenen Tieren oder von Fleisch, das von lebenden Tieren abgeschnitten wurde, scheint auch im Dionysoskult eine Rolle gespielt zu haben ${ }^{72}$. Die mit solchen Bräuchen verbundenen elementaren Vorstellungen und Erwartungen sind nicht allzu schwer zu begreifen. Lebendigem Fleisch oder Fleisch von noch lebenden Tieren traute man in höherem Masse die Fähigkeit $z u$, Leben zu vermitteln, als totem Fleisch bzw. Fleisch von toten Tieren.

Eine solche naheliegende Symbolik ist beim Kochen des Böckleins in der Milch seiner Mutter aber nicht $\mathrm{zu}$ erspüren. Es ist deshalb wohl kein Zufall, dass MAIMONIDES keinen Beleg für einen solchen Brauch nennen kann, wie er ausdrücklich sagt. Er hat einen solchen nur in Analogie zum abgeschnittenen Glied angenommen. Dennoch wurde fortan zur Begründung des Verbots ein solcher Brauch überliefert. So finden wir ihn z.B. bereits bei THOMAS VON AQUIN (um 1225-1274 n.Chr.) ohne Angabe des Autors in einem Artikel, der MAIMONIDES aber offensichtlich viel verdankt. THOMAS behandelt darin die Frage, ob sich für die Zeremonialgesetze vernünftige Gründe anführen liessen. Zum Böcklein in der Milch seiner Mutter bemerkt er : "Man kann sagen, dass die Heiden bei den Feierlichkeiten der Götzen auf diese Weise das Fleisch eines Böckleins kochten, um es zu opfern oder $\mathrm{zu}$

71 Ebd. $56 \mathrm{f}$.

72 K.H.ROLOFF, in : BARTELS/HUBER, Lexikon der Alten Welt Sp. 756; vgl. EURIPIDES, Bakchen Z. 677-774; ed. DODDS $29-32$. 
essen. Und deshalb wird im Buch Exodus, nachdem im Gesetz von den Festen die Rede war, die gefeiert werden müssen, gesagt : Du sollst ein Böcklein nicht in der Milch seiner Mutter kochen" 73 . Bei aller Kürze schimmert die Argumentationsfigur des MAIMONIDES deutlich durch.

ISAAK ABRABANEL (1437-1508 n.Chr.) hat die Ueberlieferung dahingehend präzisiert, dass er den Brauch mit den Erntedankfesten verband, bei denen die Heiden durch ihn Segen zu erlangen hofften $^{74}$. S.BOCHARTUS zitiert in seinem Hierozoicon ABRABANEL und fügt hinzu : "Es gibt auch einen anonymen karaitischen Schriftsteller, der sagt, dies (das Kochen des Böckleins in der Milch beim Erntefest) sei aus einem magischen Grund geschehen und die alten Götzendiener hätten nach dem Einsammeln der Früchte mit dieser Milch Bäume, Äcker, Gärten und Baumgärten besprengt, damit sie im folgenden Jahr ertragreicher seien" ${ }^{2}$. Wir haben es auch hier höchst wahrscheinlich mit einer spekulativen Weiterentwicklung der Intuition des MAIMONIDES zu tun. Seit MAIMONIDES wurde der von ihm postulierte heidnische Brauch immer genauer gefasst, insofern ABRABANEL sich Zeitpunkt und Zweck und der anonyme Karaite seine genaue Form vorzustellen suchten. Irgendwelche alten Ueberlieferungen liegen nicht vor. Dennoch fanden diese Spekulationen Eingang in die moderne Exegese ${ }^{76}$ und wurden gelegentlich noch durch neue angereichert, so etwa durch die unbegründete Vermutung W.R.SMITHS, die Milch sei in ihrer Funktion als Blutersatz im hebräischen Kult verboten gewesen ${ }^{77}$, eine Vermutung, die sofort bereitwillig aufgegriffen wurde ${ }^{78}$. Zusätzlichen Anlass, Ex 23,19 Par. als Ablehnung einer heidnischen

73 Summa theologiae II/I, q. 102 art. 6 ad 4; ed. CARAMELLO II/I 491 .

74 Ed. anonyma, Jerusalem 1964, 217 f.

75 Hierozoicon I $639 f$.

76 Vgl. DILLMANN, Die Bücher Exodus und Leviticus 251.

77 Religion der Semiten 167, Anm. 327.

78 HOLZINGER, Exodus 98; BAENTSCH, Exodus-Leviticus-Numeri 209. 
Kultsitte zu verstehen, gab ein Zusatz zu Ex 23,19 im Samaritanischen Pentateuch : כי עשה זאת כזבח שכח ועברה היא לאלהי יעקב, zu dem sich in einigen Septuaginta-Handschriften, hier allerdings in einem zusatz zu Dtn 14,21, eine Parallele findet : ós

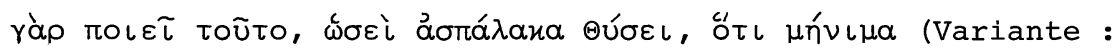

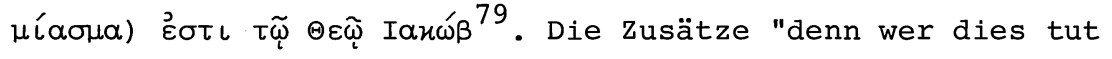
"כזבח שכח und "es ist eine Uebertretung vor dem Gott Jakobs" haben ihre Probleme. Was soll das כזבח שכח ? Die griechische

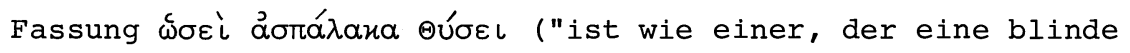
Ratte opfert") ist zwar in sich verständlich, denn åoráda erscheint in Lev 11,30 als unreines Tier. Aber gibt es eine Brücke zwischen ăorád übersetzen als "ist wie einer, der etwas Vergessenes opfert" und dabei ش שכ auf eine vergessene, obsolet gewordene Opferart beziehen ${ }^{80}$, aber da es diesen Begriff der vergessenen, obsolet gewordenen Opferart in der atl Ueberlieferung sonst nicht gibt, ist dies - von philologischen Bedenken abgesehen - eine gewagte Annahme. עברה aber kann sich auf jede Art von Uebertretung beziehen und verlangt nicht unbedingt die kultpolemische Interpretation von Ex 23,19 Par.

F.VON HUMMELAUER stellt am Ende des 19. Jhs. deshalb mit Recht fest, es könne bei keinem einzigen Volke auch nur die spur eines solchen Ritus entdeckt werden ${ }^{81}$.

b. Die kultpolemische Deutung im 20. Jh.

Ebenso schreibt M.RADIN 1923, die Annahme, Ex 23,19 Par. wolle einen heidnischen Brauch abwehren, hätte zwar alle Wahrscheinlichkeit für sich : "Aber es wurde kein direkter Beweis erbracht, dass solch ein Ritus oder irgendetwas ihm wirklich ähnliches

79 Vgl. im einzelnen DILLMANN, Exodus und Leviticus 251.

80 JThS 37 (1936) 291

81 Commentarius in Exodum et Leviticum 243. 
(tatsächlich) existiert hat" ${ }^{82}$. RADIN glaubt nun, einen solchen Brauch nahmhaft machen zu können, indem er auf die Worte eines orphisch-dionysischen Mysten verweist, der sich als Böcklein bezeichnet, das in die Milch gefallen ist ${ }^{83}$. Als Böcklein

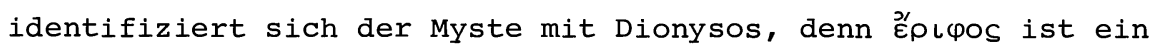
Epithet des Dionysos. Milch bedeutet Glück und Unsterblichkeit. Aber abgesehen davon, dass dionysische Riten etwas spät bezeugt sind, um vom "Bundesbuch" (Ex 23,19) oder dem "Privilegrecht Jahwes" (Ex 34,26$)$ abgewehrt $\mathrm{zu}$ werden, redet, was mir wichtiger scheint, kein dionysischer Text vom Kochen und ebensowenig von der Milch seiner Mutter.

1936 hat D.DAUBE einen neuen Anlauf gemacht. Er postuliert, im nomadischen Bereich seien die ursprünglichen Milch- und ähnlichen Gabenopfer erst relativ spät durch blutige opfer abgelöst worden. Ein Hinweis darauf sei die Geschichte von Kain und Abel, die dem blutigen Opfer den Vorzug gebe vor dem Gabenopfer. Die Milch, in der das Böcklein nicht gekocht werden soll, sei der Rest eines solch obsolet gewordenen Milchopfers, dessen Beseitigung das Gesetz verlange ${ }^{84}$. Ebensowenig wie bei SMITH oder RADIN ist hier ersichtlich, was die Präzisierung der Milch als Milch seiner Mutter soll. Die Auskünfte, die von SMITH bis DAUBE dazu gegeben werden, sind Verlegenheitsauskünfte ${ }^{85}$. Davon abgesehen ist auch die Ablösung der Milchopfer durch blutige Opfer reichlich hypothetisch. Kurzum, man ist nie über die Vermutung des MAIMONIDES hinausgekommen, es hätte vielleicht eine solche heidnische Sitte bzw. eine in Israel obsolet gewordene Opferart gegeben. Was an Belegen dafür angeführt wurde, waren Postulate oder keine echten Parallelen.

82 AJSL $40(1923 / 24) 211$.

83 Ebd. 215.

84 JThS 37 (1936) 289-291.

85 DAUBE (ebd. 290) sagt z.B. dazu : "At that period food was not bought but produced in the household. In most cases the milk in which a young animal was boiled actually was its mother's milk." Da ist der Hinweis PHILOS auf die reichlich vorhandene Milch doch realistischer (vgl. oben S. 20 ). 
Schon ein Jahr bevor DAUBE seinen Beitrag schrieb, glaubte man aber, endlich den so lange gesuchten Beweis dafür gefunden zu haben, dass Ex 23,19 Par. eine fremde Kultsitte verbiete. 1930 war in Ugarit ein Text gefunden worden, den Ch.VIROLLEAUD 1933 unter dem Titel "La naissance des dieux gracieux et beaux" publizierte $^{86}$. In der deutschsprachigen Literatur ist der Text besser unter dem Namen "Schachar und Schalim" (SS) bekannt. Ch.VIROLLEAUD las die Zeile $14 \mathrm{~b}$ th (Lücke von etwa 2 Buchstaben) $d . b$ $h l b a(?) n n h b$ hbmt und ergänzte die lücke wie folgt : thb (h.g) $d$. $b$ h.lb... Als Uebersetzung schlug er vor : "fais cuire un chevreau dans le lait, un a(?)nnh dans le beurre"87. H.L.GINSBERG hat die so interpretierte Vorschrift 1935 mit dem Verbot, ein Böcklein in der Milch seiner Mutter zu kochen, kontrastiert ${ }^{88}$. Fortan galt das kultpolemische Verständnis einer grossen Zahl von Exegeten als gesichert 89 . Noch 1975 schreibt J.HALBE : "Gesichert ist, dass im Rahmen einer Liturgie, die in ihren rezitativen Teilen Götterzeugungen beschreibt, die rituelle Anweisung begegnet '(Altar)diener mögen auf dem Feuer siebenmal (ein) Zicklein in Milch kochen :' Die nähere Funktion ist unsicher. Dass ein Fruchtbarkeitsritus anzunehmen ist, ergibt der Kontext. Aber weder die Rolle des Milch-Ritus im Rahmen der ganzen Begehung noch etwa deren ort im jährlichen Festkreis ist einigermassen zuverlässig zu bestimmen. Die Versuche, hier dadurch weiterzukommen, dass man Ex 34,26b aufs Passa-, Wochen- und Lesefest bezieht und den darin abgewehrten Fruchtbarkeitsritus dann jeweils einem entsprechenden kanaanäischen Fest zuweist, sind jedenfalls so hypothetisch, dass sie (vorerst) auf sich beruhen müssen. Die Front ist greifbarer geworden, gegen die v. 26b

86 Syria 14 (1933) 128-154.

87 Ebd. 130 und 133; vgl. dazu den Kommentar ebd. 140.

88 Journal of the Royal Asiatic Society 67 (1935) 72; Ders., Ugaritic Texts (hebr.) 78 .

89 KOSMALA, ASTI 1 (1962) 50-56; SCHOORS; in FISHER, Ras Shamra Parallels I 29-32; WILMS, Bundesbuch 174-176; weitere Belege bei HARAN, JJS 30 (1979) 26 Anm. 8 . 
steht, und damit sein rituell polemischer Charakter; das ist nicht wenig und für uns genug" 90 . Leider ist das, was den vor allem auf Abgrenzung Israels von seiner Umwelt bedachten Alttestamentlern so wichtig ist, nicht nur nicht gesichert, sondern ganz unwahrscheinlich. Abgesehen davon, dass thb nur eine Konjektur war und hinter $t b$ wahrscheinlich ein Worttrenner steht ${ }^{91}$, würde $t b h$ eher "schlachten" als "kochen" bedeuten" 92 . Schwerwiegender aber ist, dass das konjizierte gd(j) "Zicklein, Böcklein" im Ugaritischen nicht bezeugt ist. Man hat deshalb vorgeschlagen, gd "Koriander" oder "Safran" zu lesen"3. Für das dem vermeintlichen $g d j$ parallel stehende 'nnh ist aufgrund des akkadischen ananihuu "eine Gartenpflanze"94, des syrischen nānę̧ā "Minze", des klassisch arabischen nānaḩat bzw. des modern arabischen na cnāc "Minze" 95 die Bedeutung "Minze" viel wahrscheinlicher als "Lamm" oder eine andere, inhaltlich dem konjekturierten "Böcklein" entsprechende Wiedergabe ${ }^{96}$. In ihrer magistralen Uebersetzung der mythischen Texte von Ugarit übersetzen A.CAQUOT, M.SZNYCER und A.HERDNER die einschlägige Stelle : "Que sur le feu, les jeunes héros plongent sept fois le coriandre dans le lait, la menthe dans le beurre fondu" 97 . Wenn auch das "tauchen" (plonger) nicht gesichert ist, so bleibt jedenfalls nichts von einem in Milch gekochten Böcklein übrig, ganz abgesehen davon, dass nie jemand - auch die optimistischsten Vertreter ugaritisch-

90 Privilegrecht Jahwes $200 f$.

91 HERDNER, Corpus 98 Anm. 9; DIETRICH/LORETZ/SANMARTIN, Keilalphabethische Texte 67.

92 LOEWENSTAMM, UF 5 (1973) $209 f$.

93 DE MOOR, Or 37 (1968) 212-215.

94 OPPENHEIM, Assyrian Dictionary I, $2111 \mathrm{~s}$. verbo ananihu.

95 AISTLEITNER, Wörterbuch $206 \mathrm{Nr} .1794$.

96 HARAN, JJS 30 (1979) 26f. Anm. 11.

97 Textes ougaritiques 371; vgl. auch P.C.GRAIGIE, Deuteronomy and Ugaritic Studies, Tyndale Bulletin 28 (1977) 155-169. 
alttestamentlicher Parallelen nicht - behauptet hat, es sei in unserem Text von einem Böcklein in der Milch seiner Mutter die Rede. Und das ist doch ein entscheidender Punkt.

Nachdem dank dem ugaritischen Text beim "Böcklein in der Milch seiner Mutter" die antikanaanäische Erklärung gesichert schien und ihren Siegeszug angetreten hatte, wurden auch die verwandten Gebote, vor allem Lev 22,28 , so interpretiert. So schreibt $M$. NOTH in seinem viel benützten Leviticus-Kommentar : "Nach V.27 war ein Tier erst im Alter von mindestens acht Tagen zum Opfer geeignet; vorher war es als noch zu dem Muttertier gehörig anzusehen. Es könnte sein, dass mit dieser Anordnung ein in fremden Kulten üblicher Brauch verboten werden sollte, ebenso wie mit der in V.28 folgenden Bestimmung, dass ein Opfertier nicht gleichzeitig mit seinem Jungen geopfert werden durfte. Vielleicht handelt es sich hierbei (ebenso wie bei dem Verbot von 2. Mos 23 , 19b; 34,26b) um die Ablehnung von Fruchtbarkeitsriten, die in der Umwelt des Alten Testaments bekannt waren" 98 .

10 Jahre später ist aus NOTHS "vielleicht" bei W.KORNFELD bereits ein "wahrscheinlich" geworden : "Das Verbot der gleichzeitigen Schlachtung des Muttertiers und des Jungen (V.28; vgl. $\operatorname{Ex} 23,19 ; 34,26 ;$ Dtn 14,21 ) ist wahrscheinlich eine Polemik gegen die kanaanäische Sitte, durch das Opfer der Mutter mit ihrem Jungen die Fruchtbarkeitsgottheit als Quelle des Lebens zu verehren"99. Der Leser erhält hier den Eindruck, es gäbe tatsächlich eine solche sitte. Sie ist aber durch kein einziges Beispiel belegt. Und die Annahme, man hätte die Fruchtbarkeitsgottheit durch das Opfer ihres Symbols, des Muttertiers mit seinem Jungen (siehe das folgende Kapitel), geehrt, ist auch nicht gerade naheliegend. Die Tiere einer Gottheit waren in der Regel nicht Opfertiere, sondern tabu. So berichtet etwa HERODOT (um 440 v.Chr.) aus Aegypten : "Kühe zu opfern ist nicht erlaubt;

98 Das dritte Buch Mose 142.

99 Das Buch Leviticus 148. 
sie sind der Isis heilig. Die Isis wird nämlich als Frau mit Rindshörnern dargestellt"100. Weiter stellt er fest : "Alle, die zum Tempelbezirk des Zeus Thebaieus (=Amon) gehören oder überhaupt im Gau der Stadt Theben (=Luxor) wohnen, geniessen kein Fleisch von Widdern, sondern opfern Ziegen"101. Der Widder war bekanntlich das heilige Tier des Amon. Umgekehrt stellt Herodot fest : "Die Angehörigen des Tempelbezirks von Mendes, überhaupt die Bewohner des Gaus von Mendes, geniessen wiederum kein Ziegenfleisch, sondern opfern Schafe" ${ }^{102}$. Denn in Mendes wurde der berühmte Bock von Mendes verehrt ${ }^{103}$. Aehnlich wie diese ägyptischen Verbote könnten auch die biblischen, im Erbe der Kanaanäer, das Symbol einer Gottheit tabuisieren, wie ich im folgenden Abschnitt zu zeigen versuche. Die kultpolemische Deutung ist jedenfalls eine durch nichts begründete reine Vermutung.

Wie die beiden zuletzt genannten Beispiele (NOTH, KORNFELD) zeigen, stützt sich die kultpolemische Deutung von Lev 22,27f und ähnlichen Verboten auf die so geartete Deutung des Verbots, ein Böcklein in der Milch seiner Mutter zu kochen. Diese Deutung aber hat sich in den letzten 40 Jahren auf die einschlägige zeile in "Schachar und Schalim" gestützt. Nachdem sich diese Deutung als hinfällig erwiesen hat, stürzt das ganze Gebäude der neueren kultpolemischen Deutung zusammen. Ich möchte nicht einfach, wie M.HARAN zur "humanitären" Deutung PHILOS zurückkehren, sondern dessen Deutung wie auch die kultpolemische durch eine Interpretation ersetzen, die ich als "religiös" bezeichnen will.

100 Historien II 41 ; ed. HUDE I, II 41.

101 Ebd. II 42; ed. HUDE I, II 42.

102 Ebd.

103 Mendes lag im nordöstlichen Delta. Wenn in Ex 8,22 gesagt wird, die Opfer der Israeliten, die hauptsächlich aus Schafen und Ziegen bestanden, seien für die Aegypter ein Greuel gewesen, so lag der Grund vielleicht bei der von HERODOT genannten Tatsache. In der griechischen Urkunde eines Kultvereins von Hermopolis magna werden die Ziegenopfer der zugereisten Semiten als "den heimischen Opferbräuchen ganz entgegengesetzt" bezeichnet (BONNET, Reallexikon 882). 
Dabei vermag diese Deutung einzelne Aspekte der, wie gezeigt, recht komplexen Deutung PHILOS und seiner Nachfolger, die ja nicht nur humanitär (im eigentlichen sinne) ist, zu integrieren.

4. Der literarische Kontext der biblischen Vorschriften und dessen Konsequenzen für die Deutung

Das Verbot, das Jungtier vor dem achten Tag seiner Mutter wegzunehmen, steht im Bundesbuch $(\operatorname{Ex} 22,29 b)$ im Kontext der Vorschriften über die Erstgeburten (Ex 22,28b-29), die für Jahwe gefordert werden. In diesem Kontext hat das Verbot wahrscheinlich auch seinen ursprünglichen Sitz im Leben, denn hier lag die Frage nahe, wann genau sie darzubringen seien. Die Antwort besteht nur in einer Einschränkung : Nicht vor dem achten Tag. Sieben Tage sollen die Neugeborenen bei ihrer Mutter bleiben.

Im Heiligkeitsgesetz steht die Einschränkung immer noch im Rahmen von Opfervorschriften (Lev 22,27) aber nicht mehr speziell in dem von solchen über die Darbringung der Erstgeburt. Ganz generell wird gesagt, erst vom achten Tag an sei ein Jungtier als Opfergabe Jahwe wohlgefällig. Hier ist übrigens in dem ירצה....ליהוה das für Opfer- und Reinheitsvorschriften typische deklaratorische Element erhalten.

Interessanterweise steht das Verbot, ein Böcklein in der Milch seiner Mutter $\mathrm{zu}$ kochen, im Bundesbuch $(\operatorname{Ex} 23,19 \mathrm{~b})$ und im sogenannten "Privilegrecht Jahwes" $(34,26 \mathrm{~b})$ ebenfalls im Kontext der Darbringung der Erstlinge. Den grösseren Rahmen bilden dabei die drei jährlichen Erntefeste, die in Ex 23,14-19 mit ihren ältesten bekannten Namen als "Fest der ungesäuerten Brote"

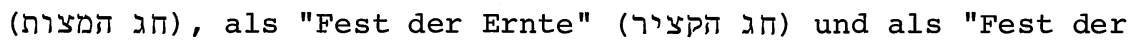
Lese" (חו הזסף) bezeichnet werden, während in Ex 34,18-26 ebenfalls vom "Fest der ungesäuerten Brote" und vom "Fest der Lese" 
(דוג האסיף) die Rede ist, ist das "Erntefest" schlechthin aber durch das "Wochenfest" (חו שבעת) ersetzt. Dieser und zahlreiche ähnliche kleine Unterschiede machen wahrscheinlich, dass die beiden Texte eine getrennte Traditionsgeschichte haben ${ }^{104}$.

Nebst den Vorschriften $\mathrm{zu}$ den drei Jahresfesten und den Erstlingen erscheinen in diesem Kontext (Ex 23,14-19 und $\operatorname{Ex} 34,18-26$ ) noch die Vorschriften, das Blut der Schlachtopfer nicht zu Gesäuertem darzubringen (Ex 23,18a und 34,25a) und das Fett der Festopfer bzw. das Schlachtopfer des Päsach nicht bis zum Morgen übrig zu lassen (Ex $23,18 \mathrm{~b}$ und $34,25 \mathrm{~b}$ ).

Erst im Deuteronomium wird das Verbot, ein Böcklein in der Milch seiner Mutter $\mathrm{zu}$ kochen, in einen allgemeineren Kontext gestellt. Es steht in Dtn 14,2lc, wie schon MAIMONIDES bemerkt hat, am Ende von Speisevorschriften, nämlich den Bestimmungen über reine und unreine Tiere (Dtn 14,3-20) und denen über die Verwendung von nicht rituell geschlachteten Tieren (Dtn 14,2la-b). Immerhin ist $\mathrm{zu}$ beachten, dass gleich danach die Bestimmungen über die Darbringung der Erstlinge zu finden sind (Dtn 14,22-26).

Die dritte hier behandelte Vorschrift, eine Kuh und ihr Kalb bzw. ein Stück Kleinvieh und sein Junges nicht am gleichen Tag zu schlachten (Lev 22,28 ), ist wie Lev 22,27 im Rahmen von Opfervorschriften $z$ finden.

Nun ist der Kontext ja das einzige, was uns bei solch konkreten und von der Ueberlieferung weiter nicht erklärten Vorschriften Aufschluss über deren Sinn geben kann. Der Kontext aller drei Vorschriften scheint aber ziemlich eindeutig der des Opfers zu sein. Wenn wir uns auf die ältesten Texte (Bundesbuch, Privilegrecht Jahwes) verlassen, dann können wir diesen Kontext auf die

104 RICHTER, Recht und Ethos 94. Problematisch ist mir das 1iterarkritische Urteil zu Ex 23,18f : "wohl redaktionell oder spätere Uebernahme" angesichts der zugegebenen Unverständlichkeit in bezug auf den Sinn des Gebots und der Prohibitive. Eine inhaltliche Zusammenhangslosigkeit zweier Teile kann doch nur behauptet werden, wenn der Sinn beider Teile je für sich genommen klar ist. 
Darbringung der Erstlinge im Zusammenhang mit den Jahresfesten einengen.

Weder diese Jahresfeste noch die Darbringung der Erstlinge sind aber etwas spezifisch Israelitisches. Zu den in Ex 23,14-19 genannten Jahresfesten schreibt MARTIN NOTH, indem er damit wohl einen weitgehenden Konsens der Alttestamentler zum Ausdruck bringt : "Die drei Feste stammen aus der Kulturlandtradition und sind mit dem Kulturlandleben und seinem natürlichen Ablauf aufs engste verbunden. Das geht aus ihrer Charakterisierung eindeutig hervor. Sie sind also gewiss erst im Kulturland von Israel übernommen worden" 105 .

Ebenso gehört die Darbringung der Erstgeburten nicht gerade zum Sondergut israelitischer Kultbräuche. Im Alten Testament scheint man sich das erste, von den Menschen dargebrachte opfer als eine Darbringung der Erstlinge vorzustellen (Gen 4,3f). ARISTOTELES hat im Erstlingsopfer die älteste Form des Opfers überhaupt gesehen $^{106}$. Das Opfer der Erstlinge ist ausserordentlich weit verbreitet und scheint sehr alt $\mathrm{zu} \operatorname{sein}^{107}$.

Endlich sind die Opferbräuche Israels im allgemeinen anscheinend in beträchtlichem Mass von den kanaanäischen abhängig ${ }^{108}$.

Angesichts dieser Sachverhalte und der Tatsache, dass unsere Verbote ihr Schwergewicht in alten Zusammenhängen (Bundesbuch, Privilegrecht Jahwes) haben und im Deuteronomium eher zurücktreten, scheint mir die Annahme, es handle sich hier um Kultpolemik, ziemlich abwegig, denn antipolytheistische und damit in zusam-

105 Das zweite Buch Mose 154; vgl. DE MOOR, New Year II bes. 28f. BOECKER, Recht 123.

106 Nikomachische Ethik VIII, 11; ed. BEKKER II 1160a, 25-28.

107 Vgl. zum Ganzen HENNiNGER, Fêtes des Printemps 179-199 und die dort genannte Lit.

108 Zum Opfer vgl. DUSSAUD, Origines; FURLANI, Il sacrificio 249f; DE VAUX, Sacrifices 41. 
menhang stehende kultpolemische Tendenzen werden erst von Elija und Elischa an virulent und erreichen erst in der deuteronomischdeuteronomistischen Bewegung Durchsetzungsvermögen und gesetzliche Verankerung ${ }^{109}$.

Wenn die drei genannten Vorschriften vom ursprünglichen Kontext her kaum als antikanaanäisch zu begreifen sind, stellt sich die Frage, welche Bedeutung sie als ursprünglich kanaanäische Vorschriften haben konnten. Man darf davon ausgehen, dass opfer den allgemeinen Zweck haben, das Wohlgefallen der Gottheit zu gewinnen. Alles, was die Gefühle der Gottheit, der das opfer gilt, beleidigen könnte, muss vermieden werden. Nun haben wir bei HERODOT im Hinblick auf Aegypten gesehen, dass man es vermied, einer Gottheit Tiere zu opfern, die ihr in irgendeiner Weise heilig waren. In Theben opferte man deshalb, wie gesagt, keine Widder, in Mendes keine Ziegen und in ganz Aegypten keine Kühe, weil sie der im 5. Jh.v.Chr. allgegenwärtigen Isis heilig waren. Zwar schlachtete man kühe ${ }^{110}$, aber man opferte sie - wenigstens in der Regel - nicht. Aehnliche Opfertabus scheinen in Syrien gegolten $\mathrm{zu}$ haben. So erzählt etwa LUKIAN vom Tempel der syrischen Göttin in Hierapolis, der die Taube heilig warlll : "Von Vögeln ist die Taube für sie (die Leute von Hierapolis) das heiligste Ding, und sie halten es nicht einmal für recht, sie zu berühren; wenn sie sie wider Willen berühren, sind sie jenen Tag lang verflucht. Deshalb leben sie (die Tauben) mit ihnen zusammen, kommen in ihre Häuser und leben meist auf der Erde"112.

109 Vgl. dazu STOLZ, in : KEEL, Monotheismus 174-182.

110 EGGEBRECHT, Schlachtungsbräuche 58; BONNET, Reallexikon 405.

111 WINTER, in : KEEL, Vögel als Boten 37-78.

112 LUKIAN, De Dea Syra 54; ed. IACOBITZ III 539; Uebersetzung von CLEMEN, Lukians Schrift 26. 
Nun darf man bei diesen Dingen keine allzu grosse Konsequenz erwarten. Denn die Aussparung der Symboltiere einer Gottheit vom Opfer mochte oft mit der Vorstellung vom Opfer als Speise kollidieren, nach der man, was einem selber zur Speise diente, auch der Gottheit zum Opfer brachte. Endlich mag es auch vorgekommen sein, dass man einer Gottheit ausgerechnet ihr Lieblings- oder Symboltier geopfert hat.

Diese möglichen Einwände im Auge behaltend, möchte ich aus den genannten Gründen (kanaanäische Herkunft der Verbote, säugendes Muttertier als Symboltier ägyptischer und vorderasiatischer Göttinnen, Vorwiegen der Tabuisierung der Symboltiere in Aegypten und Palästina-Syrien) die atl Opfervorschriften, die das Muttertier und sein Junges betreffen, als solche Tabuisierung eines Symboltieres verstehen. Denn nicht die Kuh, das Schaf oder die Ziege, sondern die säugende Kuh, bzw. die säugende Ziege erscheinen im vorderasiatischen Raum, wie im nächsten Abschnitt gezeigt werden soll, vom 4. Jt. bis zum 3. Jh. v.Chr. und gerade auch in Israel am Anfang des 1. Jt.v.Chr. als Symbol gottgeschenkter Fruchtbarkeit und göttlicher Sorge und Liebe, die vor allem durch bestimmte Muttergottheiten repräsentiert werden.

Israel scheint solche Opfertabus, gelegentlich vielleicht ohne ihren Sinn genau zu kennen, von den Kanaanäern übernommen $\mathrm{zu}$ haben. Sie scheinen in Israel dann zu allgemeinen Speisevorschriften und wenigstens in einem Fall zum Ausdruck des Respekts vor einer grundlegenden Schöpfungsordnung geworden zu sein.

Das Verbot, eine Vogelmutter zusammen mit ihrer Brut zu behändigen, ist offensichtlich schon vom Deuteronomium im Sinne der Achtung einer besonders geheiligten Schöpfungsordnung, nämlich der Eltern-Kind-Beziehung, und damit im Sinne PHILOS und seiner Nachfolger verstanden worden. Denn das Deuteronomium lässt der Einhaltung dieses Verbots die gleiche Verheissung zuteil werden, wie der Einhaltung des Gebots, die Eltern zu ehren (Dtn 22,7; vgl. 5,16; Ex 20,12). Ich wüsste auch keine Belege dafür anzu- 
führen, dass eine Vogelmutter mit ihrem Gelege oder ihren Jungen als Symbol einer Gottheit eine Rolle gespielt hätte. Die Metapher in Dtn 32,1l genügt nicht, eine solche zu postulieren.

So lässt sich, wenn man den Kontext der biblischen Verbote verfolgt, eine Entwicklung vom Opfertabu zum Ausdruck des Respekts vor einer besonders in die Augen springenden Schöpfungsordnung, dem Mutter-Kind-Verhältnis, beobachten. Zwischen beiden besteht ein natürlicher Zusammenhang. Das zeigt die Darstellung des Motivs in der Bildkunst sehr deutlich. Es lässt sich da nämlich nicht immer mit Bestimmtheit sagen, ob wir es mit der genrehaften, im besten Sinne als rührend empfundenen Darstellung des Verhältnisses zwischen dem Muttertier und dem neugeborenen Jungen oder mit der Darstellung des Symbols einer Muttergottheit zu tun haben. Beiden liegt das Betroffensein von der Sorge der Natur um die Weitergabe des Lebens zugrunde. Im einen Falle bleibt die Betroffenheit beim Phänomen stehen und schreckt instinktiv davor zurück, es zu zerstören. Im andern Fall kann das Phänomen als Manifestation einer göttlichen Macht erfahren werden, die beleidigt wird, wenn man ihre lebendige Ikone sozusagen vor ihren Augen (beim Opfer) zerstört. Dort, wo diese göttliche Macht (etwa aufgrund der antipolytheistischen Tendenz) in den Hintergrund treten muss, kann das Gebot wiederum ganz einfach die Betroffenheit vor dem Phänomen ausdrücken, oder das Phänomen kann, wie ev. schon in Dtn 22,6f, sicher aber bei PHILO, statt als Manifestation einer bestimmten, persönlich gedachten Macht als Manifestation einer unpersönlichen heiligen Schöpfungs- und Weltordnung ( $\varphi$ úoıs) verstanden werden. Auf welchem Punkt dieser Linie das Verständnis dieser Verbote im konkreten Fall jeweils genau anzusetzen ist, bleibt schwer zu sagen, aber der Sinn dieser Verbote scheint mir doch auf dieser Linie zu liegen. Wem der Schutz, den unsere Verbote dem Muttertier und seinem Jungen gewähren, zu wenig radikal erscheint, der möge bedenken, dass unsere Gerechtigkeit von Kompromissen geschwächt stets fragmentarisch und symbolisch bleibt. Aber von solchen Symbolen leben Glaube, Hoffnung and Liebe. 
5. Der zeitgenössische Horizont der biblischen Vorschriften

Im folgenden soll zu zeigen versucht werden, wie der altorientalische Mensch von der Intensität des Verhältnisses zwischen dem Muttertier und seinem Jungen betroffen war und wie diese Betroffenheit sich in der Tatsache konkretisierte, dass das säugende Muttertier Symbol verschiedener Gottheiten wurde. Diese Tatsachen bilden das Referenzsystem der in Abschnitt 4 vorgetragenen Deutung.

a. Der Sinn für das besondere Verhältnis zwischen Muttertier und Jungem im Alten Orient

Wie der Beginn des 3. Abschnitts gezeigt hat, wurde die "humanitäre" Deutung kritisiert, weil sie ein sentimentales Verhältnis zum Tier nahelege, das dem antiken Menschen im allgemeinen und dem Tenor des Bundesbuches im besonderen fern gelegen hätte. Das Verhältnis zum Tier scheint im Alten orient, wenn auch nicht so extrem, so doch ähnlich zwiespältig gewesen zu sein wie heute. Für uns ist das Tier einerseits in extremem Mass eine Nutzware (Tierfabriken), andererseits aber in ebenso extremem Mass ein Träger emotional-symbolischer Werte (Verhätschelung von Katzen, Hunden, Pferden etc.).

Wenn wir z.B. die reiche Dokumentation der ägyptischen Grabreliefs mit landwirtschaftlichen szenen aus dem 3. und 2. Jt. v. Chr. betrachten, dann fällt auf, mit welchem Realismus, mit welcher Selbstverständlichkeit und Häufigkeit Schlachtungsszenen dargestellt werden ${ }^{113}$. Daneben aber finden sich szenen, die eine warme Anteilnahme z.B. am Verhältnis, das Kuh und Kalb oder die Gazelle und ihr Junges verbindet, bezeugen.

113 VANDIER, Manuel V 128-185, 234-250; EGGEBRECHT, Schlachtungsbräuche. 


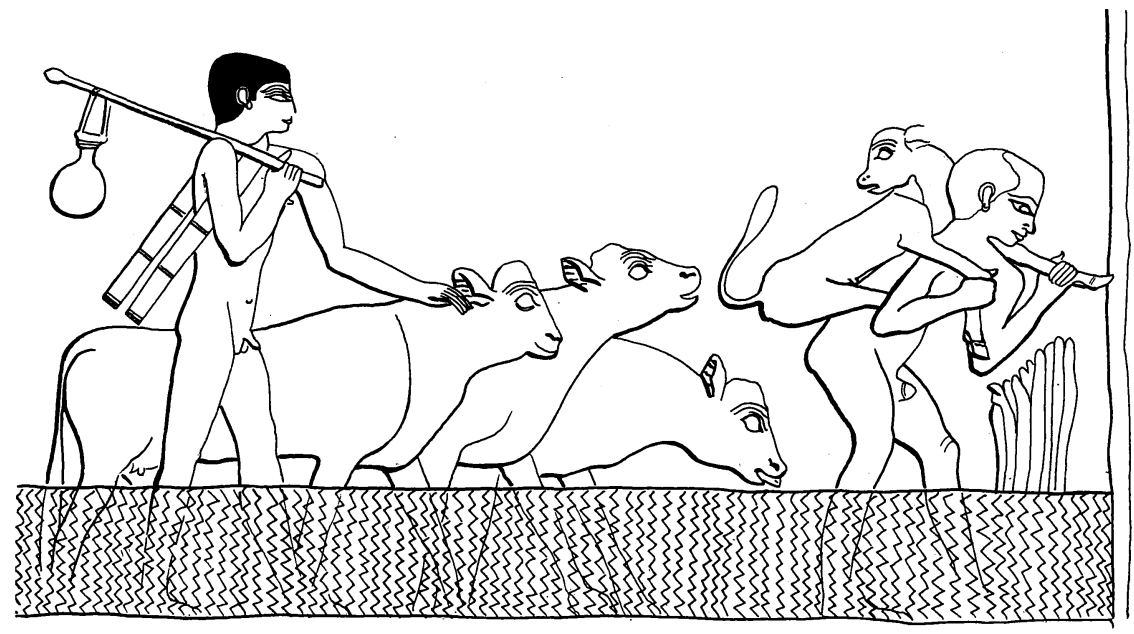

Abb.3 Relief aus dem Grab des Ti, 5.Dyn.; KEEL, AOB PS Abb.312.

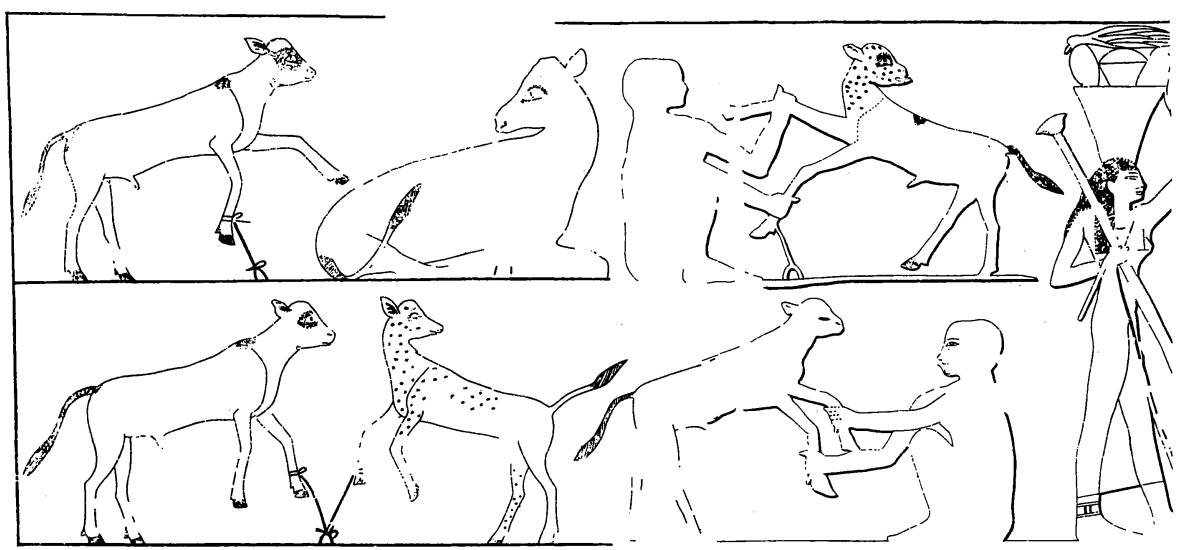

Abb.4 Relief aus dem Grab des Ptahhotep und des Achethotep, 5.Dyn., DAVIES, Ptahhetep II PI.XI. 
Ein bekanntes Relief im Grab des Ti (5. Dynastie) in Saqqara zeigt, wie ein Hirte ein Kalb durch einen Kanal trägt. Es blickt ängstlich nach dem Muttertier zurück. Dieses geht mit erhobenem Kopf muhend hinter ihm her (Abb.3) ${ }^{113 a}$

In der Mastaba des Ptahhotep und des Achethotep (ebenfalls in Saqqara und ebenfalls aus der 5. Dynastie) sieht man, wie angebundene oder von speziellen Kälberhirten ( $I_{j j w}$ bhsw) gehaltene Kälber zu den Muttertieren drängen $\left(\underline{\mathrm{Abb} .4}^{114}\right.$.

Eindrücklicher zeigt die gegenseitige Bindung der beiden Tiere ein Relief aus dem Grab G 2184 aus Giza aus der Zeit des Uebergangs von der 5. zur 6. Dyn. (Abb.5). Während ein Hirte die Kuh melkt, zieht ein anderer Hirte das Kälbchen von ihr weg. Die Kuh dreht ihren Kopf mit heraushängender zunge zum Kälbchen hin.

Weniger bewegten, dafür umso innigeren Ausdruck hat der gleiche Vorgang auf den Kalksteinsärgen der Prinzessinnen Kauit (Abb.6) und Kemsit (Abb.7) aus der Zeit Mentuhotep Nebhetepre's (11. Dyn.) aus Der el-Bahari gefunden. Das Relief vom Sarg der Kauit und die Bruchstücke von dem der Kemsit zeigen eine ruhig dastehende, nicht gefesselte Kuh, die gemolken wird. Ihr Kälbchen ist an einem ihrer Vorderbeine angebunden und hält den Kopf traurig gesenkt, während die Kuh über die Zweckentfremdung ihrer Milch eine Träne vergiesst.

Die Sorge der Kuh um das Kalb bringt sehr schön eine Grabmalerei aus Gebelein (ebenfalls aus der 11. Dyn.) zur Anschauung. Die Kuh, bei der noch die Reste der Placenta zu sehen sind, leckt das auf schwachen Füssen stehende Neugeborene (Abb.8). W.WOLF spricht im Zusammenhang mit Abb.6 von einem liebenswerten Zug menschlichen Empfindens, "der hier dem Tier unterstellt wird"115.

$113 a$ Dieses Motiv kehrt bis in die hellenistische Zeit immer wieder. Vgl. Abb.13,21,23,27a.

114 Vgl. dazu HERMANN, Liebesdichtung 30.

115 WOLF, Kunst 359. 


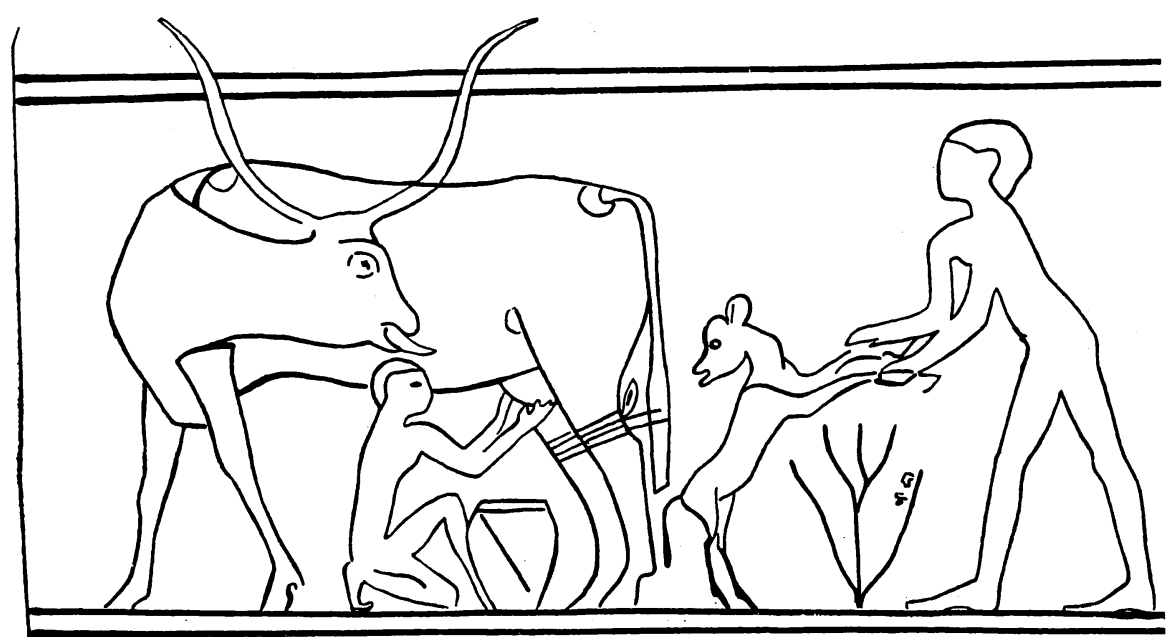

Abb.5 Relief aus Grab 2184 in Giza; Uebergang von der 5. zur 6.Dyn.; SMITH, History $208 \mathrm{Fig.} 79$.

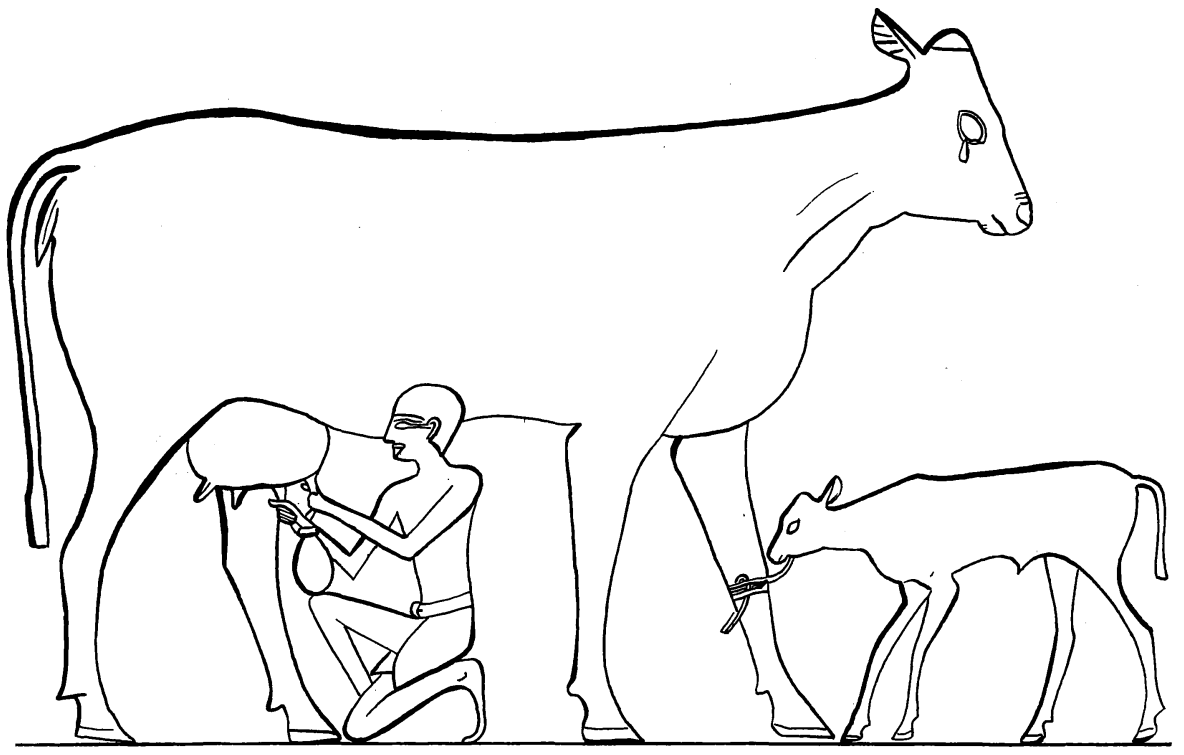

Abb.6 Relief auf dem Sarg der Kauit, Museum Kairo Nr. 623; 11.Dyn.; WOLF, Kunst 357. 


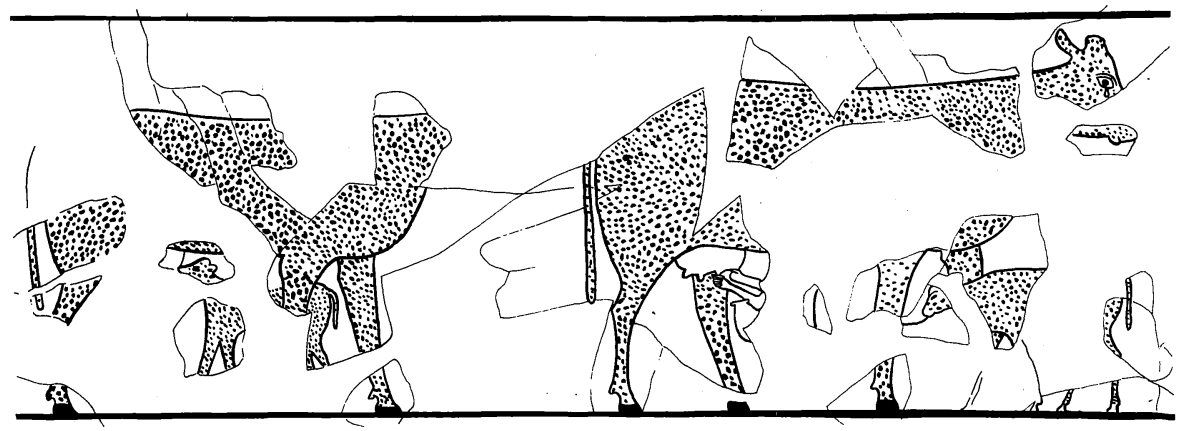

Abb.7 Reliefbruchstücke vom Sarg der Kemsit, Britisches Museum Nr. 43037; 11.Dyn.; NAVILLE, XIth Dynasty Temple I Pl.XXII.

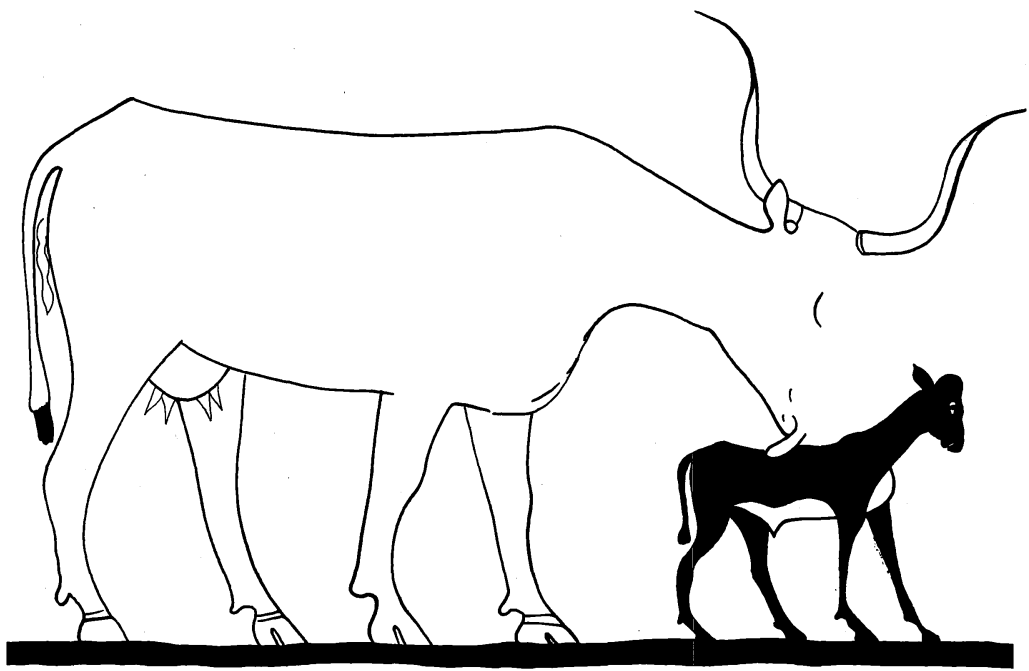

Abb.8 Malerei aus Gebelein, Aegyptisches Museum, Turin; 11.Dyn.; SCAMUZZI, Egyptian Art PI.XV. 
Das heute noch zu beobachtende Schwanken zwischen der brutalen Verwertung des Tiers als Nahrungslieferant und seiner Vermenschlichung war anscheinend schon den alten Aegyptern nicht fremd.

Aber nebst diesen extrem anthropozentrischen Verhaltensweisen ist nicht $\mathrm{zu}$ vergessen, dass der Alte Orient dank seines intensiven Umgangs mit der Tierwelt weitreichende Kenntnisse biologischer Vorgänge und tierischen Verhaltens hatte und sich seiner Verantwortung dem Haustier gegenüber grundsätzlich bewusst war. Einer der ersten Sätze im sogenannten negativen Sündenbekenntnis des ägyptischen Totenbuchs lautete :

"Ich habe kein Unrecht gegen Menschen begangen, und ich habe kein Tier misshandelt"115a.

Das gilt auch für das alte Israel. Das Buch der Sprüche bezeichnet es als ein Signum des rechten Menschen (des Menschen der in Ordnung ist, kurz des צדיק), dass er die Bedürfnisse seines Viehs kennt, während der עשר, der notorisch schuldige Typ, grausam ist.

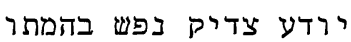

ררחמי רשעים אכזרים ביפים

"Ein Gerechter weiss um die Bedürfnisse seines Viehs, das Gefühl der Frevler aber ist grausam" (Spr 12,10).

Ausdruck dieser Art von Gerechtigkeit dürfte im AT etwa das Gebot sein, ähnlich wie knecht und Magd auch Rind und Esel, ja jedes Tier, am Sabbat ruhen zu lassen (Dtn 6,14; Ex 20,10), oder das Verbot, dem dreschenden Rind das Maul zu verbinden (Dtn 25,4).

Vor allem aber weiss das AT auch um die spezielle Bindung zwischen dem Muttertier und seinem Jungen. Wenn zwei säugende Kühe nicht ihren kälbern folgen, sondern den wagen mit der Lade von den Kälbern weg nach Bet Schemesch ziehen, dann ist das ein ganz klarer Beweis dafür, dass die kühe von einer Gottheit geführt wurden (1 Sam 6,7-12), denn alle Instinkte der Kuh drängen sie zu ihrem Kalb.

115a HORNUNG, Totenbuch 234, Spruch 125, Z. 13 f. 
Aber der Israelit kennt nicht nur die besondere Beziehung zwischen Muttertier und Jungem, sondern es ist für ihn darüber hinaus selbstverständlich, dass ein Hirte - schon im eigenen Interesse - auf diese besondere Beziehung und auf die Empfindlichkeit der Neugeborenen und der säugenden Muttertiere Rücksicht nimmt. Esau akzeptiert ohne weiteres die Entschuldigung Jakobs, der ihm nicht folgen will, er könne nicht schnell gehen, denn er habe für säugendes (עלות) von II עול , עלו Gross- und Kleinvieh zu sorgen (Gen 33,13). Und nicht anders als Jakob führt der göttliche Hirte die säugenden Muttertiere mit besonderer Umsicht (Jes 40,11 ; vgl. Ps 78,71). Noch der Städter PHILO aus Alexandrien begründet um die Zeitenwende das Verbot, ein Jungtier unmittelbar nach der Geburt zu schlachten, nicht ausschliesslich mit erhabenen Gedanken über die Weltordnung, sondern ganz handfest auch mit dem Hinweis auf Probleme des sonst gestörten Milchhaushalts beim Muttertier ${ }^{116}$.

Ueber die Bedürfnisse seines Viehs hinaus respektiert der rechte Hirte, wenn er dem Muttertier und seinem Jungen die nötige Pflege angedeihen lässt, den Segen, der sich im Werfen der Herden und im Vorhandensein genügender Milch kundtut. Dem Israel, das den Willen Jahwes ernst nimmt, verheisst das Deuteronomium : "Er wird dich lieben und segnen und dich vermehren. Er wird die Frucht deines Leibes und die Frucht deines Ackers segnen, dein Getreide, deinen Traubensaft und dein Oel, den Wurf deiner Rinder und den Zuwachs (עשתרת) deines Kleinviehs" (Dtn 7,13; vgl. Dtn 28,4.18.51). Dass, was als segen gilt, gleichzeitig als schön empfunden wird, ist im AT selbstverständlich (vgl. Ps 144,13f). Die Zähne der Geliebten schliessen dicht zusammen, wie (säugende) Mutterschafe mit ihren Lämmern eine Einheit bilden 117 .

Es ist eigentlich $z$ u erwarten, dass man diese heilige sphäre des Segens und der Schönheit mit gewissen Tabus umgeben hat, d.h.

116 De virtutibus $\$ 128$; ed. WENDLAND V 304. Vgl. oben s. 18.

$117 \mathrm{Zu}$ dieser Interpretation siehe ROBERT/TOURNAY/FEUILLET, Cantique des Cantiques 161. 
dass man gewisse radikale und heftige Eingriffe in sie unter Verbot stellte ${ }^{118}$.

Mein Kollege D.BARTHÉLEMY hat mich darauf aufmerksam gemacht, dass ähnliche Einschränkungen im Hinblick auf die Nutzung der Pflanzenwelt zu finden seien. Dem Verbot, die Jungen vor dem achten Tag ihren Muttertieren wegzunehmen, entspricht das Verbot, von den Bäumen vor dem vierten Jahr Früchte zu ernten (Lev 19,23-25). Gegen eine radikale Ausbeutung richtet sich auch das Gesetz, das Feld nicht bis zum äussersten Rand abzuernten (Lev $19,9 a ; 23,22 a)$ und keine Nachlese $\mathrm{zu}$ halten. Diese letztere Bestimmung wird im heute vorliegenden Wortlaut sozial gedeutet, insofern die Nachlese den ökonomisch Schwachen überlassen werden soll (Lev 19,9b-10; 23,22b; Dtn 24,19-22). Das Gleiche gilt vom Sabbatjahr, das vorschreibt, den Ackerboden jedes siebte Jahr brach zu lassen, mindestens in der Version von Ex 23,10-12. Die Parallelstelle in Lev 25,1-7, die vom Brachjahr redet, ohne den sozialen Aspekt zu nennen, scheint aber nahezulegen, dass es auch hier primär um eine tiefsitzende scheu vor einer radikalen und konsequenten Ausnützung der Aecker geht, durch die man dem Segen und der Gottheit, die ihn gibt, zu nahe zu treten glaubte.

118 Von einem solchen Tabu berichtet H.A.WINKLER von den Abbade, einem Nomadenstamm in den wüstenhaften Gebieten östlich vom Nil. Es betrifft die Milch : "Seine Milch verkauft der abbadische Hirte nicht... Die Milch ist ein Segen (baraka). Jeden Morgen und jeden Abend ist sie von selber da. Würde man diesen Segen verkaufen, würde man damit den Schafen und anderem Milchvieh schaden... Wenn er in guten Zeiten sehr viel Milch hat, so verschenkt er sie" (Aegyptische Volkskunde 339). J.G.FRAZER hat eine Menge Material, besonders aus Afrika und Ostasien, gesammelt (Folklore III 111-164), das das Muttertier und seine Milch zum Gegenstand hat. Darunter ist viel, was mit unseren Vorschriften kaum etwas zu tun hat, so das Verbot Milch zu kochen oder Milch mit Fleisch in Berührung zu bringen. H.CAZELLES kann wohl mit Recht darauf hinweisen, dass Israels Nachbarstämme - und Israel selber wahrscheinlich auch - Zicklein in Milch gekocht hätten (Etudes 102). Wenn aber z.B. bei den Thonga, einem Bantu-Stamm Südost-Afrikas, die Milch einer Kuh, die eben gekalbt hat, tabu ist und nur von ihrem Kalb oder von Kindern getrunken werden darf (Ebd. 121, 143; vgl. 37), so liegt hier eine Tabuisierung der Beziehung zwischen dem Muttertier und seinem Jungen vor, die von derjenigen, die die atl Verbote anstreben, nicht allzu weit entfernt ist. 
Im säugenden Muttertier aber hat man nicht nur eine Manifestation des Segens, sondern gelegentlich sogar eine Art lebendige Ikone der Gottheit gesehen.

b. Das säugende Muttertier als Symbol des Segens und der sorgenden Liebe der Gottheit

Nicht jedes Bild eines säugenden Muttertiers ist das Bild einer Gottheit. Aber da die Grenze zwischen realistischer Darstellung und Symbol fliessend ist, soll hier kurz die Geschichte des Motivs an sich skizziert werden. Diese Geschichte ist lang und abwechslungsreich, und verschiedene ihrer Aspekte waren schon Gegenstand von Untersuchungen ${ }^{119}$.

F.POULSEN hat 1912 die Kuh mit dem Kalb auf phönizischen Metallschalen und Elfenbeinen als dem ägyptischen Repertoire zugehörig bezeichnet ${ }^{120}$. C.WATZINGER, der auf die Fayencegruppen mit der säugenden Kuh und der säugenden ziege aus der mittelminoischen Zeit (2000-1550 v.Chr.) vom Palast von Knossos verweist, scheint einen kretischen Ursprung der Gruppe anzunehmen, wenn er sagt : "Das Bild der Kuh mit dem Kälbchen als Abbild einer göttlichen Kurotrophos ist in der Folgezeit über Phönikien, Kleinasien und Griechenland weiter verbreitet (sic!) und scheint in Griechenland vornehmlich mit dem Kult der Hera verknüpft zu sein"121. In der Publikation der Arslan-Tasch-Elfenbeine aus Nordsyrien, bei denen das Motiv der säugenden Kuh sehr häufig ist, haben die Ausgräber auf die ägyptisch-ägäische Abhängigkeit dieser Gruppe hingewiesen ${ }^{122}$.

In seiner grossen Publikation des Palastes von Knossos stellt A.EVANS fest : "The traditional scheme of the cow suckling its

119 Es ist hier kein vollständiger Forschungsbericht angestrebt. Es soll nur auf ein paar Gesichtspunkte hingewiesen werden.

120 Der Orient 29, 55.

121 Adonisfest (1928) $264 \mathrm{f}$.

122 THUREAU-DANGIN / BARROIS / DOSSIN / DUNAND, Arslan-Tash (1931) 119-126. 
calf goes back, on Egyptian monuments, to the old Empire... From the beginning to the end however, the Egyptian versions are little more than pictographs, schematically recording a certain phase in a cows career... Generally speaking, in Egypt, the Cow and Calf motive had been little more than genre - though it is probable that the formal type had reached Crete, as it did the Syrian coastlands, from that source. That, from the Minoan point of view, however, it had also a religious reference might in itself be gathered from the occurence of the faience reliefs in the Temple Repositories, and, as already shown, there are reasons for supposing that in this respect the palace cult had a direct relation to that of the Delta Goddess Wazet, a form of Hathor, whose symbole was the papyrus wand"123. Mit diesem letzten Satz wäre aber auch schon gesagt, dass sich der ägyptische Einfluss nicht bloss auf die "Hülle", sondern auch auf den Inhalt beziehen würde. Der Bedeutung der Wildziegen auf Kreta entsprechend, auf die WATZINGER hinweist, wäre dann aber zum Bild der säugenden Kuh als Symbol der Muttergötting das der säugenden Ziege getreten.

Während diese Arbeiten die früheste Geschichte des Motivs vor allem im ägyptisch-ägäischen Raum zu orten suchten, wies R.D. BARNETT 1935 darauf hin, dass die säugende Kuh seit frühester Zeit ein Symbol der mesopotamischen Ninchursag/Ischtar gewesen sei ${ }^{124}$. Ein reiches Material zu säugenden Tieren als Symbol vorderasiatischer Göttinnen hat 1945 E.D.van BUREN vorgelegt ${ }^{125}$. B. BUCHANAN wollte dann aber 1957 die mit zum Kalb bzw. Kitz rückwärts gewendetem Kopf säugende Kuh bzw. Ziege auf altsyrischen und altbabylonischen Siegeln doch auf ägyptische Vorbilder zurückführen ${ }^{126}$.

123 Palace of Minos IV,2 (1935) 554; vgl. 552-559.

124 Iraq 2 (1935) 206f; stark erweiterte Beweisführung in: Ders., Catalogue 143-145.

125 Symbols 36-39.

126 JCS 11 (1957) 75. 
Die meines Wissens gründlichste und ausführlichste bisher erschienene Studie zu unserem Motiv ist die von P.MATTHIAE,"Il motivo della Vacca che allatta nell'Iconografia del Vicino Oriente antico"127. Dabei gilt sein Interesse allerdings ausschliesslich der Variante, bei der die säugende Kuh ihren Kopf rückwärts dem Kalb zuwendet. MATTHIAE fasst das Ergebnis seiner Forschungsarbeit wie folgt zusammen : "Das Thema, in profaner Absicht in der Umgebung von Memphis entstanden, verbreitet sich breitgestreut in die Nekropolen der Peripherie, bis es die Grenzen der Ikonographie des Totenkults überschreitet. Von der ersten Zwischenzeit an lässt sich beobachten, wie sich das Motiv aus seinem ursprünglichen Kontext löst, ohne dabei symbolische Implikationen, höchstens vielleicht anspielungsweise anzunehmen. Während der 12. Dynastie, wahrscheinlich, als die Beziehungen zur asiatischen Nachbarschaft enger wurden, wanderte das Motiv nach Syrien und von dort rasch nach Mesopotamien. Im mesopotamischen Raum vollzog sich eine deutliche Verbindung mit weiblichen Gottheiten. währenddem einerseits die babylonische Tradition das Thema schematisierte, wirkte die syrische Kultur in dem Sinne positiv, als sie einige neue Elemente hinzufügte. Nur wenig später wird das Thema in Kreta eingeführt, wo das Bild einen der syrischen Dynamik nahestehenden Rhythmus annimmt. Während Kreta am Ende des 2. Jts. bzw. anfangs des 1. Jts. das Bild den Erben seiner Ikonographie auf dem Festland überliefert, geben die syrischen Werkstätten das inzwischen zu ungewöhnlichem Ansehen gelangte Motiv der zyprischen Kunst weiter"128.

Ich möchte im folgenden eine, wie ich hoffe, repräsentative Auswahl von Belegen für das säugende Muttertier aus Aegypten und Vorderasien vorlegen, ohne Vollständigkeit anzustreben und ohne die Untersuchung auf einen, formal noch so interessanten Typ einzuengen, und dabei hauptsächlich die Frage im Auge behalten, ob

\footnotetext{
127 RSO 36 (1961) 21-23.

128 Ebd. $29 f$.
} 


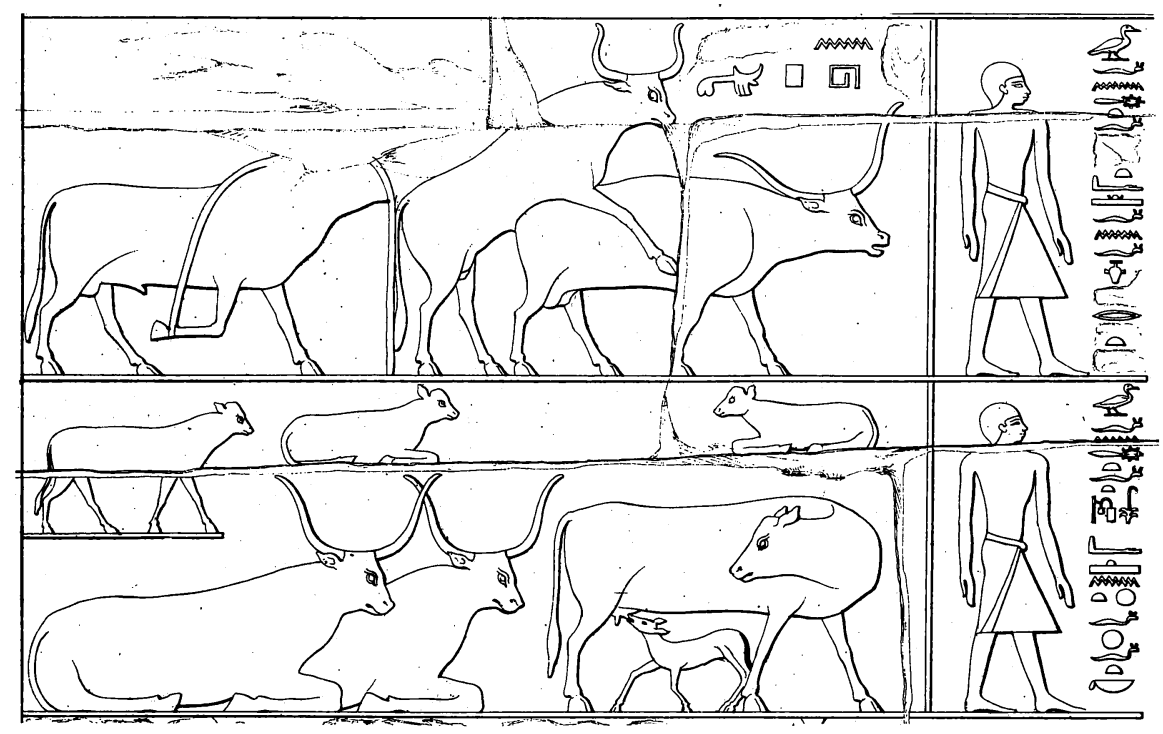

Abb.9 Relief aus Grab 27 (LEPSIUS) in Giza; 5.Dyn.; LEPSIUS, Denkmäler Bd III. BI. 77.

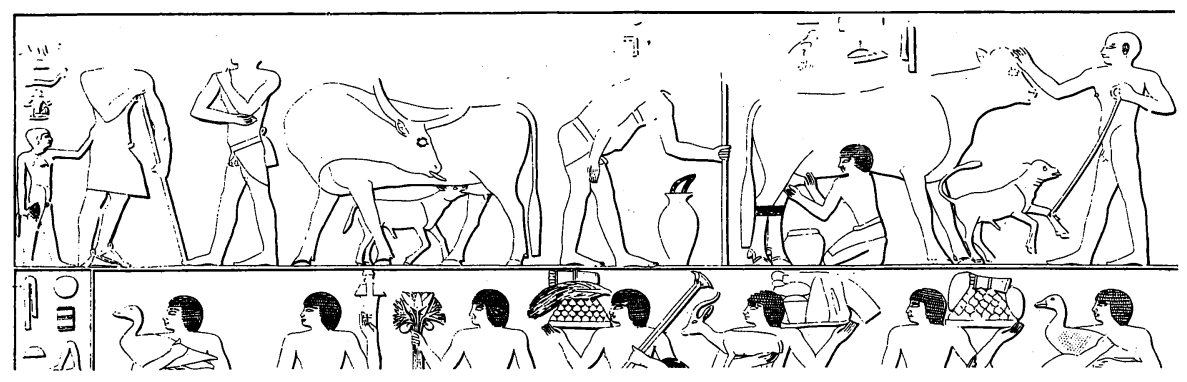

Abb.10 Relief aus dem Grab des Ptahhotep und Achethotep in Saqqara; 5.Dyn.; DAVIES, Ptahhetep II, PI. XVII. XVII. 
und, wenn ja, welche symbolische Bedeutung das Motiv habe.

Im Aegypten des Alten Reiches finden wir seit der 4. Dynastie im Rahmen landwirtschaftlicher Szenen, die das Leben auf den Gütern des Grabherrn schildern, nicht allzu häufig, aber regelmässig das Motiv der Kuh, die ein Kalb säugt. Dabei wendet sie oft den Kopf zurück (Abb.9), leckt gelegentlich das säugende Kalb (Abb.10-11). Gelegentlich leckt sie auch - wenig um das Kalb bekümmert - gleichzeitig ihre klaue, mit der sie sich kratzt (Abb.12). Seit der 4. Dynastie finden sich aber auch Beispiele, bei denen die säugende Kuh den Kopf nicht zurückwendet, sondern normal erhoben hält (Abb.13). Auf einem Grab in der Provinz (Assuan) senkt sie ihn gar zum Grasen (Abb.14) ${ }^{129}$. Das Motiv will im Rahmen der landwirtschaftlichen Szenen in Verbindung mit dem des Bespringens (Abb.9), dem der werfenden Kuh (Abb.11), oder dem von gemolkenen (Abb.10) oder von ihren Kälbern begleiteten Kühen (Abb.13) das Gedeihen und die Fruchtbarkeit der Herden des Grabbesitzers vergegenwärtigen, ähnlich wie das AT den Reichtum und Segen eines Menschen durch solche Bilder zur Anschauung bringt :

"Ihr stier bespringt und fehlt nicht, ihre Kuh wirft und hat keine Fehlgeburt" (Ijob 21,10).

"Unsere Rinder sind trächtig, ohne Unfall und ohne Fehlgeburt" (Ps $144,14 a)$ ! $129 a$

Es ist zu beachten, dass beim säugenden Rind oft noch Reste der Placenta $z u$ sehen sind, die saugenden Kälber also als neugeboren vorgestellt werden und eine glückliche Geburt signalisieren.

Das ist z.B. bei einer Wandmalerei aus dem Grab des Anchtifi in Mo'alla (1. Zwischenzeit) der Fall (Abb.15).

129 Weitere Beispiele bei KLEBS, Reliefs des Alten Reiches 62f; MATTHIAE, RSO 36 (1961) 2-4; VANDIER, Manuel V $67 f$.

129a Zu säugenden Tieren als Ausdruck des Segens vgl. die Inschrift von Sfire I A $21 \mathrm{f}$ und den Kommentar von K. GALLING in : ZDPV 83 (1967) $134 \mathrm{f}$. 


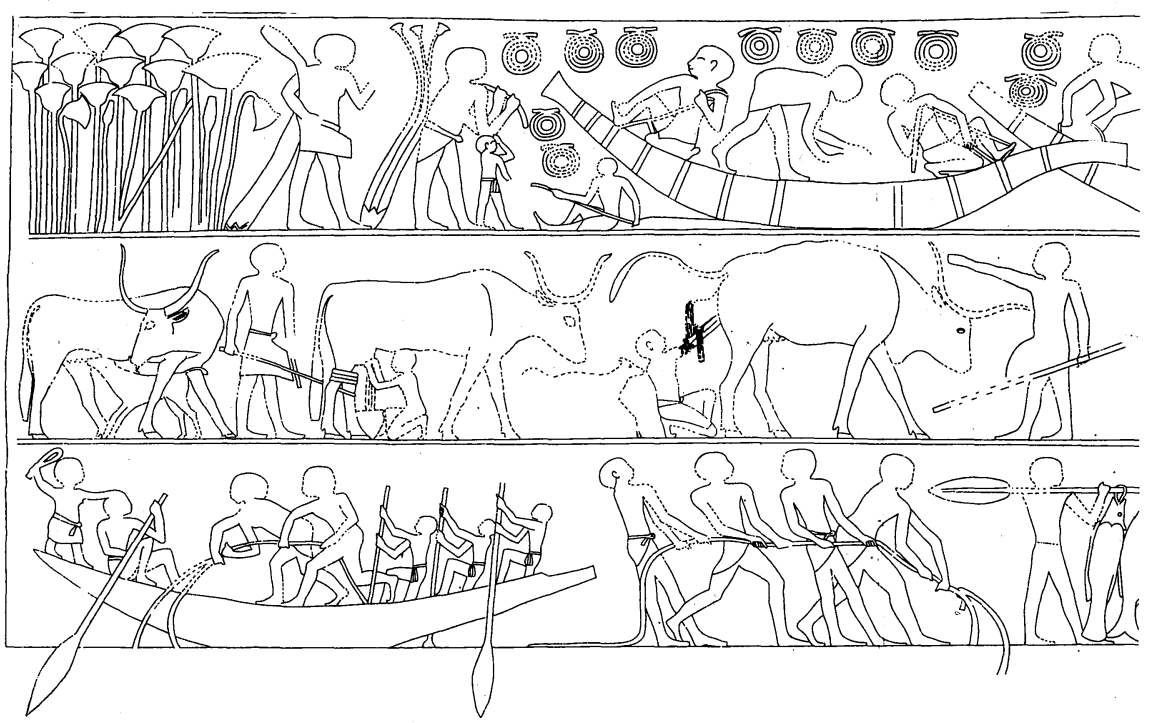

Abb.11 Relief aus dem Grab des Inti in Deschasche; 6.Dyn.; PETRIE, Deshashe PI.V.

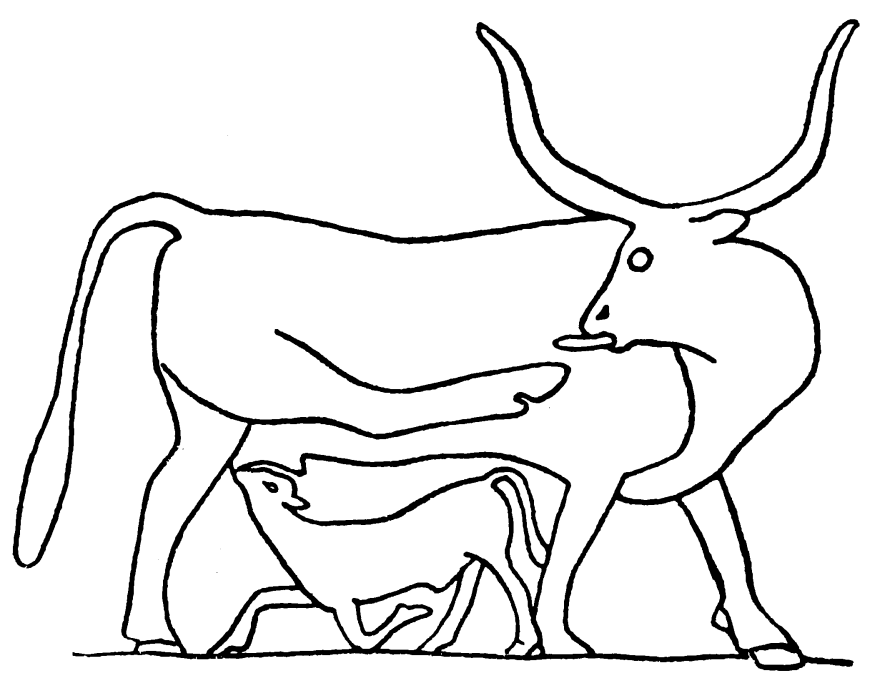

Abb.12 Ausschnitt aus einem Relief im Grab des Jasen (G 2196) in Giza; 4.Dyn.; SMITH, History 327 Fig. 205. 


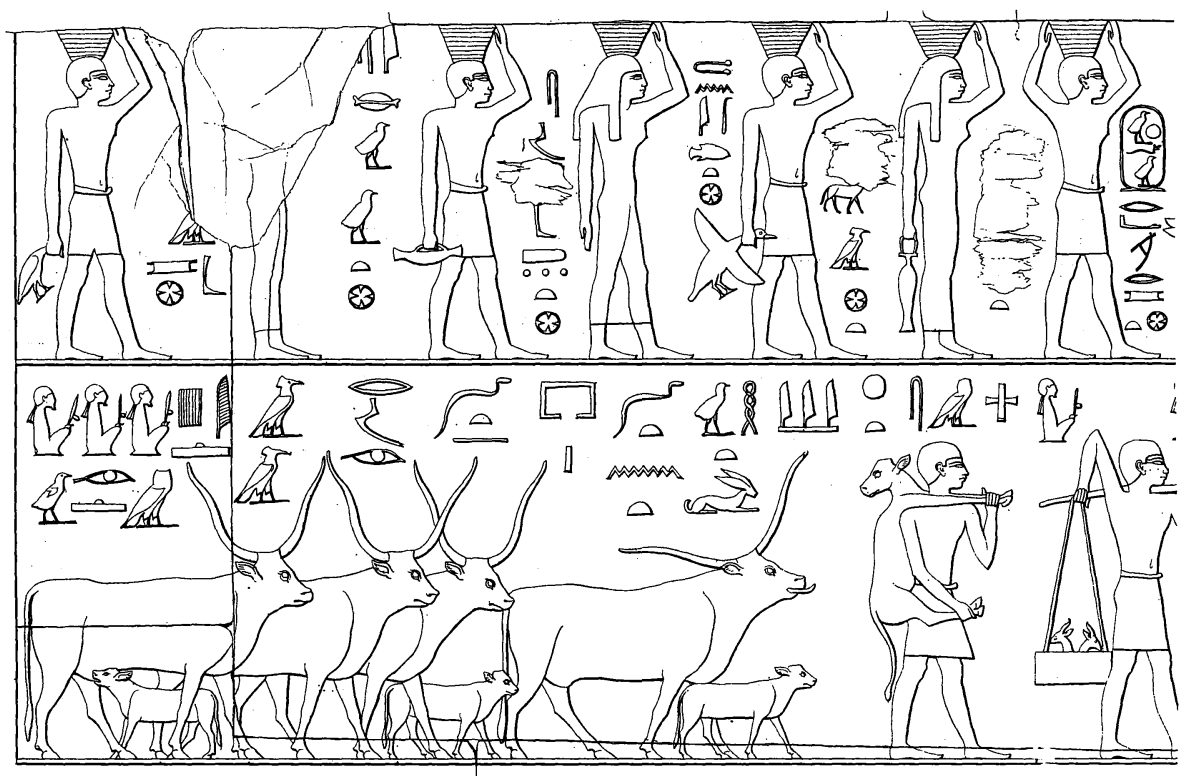

Abb.13 Relief aus Grab 47 (LEPSIUS) in Giza; 4.Dyn.; LEPSIUS, Denkmäler $B d . I I I$ BI.3I.

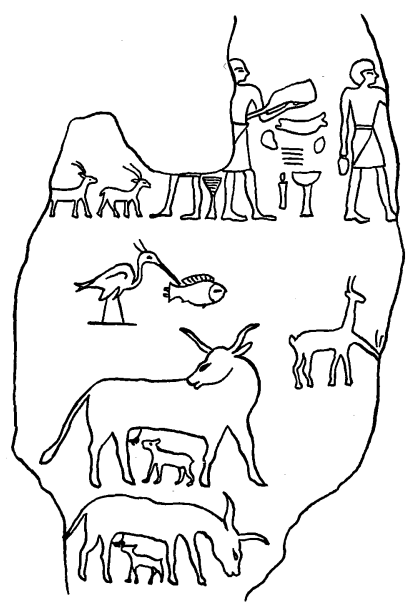

Abb.14 Relief im Grab des Chunes bei Assuan; 6.Dyn.; DE MORGAN, Catalogue I 161. 


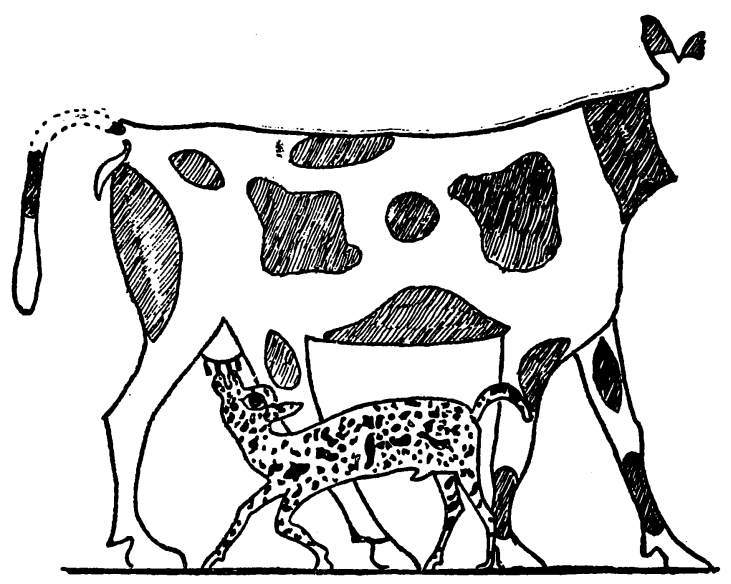

Abb.15 Malerei aus dem Grab des Anchtifi in Mo'alla; 1. Zwischenzeit; VANDIER, Manuel V 187 Abb.92,1.

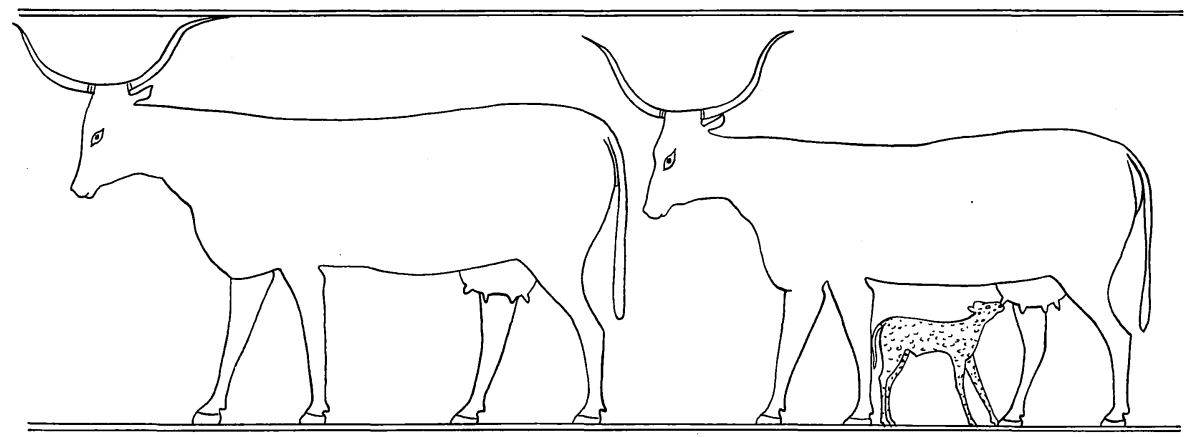

Abb.16 Fragmente eines bemalten Reliefs auf dem Sarg der Kemsit von Deir el Bahari; 11.Dyn.; NAVILLE, XIth Dynasty Temple I PI.XXIII. 

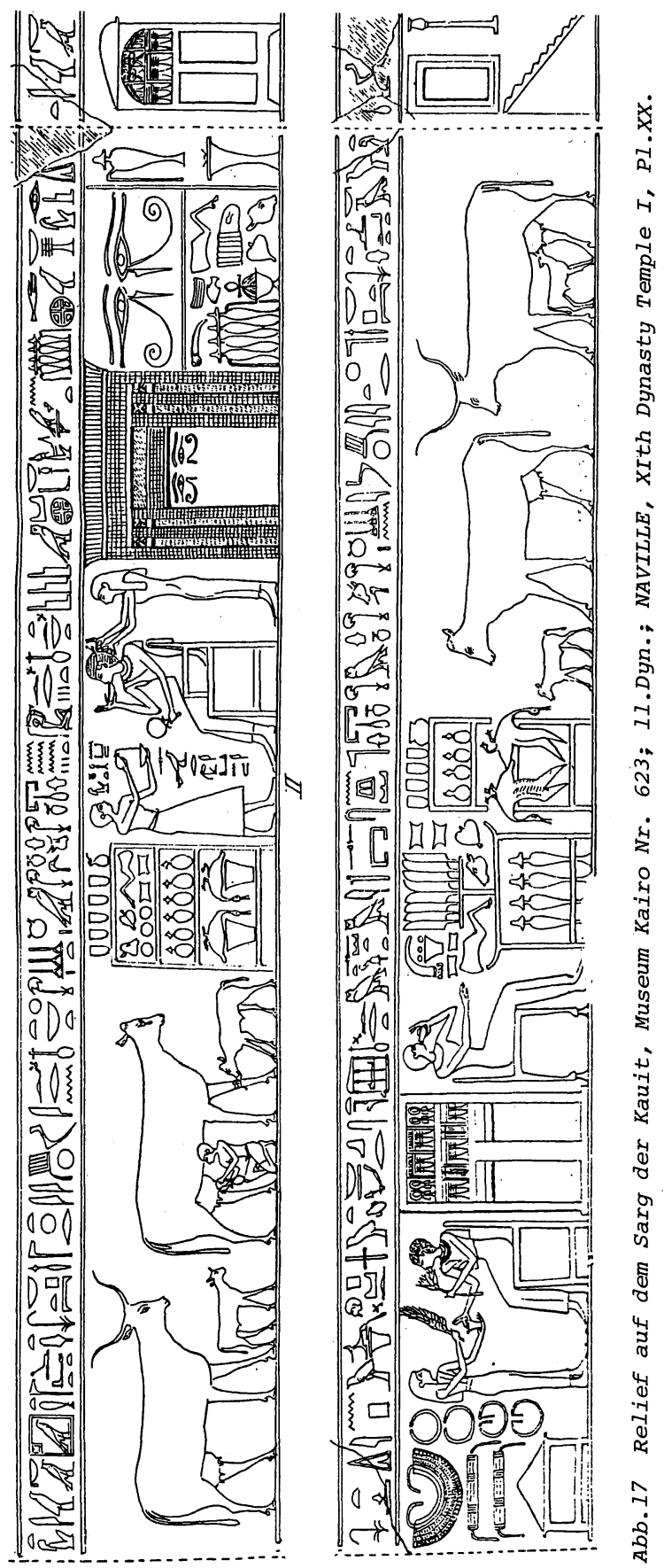


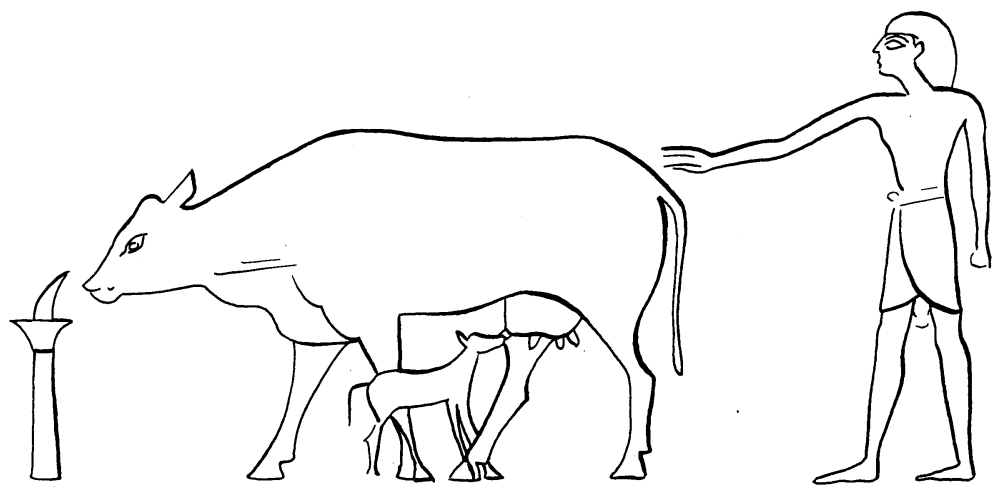

Abb.18 Relief auf dem Sarg der Aschait, Museum Kairo Nr. 6033; 11.Dyn.; LANGE/HIRMER, Aegypten Taf.83 unten.

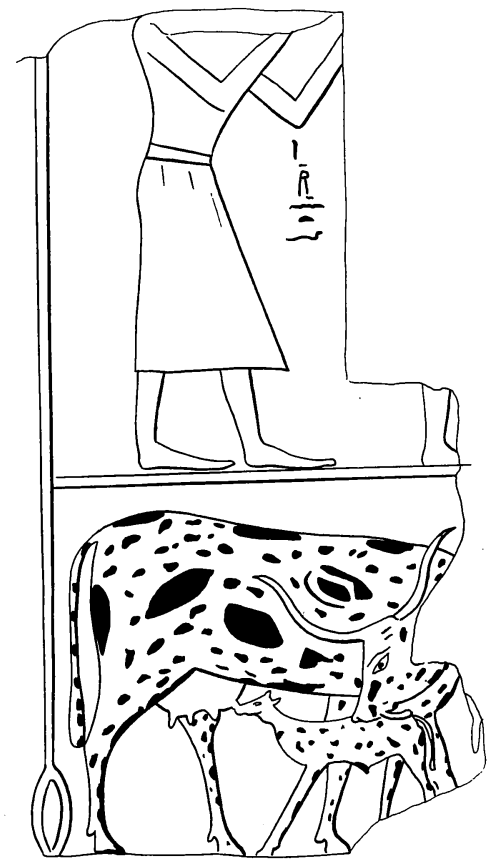

Abb.19 Bemaltes Relief von der Ostwand der Grabkapelle der Aschait; 11.Dyn.; NAVILLE, XIth Dynasty Temple II PI.XVIIA; vgI. Bd I PI.XVIII. 


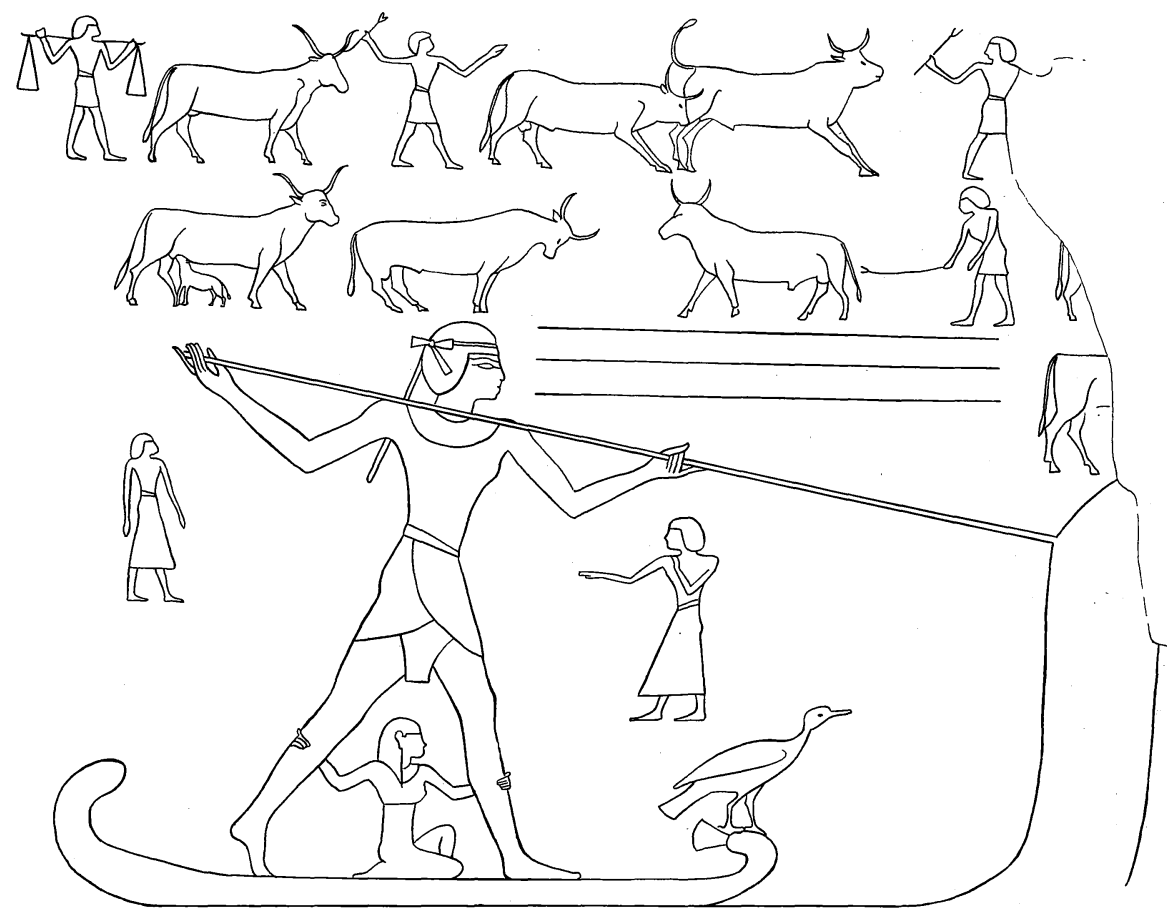

Abb.20 Relief aus dem Grab Sarenputs I. bei Assuan; 12.Dyn.; DE MORGAN, Catalogue I 187.

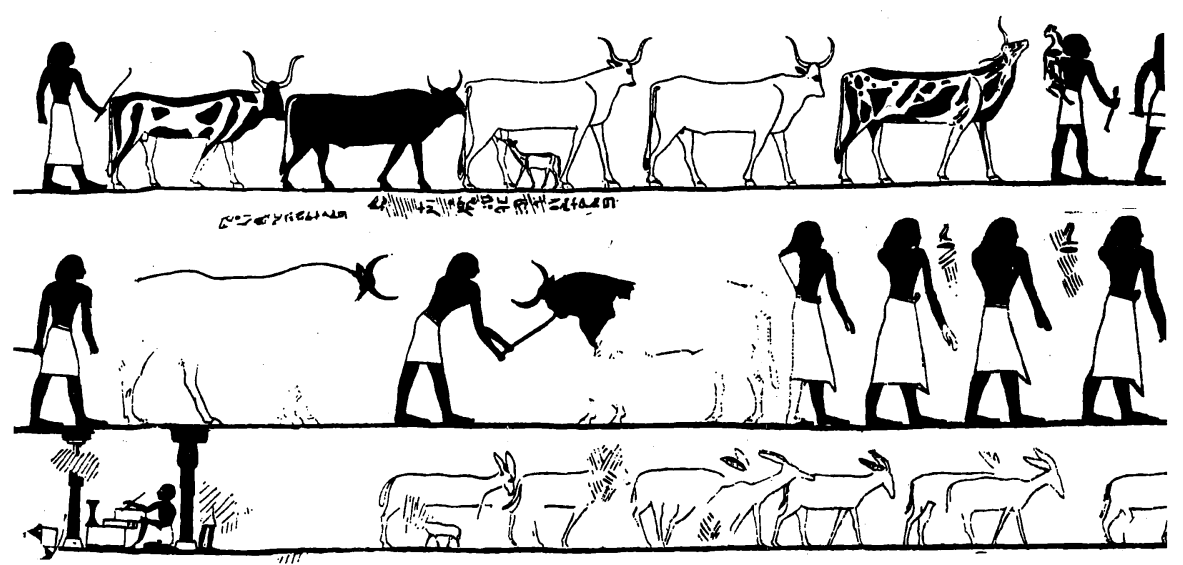

Abb.21 Wandmalerei aus dem Grab Amenemhets in Beni Hasan; 12.Dyn.; NEWBERRY, Beni Hasan I PI.XIII. 
In der 11. Dynastie ist das Motiv der säugenden Kuh auffällig häufig im Umfeld des Totentempels Mentuhotep Nebhetepre $\mathbf{c}_{\mathbf{s}}$ anzutreffen. Den Kontext stellen meist nur noch sehr rudimentäre landwirtschaftliche Szenen dar. Die auffällige Häufigkeit und das teilweise nur noch dürftige Eingebundensein der Kuh-Kälbchen-Gruppe in einen landwirtschaftlichen Kontext - einzelne Belege stehen völlig isoliert - legen den Gedanken nahe, die Verehrung der Hathor in Kuhgestalt, die im Neuen Reich hier so kräftig geblüht hat, reiche in die 1l. Dynastie zurück ${ }^{130}$ und sei nicht ohne Einfluss auf diese Vorliebe gewesen. Allerdings ist auch die Rolle von Kühen im Jenseits zu bedenken, die dem Toten dort als freundliche Nahrungsspender begegnen ${ }^{131}$.

Eine säugende Kuh mit gerade gehaltenem Hals begegnet neben der weinenden Kuh auf dem Sarg der Kemsit (Abb.7). Nebst dieser Gruppe findet sich eine zweite, die zwei schreitende Kühe zeigt, eine davon mit einem säugenden Kalb ( findet sich auf dem Sarg der Kauit (Abb.17), von dem schon unsere Abb.6 stammt. Auch auf dem Sarg einer dritten Gemahlin Mentuhotep Nebhetepre's, auf dem der Aschait, ist die säugende Kuh zweimal zu finden ${ }^{132}$. Das eine Mal schnuppert sie an einer Räucherflamme ( $\underline{\mathrm{Abb} .18})$. Ebenso wenig wie auf dem Sarg fehlt sie in der Grabkapelle der Aschait. Hier wendet die Kuh ihren Kopf dem $\mathrm{Kalb} \mathrm{zu}(\underline{\mathrm{Abb} .19})$.

Als Bestandteil landwirtschaftlicher szenen ist die säugende Kuh auch in der 12. Dynastie noch regelmässig anzutreffen, so im Grab Sarenputs I. bei Assuan (Abb.20), in dem des Gaufürsten Amenemhet in Beni Hasan (Abb.21), in dem des Uchhotep in Meir (Abb.22) . Besonders schön ist das Relief aus dem Grab des Uchhotep, dem Sohn Senbis, auf dem die Kuh das Neugeborene leckt,

130 ALLAM, Hathorkult 65f.

131 BONNET, Reallexikon 403.

132 PORTER/MOSS, Topographical Bibliography II 387. 


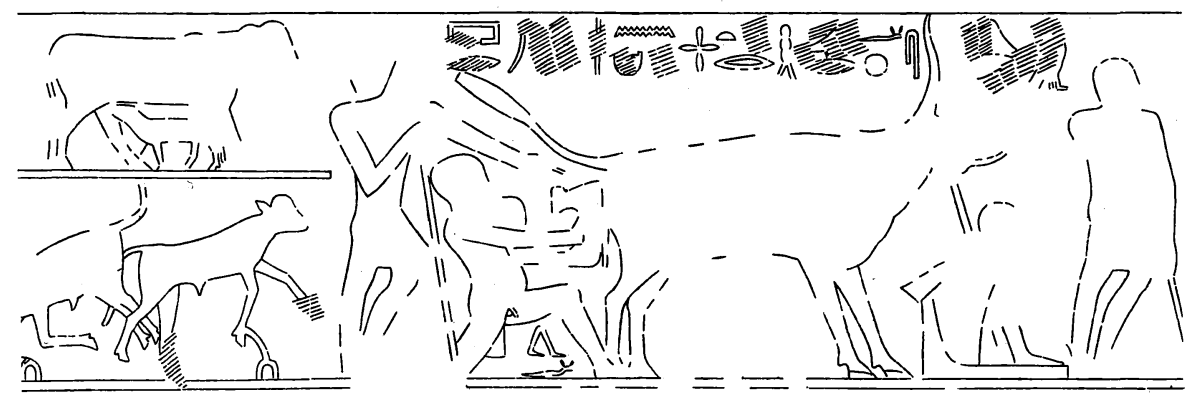

Abb.22 Relief aus dem Grab des Uchhotep in Meir (Nr. B 4); 12.Dyn.; BLACKMAN, Meir III PI.IV.

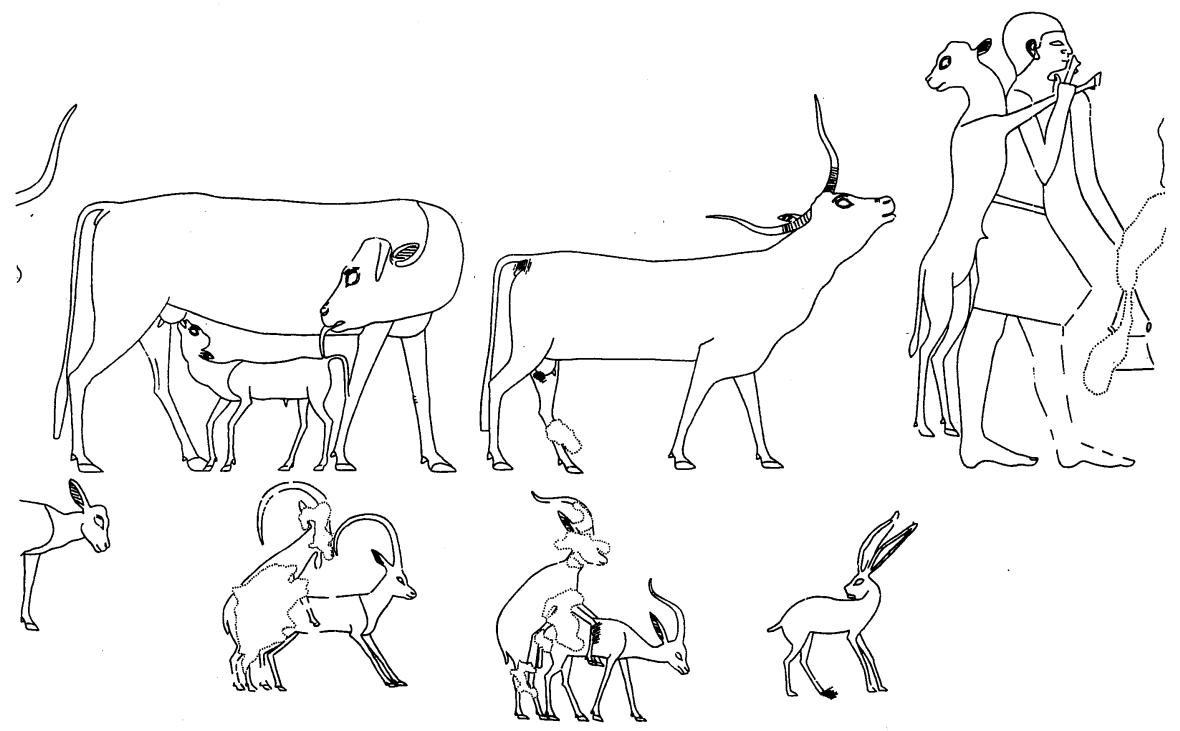

Abb.23 Relief aus dem Grab des Uchhotep, dem Sohn des Senbi in Meir (Nr. $B$ 2); 12.Dyn.; BLACKMAN, Meir II PI.VII und XXXV. 


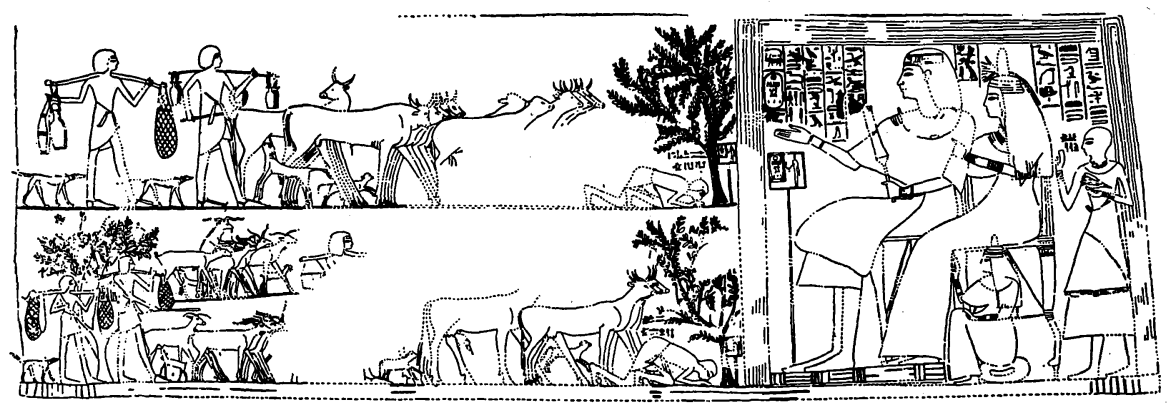

Abb.24 Wandmalerei im Grab des Chons in Abd el Qurna (Nr.31); 18.Dyn.; WRESZINSKI, Atlas I Taf.128 = 130; VANDIER, Manuel V 270 Fig.126.I.

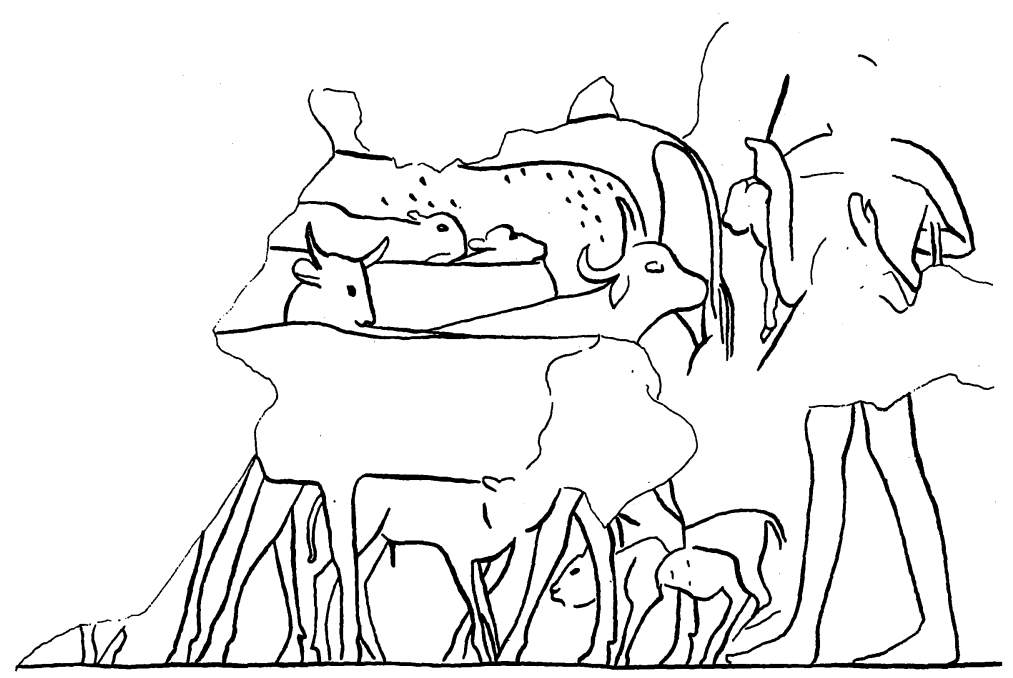

Abb.25 Wandmalerei im Grab des Zenone in Abd el Qurna (Nr.76); 18.Dyn.; WRESZINSKI, AtlaS I Taf. 244. 


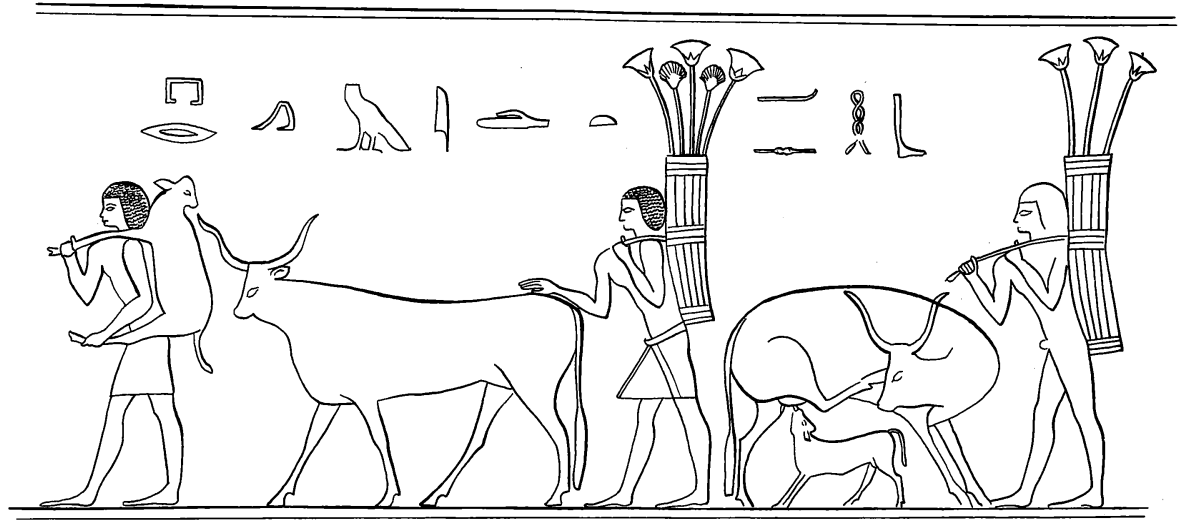

Abb.26 Relief aus Heliopolis im Museum von Kairo; 26.Dyn.; MASPERO, Le Musée égyptien II Pl.XXXV unten.

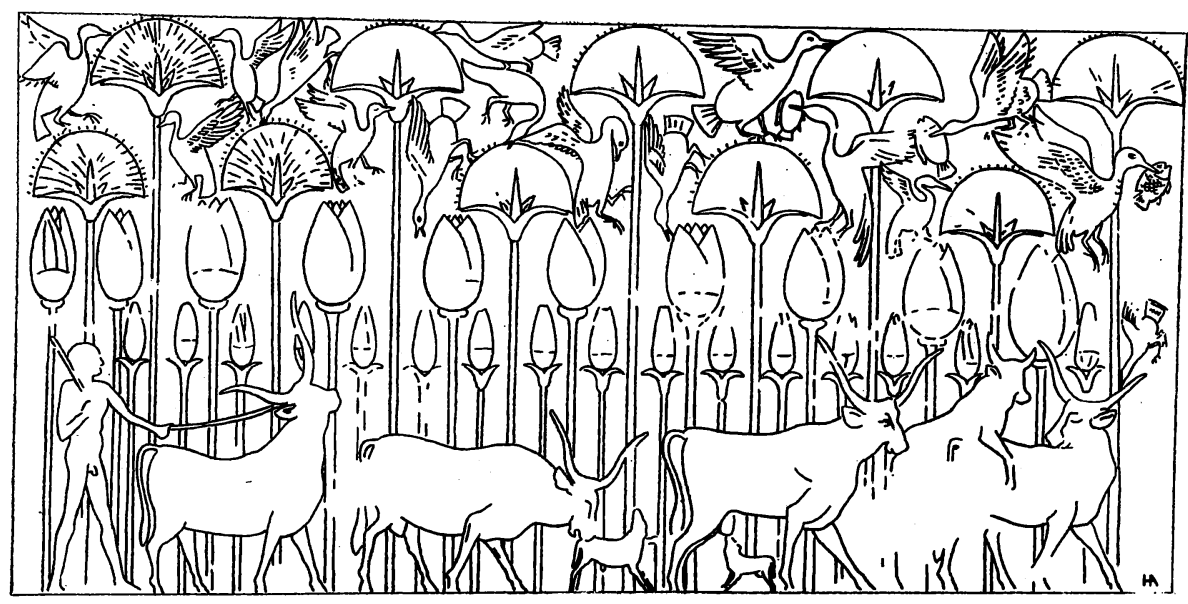

Abb.27 Relief aus dem Grab des Petosiris in Hermopolis; Mitte des 4.Jh.v. Chr.; LEFEBVRE, Petosiris Pl.XXVI. 


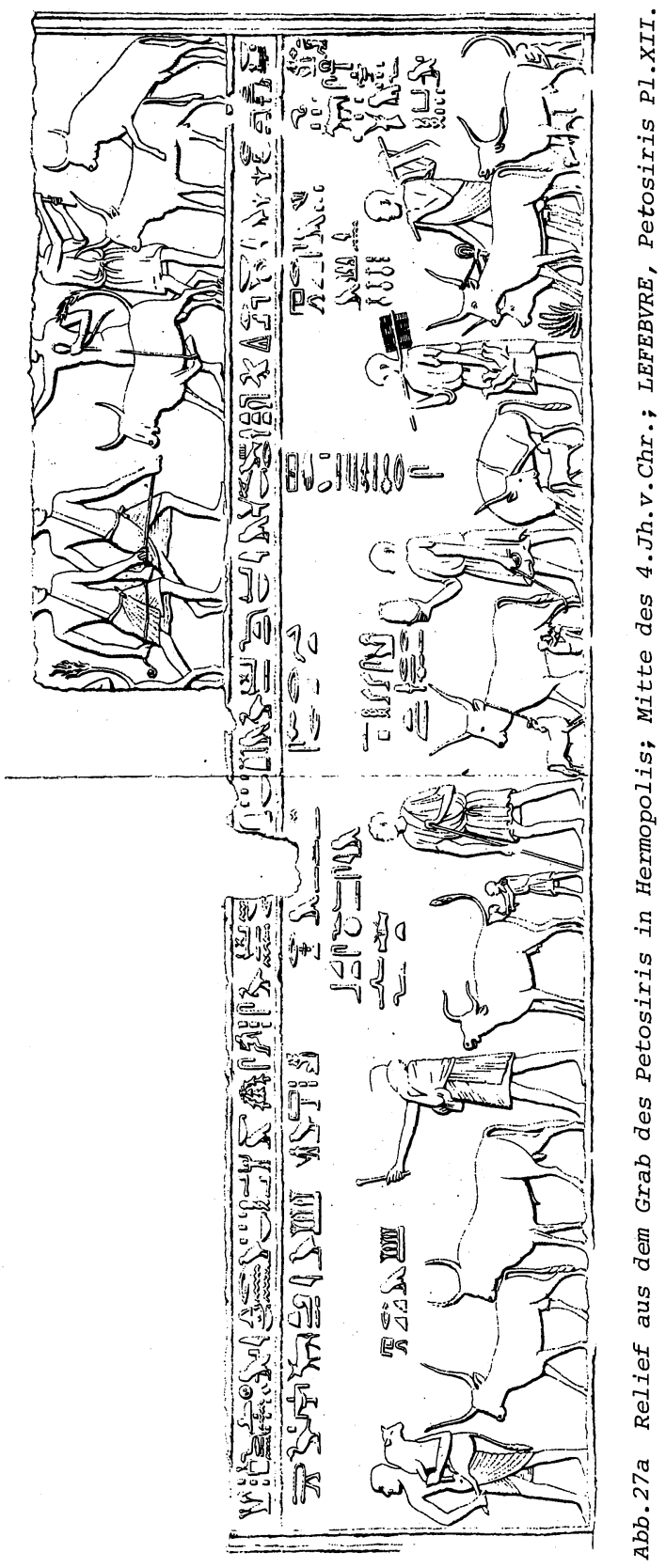




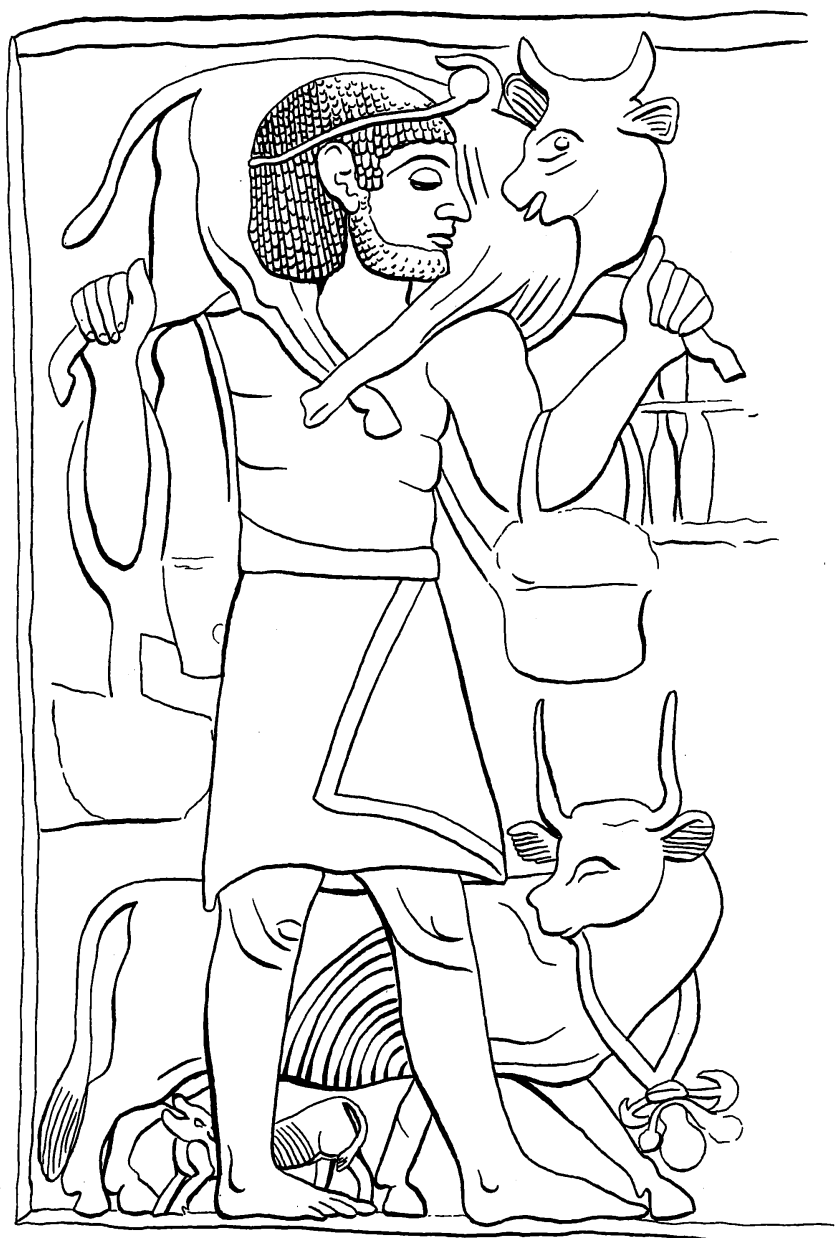

Abb.28 Reliefbruchstück im Roemer-Pelizaeus Museum in Hildesheim (Nr.2244; Ptolemäische Zeit; KAYSER, Roemer-Pelizaeus Museum Abb.92; WOLF, Kunst Aegyptens Abb. 693 
und der Kontext der sich begattenden Steinböcke die Intensität tierischer Fruchtbarkeit evoziert (Abb.23). Die den Blickkontakt mit ihrem Kalb suchende Kuh rechts aussen erinnert an $\underline{\mathrm{Abb} .3^{133}}$.

Auch im Neuen Reich findet sich die säugende Kuh noch gelegentlich im Zusammenhang mit landwirtschaftlichen Szenen, so z.B. im Grab des Chons in Abd el Qurna in der Zeit Thutmosis IV. (Abb.24) und in dem des zenone am gleichen ort und aus der gleichen Zeit $(\underline{\mathrm{Abb} .25})^{134}$.

Aus der Spätzeit sind, der Seltenheit landwirtschatlicher szenen entsprechend, nur noch vereinzelte Belege bekannt, so ein Relief aus saitischer Zeit, das die säugende kuh mit zurückgewandtem Kopf zeigt, die sich während des Säugens kratzt (Abb.26), und zwei Reliefs aus dem Grab des Petosiris in Hermopolis aus dem 4. Jh. v.Chr. (Abb.27 und 27a). Aus ptolemaischer Zeit stammt ein Reliefbruchstück, das einen Gabenträger aus einer Opferprozession darstellt, hinter dem eine säugende Kuh mit rückwärts gewandtem Kopf $\mathrm{zu}$ sehen ist $(\underline{\mathrm{Abb} .28})$.

Nebst säugenden Kühen erscheinen gelegentlich auch säugende Ziegen im Kontext landwirtschaftlicher Schilderungen. Im Grab des Nefer und Ka-Hay (5. Dynastie) in Saqqara säugt von zwei gegenständigen Ziegen, die an einem kleinen Baum knabbern, die eine ein Zicklein (Abb.29). Ebenfalls aus dem Alten Reich stammt ein Reliefbruchstück im Museum von Leiden, das nebst weidenden eine werfende und eine säugende Ziege zeigt (Abb.30). Wie die Kuh kann auch die ziege beim säugen den Kopf rückwärts wenden, wie das auf einem stark beschädigten Relief aus dem Grab des Schedu in Deschasche der Fall ist (Abb.31).

$133 \mathrm{Vgl}$. weiter KLEBS, Reliefs des Mittleren Reiches 89f; MATTHIAE, RSO 36 (1961) 5f; VANDIER, Manuel V 228.

134 Vgl. weiter KLEBS, Reliefs des Neuen Reiches 68. 


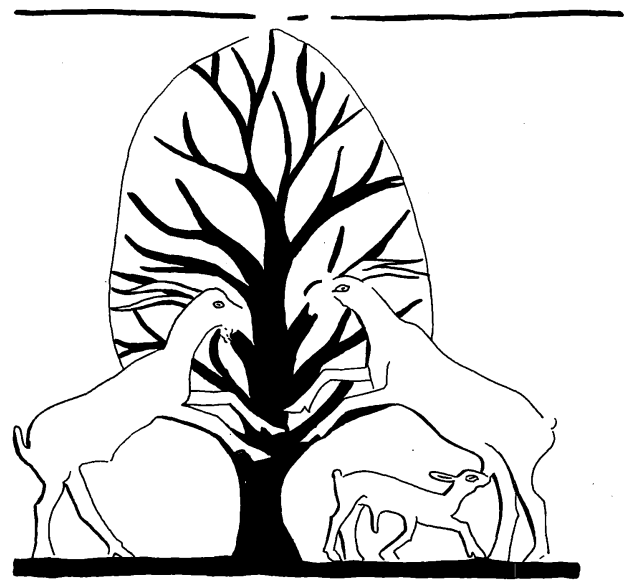

Abb.29 Relief im Grab des Nefer und Ka-Hay am Aufweg zur Unas Pyramide in Saqqara; 5.Dyn.; MOUSSA/ALTENMUELLER, Tomb of Nefer and Ka-Hay P1.19,4.

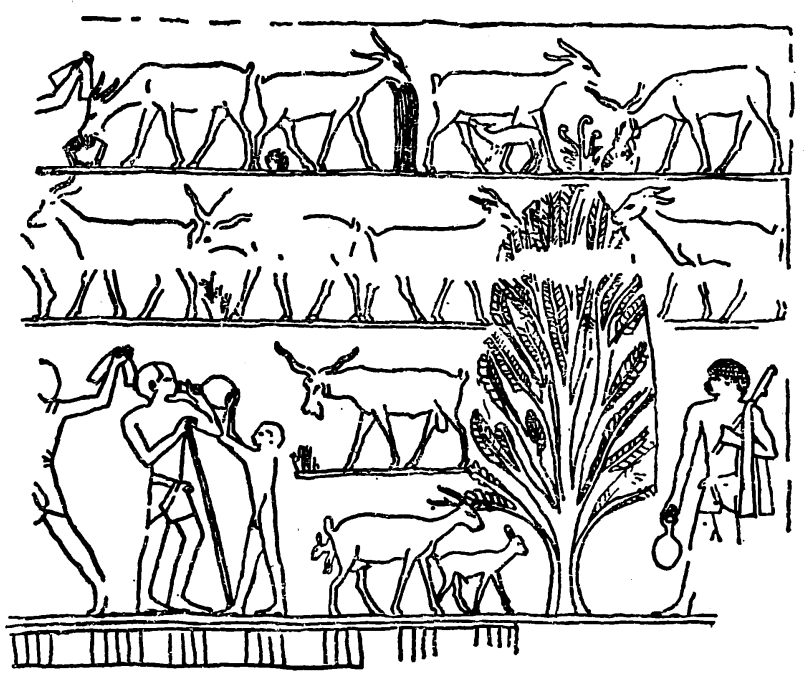

Abb.30 Reliefbruchstück aus dem Grab des Achtihotep in Saqqara, heute im Museum von Leiden; Altes Reich; VANDIER, Manuel V 87 Fig.59. 


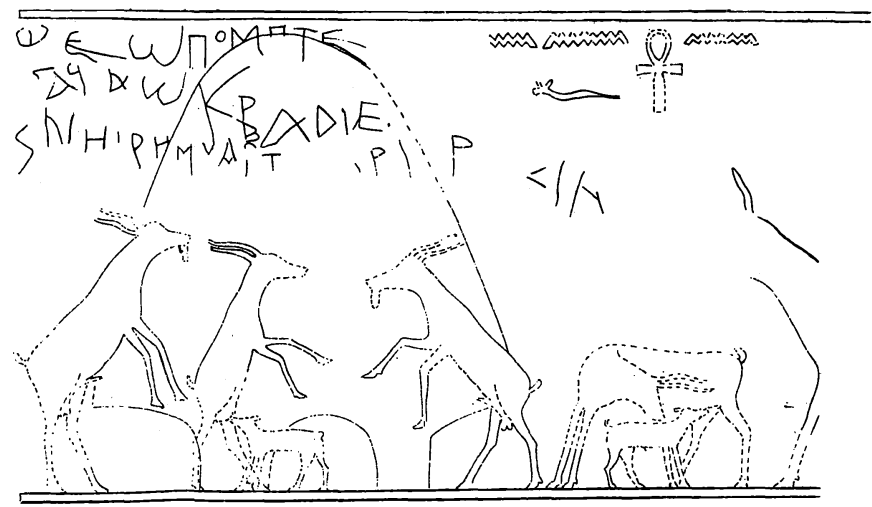

Abb.31 Stark beschädigtes Relief im Grab des Schedu in Deschasche; 6.Dyn.; PETRIE, Deshasheh PI.XV.

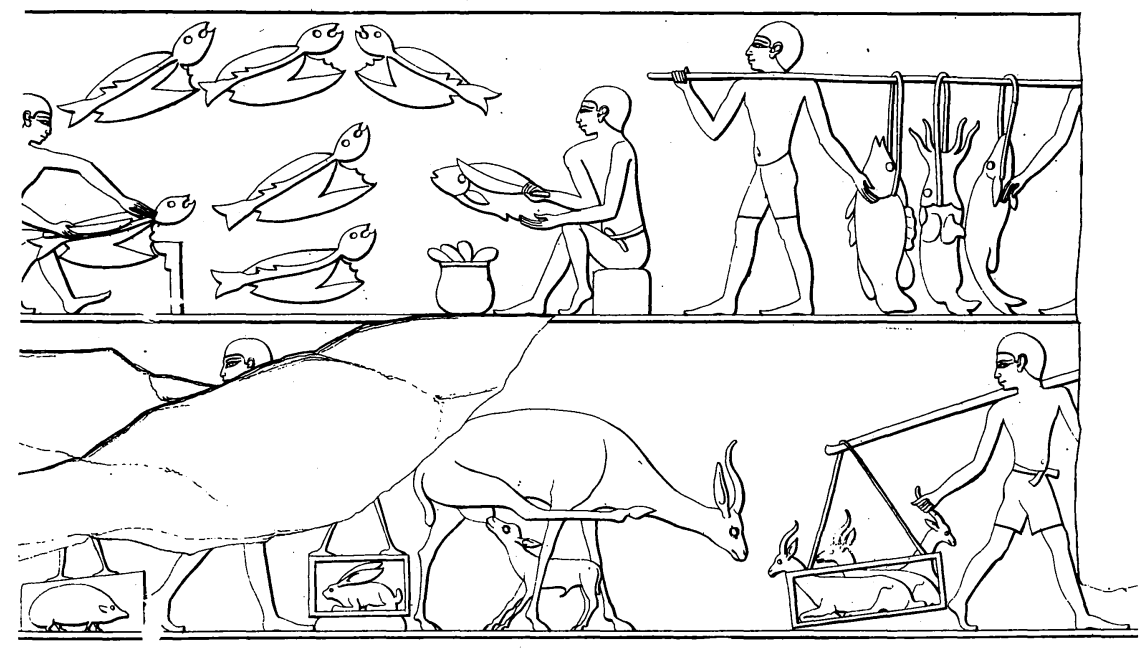

Abb.32 Relief aus dem Grab des Nebemachet in Giza; 4.Dyn.; LEPSIUS, Denkmäler Bd III BI.12 = SMITH, History 363 Fig. 237. 


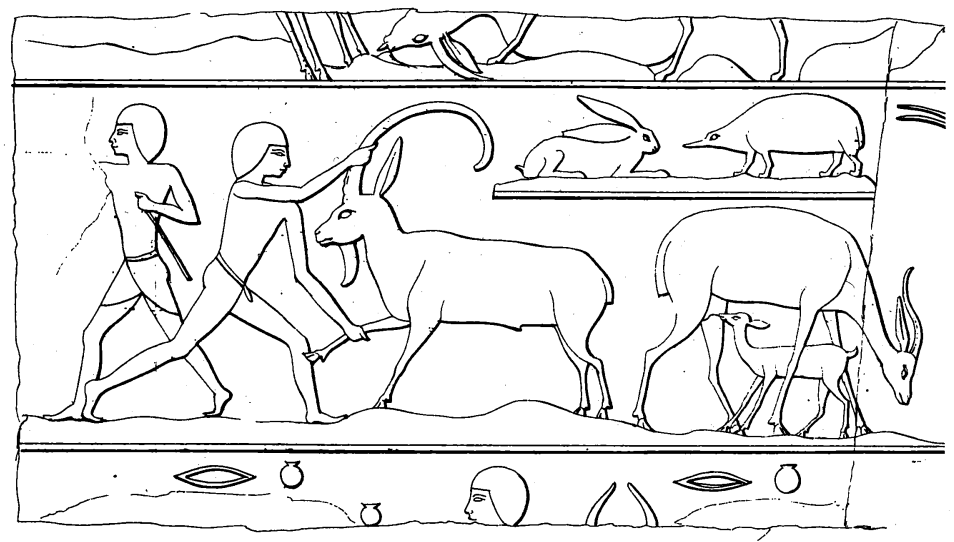

Abb.33 Relief aus Grab Nr.15 (LEPSIUS) in Saqqara; 5.Dyn.; LEPSIUS, Denkmäler Bd III BI.46.

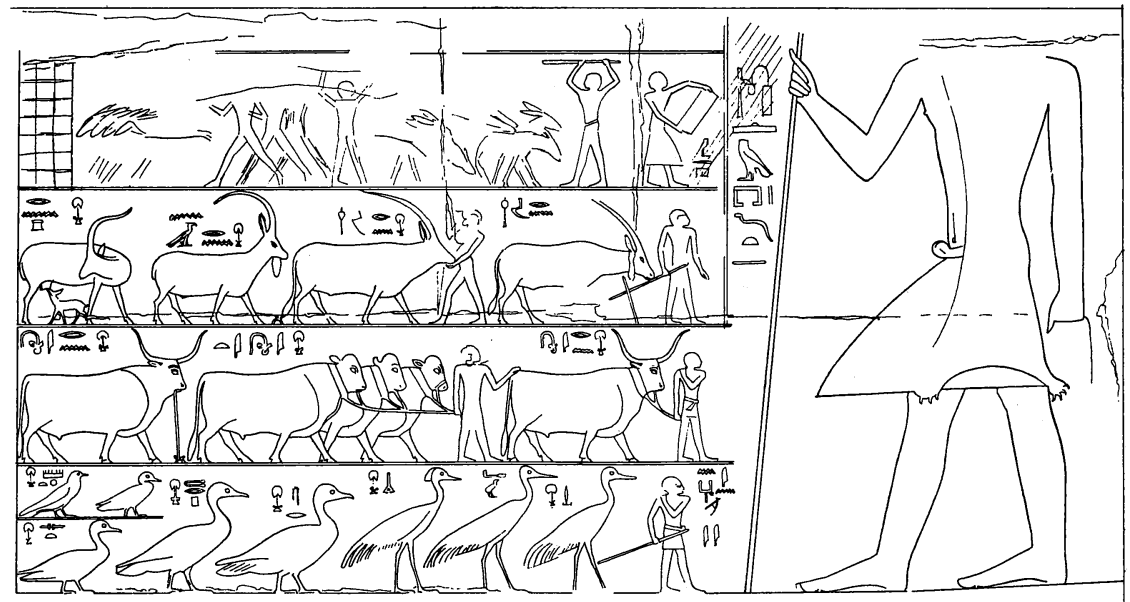

Abb.34 Relief aus Grab Nr.32 (LEPSIUS) in Giza; 4./5.Dyn.; JUNKER, Giza III $233 \mathrm{Abb} .48=$ NAVILLE/SETHE, Ergänzungsband $z u$ LEPSIUS Taf.XXV. 
Auf Szenen im Freien sind mit einer gewissen Regelmässigkeit säugende Gazellen zu finden, so im Grab des Nebemachet in Giza (4. Dynastie) (Abb.32), im Grab Nr. 15 (LEPSIUS) in Saqqara (5. Dynastie) ( Wildes in der Wüste in den der Vorführung der Schlachtopfer versetzt, im Grab Recurs II. in Giza (Abb.34) ${ }^{136}$.

Bei all den genannten Belegen dürfte das Motiv des Säugens nichts anderes als die Fruchtbarkeit der Herden und bei den Gazellen vielleicht die Intensität, die Zärtlichkeit, die wärme und Freude und dann vor allem die Regenerationsfähigkeit des Lebens signalisieren.

In der 2. Zwischenzeit aber taucht die säugende Kuh zum ersten Mal isoliert als Amulett auf, dessen Basis als Siegel gestaltet ist $(\underline{A b b} .35)$. Ob die säugende Kuh als solche oder als Bild einer Gottheit positive Kräfte vergegenwärtigen soll, ist nicht mit Sicherheit zu entscheiden, aber jedenfalls ist hier aus einem Bestandteil landwirtschaftlicher szenen ein Symbol geworden ${ }^{137}$. Ebenfalls in die 1. Zwischenzeit gehört ein Amulett, das eine säugende Kuh zeigt, die den Kopf sorglich rückwärts wendet, bei der aber anscheinend anstelle des Kalbes ein saugender Mensch zu sehen war $\left(_{\text {Abb.36) }}^{138}\right.$. BRUNNER vermutet, die Kuh könnte in diesem Fall Hathor darstellen ${ }^{139}$. Aber $\mathrm{zu}$ erweisen ist das nicht,

135 Vgl. DAVIES, Ptahhetep I Pl. XXII.

136 Weitere Belege bei KLEBS, Reliefs des Alten Reiches 62f; dies., Reliefs des Mittleren Reiches 89f; VANDIER, Manuel V 67f. Gelegentlich werden auch andere Tiere beim Säugen dargestellt, so z.B. Eselinnen (NEWBERRY, Beni Hasan I P1.XIII undII Pl.VII), aber es handelt sich dabei stets um einzelne Belege und nicht um ein festes Motiv. Im Grab des Enene in Abd el Qurna (Nr.81) wird eine säugende Antilope von einem Pfeil getroffen (WRESZINSKI, Atlas I Taf. 262).

137 Vgl. dazu MATTHIAE, RSO 36 (1961) 5.

138 BRUNTON hat dieses Amulett als "Kuh mit Melker" veröffentlicht (Qau and Badari II $10 \mathrm{Nr} .23$ ), aber BRUNNER hat es zurecht als Kuh, die einen Knaben säugt, interpretiert (Gebur des Gottkönigs 122f, Anm.4).

139 Ebd. 
denn eine Grabmalerei der 11. Dynastie in Beni Hasan zeigt im Rahmen einer landwirtschaftlichen Szene eine Kuh, die gleichzeitig ein Kalb und einen Knaben säugt (Abb.37). Hier ist es jedenfalls nicht möglich, von einer göttlichen Kuh zu sprechen, ja nicht einmal von einem Symbol. Aber noch in derselben 11. Dynastie ist das Motiv des an einer göttlichen Kuh saugenden Königs bzw. Prinzen im Totentempel Mentuhotep Nebhetepre $\mathbf{c}_{\mathbf{S}}$ in Deir el Bahri zum ersten Mal belegt (Abb.38).

Aus der Regierungszeit Amenemhets III. ist im Libanon ein Pektorale aufgetaucht, das so gut wie sicher aus Byblos stammt 140 und höchst wahrscheinlich ein ägyptisches Importstück darstellt (Abb.39) . Die Kuh ist durch die Sonnenscheibe zwischen den Hörnern als göttliche und durch das Emblem, das auf der rechten Seite unter ihrem Hals zu sehen ist, genauer als Hathor charakterisiert.

Um die Hathorkuh handelt es sich auch bei zwei grossen Reliefs aus dem Hathorheiligtum im grossen Tempel von Deir el Bahri, die die Königin Hatschepsut als Prinzen zeigen, der an ihrem Euter trinkt (Abb.40 und 4l) und mittels der Halskette (Menit) von ihr schützend umhalst wird $(\underline{\mathrm{Abb} .41})^{141}$. In einer längeren Rede teilt die göttliche Kuh mit, dass sie aus Chemmis in den Deltasümpfen zu ihr gekommen sei, wo ihr Sohn Horus, der Prototyp des jungen Königs, von ihr behütet wurde ${ }^{142}$.

In der von Thutmosis III. angelegten Kapelle der Hathorkuh in Deir el Bahri ist diese dargestellt, wie sie aus ihrem Schrein hervortritt und mit ihrer Halskette wie auf $\underline{A b b .41}$ schützend Amenhotep II., den Nachfolger Thutmosis III. umhalst, der ebenfalls gleichzeitig dargestellt ist, wie er kniend an ihrem Eu-

140 MONTET, Kêmi 16 (1962) 92ff.

141 HERMANN, Liebesdichtung 21.

142 Vgl. ebd. 43; zur Kuh als Repräsentantin von Göttinnen seit dem Alten Reich vgl. MATTHIAE, RSO 36 (1961) 17-19. 

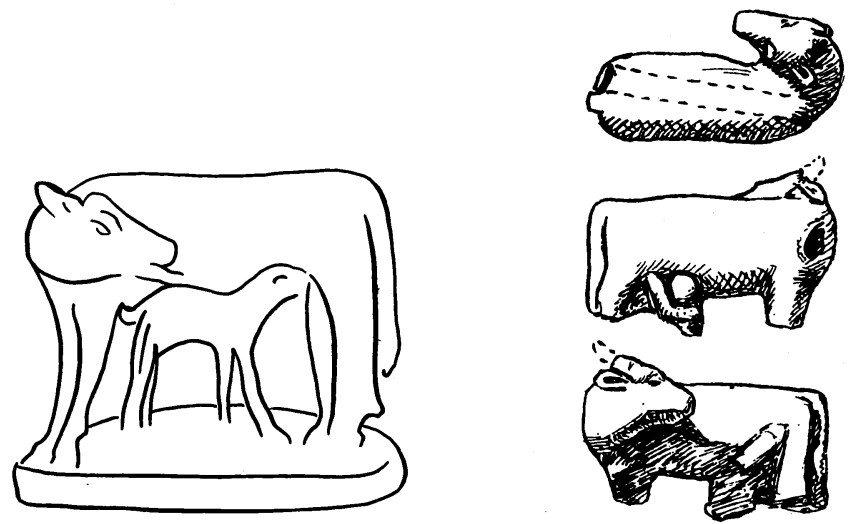

Abb.35 Siegelamulett, das aus der Timmins Sammlung ins Metropolitan Museum, New York, gelangte; 1. Zwischenzeit; HAYES, Scepter of Egypt I 142 Fig.84; NEWBERRY, The Tim(m) ins Collection PI.II Nr.20; vgl. Taf.I,I dieser Arbeit.

Abb.36 Amulett aus Qau (oder Badari); 1. Zwischenzeit; BRUNTON, Qau and Badari II Pl.XCVI Nr.23.

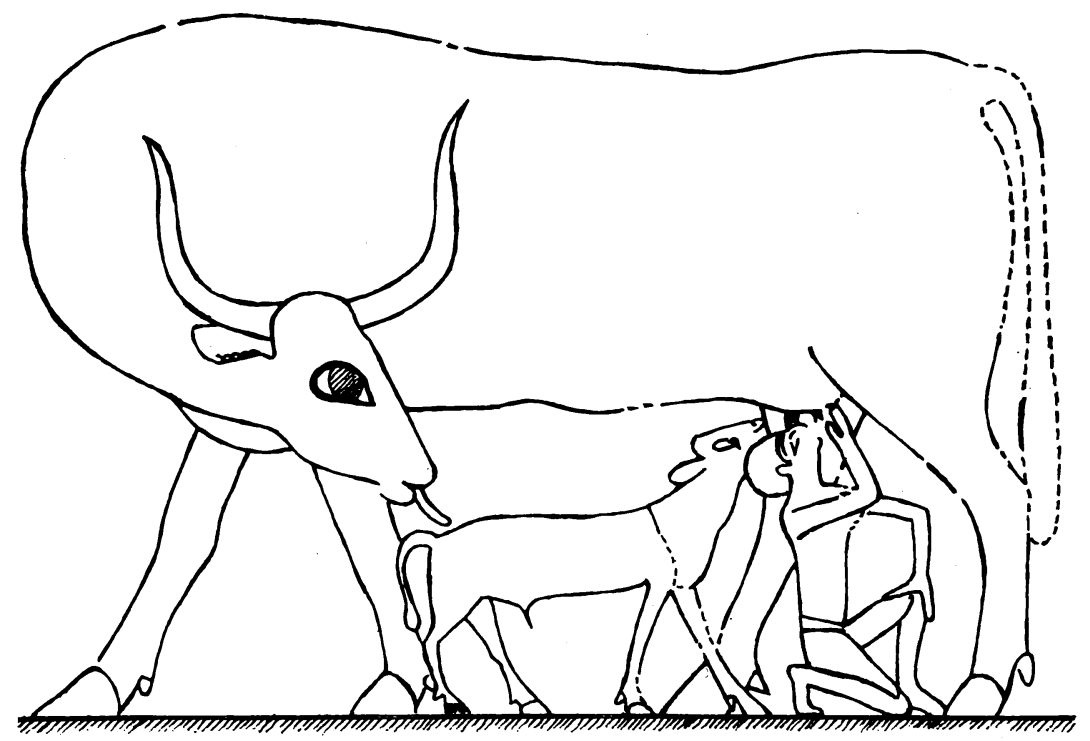

Abb.37 Wandmalerei aus dem Grab BaqtsIII. (Nr.15) in Beni Hasan; 11.Dyn.; DAVIES, Bulletin of the Metropolitan Museum Egyptian Expedition 1931/32 29 Abb.10; vgl. NEWBERRY, Beni Hasan II PI.VII. 


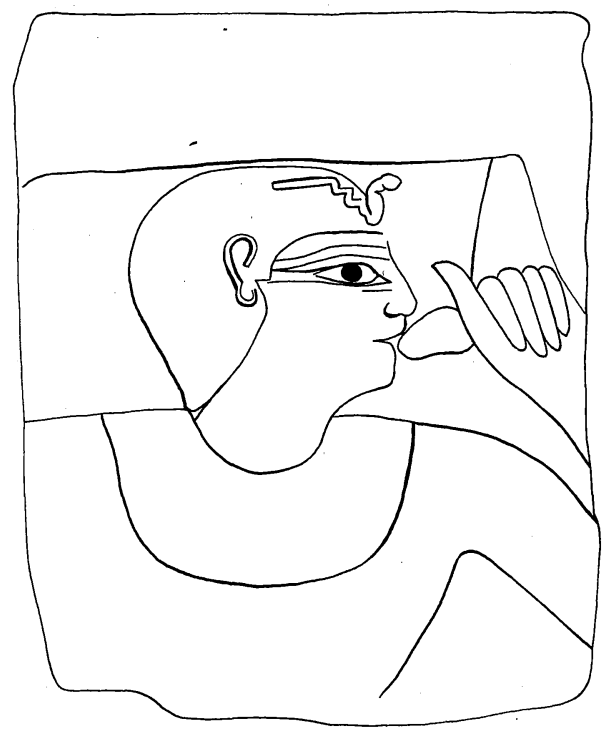

Abb.33 Reliefbruchstück aus dem Totentempel Mentuhotep Nebhetepre's in Deir el Bahri, jetzt im Kestner Museum, Hannover Inv.Nr.1935, 200, 82; 11.Dyn.; WOLDERING, Werke der ägyptischen Sammlung Abb.27.

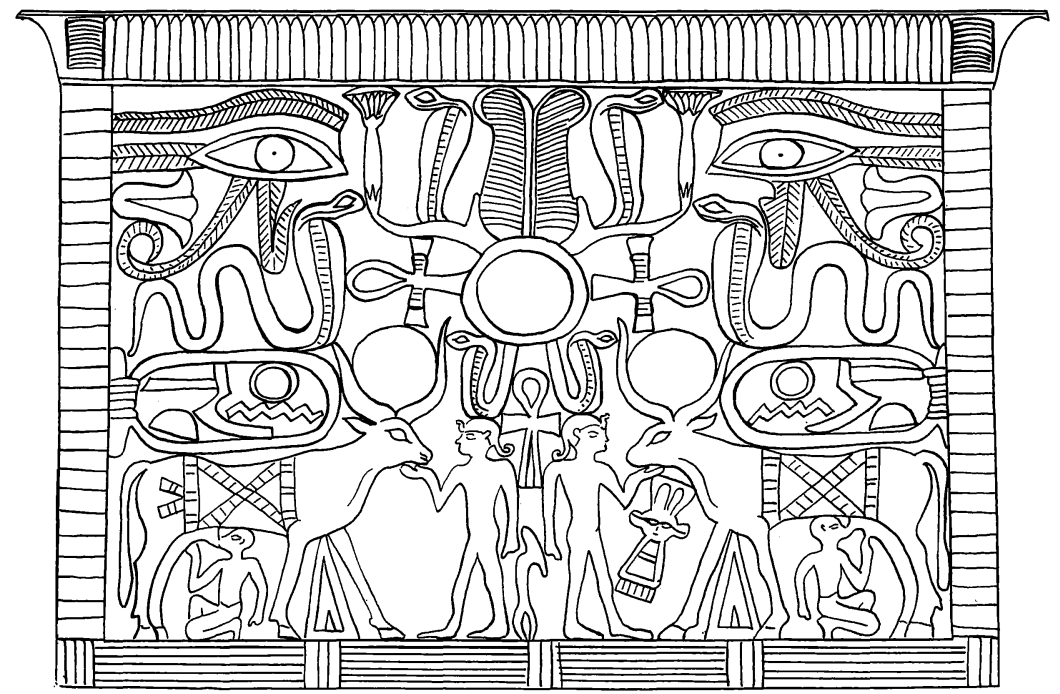

Abb.39 Pektorale aus Gold mit kostbaren Steinen eingelegt aus Byblos (?) jetzt im Museum in Beirut; 12.Dyn.; CHEHAB, Bull. Musée de Beyrouth I (1937) P1.I.; JIDEJIAN, Byblos Abb.61. 


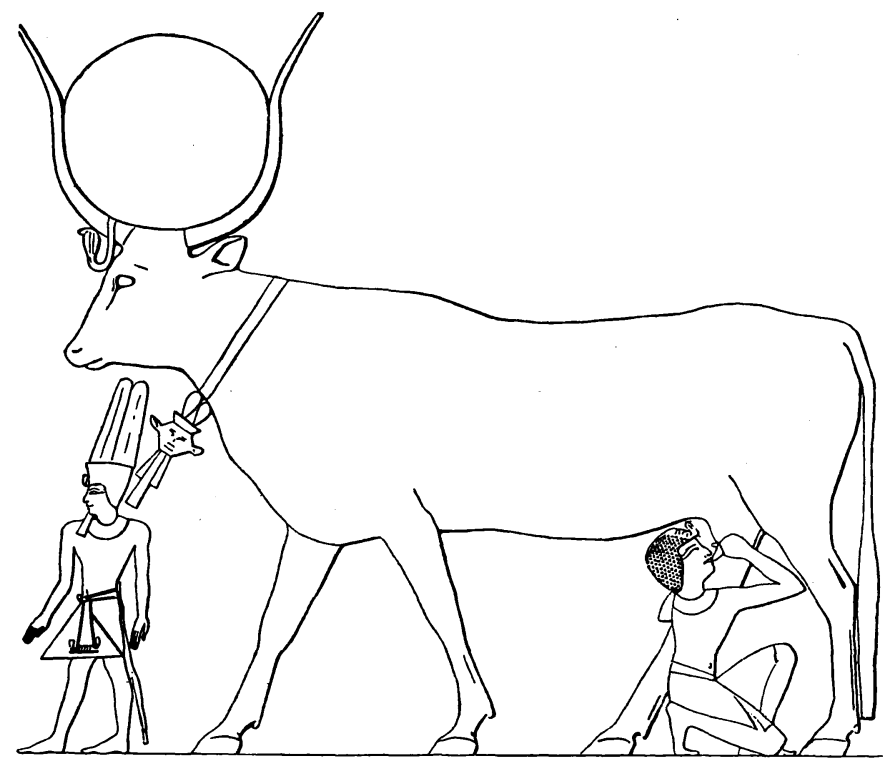

Abb.40 Relief aus dem Hathorheiligtum im grossen Tempel von Deir el Bahri; 18.Dyn.; NAVILLE, Temple of Deir el Bahari IV Pl.105;

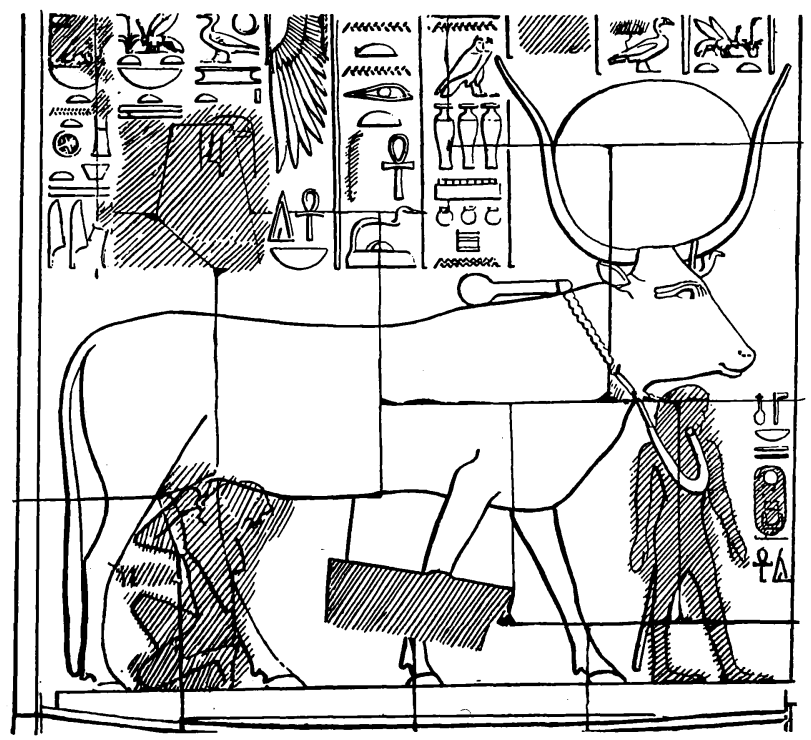

Abb.41 Relief aus dem Hathorheiligtum im grossen Tempel von Deir el Bahri; 18.Dyn.; NAVILLE, Temple of Deir el Bahari IV P1.104; HERMANN, Liebesdichtung $22 \mathrm{Abb} .4$. 
ter saugt ${ }^{143}$. Aus dieser Kapelle stammt auch die berühmte Rundplastik der Hathorkuh, die aus dem Papyrusdickicht hervortritt und den erwachsenen König Amenhotep II. schützt, der als Prinz an ihrem Euter trinkt (Abb.42).

Die Säugeszene im Rahmen des Zyklus, der im grossen Tempel von Deir el Bahari die Kindheitsgeschichte der Hatschepsut darstellt, zeigt, dass auch andere Göttinnen als Hathor in Kuhgestalt den neugeborenen Gottkönig stillen können, in diesem Falle die Schutzgöttinnen von Ober- und Unterägypten, Nechbet und Uto. Im Beleg aus der Zeit der Hatschepsut fehlt das saugende Kind ${ }^{144}$, weil Thutmosis III. es wegkratzen liess. Die kühe wenden ihren Kopf so ganz unmotiviert nach hinten. Bei der entsprechenden Szene in der Darstellung der Kindheitsgeschichte Amenhoteps III. in Luxor aber ist der saugende Prinz erhalten (Abb.43). Die göttliche Kuh, die den Kronprinzen säugt, hat sich im Rahmen des kanonischen Geburtszyklus wie auch als isolierte Kultstatue bis in die römische zeit erhalten ${ }^{145}$.

Die Frage ist nun, ob eine der säugenden Kühe, die vom Neuen Reich an auch ausserhalb der landwirtschaftlichen Szenen auftauchen, und nicht den Prinzen, sondern ein Kalb säugen, als göttliche Kuh zu verstehen ist. Das üppige Papyrusdickicht, in dem eine säugende Kuh auf einer Metallschale aus der Zeit Amenhoteps III. oder IV. auftaucht (Abb.44), suggeriert, diese Frage positiv zu beantworten. Denn das Papyrusdickicht erinnert an

143 NAVILLE, $x^{\text {th }}$ Dynasty Temple I Pl. XXVIII C; NIMS/SWAAN, Thebes Pl. X oben.

144 NAVILLE, Temple of Deir el Bahari II Pl. LIII; vgl. ebenso CHASSINAT, Mammisi d'Edfou Pl. XV und Pl. LXX. Hier ist das Kind offensichtlich nicht erst nachträglich weggekratzt worden, sondern hat von Anfang an gefehlt; vgl. JUNKER/WINTER, Geburtshaus in Philae 108 Nr. 930.

145 Vgl. BRUNNER, Geburt des Gottkönigs 125; als Beispiele für die Kultstatue vgl. CHASSINAT, Dendara V Pl. 34 lf. 


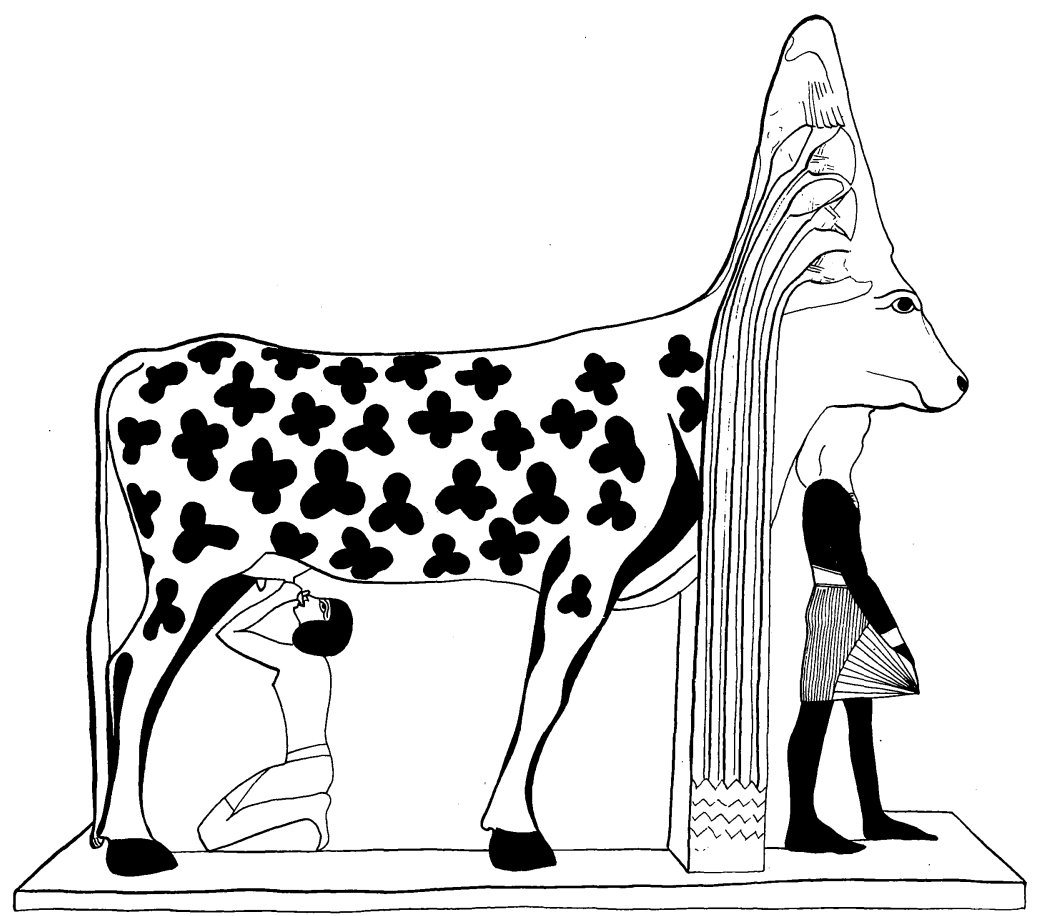

Abb.42 Rundplastik aus der Kapelle der Hathorkuh in Deir el Bahri, jetzt im Museum in Kairo (Nr.38574); 18.Dyn.; DONADONI, Egyptian Museum 98f; LANGE/ HIRMER, Aegypten Taf.146f.

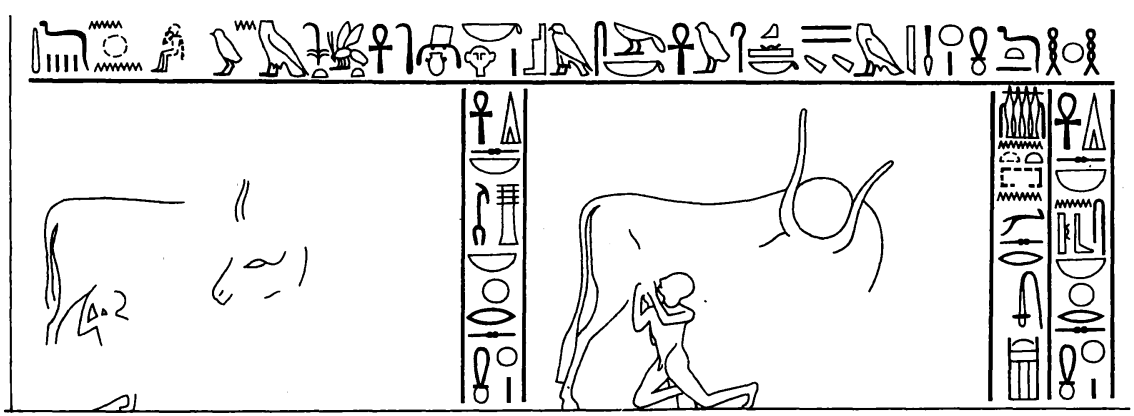

Abb.43 Relief aus dem Geburtssaal Amenhoteps III. im Tempel von Luxor; 18.Dyn.; BRUNNER, Geburt des Gottkönigs Taf.12. 
Abb.42. Aber ins Papyrusdickicht sind auch die anderen Hauptmotive der Schalendekoration plaziert : der von einem Löwen angefallene stier, die ruhig schreitende kuh und der ruhig schreitende Stier, und es dürfte schwierig sein, in ihnen allen, vom Steinbock, dem Ichnenmon, den Enten usw. ganz abgesehen, göttliche Wesen $\mathrm{zu}$ erblicken. Immerhin aber erscheint die säugende Kuh hier, im Gegensatz zu den landwirtschaftlichen Szenen, nicht mehr in einer realen, sondern in einer idealen welt ${ }^{146}$.

Aehnlich isoliert wie auf dem Siegelamulett von $\underline{\mathrm{Abb} .35}$ ist die säugende Kuh erst wieder auf einem Elfenbeingerät des Neuen Reiches aus Qau zu sehen (Abb.45). Aber hier wie dort weist nichts eindeutig auf eine göttliche Kuh hin. Das gilt auch für die säugende Kuh auf einem erheblich später anzusetzenden Kamm aus hartem, dunklem Holz (Abb.45a), der in der Literatur als phönizisch bezeichnet wird ${ }^{146 a}$. Aber weder auf den typisch phönizischen Schalen noch auf den Elfenbeinen sind Rücken und Hals der Kuh in der Weise in einem Bogen zusammengefasst wie bei diesem Kamm. Etwas Vergleichbares haben wir erst in saitischer (Abb.26) und dann vor allem in dem bereits stark griechisch beeinflussten 4. Jh.v.Chr. (Abb.27). Seit dem Neuen Reich wird der Ausdruck $3 m s$ ib "sich herzlich sorgen ${ }^{147}$, sich freuen" mit dem Determinativ der säugenden Kuh versehen (Abb.46). Insofern dürfte mit der säugenden Kuh von da an mindestens ein bestimmter geistiger Gehalt fest verbunden worden sein. Aber mit einer gewissen Sicherheit kann man die ihr Kalb säugende Kuh anscheinend erst auf Amuletten der Spätzeit als Repräsentantin der Hathor oder Isis ansprechen. Das erstaunt insofern, als eine Mutterkuh und das vor ihr liegende Kalb als symbol der Isis und des von ihr geborenen Gotteskalbes $(\underline{t} b-n \underline{t} r)$ seit urdenklicher Zeit das Zeichen

146 So hat z.B. der Steinbock in einem realen Papyrusdickicht keinen Platz.

146a WATZINGER, Adonisfest 264 Anm.2; POULSEN, Kunst 55.

147 Vgl. zum Umwenden als Liebesgestus : HERMANN, Liebesdichtung 32 . 


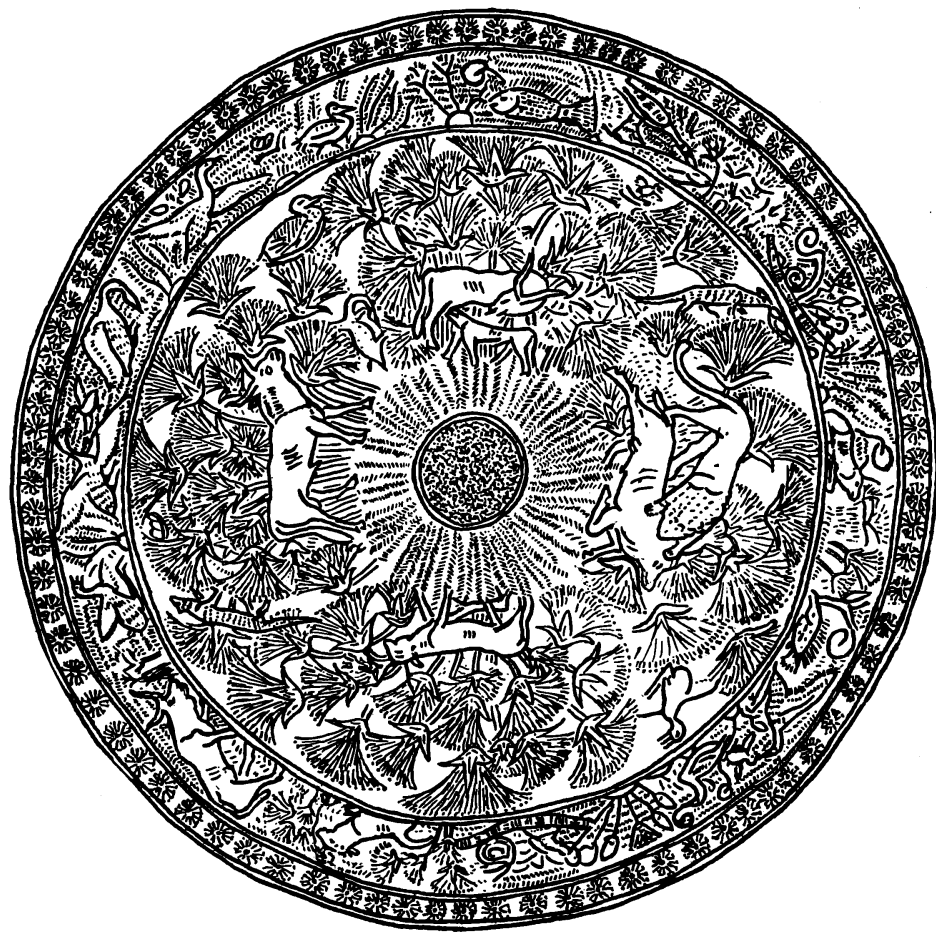

Abb.44 Metallschale aus einem Grab in Abd el Qurna (Theben West); 18.Dyn.; DARESSY, ASAE 2 (1901) Abb.10; vgl. VON BISSING, Jahrbuch des Kaiserlichen Deutschen Archäologischen Instituts 13 (1898) Taf.2.

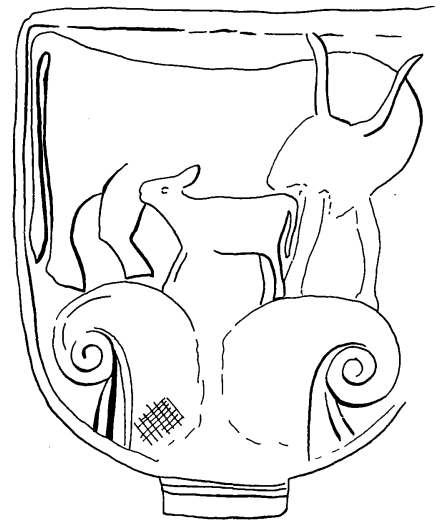

Abb.45 Elfenbeinschnitzerei auf einem Geräteteil (Spiegelgriff?) aus Qau; Neues Reich; BRUNTON, Qau and Badari III PI.36,9. 


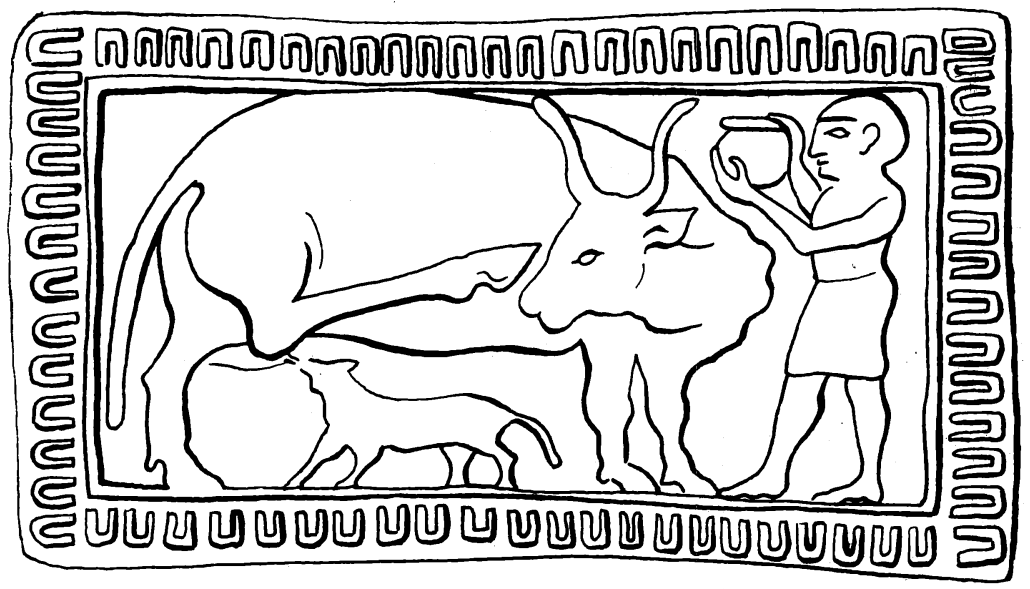

Abb.45a Mittelstück eines Kamms aus Hartholz aus Aegypten; jetzt im Louvre; 6.-4.Jh.v.Chr.; DE LONGPERIER, Oeuvres I PI.II,I.
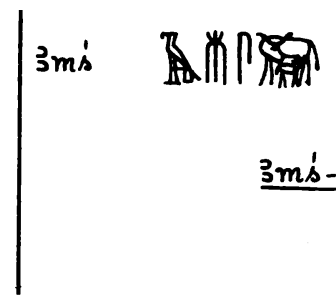

Verbum, won der Freude der

Kuh am saugenden Kalbchen $\sigma . a$.

nur im Qusdruck:

$3 m s-i b$ sich freuen 7. M.R. - Sin.

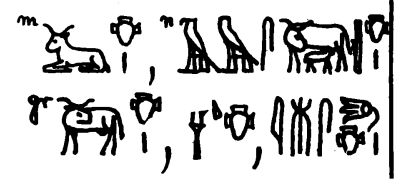

Abb.46 Ausschnitt aus ERMAN/GRAPOW, wörterbuch I II. 


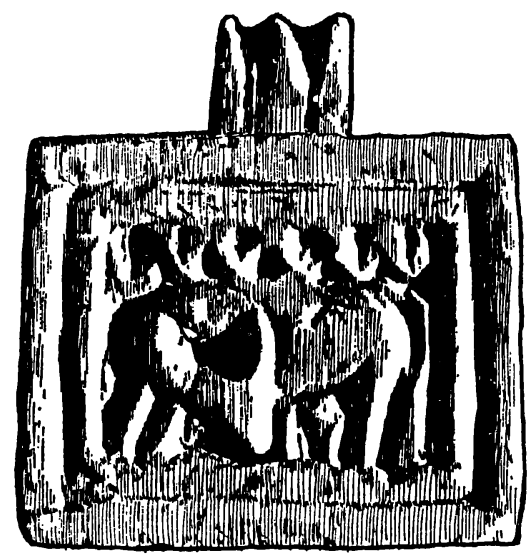

Abb.47 Fayenceamulett im Brado-Museum in Tunis; 8.-4.Jh.v.Chr.; LECLANT, Archéologie vivante $I, 2$ (1969) $101 \mathrm{Abb} .115$ und $113 \mathrm{Abb} .115$.
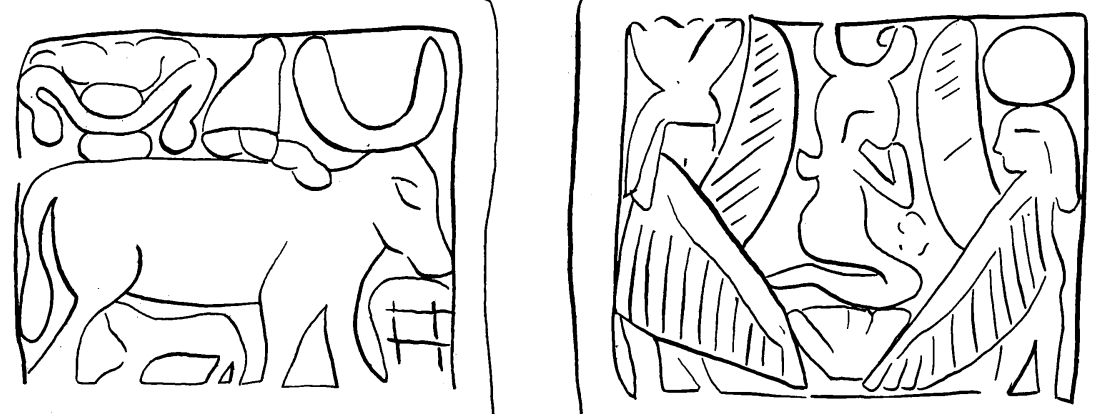

Abb.48a-b Fayenceamulett im Museum von Cagliari; 8.-4.Jh.v.Chr.; ACQUARO, Amuleti egiziani Tav.XX Nr.486. 
des 12. unterägyptischen Gaus (Sebennytos, heute Samanûd) gebildet haben ${ }^{148}$. Dennoch legen auch auf Abb.47 nur die Amulettform und das Papyrusdickicht, vor dem die kuh mit rückwärtsgewandtem Kopf ihr Kalb säugt, nahe, in ihr eine göttliche Kuh zu sehen. Bei Amulettplaketten, die auf der Vorder- und Rückseite je ein verschiedenes Motiv zeigen, verstärkt die gewählte Kombination diesen Eindruck noch, so wenn auf der einen Seite die säugende Kuh, auf der anderen Horus, das Kind auf seiner Blume, zu sehen ist $(\mathrm{Abb} .48)$.

Die säugende Gazelle, die vom Alten bis ins Neue Reich in realistischem Kontext $\mathrm{zu}$ sehen ist, erscheint vom Neuen Reich an in Zusammenhängen, die nur symbolisch zu verstehen sind. Auf der berühmten Schale des Maiherperi (Abb.49) tritt sie in zunächst recht seltsam anmutender Gemeinschaft mit einem Tilapia (Barsch) auf, der vier Lotusknospen im Maul hat, ja die säugende Gazelle hat noch zwei Tilapias an den Hals gebunden. I.GAMER-WALLERT hat gezeigt, dass Gazelle oder Oryx und Tilapia als Regenerationssymbole nebeneinanderstehen. Beide erscheinen gemeinsam am Bug der Barke des Gottes der Toten, Sokar ${ }^{149}$. Die alten Aegypter haben die wüste ähnlich wie die grosse Wassermasse als Bereiche des dem Tode verwandten Chaos empfunden ${ }^{149 a}$. Wüstenwild und Fische überleben im einen wie im andern und bestimmte Arten des Wüstenwildes und bestimmte Fische können so $\mathrm{zu}$ Symbolen der Ueberwindung des Todes und der Regeneration werden. Die säugende Gazelle bedeutet in diesem Zusammenhang eine Steigerung insofern sie in der wüste nicht nur ihr eigenes Leben erhält sondern dieses sogar reproduziert.

148 SETHE, Urgeschichte §103; vgl. HERMANN, Liebesdichtung 31.

149 GAMER-WALLERT, Fische 126-128; vgl. HORNUNG/STAEHELIN, Skarabäen Basel 138f.

149a Vgl. KEEL, Welt der altorientalischen Bildsymbolik 35, 334 ; Ders. Jahwes Entgegnung $57 \mathrm{f}$. 


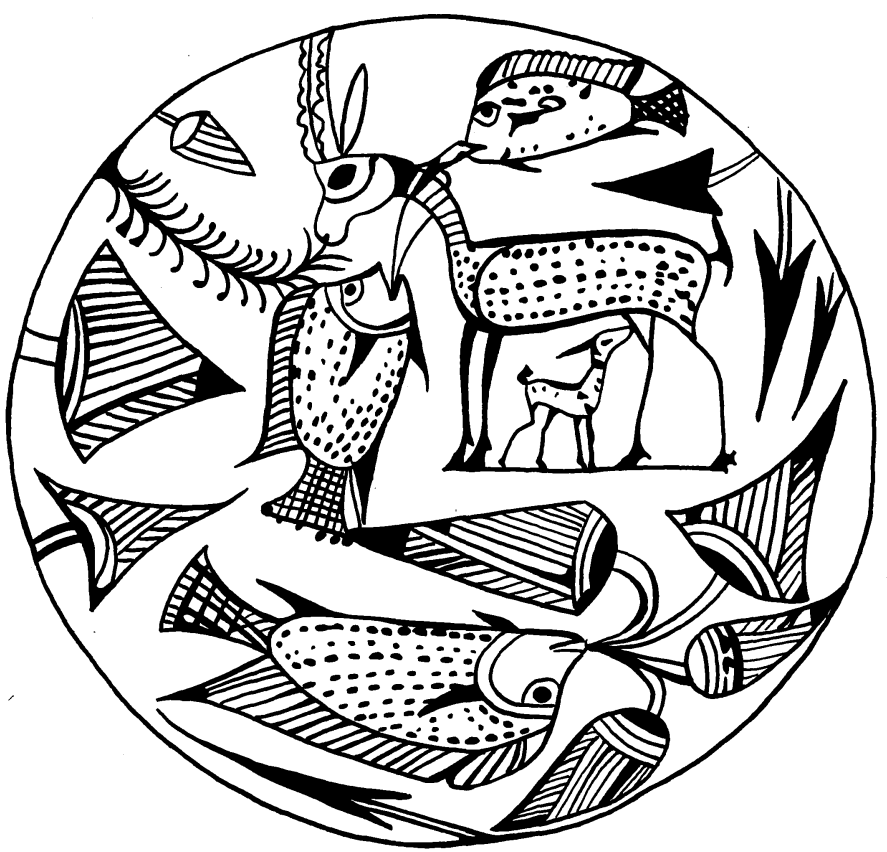

Abb.49 Innendekoration einer glasierten Schale aus dem Grab des Maiherperi im Tal der Könige; 18.Dyn.; STEINDORFF, Kunst der Aegypter 275, Nr.6 = NIMS/SWAAN, Thebes PI.78 = GAMER-WALLERT, Fische $126 f$ und Taf.XIV, 2

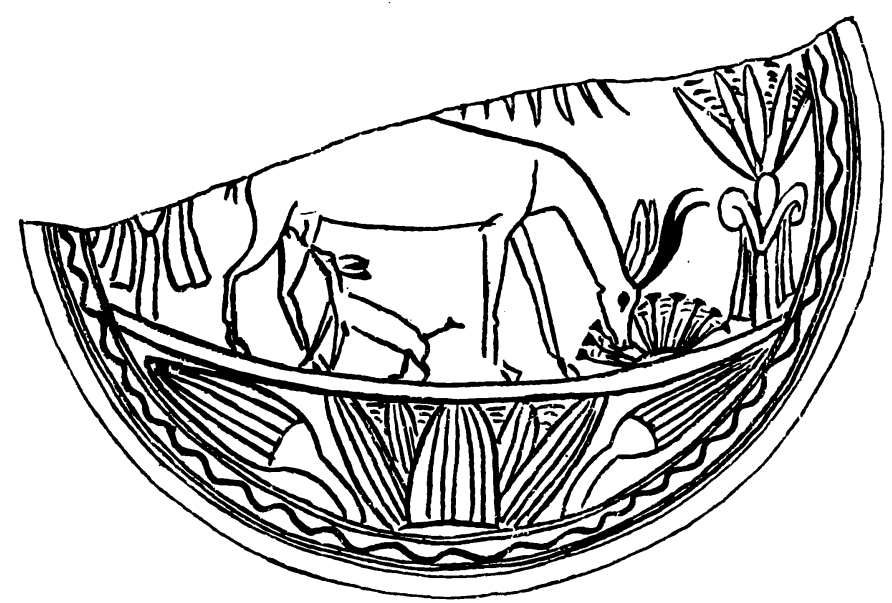

Abb.49a Blau glasierte Schale aus Gurob; 19.Dyn.; PETRIE, Illahun, Kahun and Gurob PI.XX Nr.5. 

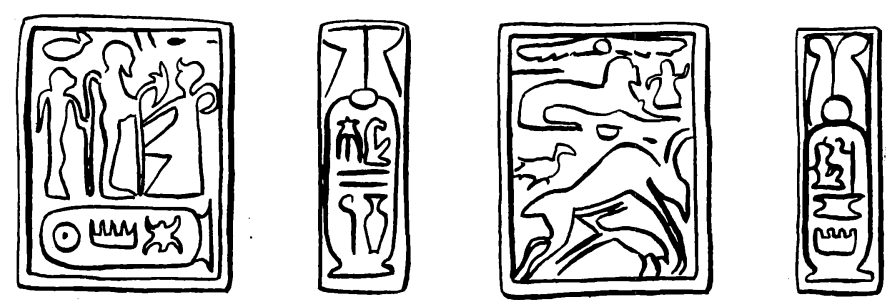

Abb.49b Graviertes Plättchen aus Geser; Zeit Ramses III (1204-1173 v.Chr.); MACALISTER, Gezer III PI.CXXI Nr.2O.
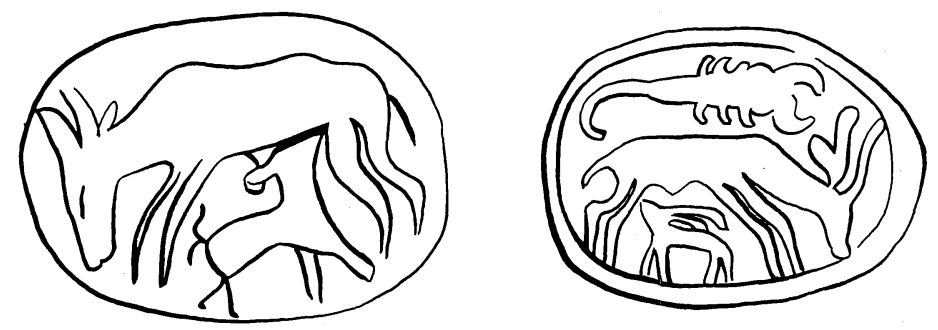

Abb.49C Skarabäus, wahrscheinlich Neues Reich (ca.1550-1200 v.Chr.); LANZONE, Dizionario di Mitologia Egizia II, Tav.LXXXIV,29.

Abb.49d Skarabäus, Neues Reich (ca.1550-1200 v.Chr.); MATOUK, Corpus du Scarabée II $113 \mathrm{Nr} .737 ; 387 \mathrm{Nr} .737$. 
Die gleiche Bedeutung hat die Gazelle, die von gewaltigen Lotosblüten umgeben weidend ihr Junges säugt (Abb.49a). Der nachts seine Blüte schliessende und ins Wasser sinkende und sie morgens wieder öffnende und emporsteigende Lotos war in Aegypten seit der Amarnazeit als Regenerationssymbol omnipräsent ${ }^{149 b}$. Vielleicht ist diese Symbolik im Hld bei den Gazellen, die unter Lotosblumen weiden $(4,5)$, nicht abwesend, da die Gedichte des Hld ja die todüberwindende Macht der Liebe beschreiben $(8,6 \mathrm{f})$.

Angesichts der Symbolik der säugenden Gazelle verwundert es nicht, sie auf Siegelamuletten zu finden, so auf einer Platte der Zeit Ramses III. (1204-1173 v.Chr.), die in einem Grab in Geser gefunden wurde (Abb.49b).

Während die säugende Gazelle auf $\underline{\mathrm{Abb} .49 \mathrm{~b}}$ in einem spezifisch ägyptischen Kontext (Flügelsonne, Sphinx, König vor Ptah und Sachmet, ägyptische Königsnamen) und auf Abb.49c ohne Kontext erscheint, ist sie auf $\mathrm{Abb} .49 \mathrm{~d}^{149 \mathrm{C}}$ mit dem Skorpion verbunden, der im vorderasiatischen Raum seit ältester Zeit regelmässig mit dem säugenden Muttertier assoziiert wird (vgl. Abb.55, 59, 62, 80, 89-93).

Der Skorpion auf Abb.49d dürfte also auf vorderasiatischen Einfluss zurückzuführen sein, zumal m. v. die Verbindung von Skorpion und säugendem Muttertier hier für Aegypten sonst nicht belegt ist.

Aehnlich wie in Aegypten scheint die Geschichte des Motivs auch in Mesopotamien mit dem säugenden Tier zu beginnen, das innerhalb einer Herde als seinem natürlichen Kontext erscheint. Da in Vorderasien in der Regel weniger grossflächige Bildträger zur Verfügung stehen als in Aegypten, die kleinräumigen Bildträger wie Gefässe und Siegel aber eine Konzentration auf Symbole begünstigen, erhält das säugende Muttertier in der vorderasiati-

149b Vgl. BRUNNER-TRAUT, in : LdA III 1091-1096; HORNUNG/STAEHELIN, Skarabäen Basel $164 f$.

149c Den Hinweis auf dieses und das Stück von Abb.49b verdanke ich Dr. B. JAEGER, Basel. 


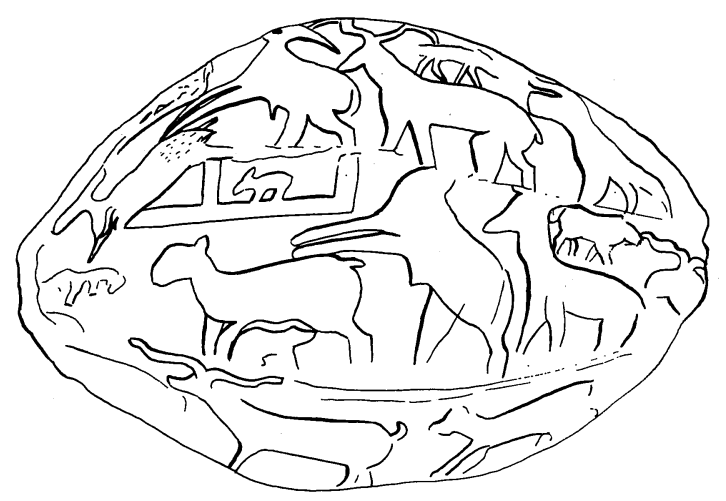

Abb.50 Gesiegelte Tonbulle aus Habuba-Kabira-Süd in Syrien; Frühsyrische zeit I, um $3200 \mathrm{v} . \mathrm{Chr}$; KUEHNE, Rollsiegel in Syrien $32 \mathrm{Nr} .1$.
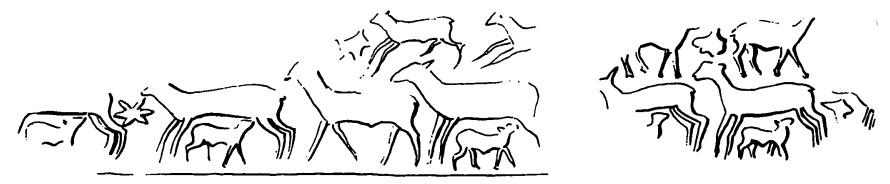

Abb.51 Gesiegelte Tontafel aus Susa; früheste Stadtkultur, um 3200 v.Chr.; AMIET, Glyptique susienne P1.14 Nr. $608=$ P1.77 Nr. 608 .

Abb.52 Gesiegeltes Tontäfelchen aus Susa; früheste Stadtkultur, um $3200 \mathrm{v}$. Chr.; AMIET, Glyptique susienne P1.14 Nr. $609=$ Pl. $77 \mathrm{Nr} .609$.
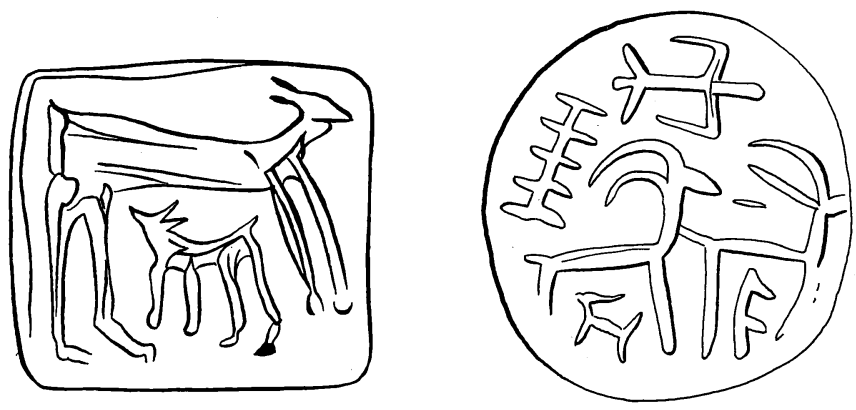

Abb.53 Rechteckiges Plakettensiegel vom Tepe Gijan; Uruk/Djemdet Nasr-Zeit, inde des 4.Jt.v.Chr.; HERZFELD, AMI 5 (1933) 103 Abb.25 Nr.2507.

Abb.54 Kalottenförmiges Stempelsiegel, das in Ekbatana gekauft wurde; jetzt in Zürcher Privatsammlung; Uruk/Djemdet Nasr Zeit; Ende des 4.Jt.v.Chr.; unveröffentlicht; vgl. Taf.I,2 dieser Arbeit. 
schen Bildkunst anscheinend früher symbolische Bedeutung als in Aegypten. Ebenfalls im Gegensatz zu Aegypten spielt in Vorderasien, dessen zahlreichen gebirgigen Gegenden entsprechend, das säugende Kleinvieh (Schaf, aber vor allem Ziege) eine grössere Rolle als in Aegypten.

Die Reihe beginnt, soweit ich sehe, mit einer Bulle vom Tell Habuba-Kabira-Süd (Abb.50) und zwei gesiegelten Tontäfelchen aus Susa (Abb.51-52), die alle drei schreitende Schafe mit saugenden Jungen zeigen. Alle drei sind um $3200 \mathrm{v} . \mathrm{Chr}$. in die urukzeitliche Phase $\mathrm{zu}$ datieren. Auf der Bulle von Habuba-Kabira scheint das Schaf beim Säugen gleichzeitig von einem Widder besprungen $\mathrm{zu}$ werden. Das Nebeneinander von Säugen und Bespringen auf den ägyptischen Bildern des Alten Reiches (vgl. Abb.9) wäre hier auf dem kleinflächigen siegel wie später auf neuassyrischen Rollsiegeln (vgl. Abb.101-105) als Miteinander gestaltet.

Etwas jünger als die genannten drei Siegelabrollungen dürften zwei Stempelsiegel sein, von denen das eine auf dem Tepe Gijan im iranischen Bergland gefunden (Abb.53), das andere nicht allzu weit davon in Ekbatana gekauft wurde (Abb.54) ${ }^{150}$. Das Tepe-GijanSiegel zeigt eine kurzhörnige Capride mit saugendem Jungen, das Ekbatana-Siegel zwei langhörnige Capriden, eine mit einem saugenden Jungen, die andere mit einem Zweig zwischen den Beinen. Ein weiterer Zweig und ein über den Capriden fliegender Vogel deuten eine Art Landschaft an 150a.

Auf einem Djemdet-Nasr-zeitlichen Gefäss vom Ort, der dieser Periode den Namen gegeben hat, steht die säugende ziege neben dem Skorpion (Abb.55), der später regelmässig mit der Göttin

150 Abb.54 ist bisher unveröffentlicht. Das kalottenförmige Stempelsiegel besteht aus dunkelgrauem Serpentin. Es hat einen Durchmesser von 30-31 mm, eine Höhe von $12 \mathrm{~mm}$ und gelangte vor kurzem aus der Sammlung F.S.MATOUK in eine Zürcher Privatsammlung, deren Besitzer freundlicherweise die Publikationserlaubnis gab.

150a Von Realismus kann allerdings nicht die Rede sein,denn u. a. haben saugende Capriden- und Gazellenjunge entgegen dieser und der Darstellungen von $\underline{A b b .49 b}$ und $\underline{d}, \underline{59,60}$ u.a. kein Gehörn. 


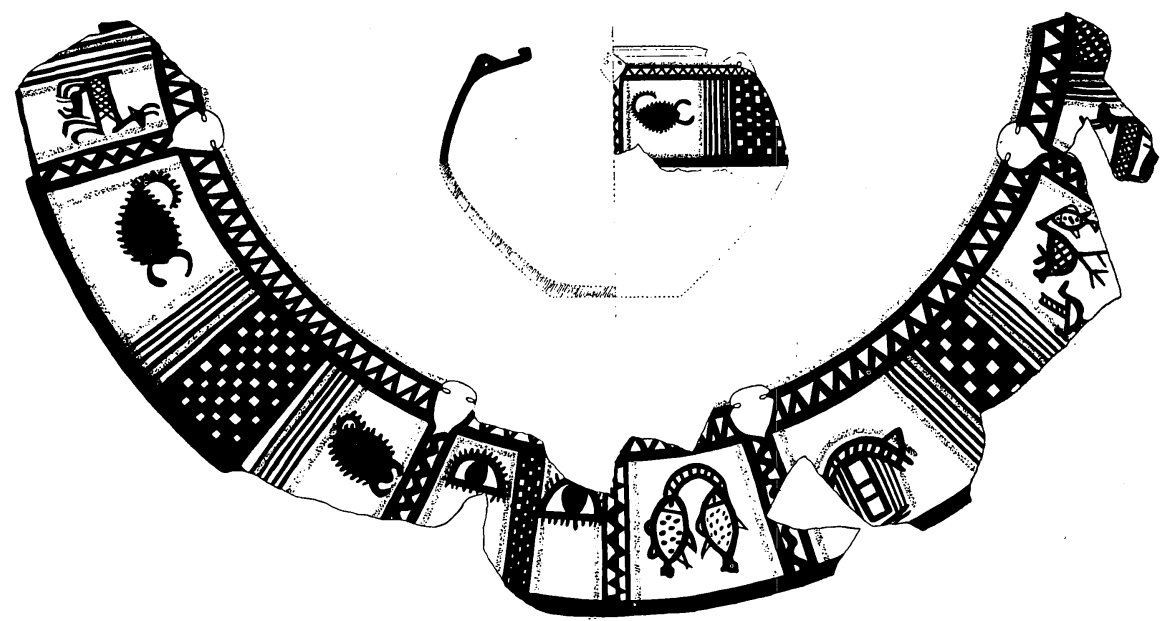

Abb.55 Bemaltes Tongefäss aus Djemdet Nasr; Djemdet Nasr-Zeit, um $3000 \mathrm{v}$. Chr.; FIELD/MARTIN, AJA 39 (1935) PI.XXXI = GOFF, Symbols Fig. 346.

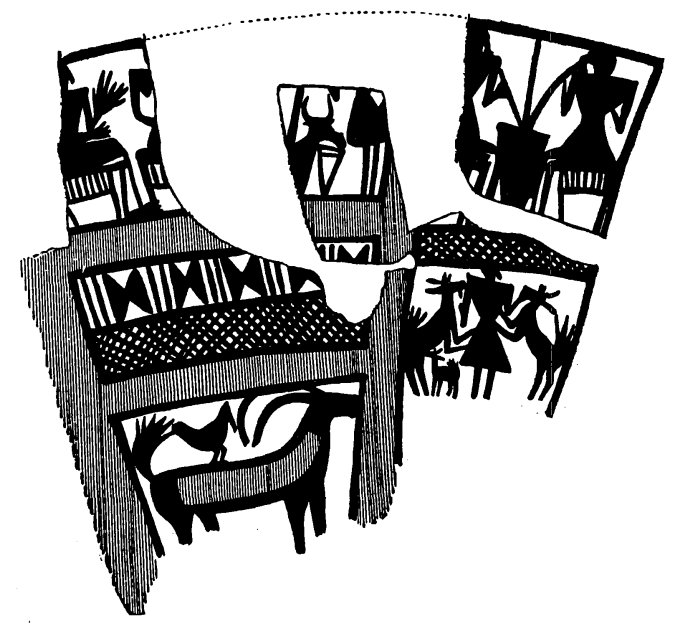

Abb.56 Bemaltes Tongefäss von Chfadji; Djemdet Nasr Zeit; SMITH, BMQ 8 (1933/34) 38-4I Fig.1-3. 
Ischchara, der Mutter von sieben Kindern ${ }^{151}$, und den Darstellungen des Hieros Gamos ${ }^{152}$ verbunden ist. Symbolische Motive wie Skorpion und Augen scheinen auf diesem Gefäss mit realistischen Motiven wie dem fischenden Wasservogel und mit reinen Ornamenten abgewechselt zu haben.

Die gleiche Kombination von realistischen, symbolischen und ornamentalen Elementen findet sich auf einem Gefäss aus Chafadji, das SMITH in die Djemdet-Nasr-Zeit datiert ${ }^{153}$. U.a. erscheint hier der "Herr der Tiere" mit zwei Ziegen von denen eine ein Junges säugt (Abb.56).

Auf einem andern Gefäss von Chafadji stehen zwei ziegen, wovon eine säugend, zwei Böcken am Lebensbaum gegenüber (Abb.57). Nebst rein geometrischen und Pflanzenmustern sind auf dem Gefäss noch ein Mann und eine Frau zu sehen, wobei, wie das in der späteren mesopotamischen Mythologie (Inanna, Ischtar) die Regel ist, die Frau aktiv den Mann zu umwerben scheint.

Bei den drei zuletzt genannten Beispielen scheint die säugende Ziege die Potenz der Lebensmächte zu visualisieren, die durch den Skorpion, den "Herrn der Tiere", den Lebensbaum und das menschliche Paar repräsentiert werden.

Die frühdynastische zeit I scheint eine andere Richtung einzuschlagen. Auf einem bemalten Gefäss vom Tell Agrab (Dijala-Gebiet) ist eine säugende Capride in eine durch stilisierte Pflanzen, Fische und fischende Wasservögel angedeutete Landschaft gestellt. Auch die Reihe von Ziegen (Abb.58 zeigt nur einen Ausschnitt), die nebst der säugenden Bogenhornziege aus einem Bogenhornbock und einer Drehhornziege besteht, signalisiert den willen, eine ziegenherde einigermassen realistisch wiederzugeben.

151 EDZARD, in : HAUSSIG, WAM I 90.

152 Vgl. VAN BUREN, AfO 12 (1937/39) 1-28; vgl. z.B. PRITCHARD, ANEP Abb.680; SEYRIG, Syria 32 (1955) Pl. IV, 3.

153 BMQ $8(1933 / 34)$ 38-41. 


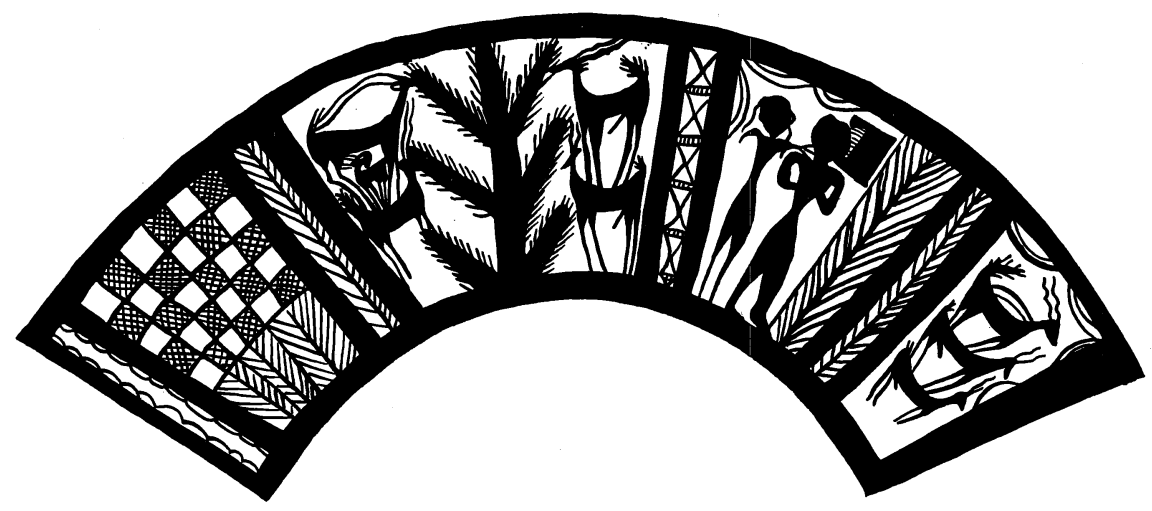

Abb.57 Bemaltes Tongefäss von Chafadji; Anfang der frühdynastischen Zeit I; DELOUGAZ, Illustrated London News vom 3. Dez. 1938, 1027.

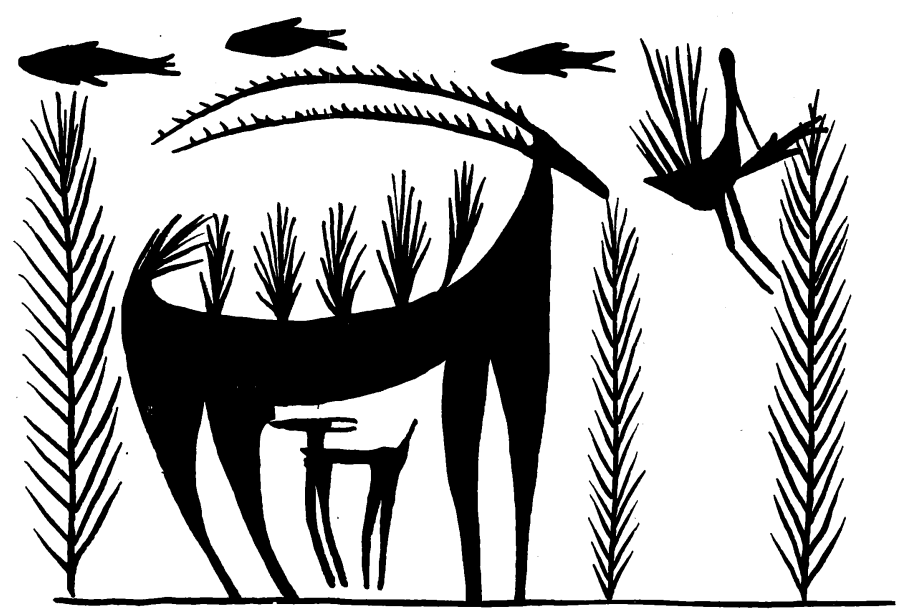

Abb.58 Bemaltes Tongefäss vom Tell Agrab; Frühdynastische zeit I; FRANKFORT, Illustrated London News vom 26.Sept.1936, Farbseite $D=$ STROMMENGER, Garten Eden $117 \mathrm{Nr} .75$. 
In den peripheren Regionen hingegen finden wir noch in der frühdynastischen Periode II die für die Djemdet-Nasr-Zeit typische Kombination ornamentaler symbolischer und realistischer Elemente, so auf Abdrücken eines Siegels vom Tell Brak in Nord-Ost-Syrien und einigen Scherben aus Ninive Stratum V. Bei der säugenden Capride auf den Rollsiegelabdrücken vom Tell Brak (Abb.59) ist zwischen Gehörn und Rücken des Muttertiers das Bild eines Gestirns angebracht. Es scheint an einem Baum zu fressen, der allerdings nur auf einer Seite mit Aesten versehen ist. Das gleiche Siegel zeigt eine Kuh mit rückwärtsgewandtem Kopf ${ }^{154}$ und einem Skorpion darunter. Zwischen Kuh und Ziege steht ein Mensch. Auf den bemalten Scherben von Ninive (․ㅡb.60) sind neben der säugenden Ziege u.a. ein Fisch und geometrische Ornamente $z u$ sehen.

In der Periode Frühdynastisch III (Ur I) taucht in Mesopotamien, soweit ich sehe, zum ersten Mal das Bild einer säugenden Kuh auf (Abb.61). Sie ist von einem Löwen angegriffen. Ein bewaffneter Mann sucht sie in Sicherheit zu bringen. Auf den ersten Blick denkt man an ein Erscheinungsbild, aber als solches ist es doch nicht recht vorstellbar, und der symbolische Sinn ist leicht zu erahnen. Der Unterschied ist sowieso oft nur der des Akzents, denn selbst reine Erscheinungsbilder werden oft wegen ihres starken emotionalen oder gedanklichen Gehalts fixiert. Noch weniger ist das Fragment eines Rollsiegels im Allard-Pierson-Museum in Amsterdam aus der gleichen Zeit (Mitte des 3. Jts. v.Chr.) als Erscheinungsbild zu verstehen (Abb.62). "Wir sehen eine Anzahl lebender Wesen sich zum Gott hin drängen, der eine Aehre hält. Zuvorderst bemerken wir einen Fisch, über dem Wasser angedeutet ist. Dieses liegt unter einer Bruchstelle in der Siegelfläche, die die Vorderbeine eines liegenden Steinbocks mit deutlich knotigen Hörnern verwischt. Darüber ist ein Skorpion"155. Rechts

154 Nicht ein Ibex, wie B.BUCHANAN will (Ashmolean Museum 140 $\mathrm{zu} \mathrm{Nr}$. 758).

155 FRANKFORT, Cylinder Seals 70f. Zum Skorpion vgl. VAN BUREN, AfO $12(1937 / 39) 14 \mathrm{f}$. 


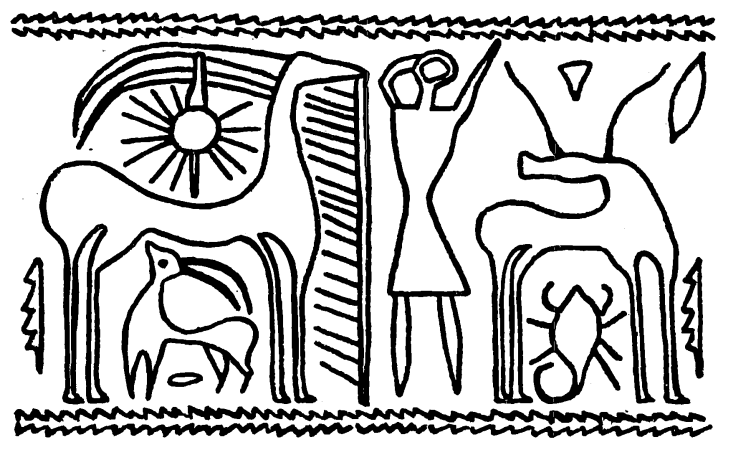

Abb.59 Abrollungen eines Siegels vom Tell Brak; frühdynastische Zeit II; BUCHANAN, Ashmolean Museum Nr.758.
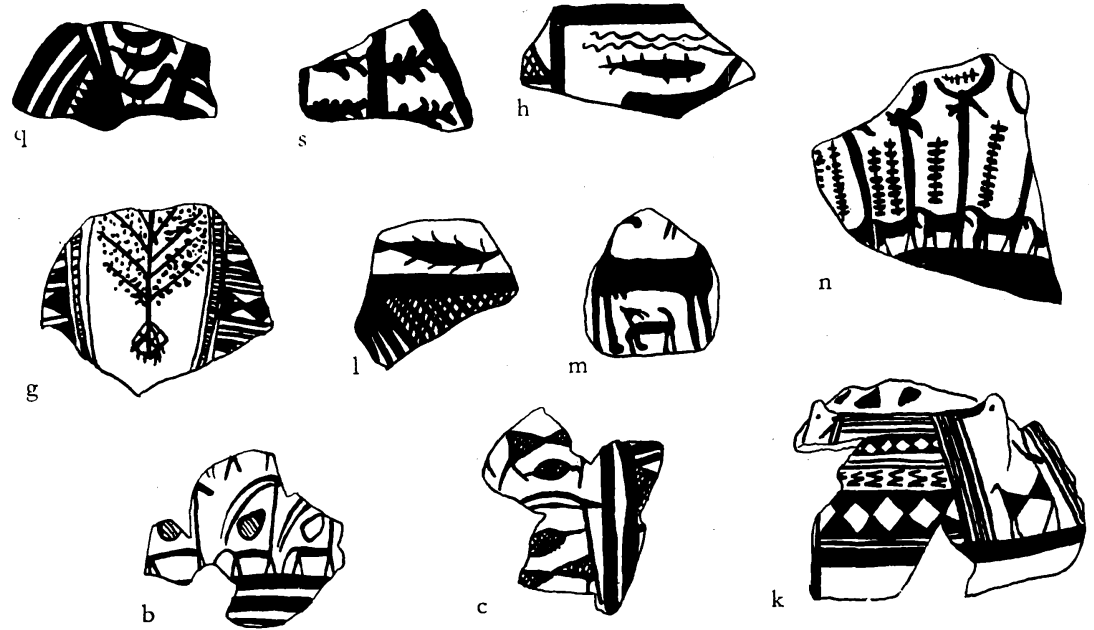

$A b b .60$ Scherben von bemalten Tongefässen aus Ninive, Stratum $V$; frühdynastische Zeit II; NAGEL, Djamdat Nasr Kulturen, Taf.47m. 


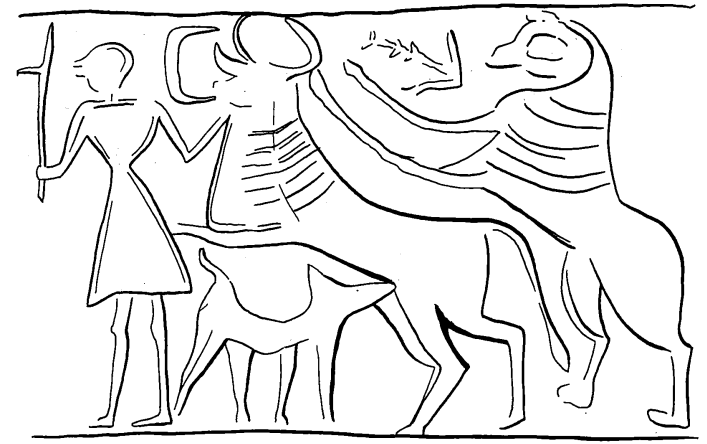

Abb.61 Rollsiegel aus der Sammlung Clercq; frühdynastische Zeit III; MENANT, Collection Clercq PI.II Nr.13.

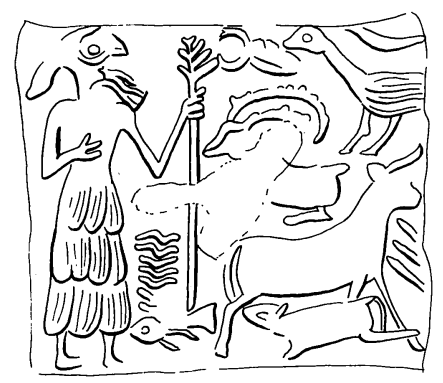

Abb.62 Fragment eines Rollsiegels im Allard Pierson Museum, Amsterdam; frühdynastische Zeit III; FRANKFORT, Cylinder Seals Pl. XVh; Ders. JEOL 3 (1935) 155f; Pl.XV 5 und 7.

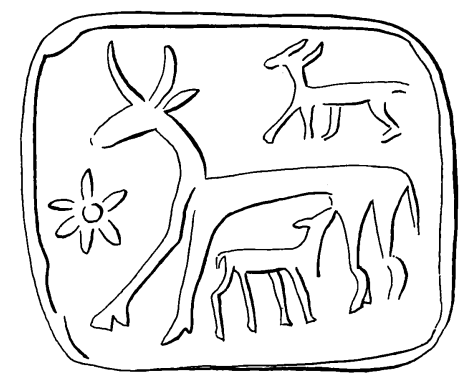

Abb.63 Giebelsiegel vom Tell Bascher, jetzt im Ashmolean Museum Oxford; 1. Hälfte oder Mitte des 3.Jt.v.Chr.; HOGARTH, Hittite Seals 62 Fig. 64. 


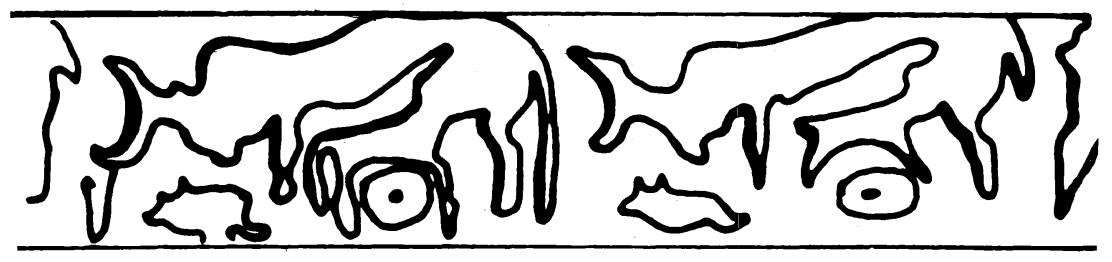

Abb.64 Siegelabrollung von Bet Jerach; Bronzezeit IV; 2350-2200 V.Chr.; BEN TOR, Cylinder Seals 10,28(Nr.49 IIC-3), 57.

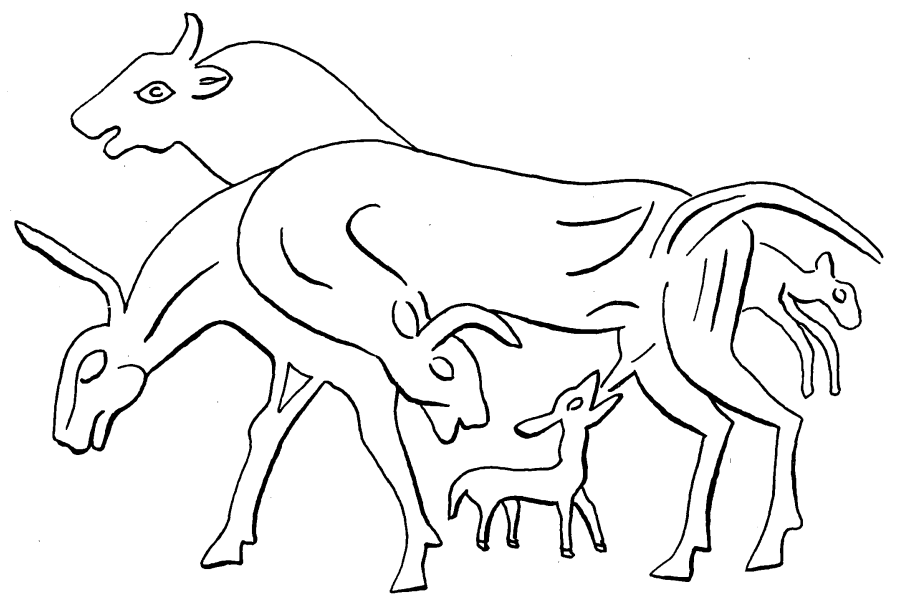

Abb.65 Rundes Stempelsiegel vom Tell Brak; akkadzeitliche Schicht; MALLOWAN, Iraq 9 (1947) $117 f$ und PI.XVI, 8f. 
davon ist ein nicht zu identifizierender Vierfüssler, wahrscheinlich eine Gazelle und unten rechts eine säugende Kuh, die vor einem teilweise weggebrochenen Baum steht.

Ungefähr in die Mitte des 3. Jts.v.Chr. dürfte auch ein Giebelsiegel vom Tell Bascher im Sajur-Tal westlich vom oberen Euphrat gehören (Abb.63), auf dem eine grob geschnittene säugende Kuh mit einer Rosette davor und einer Gazelle (?) darüber zu sehen ist. Aus etwas späterer Zeit, nämlich einer Schicht der Bronzezeit IV, die zeitlich ungefähr mit der Akkadzeit (2350-2150 v. Chr.) zusammenfällt, stammt eine Abrollung aus Bet Jerach am südlichen Ausgang des Sees Gennesaret in Israel. Die Kuh, die ihr Kalb säugt, bildet das Hauptmotiv (․bb.64). Der Kreis mit dem Punkt und der auf dem Kopf stehende Vogel sind als Nebenmotive $\mathrm{zu}$ werten.

Aus einer akkadzeitlichen Schicht, nämlich vom Boden des Naramsin-Palastes in Tell Brak, stammt auch ein merkwürdiges stempelsiegel, das P. AMIET als Produkt der frühdynastischen zeit verstehen will 156 , das aber höchst wahrscheinlich doch aus der Akkadzeit stammt und von einer syrischen Tradition abhängig ist ${ }^{157}$. Das Siegel zeigt eine Kuh in drei entscheidenden Phasen ihres Daseins : wie sie von einem Stier besprungen wird ${ }^{158}$, wie sie ein Kalb wirft und wie sie dieses Kalb, zu dem sie sorgend den Kopf zurückwendet, säugt $(\underline{\mathrm{Abb} .65})^{159}$. Das Siegel bringt in einzigartig konzentrierter Form den Fluss des Lebens zur Anschauung. Erst in neuassyrischer Zeit finden wir dieses Thema wieder, wenn auch formal verschieden gestaltet (vgl. Abb.10l-105).

156 Glyptique archaĭque 25, Pl. $8 \mathrm{Nr} .170$.

157 MALLOWAN, Iraq 9 (1947) 117f, Pl. XVI, 8f; AMIRAN, Iraq 18 (1956) 57-59.

158 AMIRAN, a.a.o., meint, die erste Phase zeige die Kuh beim Weiden. Aber der mächtige Schädel mit dem kurzen Horn über gebeugten schmaleren Kuhkopf ist eher der eines Stiers als der einer Kuh.

159 Dieses Siegel macht die These von P.MATTHIAE (RSO 31 (1961) 1-31) fraglich, das Motiv der Kuh, die den gesenkten Kopf zum Kalb zurückwende, sei aus der ägyptischen in die vorderasiatische Kunst eingedrungen. 
Im ersten Viertel des 2. Jts. v.Chr. begegnet auch die säugende Capride, die für Vorderasien typisch ist, mit zurückgewandtem Kopf. Auf einem altsyrischen Siegel ist sie nebst einem liegenden Greif hinter der sich entschleiernden, typisch syrischen Göttin zu sehen. Die ganze Gruppe ist auf einen Thronenden ausgerichtet, der mit seinem Stufenkleid noch stark an die Thronenden der neusumerischen Ur-III-Glyptik erinnert (Abb.66) .

Die Kombination der nackten Göttin mit dem sogenannten Gottkönig als Krieger (Abb.67) ist hingegen typisch für die altbabylonische Zeit. Das Flechtband u.ä. aber verraten die syrische Herkunft, und syrisch ist auch die säugende Capride anstelle der auf den altbabylonischen Siegeln mit der Göttin assozierten säugenden Kuh.

Die nackte Göttin tritt auf Abb.68 aus ihrer frontalen Statik heraus und wendet sich, wie auf einem peripheren altbabylonischen Siegel der Pierpont Morgan Library ${ }^{160}$, ihrem von ihr abgewandten "Kollegen" $\mathrm{zu}^{161}$. Wie schon auf $\underline{\mathrm{Abb} .66}$ trennt das Flechtband eine Sphäre des Todes von einer Sphäre intensiven Lebens. Letzteres wird u.a. durch eine säugende Capride und einen nicht näher bestimmbaren Vierfüssler, der einen anderen bespringt, repräsentiert. Die säugende Capride wendet den Kopf nach hinten, aber nicht nach unten.

160 PORADA, Pierpont Morgan Library Nr. 488.

$161 \mathrm{Abb} .68$ ist bisher unveröffentlicht. Das Rollsiegel besteht aus dunkelgrauem Hämatit. Es ist 2,24 cm lang und hat einen Durchmesser von $1,31 \mathrm{~cm}$. Es ist vor einigen Jahren aus der Sammlung R.SCHMIDT, Solothurn, in eine zürcher Privatsammlung gelangt. Ich danke der Besitzerin für die Publikationserlaubnis. 


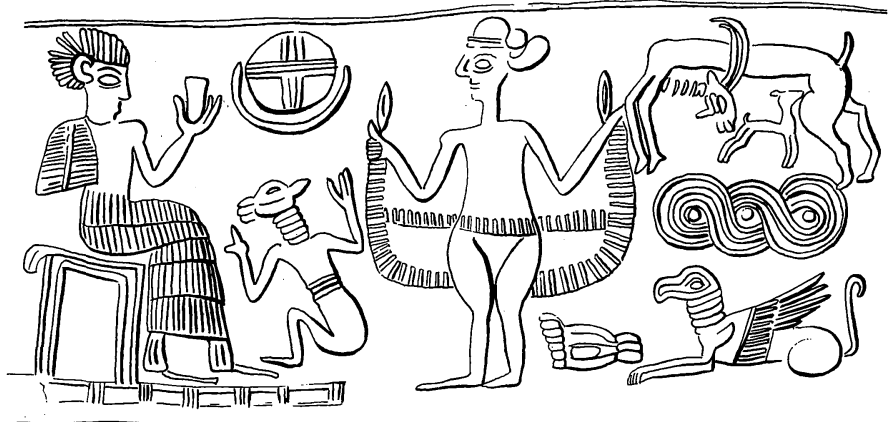

Abb.66 Altsyrisches Rollsiegel in den Musées Royaux in Bruxelles; l. Viertel des 2.Jt.s V.Chr.; SPELEERS, Catalogue I6Of Nr.1393 (Zeichnung nach Abrollung, die Frau D.HOMES-FREDERICQ freundlicherweise zur Verfügung stellte); vgl. Taf. II, 1 dieser Arbeit.

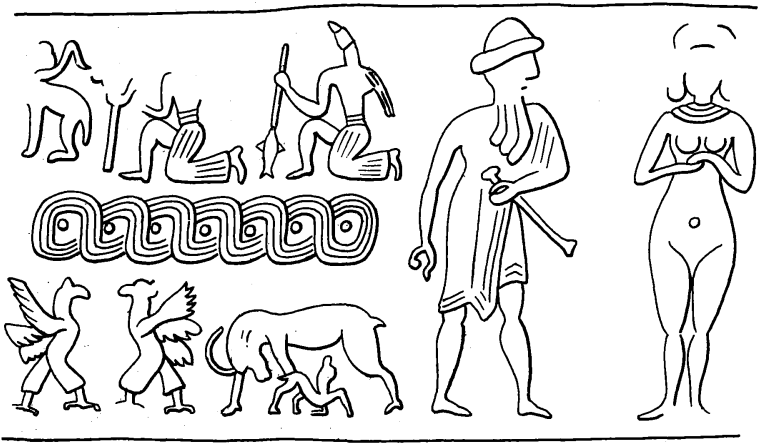

Abb.67 Altsyrisches Rollsiegel in der Bibliothèque Nationale, Paris; 1.Viertel des 2.Jt.s v.Chr.; DELAPORTE, Bibliothèque Nationale Nr.452.

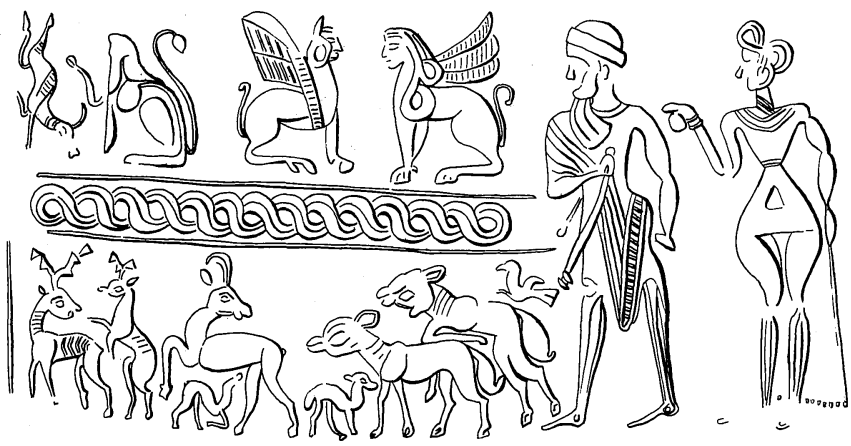

Abb.68 Altsyrisches Rollsiegel in Schweizer Privatbesitz; 1. Viertel des 2.Jt.s v.Chr.; unveröffentlicht. Vgl. Taf.II,2 dieser Arbeit. 
Nebst den für die vorderasiatische Tradition typischen säugenden Capriden finden wir in der altsyrischen Glyptik, ebenfalls im Umfeld der nackten Göttin, die säugende Kuh; so auf eịnem Rollsiegel aus Mari aus der Regierungszeit Samsuilunas, des Nachfolgers Hammurabis (Abb.69) ${ }^{162}$. Wie schon auf den stücken von Abb.66-68 ist hier kein ägyptischer Einfluss festzustellen.

Zweimal ist das Motiv der säugenden Kuh zusammen mit der jugendlichen, geflügelten, typisch syrischen Göttin belegt (Abb.70-71) . Auf $\underline{\mathrm{Abb} .70}$ ist das Kalb liegend dargestellt. Auf Abb.71 kratzt sich die Kuh während des Säugens mit dem einen Hinterbein, wie das auf ägyptischen Bildern seit der 4. Dynastie zu sehen ist (Abb.12), wie es aber auch in der Natur leicht beobachtet werden kann.

Liegende Kälber säugen auch die Kühe, die nebst zwei Gabenträgern $^{163}$ und zwei Adoranten ein syrisches Siegel aus dem zweiten Viertel des 2. Jts.v.Chr. schmücken ( $\underline{\mathrm{Abb} .72})$. Da sonst keine Göttexfigur zu sehen ist, kann man sich fragen, ob die (verdoppelt) säugende Kuh hier nicht, wie später auf Abb.100, direkt als Kultbild $\mathrm{zu}$ verstehen ist. Die wilde Jagd im obersten Teil des Siegels wäre als Füll- bzw. Kontrastmotiv zu verstehen.

Wie eine Statuengruppe oft auf eigener Standlinie stehend, erscheint die Kuh, die ihren Kopf zum säugenden kälbchen zurückwendet, auf einer Reihe von altbabylonischen Siegeln. Ihre Präsenz daselbst ist schon wiederholt als ägyptischer Einfluss gewertet worden. Denn die mit rückwärts gewendetem Kopf säugende Kuh hat im mesopotamischen Kernland keine Tradition ${ }^{164}$. Aber angesichts der stücke von $\underline{A b b .65}$ und $\underline{A b b .66-68}$ scheint es mir frag-

162 Vgl. dazu AMIET, Syria 37 (1960) 223 und DERS., Syria 38 (1961) $5 f$.

163 Zum Tragen des Opfertiers auf den Schultern vgl. PARROT, Le "Bon Pasteur" 178-181. Die Beispiele, die PARROT anführt, stammen allerdings erst aus dem 1. Jt.v.Chr.

164 BUCHANAN, JCS 11 (1957) 74-76; OPIFICIUS, in : Moortgat Fs 219; MATTHIAE, RSO 36 (1961) 25. 


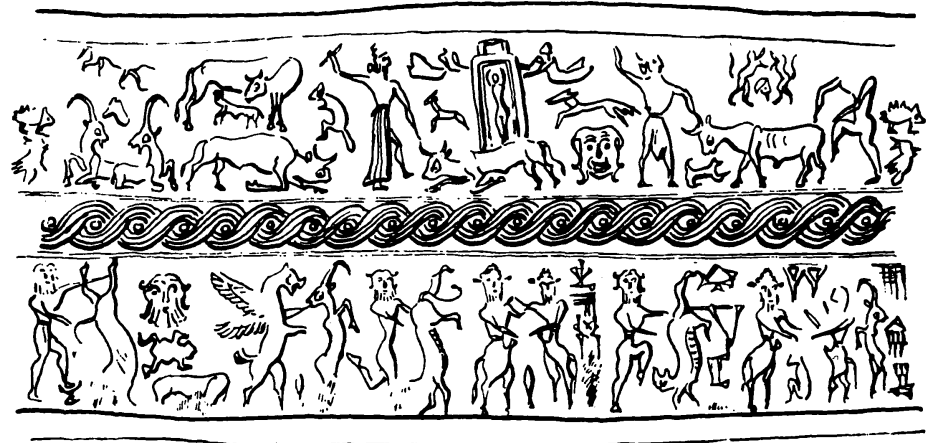

Abb.69 Rollsiegelabdruck aus Mari; Regierungszeit Samsuilunas ; 18.Jh.v.Chr.; AMIET, Syria 37 (1960) 222 Fig. 7.

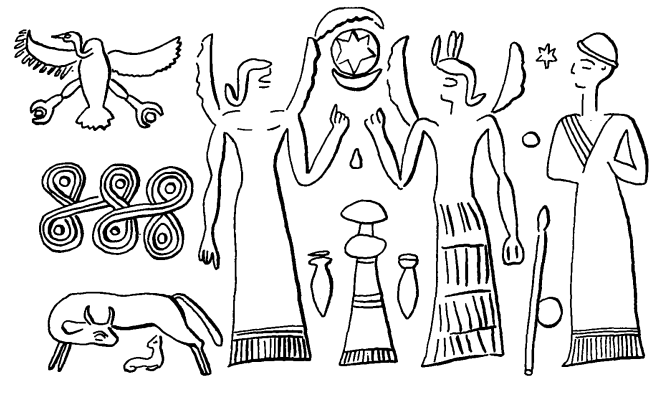

Abb.70 Altsyrisches Rollsiegel in der Sammlung Moore; 1. Viertel des 2. Jt.s v.Chr.; EISEN, Collection Moore Nr. 150; SAFADI, Entstehung Abb. 100.

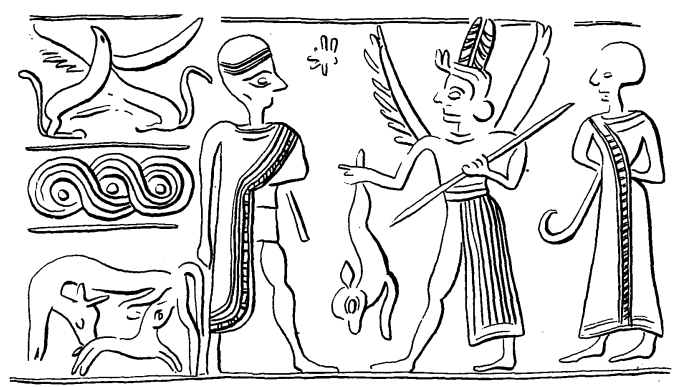

Abb.71 Altsyrisches Rollsiegel in der Sammlung de Clercq; 1. Viertel des 2.Jt.s v.Chr.; MENANT, Collection Clercq Pl.XXXV Nr.390. 


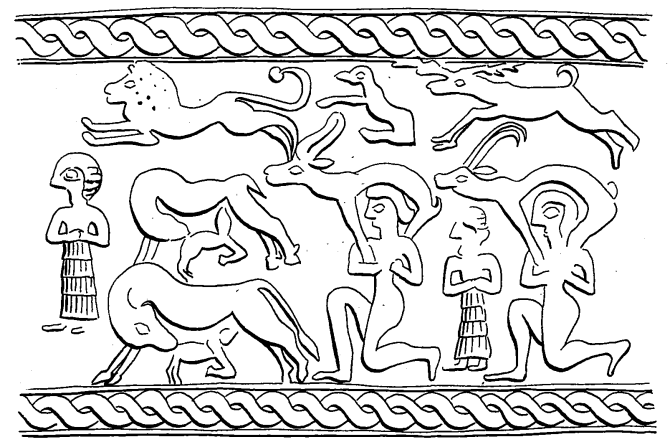

Abb.72 Altsyrisches Rollsiegel; 2.Viertel des 2.Jt.s v.Chr.; OPIFICIUS, Geschnittene Steine Nr.46.

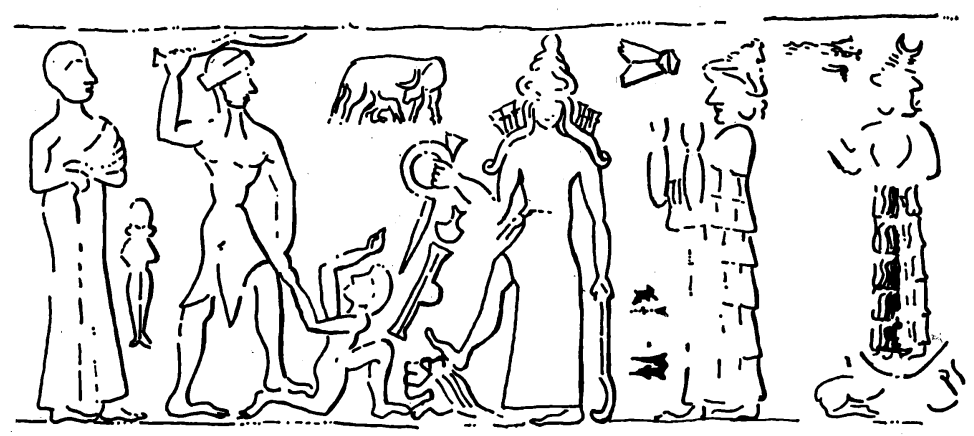

Abb.73 Altbabylonischer Rollsiegelabdruck in der Columbia University Library, New York; altbabylonisch, Zeit Apilsins, 1830-1813 v.Chr.; PORADA, JCS 4 (1950) 159 Abb.I.

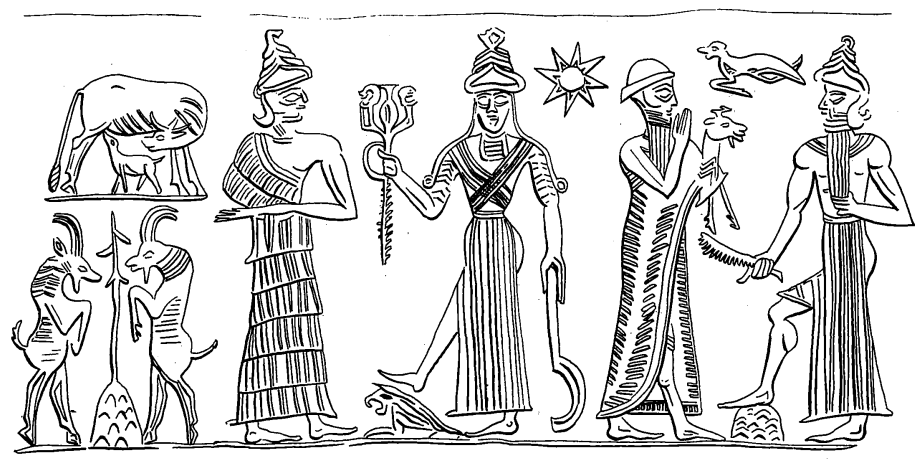

Abb.74 Altbabylonisches Rollsiegel vom Tell Asmar; jetzt im Oriental-Institut in Chicago; 19./18.Jh.v.Chr.; FRANKFORT, Stratified Cylinder Seals Pl.70 Nr.770. Vgl. Taf.II,3 dieser Arbeit. 
lich, ob nicht auch an syrischen Einfluss zu denken wäre.

Für unsere Fragestellung wichtig ist, dass die säugende Kuh auf den altbabylonischen Siegeln ebenso regelmässig wie auf den altsyrischen in Verbindung mit einer Göttin auftaucht. Hier ist es in der Regel die kriegerische Ischtar. Das ist schon auf dem ältesten sicher datierbaren Stück, auf einer Siegelabrollung aus der Zeit eines der Vorgänger Hammurabis, nämlich Apilsins, der Fall ( Kuh-Kälbchen-Gruppe auch auf einem altbabylonischen Siegel vom Tell Asmar zu sehen (Abb.74). Die Gruppe steht dabei wie ein Kultbild auf einer eigenen Standlinie. Auch die anderen Nebenmotive wie der achtstrahlige Stern und der von Ziegen flankierte Baum stehen mit der Göttin in Zusammenhang. Auf einem weiteren altbabylonischen Siegel ist die kriegerische Ischtar von der nackten Göttin und der Kuh-Kälbchen-Gruppe flankiert (Abb.75), auf einem anderen ist der "Gott-König als Krieger", der vor Ischtar steht, in diese Flankierung eingeschlossen, während der Sonnengott und die stiermenschen mit der standarte einen zweiten Komplex bilden (Abb.76). Auf einem Siegel aus der Southesk Collection ist die Partie vor der kriegerischen Göttin weggebrochen $(\underline{A b b} .77)$. Vielleicht ist sie auch hier von diesen beiden Begleitmotiven flankiert worden. Wie auf Abb.74 steht die KuhKälbchen-Gruppe hier auf einer eigenen Standlinie.

Bei einer Abrollung auf einer Keilschrifttafel aus Sippar fehlt die Ischtar ganz, und es sind nur die flankierenden Lamagöttinnen, die Kuh-Kälbchen-Gruppe und die en face dargestellte nackte Göttin übriggeblieben $(\underline{\mathrm{Abb} .78})^{165}$. SCHEIL datiert die Tafel in die Zeit Hammurabis oder Samsuilunas ${ }^{166}$.

165 Ein ähnlicher Sachverhalt scheint auf einem Siegel in der Sammlung ERLENMEIER vorzuliegen. Neben der Szene mit dem Sonnengott (vgl. Abb.74 und 76) finden sich degenerierte Reste einer Ischtarszene (ERLENMEYER, Or 30 (1961) Taf.40 $\mathrm{Nr}$. 23) .

166 SCHEIL, RT 20 (1898) 62. 


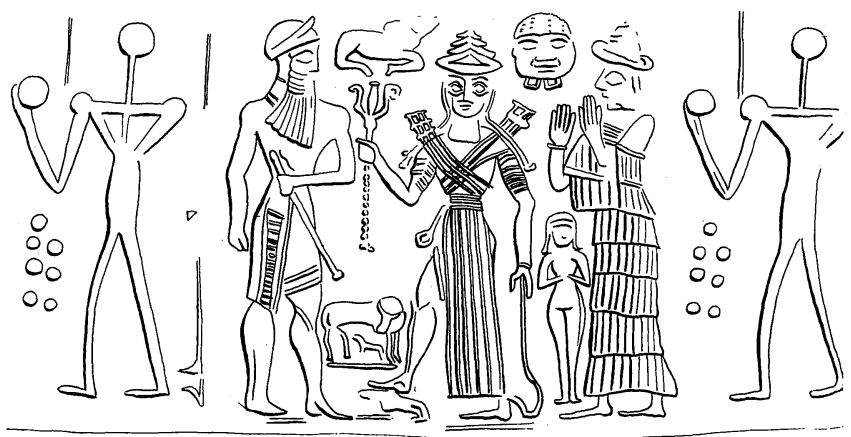

Abb.75 Altbabylonisches Rollsiegel aus der Sammlung Dieulafoy; im Louvre; 19./18.Jh.v.Chr.; DELAPORTE, LOuvre Pl.51 Nr.19.

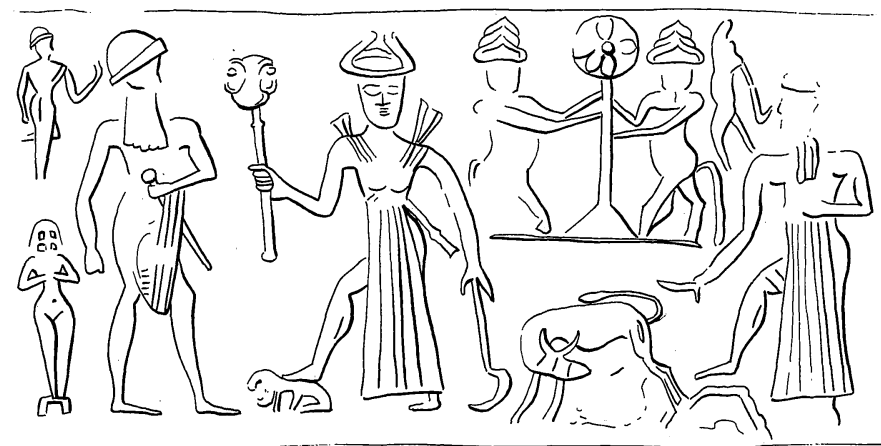

Abb.76 Altbabylonisches Rollsiegel aus der Sammlung de Clercq; 19./18.Jh. v.Chr.; MENANT, Collection Clercq Pl.XXIII Nr.236.

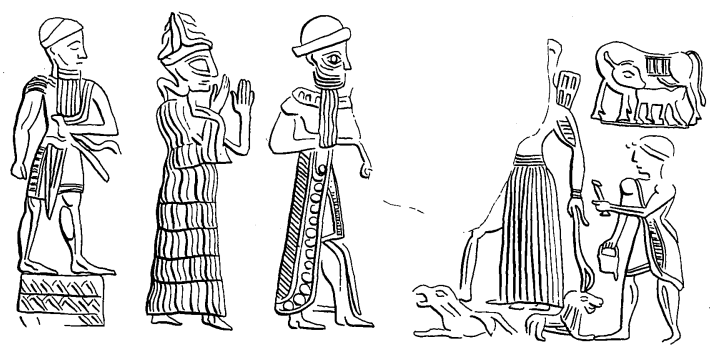

Abb.77 Altbabylonisches Rollsiegel aus der Southesk Collection; 19./18.Jh. v.Chr.; FRANKFORT, Cylinder Seals Pl.XXVI i. 
Es stellt sich hier die Frage, was die Vergesellschaftung der säugenden Kuh mit der kämpferischen Ischtar und der nackten Göttin bedeutet. V.SCHEIL wollte in der säugenden Kuh ein Symbol der Ischtar sehen 167 und verwies zur Begründung auf ein Wort Nabus an Assurbanipal, in dem es heisst, Nabu hätte Assurbanipal an den vier Brüsten Ischtars trinken lassen ${ }^{168}$. Aber in der vorausgehenden Zeile lässt ihn Nabu auf ihrem Schoss sitzen und das verbietet, an Kuhgestalt zu denken, zumal die Verdoppelung von Gliedern bei Göttern auch sonst vorkommt ${ }^{169}$. Hingegen wird Ischtar gelegentlich "Wildkuh" (rimtu) genannt, "Wildkuh, die die Weltgegenden niederstösst", "hohe Wildkuh" u.ä.170. Diese Epitheta betonen aber nicht gerade die mütterlichen züge Ischtars.

Andere Autoren haben deshalb die Identifikation der säugenden Kuh mit Ninhursag, der "Herrin des Gebirges" vorgezogen ${ }^{171}$. In der Einleitung zum sumerischen Streitgespräch zwischen Sommer und Winter begattet sich Enlil in Gestalt eines riesigen Stiers mit (Nin) Hursag und zeugt so Sommer und Winter ${ }^{172}$. Diese ist hier also wohl kuhgestaltig vorgestellt. Besonders charakteristisch für Ninhursag ist es, dass sie die künftige könige säugt ${ }^{173}$.

Neben Ischtar und Ninhursag tragen verschiedene andere Göttinnen das Epitheton "Wildkuh" und werden als Nährerinnen der Kron-

167 Ebd.

168 FALKENSTEIN/VON SODEN, Hymnen und Gebete 294; auch BARNETT, Iraq 2 (1935) 207 und Catalogue 143, stützt sich bei seiner Identifizierung der säugenden Kuh mit Ischtar auf diesen Text.

169 Ebd.

170 TALLQUIST, Götterepitheta 338.

171 HEHN, Gottesidee 301f; DEIMEL, Pantheon $208 \mathrm{Nr}$. 2576,5; FRANKFORT, Cylinder Seals 177.

172 JACOBSEN, Treasures of Darkness $104 \mathrm{f}$.

173 BOISSIER, OLZ 11 (1908) 234-236; VAN BUREN, AfO 9 (1933/34) 169f; DHORME, Religions de Babylonie 48 . 


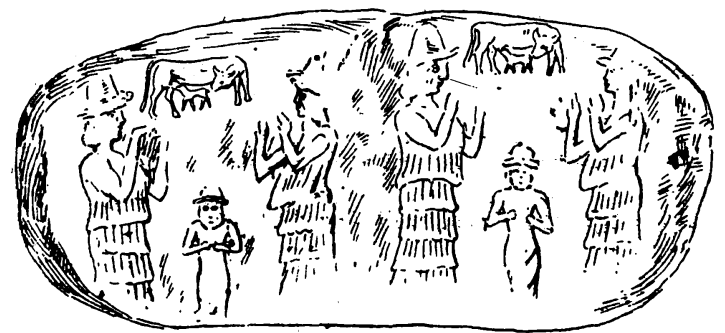

Abb.78 Altbabylonische Siegelabrollung aus Sippar; 18.Jh.v.Chr.; SCHEIL, $R T 20$ (1898) 62 .

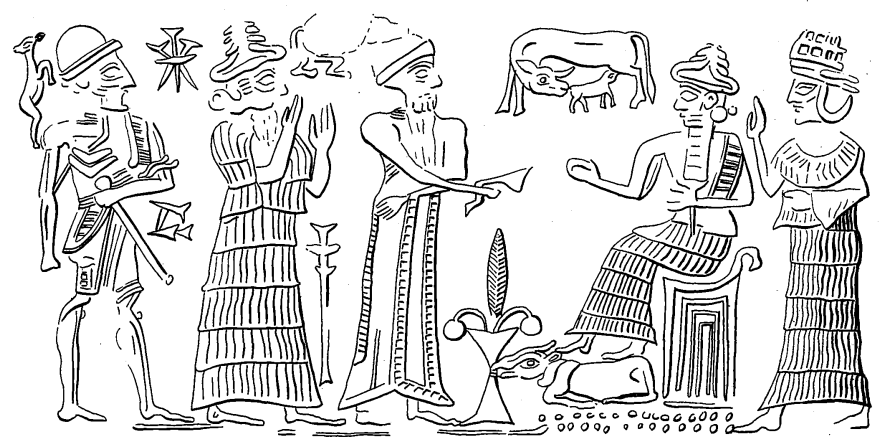

Abb.79 Altbabylonisches Rollsiegel in der Sammlung Newell; 19./18.Jh.v.Chr.; VON DER OSTEN, Newell Collection Nr.180.

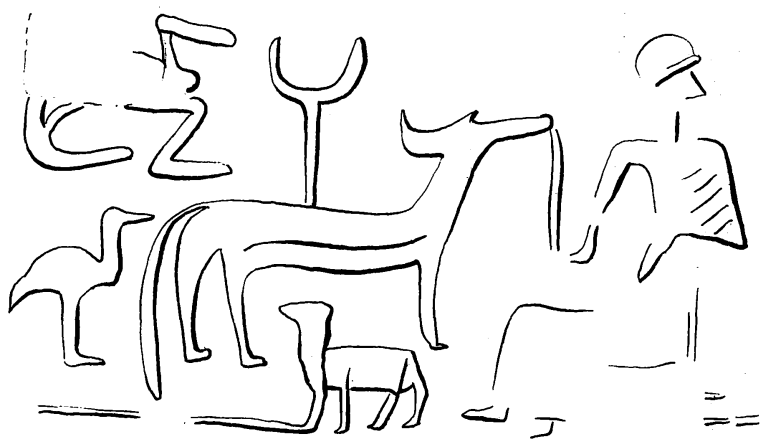

Abb.80 Altbabylonisches Rollsiegel; 18./17.Jh.v.Chr.; DELAPORTE, Musée Guimet Nr.33. 
prinzen gefeiert ${ }^{174}$

Ob die säugende Kuh neben der kriegerischen Ischtar einen ihrer Aspekte oder eine andere, zur kriegerischen Ischtar sozusagen komplementäre Göttin oder gar paradigmatisch den von Ischtar geschenkten Segen verkörpert, jedenfalls bilden die kriegerische Ischtar und die säugende Kuh in der altbabylonischen Glyptik zwei fest verbundene Motive, und die säugende Kuh ist so oder so als Manifestation dieser Göttin bzw. ihres Wirkens zu verstehen.

Nur ganz ausnahmsweise erscheint die säugende Kuh auf altbabylonischen Siegeln in Verbindung mit einem bärtigen ${ }^{175}$ thronenden Gott, der seine Füsse auf einen Stier stellt, der seinerseits, wie der Thron des Gottes, auf einem Berg ruht (Abb.79). Vielleicht bilden der Stier des Gottes zusammen mit der Kuh und ihrem Kalb eine Triade ${ }^{176}$. In diesem Falle würde die Kuh auch hier die Göttin vertreten ${ }^{177}$.

Singulär ist ein recht summarisch geschnittenes altbabylonisches Siegel mit einer thronenden Gottheit, vor der eine säugende Kuh mit einer Mondsichel steht ( sind oben ein Skorpion, der im Zusammenhang mit dem säugenden Muttertier schon öfters begegnet ist (vgl. Abb.55, 59, 62), und unten ein Vogel zu sehen. Die Kombination von säugender Kuh und Sichelmondstandarte erinnert an den altbabylonischen Mythos

174 VON SODEN, Akkadisches Handwörterbuch II 986; BARNETT, Catalogue 143-145; MATTHIAE, RSO 36 (1961) 21-23.

175 Der Bart auf dem Photo ist nicht über alle Zweifel erhaben, doch liesse nur ein Augenschein am Original eine sichere Entscheidung $\mathrm{zu}$.

$176 \mathrm{Vgl}$. dazu Abb.69 und PARROT, Mission archéologique de Mari II. Le Palais III 213 Anm.2.

177 Eine ähnliche, an entscheidenden Stellen aber zerstörte Komposition ist auf der Siegelabrollung auf einem Brief aus dem 35. Jahr Hammurabis zu sehen (DELAPORTE, Louvre Pl. 115 Fig. ld = Nr. A.527). 
vom Mondgott und der Kuh Amat-Sin "Magd des Sin"178.

In einem mittelassyrischen magisch-medizinischen Text wird auf diesen Mythos mit folgenden Worten Bezug genommen :

51 "Gi-Sin, 'Magd des Sin', hatte Schmerzen bei der Niederkunft; das Kindlein

52 steckte fest, das Kindlein steckte fest. Der Riegel war sicher - um das Leben zu Ende zu bringen,

53 das Tor war festgemacht - gegen den Säugling. Sin sah sie,

54 er liebte sie, er weidete sie im saftigen Gras, in den Wiesen...

55 Er gab ihr zu trinken. Ein ungestümer Stier (buru) besprang die Kuh (arhu).

56 Nachdem ihre Tage erfüllt, ihre Monate vollendet waren...

57 kniete die Kuh nieder und wand sich...

58 Auf ihr Schmerzensgebrüll hin, Sin, das Licht des Himmels...

59 Die zwei Töchter des Anu kamen vom Himmel herab. Die eine trug Wasser der Geburtswehen, die andere

60 trug Oel in einem Krug (und) Wasser der Geburtswehen. Er berührte ihre Braue mit Oel aus dem Krug und (besprengte)

61 ihren ganzen Körper. Genauso wie Gi-Sin, 'Magd des Sin',

62 so möge diese junge Frau gebären. Enenuru" 179 .

Ein genaueres Durchkämmen der Literatur unter diesem Gesichtspunkt würde wahrscheinlich zeigen, dass in Mesopotamien ganz ähnlich wie in Aegypten verschiedenste Göttinnen und göttliche Wesen in Kuhgestalt erscheinen konnten und dass vor allem die werfende und säugende Kuh numinose Aspekte hatte.

Ungefähr am Ende der altbabylonischen zeit taucht die mit zurückgewendetem Kopf ihr saugendes Kalb leckende Kuh auch in Kreta auf. Ein Fayence-Relief mit diesem Motiv ist in einem Tempel in Knossos in einer Schicht, die der mittelminoischen Zeit III (ca. 1700-1550 v.Chr.) angehört, gefunden worden (Abb. 81). EVANS denkt, wie schon gesagt, an ägyptischen Einfluss. Da für die mittelminoische zeit altbabylonische siegel auf Kreta

178 Die Literatur $\mathrm{zu}$ diesem Mythos ist aufgelistet bei BORGER, Handbuch III 63; ergänze : DE LIAGRE BOEHL, JEOL 4 (1936) 202-204.

179 LAMBERT, Iraq 31 (1969) $31 f$. 
111

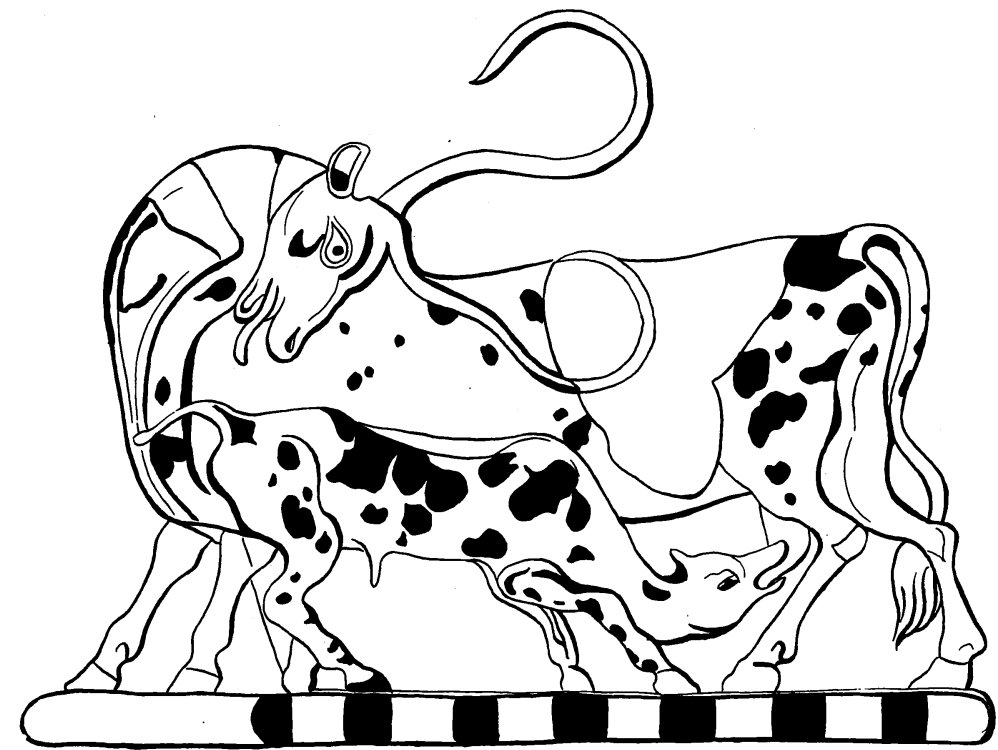

Abb.81 Fayence-Relief aus Knossos; mittelminoisch III; 18.-16.Jh.V.Chr.; EVANS, Palace of Minos I $511 \mathrm{Fig} .367$.

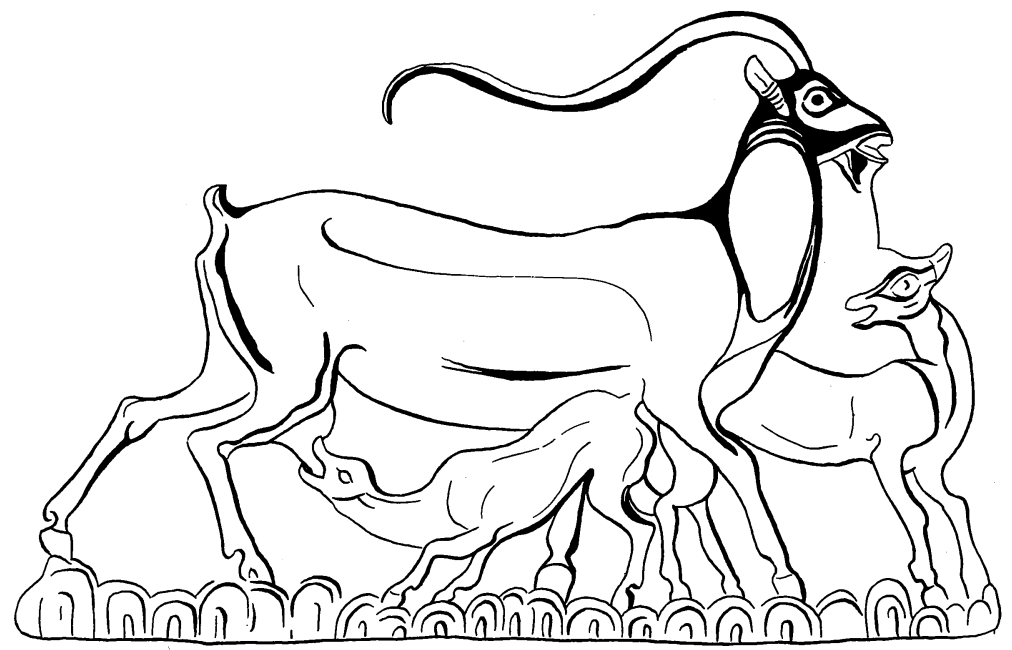

Abb.82 Fayence Relief aus Knossos; mittelminoisch III; 18.-16.Jh.V.Chr.; EVANS, Palace of Minos I $510 \mathrm{Fig.} 366$. 
nachgewiesen sind ${ }^{180}$, ist auch ein möglicher Einfluss von dieser Seite $z u$ erwägen. Stilistisch ist das Motiv jedenfalls völlig der einheimischen Kunst assimiliert.

Das scheint auch inhaltlich der Fall zu sein, denn neben der säugenden Kuh erscheint von Anfang an die für Kreta so typische Wildziege (Abb.82). Der Fundort macht die Verbindung der beiden säugenden Tiere mit einer Göttin wahrscheinlich. Gelegentlich sollen die beiden vermischt erscheinen. So zeigt nach EVANS der Abdruck des Stempelsiegels von $\underline{\mathrm{Abb} .83}$ eine säugende Ziege mit einem Kuhschwanz ${ }^{181}$. Ein genaues Hinsehen zeigt aber, dass wir es mit einer übertrieben schlanken Kuh zu tun haben. Der typische Ziegenbart fehlt.

Aehnlich überelegante Kühe wie auf Abb.83 finden sich auch auf zwei syrischen Siegeln, die ihrerseits deutlich minoisch beeinflusst sind. Beim einen handelt es sich um ein Rollsiegel in der Newell Collection (Abb.84). VON DER OSTEN hat das säugende Tier in der Mitte oben als Antilope bezeichnet ${ }^{182}$. VAN BUREN hat auf den langen Schwanz hingewiesen und vermutet, dass doch die Absicht bestand, eine Kuh darzustellen ${ }^{183}$.

Ein linsenförmiges Stempelsiegel, das ebenso eindeutig wie das Stück von $\underline{A b b .84}$ der spätminoischen Kunst verpflichtet ist, wurde in Karkemisch in Nordsyrien erworben (Abb.85) ${ }^{184}$. Man denkt beim Tier spontan an eine Gazelle oder etwas Aehnliches. Aber der lange Schwanz suggeriert, dass der Künstler auch hier, wie bei $\underline{A b b} .83$ und $\underline{84}$, eine Kuh intendierte.

Ein linsenförmiges Siegel, das in Form und Stil ebenfalls grosse Aehnlichkeit mit spätminoischen Siegeln aufweist, ist in Rabbat-

180 PLATON, Corpus der minoischen Siegel II, I Nr.306; KENNA, AJA 72 (1968) 321-336.

181 Palace of Minos IV, 2552.

182 Collection Newell $55 \mathrm{Nr} .358$.

183 Symbols of the Gods 38.

184 DUSSAUD, Syria 15 (1934) 392. 


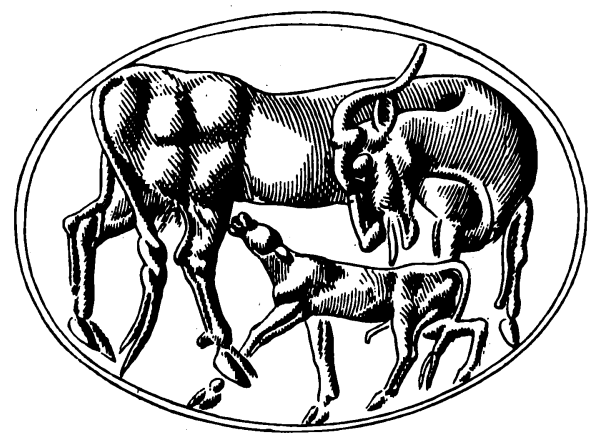

Abb.83 Abdruck eines Stempelsiegels; mittelminoisch III oder spätminoisch; EVANS, Palace of Minos IV,2 552 Fig.512.

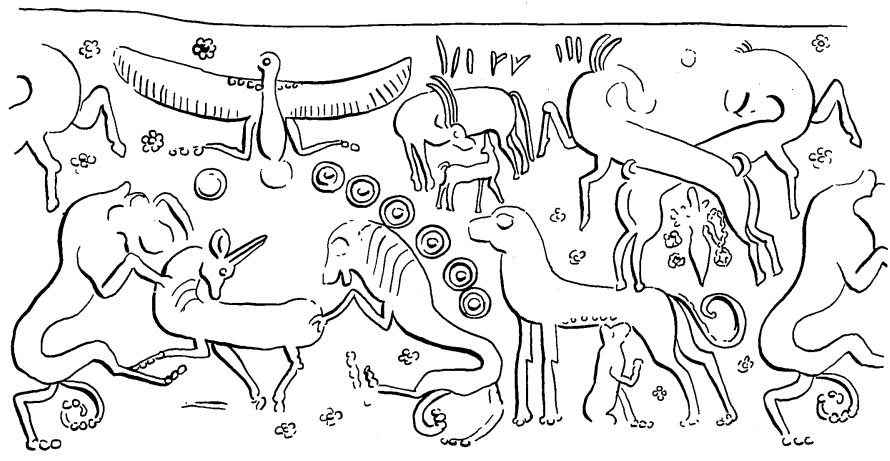

Abb.84 Rollsiegel in der Newell Collection; 2. Hälfte des 2.Jt.s v.Chr.; VON DER OSTEN, Newell Collection Nr. 358.
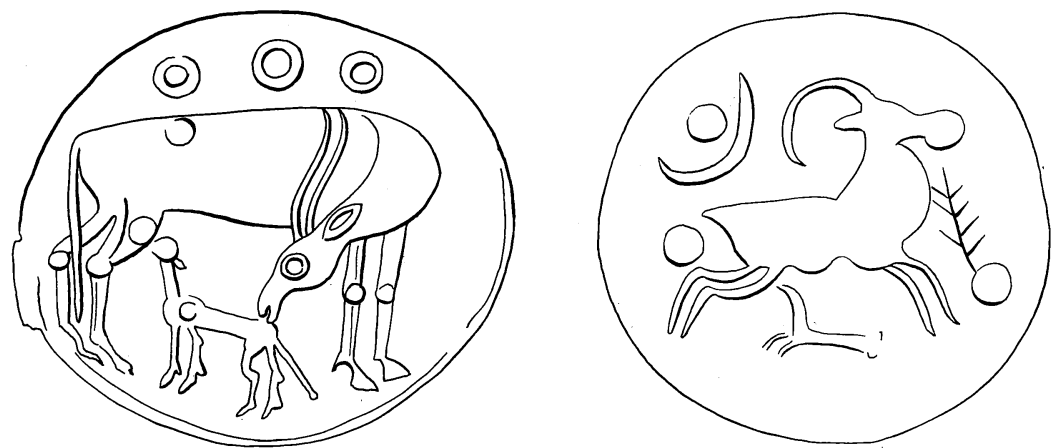

Abb.85 Linsenförmiges Stempelsiegel aus Karkemisch; jetzt im Britischen Museum; 1400-1200 v.Chr.; BARNETT, BMQ 8 (1933/34) Pl.45,10.

Abb.86 Linsenförmiges Stempelsiegel aus Rabbat Moab; 14./13.Jh.v.Chr.; KENNA, $A D A J 18$ (1973) 79. 
Moab in Transjordanien aufgetaucht (Abb.86). Es zeigt eine langhörnige Ziege, die ein Junges säugt. Vor ihr ist ein Zweig, über ihr ein Astralsymbol zu sehen.

Wenn Kreta vor Beginn der zweiten Hälfte des 2. Jts. v.Chr. von Vorderasien her beeinflusst wurde, so hat es nunmehr kräftig dorthin zurückgewirkt, wie diese drei Siegel zeigen. Ich werde bei den Belegen aus der syro-palästinischen Kunst des 1 . Jts. darauf zurückkommen.

Säugendes Kleinvieh finden wir aber in der 2. Hälfte des 2.Jts. v.Chr. nicht nur auf dem minoisch beeinflussten syro-palästinensischen Siegel von $\underline{A b b} .86$, sondern auch auf mittelassyrischen Stücken. Auf einem Siegel aus Assur steht ein säugendes Fettschwanzschaf vor einem Baum ( $\underline{\mathrm{Abb} .87)}$ ). Interessant ist das Gotteszeichen ("Stern", din-gir), das über dem Rücken des Schafes angebracht ist und die ganze Gruppe so als "Götterbild" charakterisiert.

Ein weiteres mittelassyrisches Rollsiegel zeigt das bereits für die Djemdet-Nasr-Zeit belegte Motiv (Abb.57) einer säugenden Capride am Lebensbaum (Abb.88). Das Junge saugt liegend. Ein Zusammenhang mit der altbabylonischen oder syro-palästinensischen Glyptik der zweiten Hälfte des 2. Jts.v.Chr. ist nicht erkennbar.

Das gilt auch für ein halbes Dutzend Siegel aus dem Palästina des 10.-9. Jhs.v.Chr., das bisher in diesem Zusammenhang nicht beachtet wurde, für unsere Frage aber von grosser Bedeutung ist, da es zeigt, dass die säugende Capride im früheisenzeitlichen Israel ein ebenso beliebtes wie autochthones Symbol war. Die fünf konischen Siegel und der Skaraboid stammen vom Tell FaracNord $(\underline{\mathrm{Abb} .89})^{185}$, aus Taanach $(\underline{\mathrm{Abb} .90})^{186}$, aus Megiddo $(\underline{\mathrm{Abb} .91})^{187}$

185 Schicht III; ca. 1000-900 v.Chr.

186 Eisen II Locus; um 900 v.Chr.

187 Schicht V; um 1000 v.Chr. 


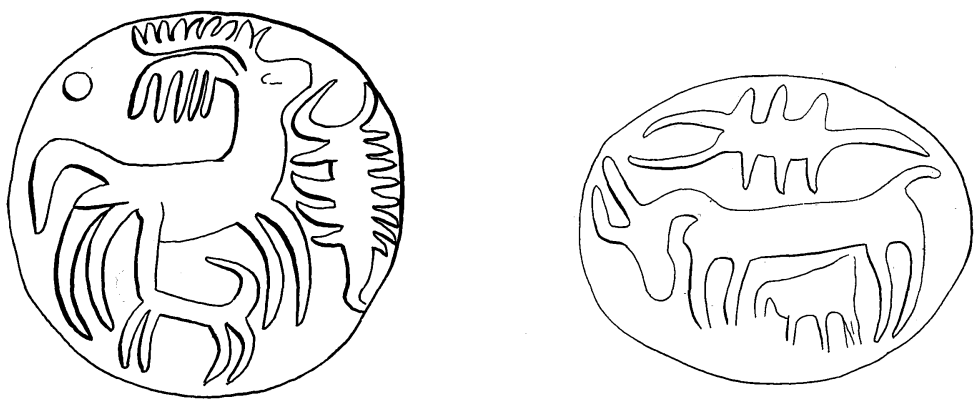

Abb.91 Konisches Stempelsiegel von Megiddo; um 1000 v.Chr.; LAMON/SHIPTON, Megiddo I P1.69 Nr.22 und P1.70 Nr.22.

Abb.92 Skaraboid vom Tell en Nașbeh, $10 \mathrm{~km}$ nördlich von Jerusalem; 9./8. Jh.v.Chr.; MC COWN, Tell en Nașbeh I Pl.54 Nr.19
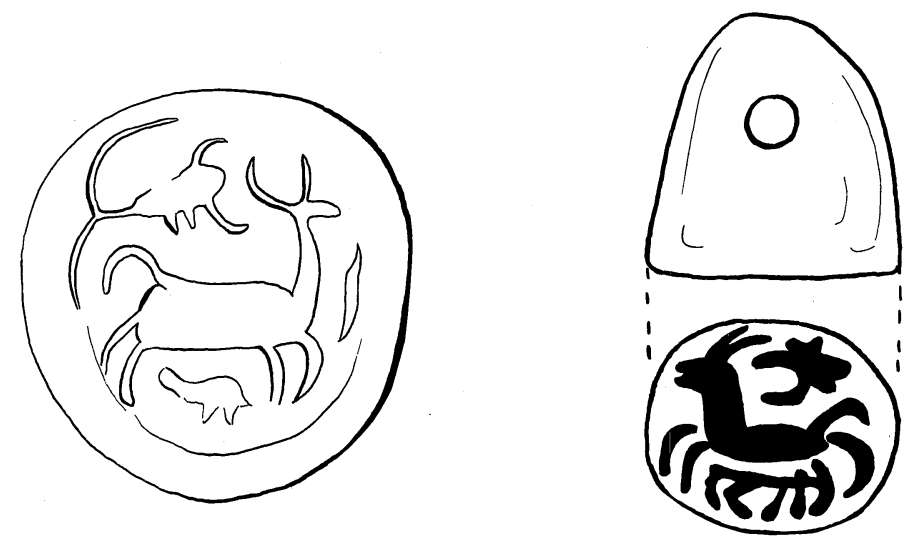

Abb.93 Konisches Stempelsiegel von Sichem; 12.-8.Jh.v.Chr.; WRIGHT, BASOR 167 (1962) 11-13 Fig. 4.

Abb.94 Konisches Stempelsiegel von Bet Schemesch, ca. $25 \mathrm{~km}$ westlich von Jerusalem; 9./8.Jh.v.Chr.; GRANT, Ain Shems III Fig.3 Nr.16.
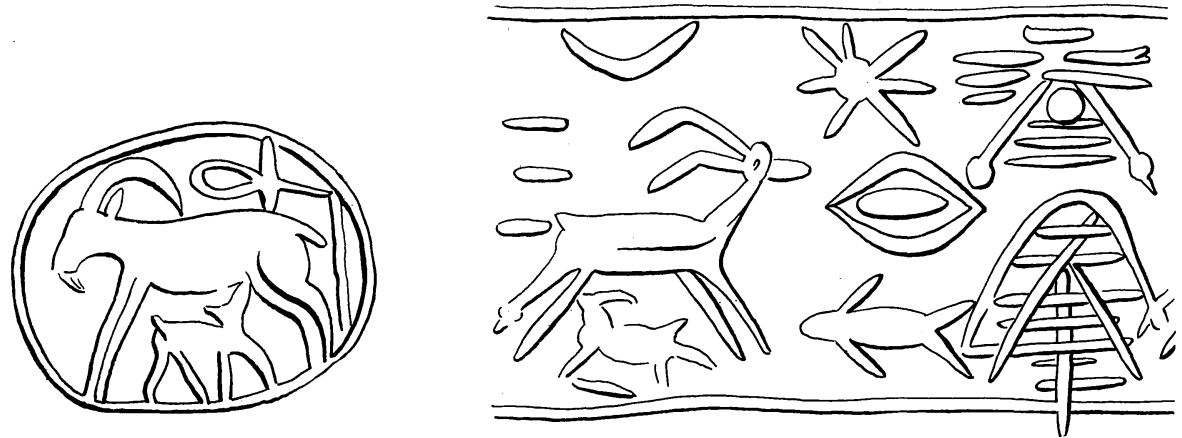

Abb.95 Konisches Stempelsiegel mit elliptischer Basis aus Sidon; jetzt im Louvre; 8.Jh.v.Chr.; DELAPORTE, Louvre PI.104 Nr.3la und b.

Abb.96 Rollsiegel in den Staatlichen Museen, Berlin; 8.Jh.v.Chr.; MOORTGAT, Vorderasiatische Rollsiegel Nr.629. 


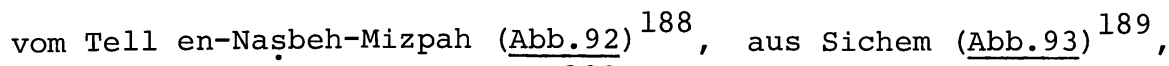
und aus Bet Schemesch (Abb.94) ${ }^{190}$.

Die qualitativ anspruchslosen siegel zeigen bei aller stilistischen und darstellerischen Verschiedenheit ikonographisch eine erstaunlich feste Bildtradition. Eine Capride säugt ein Zicklein. G.E.WRIGHT redet im Zusammenhang mit Abb.93 zwar von einem "twohorned quadruped of the deer family"191, aber die beiden einfachen Hörner lassen die Identifikation mit Hirsch oder Reh abwegig erscheinen; eher ist bei dem Stück aus Megiddo (Abb.91) an einen Hirsch zu denken. Aber Hirschkühe tragen kein Geweih, und so ist vielleicht auch hier an eine steingeiss (Ibex) gedacht. Allzu viel Realismus darf man allerdings nicht erwarten (vgl. Anm 150a). Vor oder über dem Bild der säugenden Capride ist bei allen 6 Belegen das Bild eines Skorpions angebracht. Der Skorpion ist schon auf den $\underline{A b b} .55, \underline{59}, \underline{62}$ und $\underline{80}$ in Verbindung mit einem säugenden Muttertier begegnet. Seine Beziehung zu allem, was mit der Weitergabe des Lebens zu tun hat, ist gut gesichert ${ }^{192}$. Die Stereotypie der ikonographischen Elemente bei gleichzeitiger stilistisch-darstellerischer varietät suggeriert, dass wir es hier viel stärker mit einer gedanklichen als mit einer eigentlichen Bildtradition zu tun haben. Die Verbindung der säugenden Capride mit dem Skorpion erfolgte vielleicht viel häufiger in verbalen Medien als in der relativ schwach entwickelten Bildkunst. Da formal, wie gesagt, keine Abhängigkeit von Aegypten oder einem andern grossen Kunstzentrum spürbar wird, haben wir es hier wohl mit einem bodenständigen Erzeugnis zu tun, dessen Motiv aber eine im vorderasiatischen Raum weitverbreitete Vorstellung wiedergibt. Die säugende Capride wie der Skorpion ver-

188 Skaraboid aus Grab 32; 9./8.Jh.v.Chr.

189 Unklarer stratigraphischer Zusammenhang; 12.-8. Jh.v.Chr.

190 Oberflächenfund.

191 BASOR 167 (1962) 12.

192 Vgl. oben Anm. 152 und KEEL, in: BRIEND / HUMBERT, Tell Keisan 272 f. 
gegenwärtigen die Lust der Zeugung und die Fruchtbarkeit. Mit anderen Worten : sie vergegenwärtigen in ähnlicher Weise den Fluss des Lebens wie auf neuassyrischen Siegeln das gleichzeitige oder etwas jüngere Motiv mit dem Stier, der eine säugende Kuh bespringt (vgl. Abb.101-105) .

Eine säugende Capride zeigt auch ein phönizisches Kegelsiegel (Abb.95). An der Stelle des Skorpions steht das ägyptische Lebenszeichen. K.GALLING datiert es ins 7.Jh.v.Chr. ${ }^{193}$; aufgrund der Formen der Inschrift auf dem Rücken dürfte es aber ins späte 8. Jh.v.Chr. gehören.

Ebenso selten wie in der phönizischen sind säugende Capriden in der zeitgenössischen assyrischen kunst. Ein neuassyrisches Rollsiegel des 8. Jh.v.Chr. zeigt : "Von links nach rechts : Mondsichel, darunter eine Ziege, die ihr Junges säugt; Stern, 'Auge', Fisch und Flügelsonne über stilisiertem Baum." MOORTGAT bemerkt dazu : "Wohl alles Göttersymbole"194.

Viel grössere Bedeutung als die säugende Capride hatte in der neuassyrischen und phönizischen Kunst die säugende Kuh. Diese findet sich ähnlich wie das säugende Kleinvieh gelegentlich in der mittelassyrischen Glyptik, ohne dass - mindestens formal ein Zusammenhang mit der altbabylonischen Glyptik sichtbar wird. Jeder der beiden mir bekannten Belege stellt ein Unikat dar.

Eine Siegelabrollung aus Assur in rein mitannischem Stil aus der Zeit Eriba Adads I. (ca. 1390-1364 v.Chr.) zeigt über einem Flechtband zwei Männer, die eine säugende Kuh am Schwanz und an den Hörnern halten (Abb.97). Diese Ikonographie erinnert entfernt an das frühdynastische Siegel, das eine säugende kuh zeigt, die ein Mann von einem angreifenden Löwen wegzerrt (vgl. Abb.6l), wenn hier auch kein Angreifer zu sehen ist. Eine säugende Kuh und ein säugendes Stück Kleinvieh, je mit einer eigenen Stand-

193 ZDPV 64 (1941) Nr. 35.

194 Vorderasiatische Rollsiegel $68 \mathrm{Nr} .629$. 


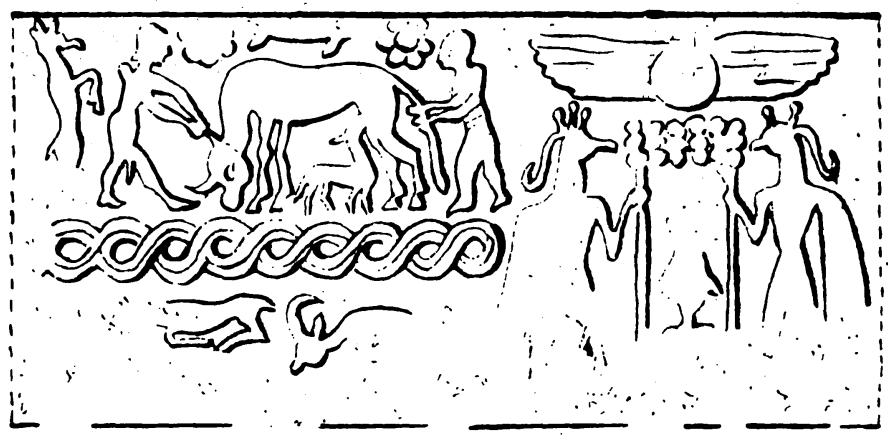

Abb.97 Siegelabrollung aus Assur; Staatliche Museen in Berlin; 1. Hälfte des 14.Jh.S v.Chr.; BERAN, ZA 52 (1957) 192 Abb.89.

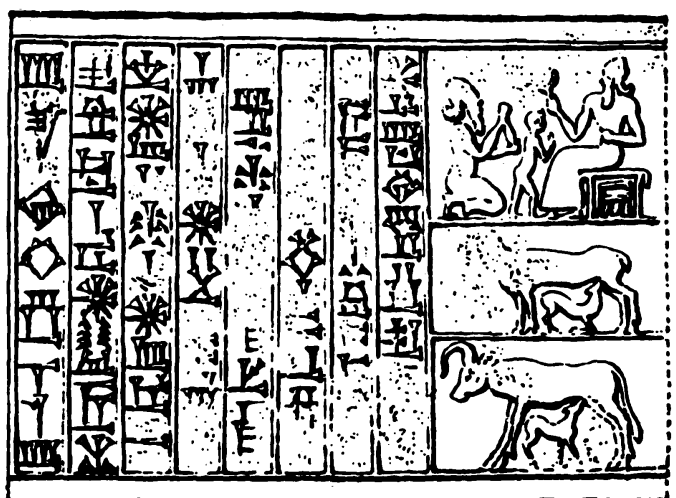

Abb.98 Siegelabrollung aus Assur; Staatliche Museen, Berlin; Anfang des 13. Jh.v.Chr.; MOORTGAT, ZA 14 (1944) $24 f$ Abb.l.

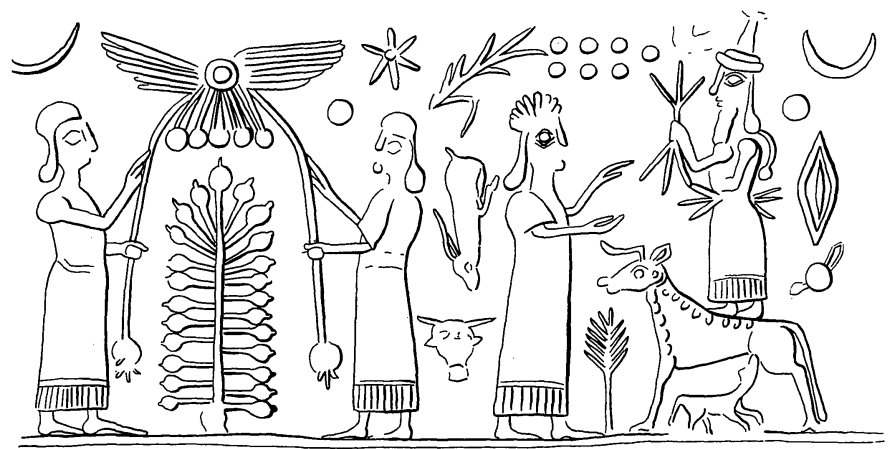

Abb.99 Neuassyrisches Rollsiegel aus der Sammlung de Clercq; 9./8.Jh.v.Chr.; MENANT, Collection de Clercq PI.XXXII Nr.344. 
linie, sind auf einer kassitischen Siegelabrollung vom Beginn des 13. Jhs.v.Chr. zu sehen, die im Archiv Tiglatpilesers I. (1112-1074) gefunden wurde (Abb.98). Das Bild über den beiden säugenden Tieren zeigt, wie eine kniende Gestalt einer thronenden ein Kind übergibt. Vielleicht sollen die säugenden Tiere die liebende Sorge beschwören, die dem Kind zuteil werden soll. Die Gehäuse, in die die säugenden Tiere gestellt sind, erwecken den Eindruck, es handle sich hier um die Darstellung von Kultbildern.

Auf einem neuassyrischen Rollsiegel dient eine säugende Kuh, statt des sonst üblichen Stiers, als Podest für den Wettergott (Abb.99) ${ }^{195}$.

Das Vorhandensein von sakralen Monumentalplastiken, die die säugende Kuh darstellten, liefert ein leider verlorenes Relief Sargons II. aus Chorsabad. Es zeigt die Plünderung des Tempels von Muzazir in Urartu (nordöstlich von Assur). Vor dem Tempel steht die anscheinend lebensgrosse skulptur einer Kuh, die ihr Kalb säugt (Abb.100) ${ }^{196}$. Die bildliche Darstellung wird interessanterweise durch die Annalen des gleichen Königs ergänzt, der berichtet, er hätte aus dem Tempel des Haldia und der Bagbartu in Muzazir nebst vielen anderen Kostbarkeiten die Bronzeskulptur eines Stiers und einer Kuh samt ihrem Kalb weggeschafft, vor der, wenn ich den Text recht verstehe, die Statue des Ischtarduri gestanden hätte ${ }^{197}$.

Vom Stier und der Statue des Mannes ist auf dem Relief nichts $\mathrm{zu}$ sehen. Aber eine auf neuassyrischen Rollsiegeln mehrfach belegte Komposition zeigt zusätzlich zur säugenden Kuh einen Mann, der vor ihr steht, und einen Stier, der sie bespringt.

195 Ein leider nicht sehr klares Siegel in der Bibliothèque Nationale, Paris, scheint ebenfalls eine säugende Kuh als Podesttier zu zeigen (DELAPORTE, Bibliothèque Nationale $\mathrm{Nr} .474$ ).

196 Der Schwanz ist für den einer Kuh zwar etwas kurz, für den einer Ziege aber, besonders beim Kalb, zu lang.

197 LUCKENBILL, Ancient Records II 98 \$173. 


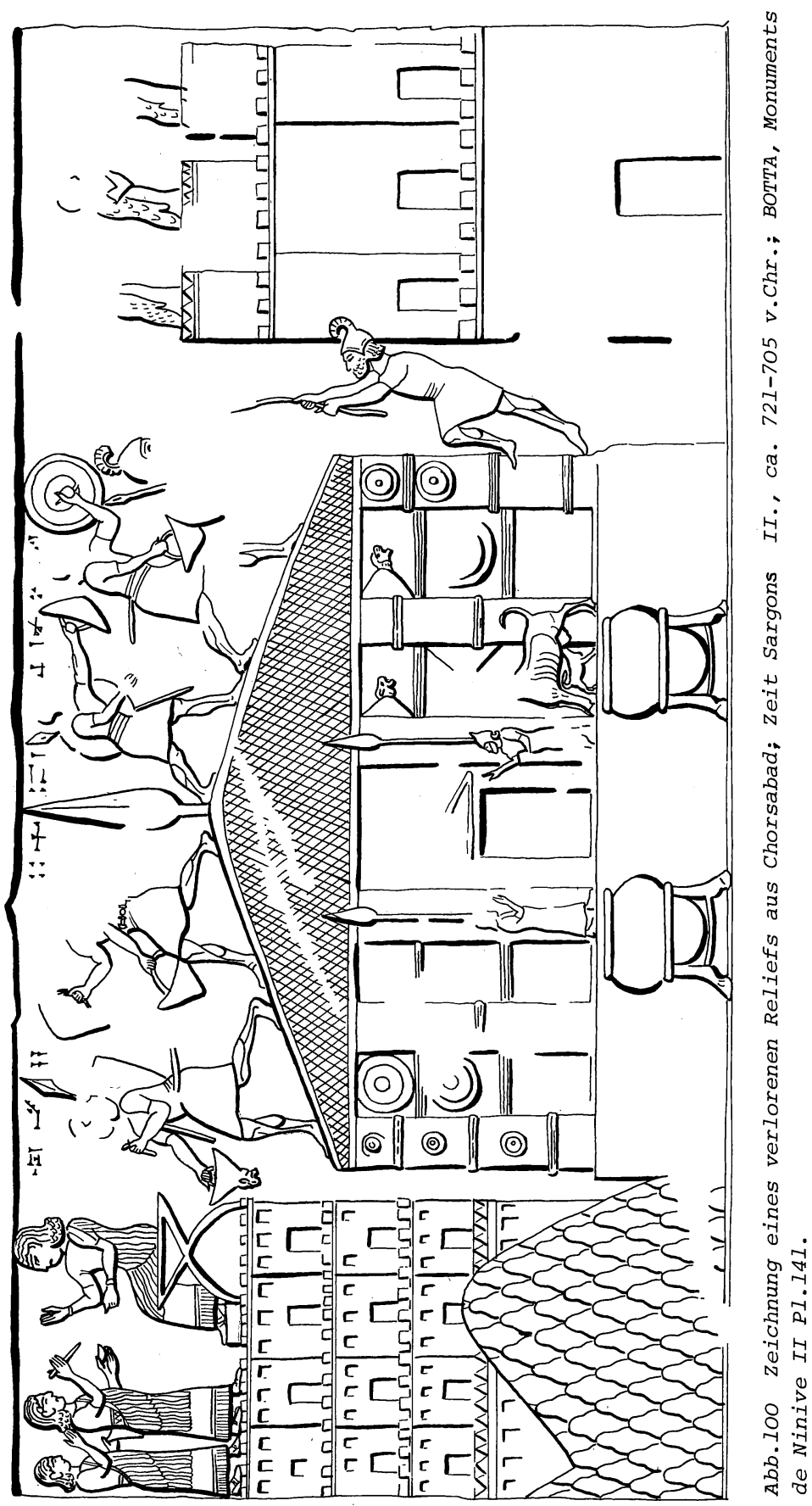


Auf einem neuassyrischen Rollsiegel mit zwei Registern ist oben der Kult am heiligen Baum und unten das Bespringen einer Kuh und das Säugen des Kalbes dargestellt ( $\underline{\mathrm{Abb} .101})$. Die menschliche Gestalt vor der Kuh trägt die gleiche Tracht und nimmt die gleiche Haltung ein wie im oberen Register die Figuren, die den Lebensbaum flankieren. Es scheint sich bei der Tiergruppe, ähnlich wie beim Lebensbaum, um eine Art symbolischer Vergegenwärtigung der Lebensordnung $\mathrm{zu}$ handeln, deren Pflege (Kult) die Voraussetzung für ein gedeihliches Leben ist.

H.FRANKFORT hat unsere Szene auf einem Rollsiegel im Britischen Museum ( $\mathrm{Abb} .102)$ als Deckung einer Stute durch einen Hengst interpretiert und darin einen Beweis dafür sehen wollen, dass die Landwirtschaft die Assyrer nicht interessierte, ausser wenn sie im Dienste der Armee (Pferdezucht) stand ${ }^{198}$. Hörner und Schwanz der Tiere lassen aber keinen Zweifel an ihrer Identität. Genau die gleiche Szene, wie auf dem Stück von $\underline{\mathrm{Abb} .102}$ findet sich auf einem Siegel in Berlin (Abb.103). Ueber dem Kopf der Kuh sind der Sichelmond, über ihrem Rücken der achtstrahlige Stern und über dem Stier die Pleiaden zu sehen. Das Kalb hat sich auf allen Stücken der Gruppe mit den Vorderbeinen auf die Knie niedergelassen. Der Mann, der vor der Kuh steht, scheint sie mit der einen Hand am Horn zu halten, mit der andern zu füttern. Die einzigen Unterschiede zwischen $\underline{\mathrm{Abb} .102}$ und 103 sind die Ranke vor der Kuh von 102 im Gegensatz zum Bäumchen bei derjenigen von 103 sowie das kurze Kleid des Mannes auf 103 im Gegensatz zum langen auf 102 .

Dass wir es hier, ähnlich wie bei der säugenden Capride der israelitischen Siegel von Abb.89-94, mit einem fest geprägten Typ zu tun haben, zeigt nebst dem allen stücken gemeinsamen stil

(Kerbschnitt) ein weiteres Belegstück aus einem Auktionskatalog (Abb.104): R.OPIFICIUS beschreibt es wie folgt : "Bärtiger Mann

198 Cylinder Seals 197. 


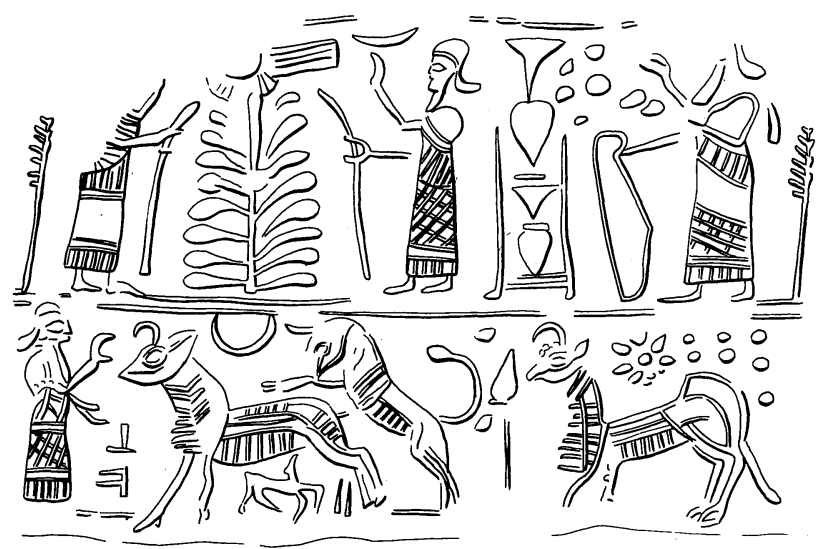

Abb.101 Rollsiegel in der Pierpont Morgan Library, New York; 8.Jh.v.Chr.; PORADA, Pierpont Morgan Library Nr. 647.

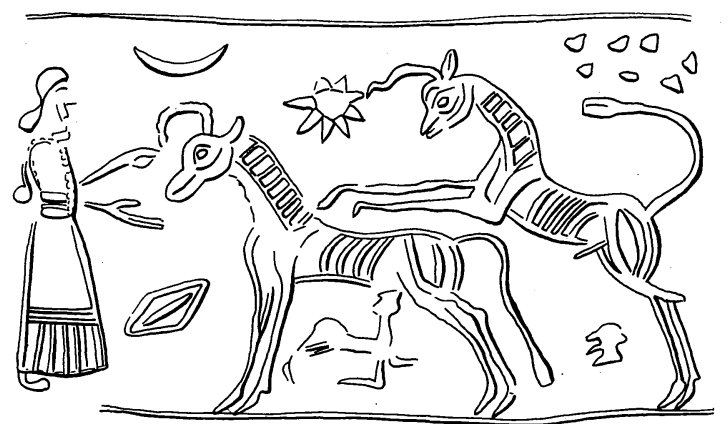

Abb.102 Rollsiegel im Britischen Museum (Nr.89620); 8.Jh.v.Chr.; FRANKFORT, Cylinder Seals Pl.XXXV g.

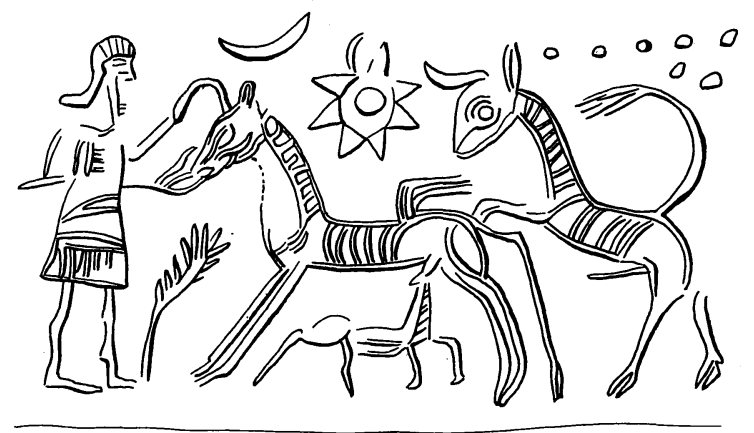

Abb.103 Rollsiegel in den Staatlichen Museen, Berlin; 8.Jh.v.Chr.; MOORTGAT, Vorderasiatische Rollsiegel Nr.682. 
in kurzem mit Fransen besetzten Schurz hat die eine Hand im Verehrungsgestus erhoben, die andere ist geöffnet (dass er das Horn des vor ihm stehenden Rindes berührt, ist ein irrtümlicher Eindruck). Vor ihm eine Gruppe von Rindern : Muttertier, Junges säugend, gedeckt von einem Stier. Ueber der Kuh als 'Füllmuster' die Pleiaden, über dem Stier ein achtstrahliger Stern, zwischen Mann und Kuh ein in einer Hülle steckender Griffel, das Symbol des Schreibergottes Nabû, zwischen Kuh und Stier eine Raute, Scheinkeilinschrift hinter dem Beter"199. Ein weiterer Beleg findet sich in der Sammlung Newell (Abb.105). Das Siegel ist stark abgewetzt, und manche Details der Komposition sind deshalb nicht mit Sicherheit $\mathrm{zu}$ erkennen. Es bleiben aber eine genügende Anzahl deutlich erkennbar, um mit Sicherheit die Zugehörigkeit zu unserer Gruppe feststellen zu können, so der Mann im kurzen, mit Fransen besetzten Schurz, die Kuh mit dem auf allen Belegen nach unten gebogenen und der stier mit dem ebenso stereotyp nach oben gebogenen Horn ${ }^{200}$. Der Typ scheint ebenso wie Abb.65 nicht so sehr eine bestimmte Gottheit bzw. bestimmte Gottheiten zur Darstellung bringen zu wollen, sondern vielmehr ein Symbol der durch die Götter garantierten und in Gang gehaltenen Lebensund Segensordnung zu sein, deren Kult entsprechend Leben und Segen garantiert.

Auf zwei neuassyrischen Chalzedonsiegeln ist die säugende Kuh einmal mit einem Löwen, der von einem Adler angegriffen wird und seinerseits die säugende Kuh angreift (?) (Abb.106), und einmal mit einer Jagdszene (Abb.107) kombiniert. Die Kopfhaltung der Kuh von $\mathrm{Abb} .107$ findet sich auf 3 neuassyrischen Stempelsiegeln. Sie hat den Kopf nach rückwärts, aber nicht nach unten gewendet.

199 OPIFICIUS, Geschnittene Steine $34 \mathrm{zu} \mathrm{Nr} .66$.

200 VON DER OSTEN (Collection Newell $61 \mathrm{Nr} .409$ ) hat die Tiere unerklärlicherweise für Einhörner gehalten. Selbst ein Philologe wie J.J.HESS hat doch gesehen, dass das eine Horn bei assyrisch-babylonischen Rinderdarstellungen eine stilistische Konvention ist (ZAW 35 (1915) 121-123). 


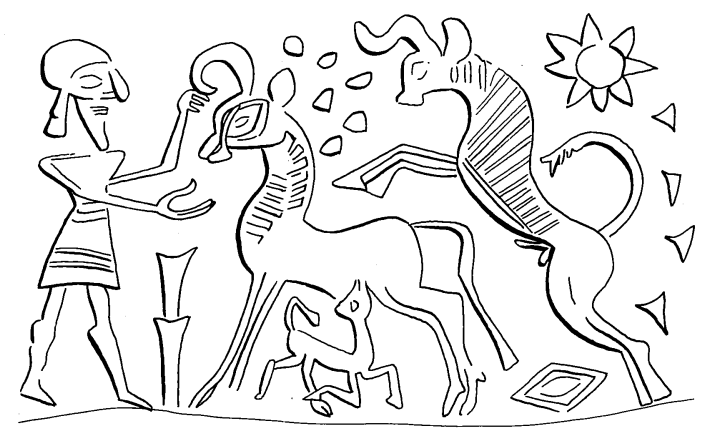

Abb.104 Rollsiegel; 8.Jh.v.Chr.; OPIFICIUS, Geschnittene Steine Nr.66.

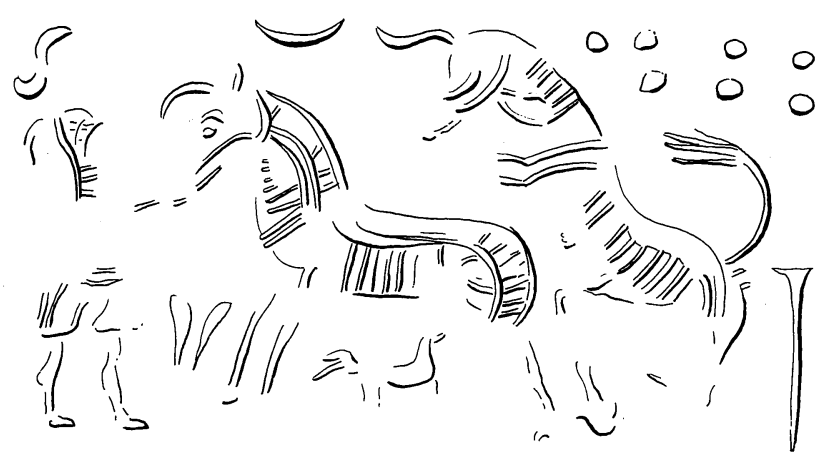

Abb.105 Rollsiegel in der Sammlung Newell; 8.Jh.v.Chr.; VON DER OSTEN, Collection Newell Nr.409.

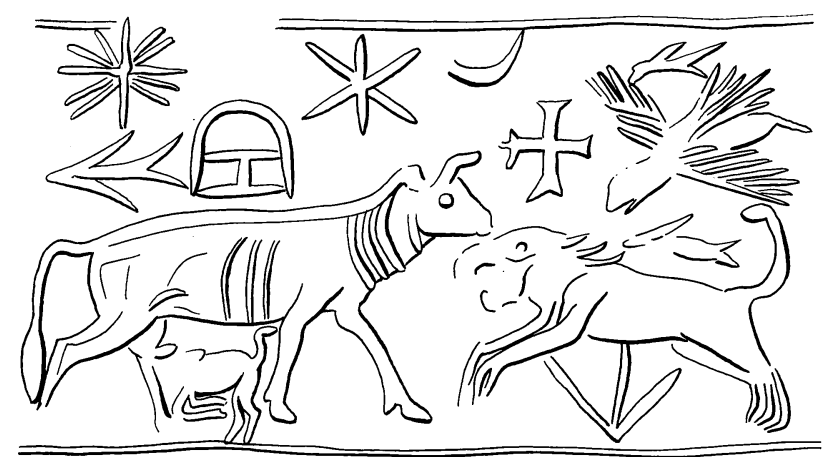

Abb.106 Rollsiegel in den Staatlichen Museen, Berlin; 9./8.Jh.v.Chr.; MOORTGAT, Vorderasiatische Rollsiegel Nr.630. 
Der Abdruck eines Stempelsiegels (Abb.108) ist durch die Keilschrifttafel, auf der er sich befindet, ins Jahr 666 v.Chr. datiert. Als Füllmotive erscheinen neben der säugenden Kuh wie schon auf Abb. 101-105 der Sichelmond, der achtstrahlige Stern und die Pleiaden. Bei Abb.109 fehlen die Pleiaden; dafür haben wir Raute und Zweig. Die Abb.110a-c rühren von einem konischen Siegel, das wahrscheinlich ein bisschen älter ist als die beiden vorangehenden ${ }^{201}$. Die Gravierung der Basis stellt einen Priester vor einem Opfertisch dar. Links von diesem ist eine Keule, ev. ein Symbol für den König. Auf der einen Seite des Konus ist der Schlangendrache mit den Symbolen des Marduk und des Nabu, auf der andern die säugende Kuh unter Sichelmond und Stern zu sehen. Wie diese und wie der Schlangendrache mit den Symbolen, so scheint auch die säugende Kuh hier als Symbol für eine Gottheit verstanden werden $\mathrm{zu}$ müssen.

Grösser als in der neuassyrischen war die Bedeutung des Motivs der säugenden Kuh in der phönizischen Kunst des 1. Jts.v.Chr. Im ausgehenden 2. Jt. ist es zwar weder in der ägyptischen, noch in der syro-palästinensischen Kunst in beachtlichem Umfang bezeugt. Aber die wenigen Belege genügen, die Inspirationsquellen für die spezifische Gestaltung des Motivs im phönizischen Metallund Elfenbeinkunsthandwerk des 1. Jts. namhaft zu machen : Aegypten und die minoisch-mykenische welt.

Im Rahmen einer idealisierten Landschaft ist die säugende Kuh schon auf einer ägyptischen Metallschale des Neuen Reiches begegnet (Abb.44). Die Abhängigkeit der phönizischen Metallschalen des 8./7. Jh.v.Chr. von dieser handwerklichen Tradition ist evident. Wenn eine solche Schale aus Kurion auf Zypern die säugende Kuh aber mit einem nachdrücklichen Streifenmuster am Hals zeigt (Abb.111), dann haben wir es bei diesem Element nicht mit ägyptischem, sondern mykenischem Einfluss zu tun, wie schon die

201 PORADA, Pierpont Morgan Library I $96 f$. 


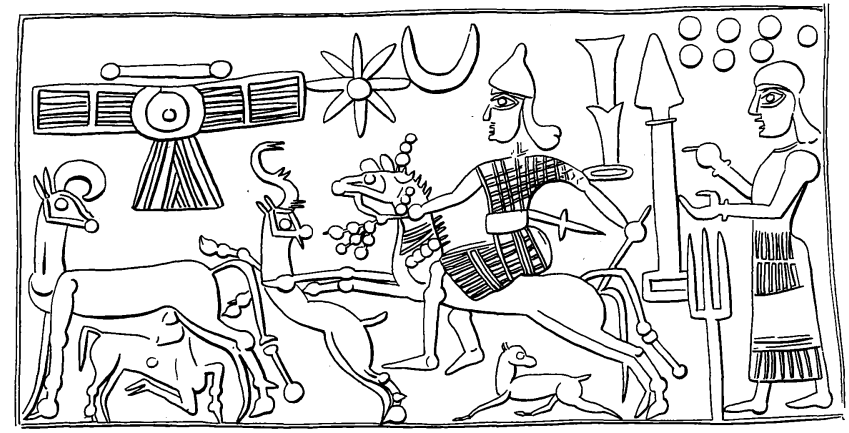

Abb.107 Rollsiegel im Britischen Museum (Nr.89331); 9./8.Jh.v.Chr.; FRANKFORT, Cylinder Seals Pl.XXXIV i.
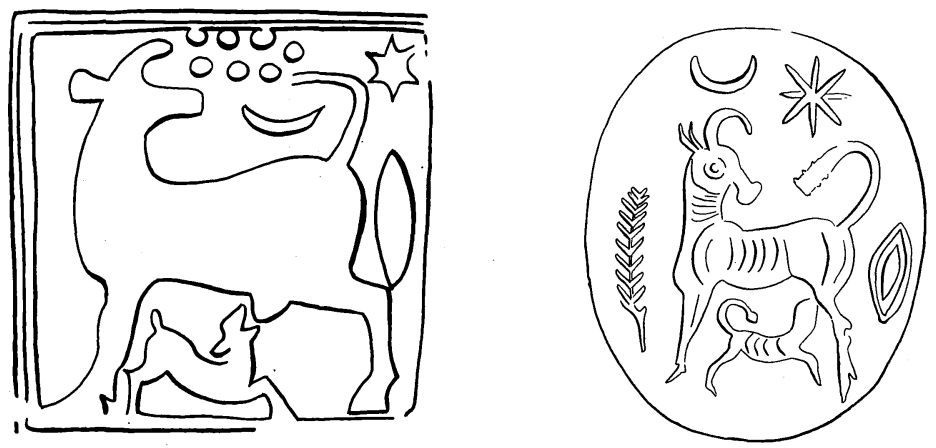

Abb.108 Abdruck eines Stempelsiegels aus Nimrud; 7.Jh.v.Chr.; MALLOWAN, Nimrud I 199 Fig.134,5.

Abb.109 Skaraboid aus Nimrud; 7.Jh.v.Chr.; MALLOWAN, Nimrud I 259 Fig.24l.
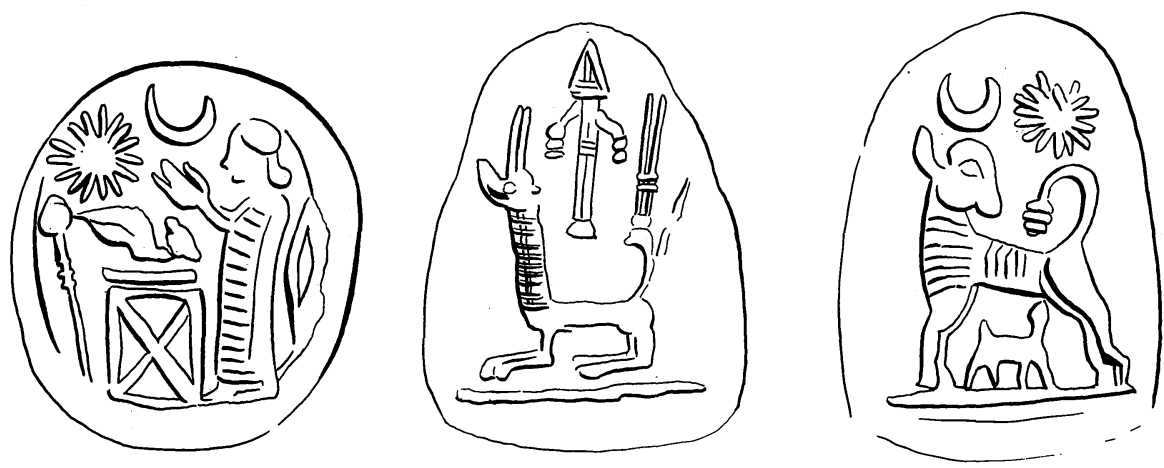

Abb.110 Konisches Siegel in der Pierpont Morgan Library, New York; Ende des 8.Jh.v.Chr.; PORADA, Pierpont Morgan Library Nr.789. 


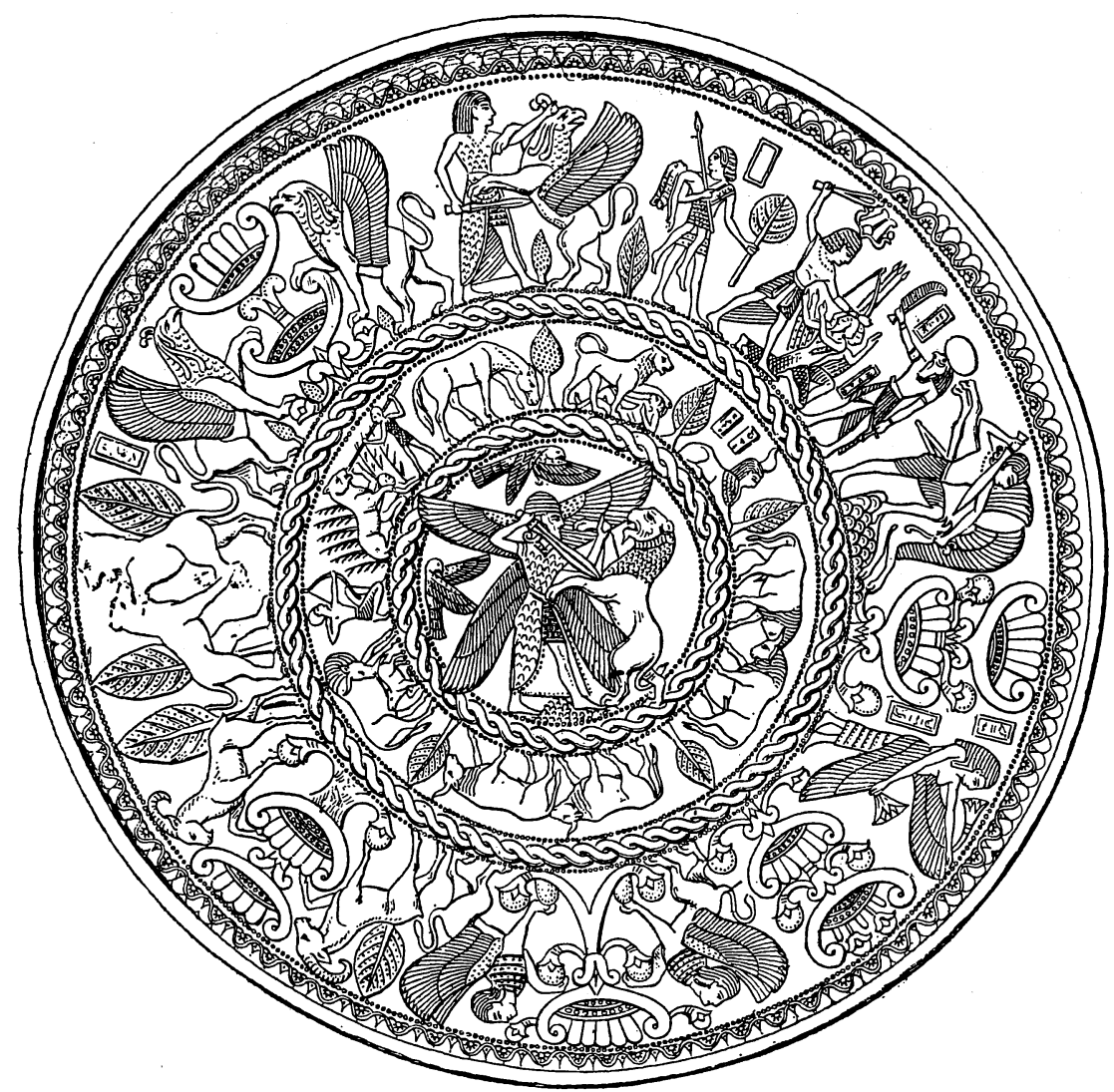

Abb.111 Phönizische Metallschale aus Kurion Zypern; 8./7.Jh.v.Chr.; FRANKFORT, Art and Architecture 201 Fig. 98. 


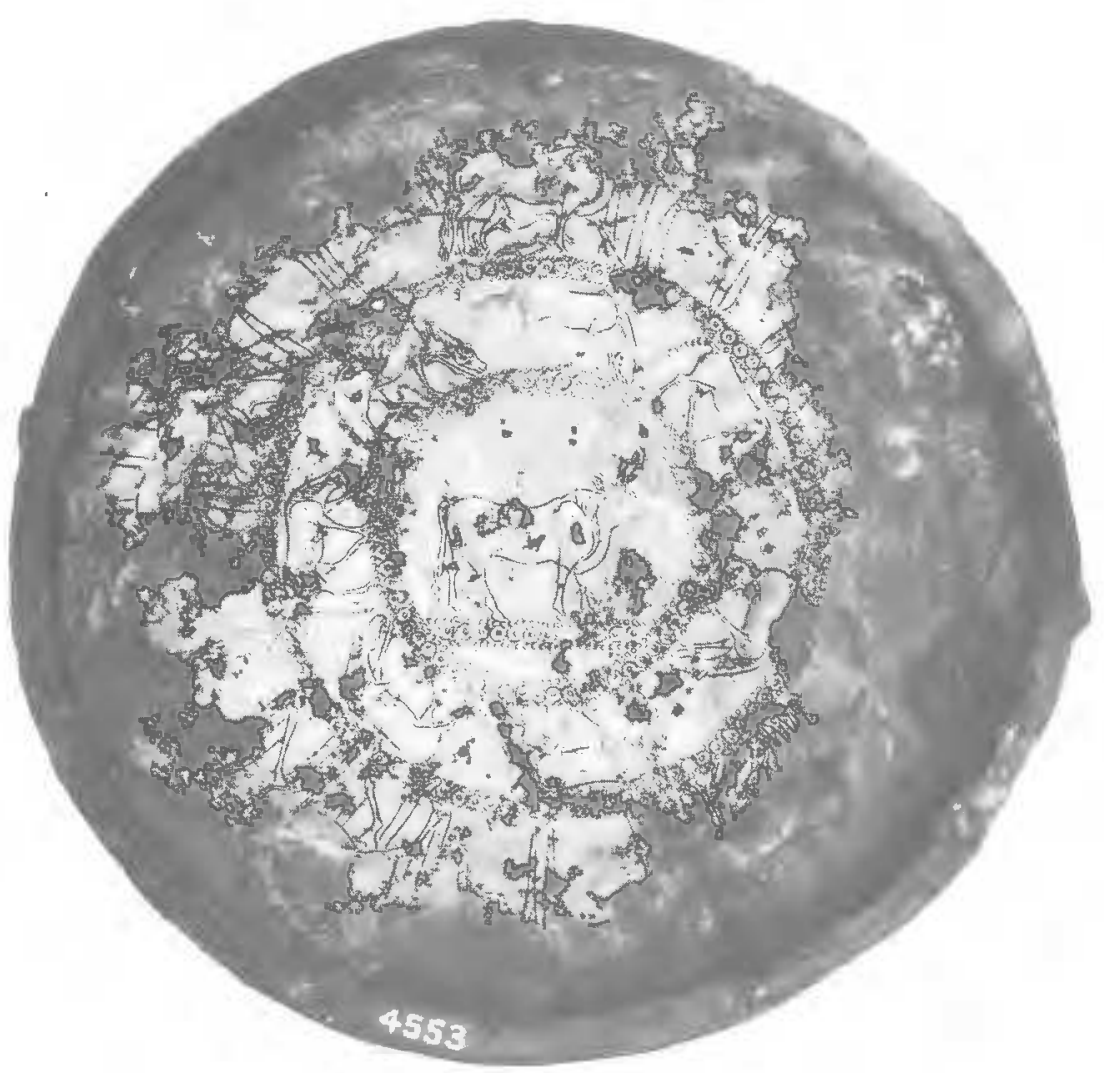

Abb.112 Phönizische Metallschale aus der Cesnola Sammlung, im Metropolitan Museum, New York; 8./7.Jh.v.Chr.; nach Photo. 
Ausgräber von Arslan-Tasch nachgewiesen haben ${ }^{202}$. Die säugende Kuh erscheint auf der Kurion-Schale im Rahmen einer rudimentären landwirtschaftlichen szene, die mit verschiedensten anderen Szenen kombiniert ist.

Auf einer andern phönizischen Schale ist die säugende Kuh isoliert. Der geradeaus gerichtete Hals und das schüttere Papyrusdickicht, vor das die zweimal in dieser Weise dargestellte Kuh plaziert ist, lassen an die Hathorkuh denken. (Abb.112). Allerdings stellt sich dann die Frage, welche Göttin mit der vor der gleichen Szenerie abwechslungsweise mit der säugenden Kuh dargestellten säugenden stute gemeint sein könnte. Vielleicht Astarte ? ${ }^{203}$

Weniger problematisch scheint die Identifizierung der säugenden Kuh mit der Hathorkuh bei einer Schale aus Caere, bei der die Kuh vor dem Papyrusdickicht das zentrale Medaillon füllt (Abb. 113). Gegen eine allzu unbeschwerte Deutung auf Hathor und Horus spricht allerdings das zweite Kalb. Die bei dem geradeaus gerichteten Hals völlig unmotivierten Streifen an demselben verraten, dass die Kuh nicht nur ikonographisch, sondern auch stilistisch nebst der Hathorkuh noch andere Ahnen haben dürfte.

Aehnlich wie in der Metallkunst scheint die säugende, hier regelmässig den Kopf rückwärts wendende Kuh der phönizisch-syrischen Elfenbeinarbeiten auf ägyptische (vgl. Abb.45) und minoischmykenische 204 Vorbilder zurückzugehen, wobei sie bei den Elfenbeinarbeiten eine zentrale Bedeutung gewann und eines der be-

202 THUREAU-DANGIN/BARROIS/DOSSIN/DUNAND, Arslan Tash $125 f$. Es scheint sich ursprünglich um eine Halsmähne (besonders bei Stieren) gehandelt zu haben, die in der Folgezeit missverstanden wurde. Als Belege erwähnen sie u.a. zwei Tonbullen aus Knossos (EVANS, Journal of Hellenic Studies 41 (1921) $254 \mathrm{Abb} .6 \mathrm{f}$ ); mykenische Siegel (FURTWAENGLER, Die antiken Gemmen Taf.III Nr. 50,51); eine mykenische Elfenbeinschnitzerei aus Spata (BUCHHOLZ/KARAGEORGHIS, Altägäis $385 \mathrm{Abb} .1285)$; die berühmte Elfenbein-Spielschachtel aus Enkomi, um $1200 \mathrm{v} . \mathrm{Chr}$. (Ebd. $482 \mathrm{Abb} .1749$ ) und den Schild von Amathont (PERROT/CHIPIEZ, Histoire de l'Art III 871 $\mathrm{Abb}$. 639).

203 Vgl. Keel, in : BRIEND/HUMBERT, Tell Keisan 272.

204 Vgl. Anm. 202. 


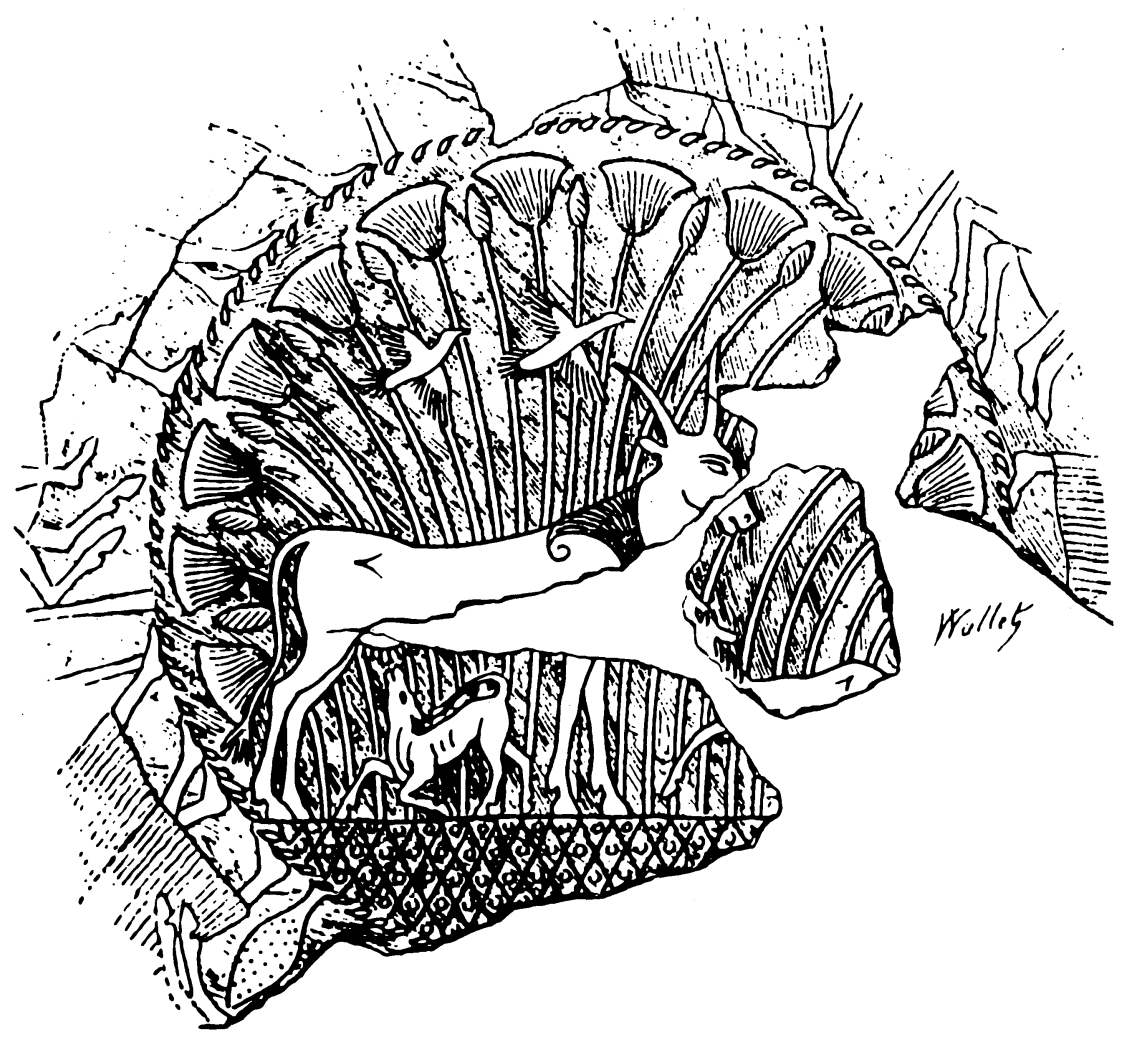

Abb.113 Phönizische Metallschale aus Caere, im Vatikan; 8./7.Jh.v.Chr.; PERROT/CHIPIEZ, Histoire de I'Art III 790 Fig.553. Vgl. Taf.III dieser Arbeit. 
liebtesten Motive wurde. Allein aus Arslan Tasch wurden $21 \mathrm{Be}$ lege und Fragmente von Belegen veröffentlicht ${ }^{205}$. Von diesen ist ein Teil in durchbrochener Arbeit (Abb.114-115), ein Teil als reliefierte Plättchen ausgeführt ( schrift "... für unseren Herrn Hasaël" auf einem der Elfenbeine und aufgrund der Identifizierung dieses Hasaël mit einem damaszenischen König gleichen Namens wird wohl mit Recht angenommen, die Stücke stammten aus dem Damaskus des 9.Jhs.v.Chr. ${ }^{206}$.

Ebenfalls ins 9.Jh.v.Chr. gehört ein Fragment der Samaria-Elfenbeine, das wahrscheinlich von einer säugenden Kuh stammt ${ }^{207}$.

Aus den Räumen $V$ und $W$ im Nord-West-Palast in Nimrud hat R.D. BARNETT Reste von 9 Kühen und 6 kälbern veröffentlicht (Abb. 117) 208 . Die von H.A. Layard entdeckte Gruppe ist wahrscheinlich von Sargon II. (um 721-705 v.Chr.) in den Nord-Palast verbracht worden $^{209}$, kann aber längere Zeit vor Sargon II. entstanden sein. Weitere Stücke haben die Grabungen von M.E.L. MALLOWAN in Nimrud zutage gefördert. MALLOWAN spricht von vielen Dutzenden von Elfenbeinen, die die Kuh, die ihr Kalb säugt, darstellen und die an verschiedenen orten in Nimrud gefunden wurden 210 . Auch bei diesen Stücken findet man wieder reliefierte Plättchen

(Abb.118) und durchbrochene Arbeiten. Als schönstes Beispiel der letzteren Art bezeichnet MALLOWAN ein durchbrochenes Relief aus dem Raum SW2 in Fort Shalmaneser, das Kuh und Kalb vor einem lockeren Papyruswuchs zeigt (Abb.119). Dieses ägyptische Element

205 THUREAU-DANGIN/BARROIS/DOSSIN/DUNAND, Arslan Tash 119-i23 P1.37 No.63-P1.43 No.83; zu den Arslan-Tasch-Elfenbeinen vgl. THIMME, Phönizische Elfenbeine XIII-XVI, XXIf und Kommentar zu den Stücken Nr.23-26.

206 DECAMPS DE MERTZENFELD, Inventaire 125f; THIMME, Phönizische Elfenbeine XVI; MALLOWAN (Nimrud II 520) möchte die ganzen Elfenbeine ins 8.Jh.v.Chr. hinunterdatieren.

207 CROWFOOT, Early Ivories Pl.X,7.

208 Catalogue $173 \mathrm{f}$ und $\mathrm{Pl} . \mathrm{V}$.

209 Ebd. 134f.

210 MALLOWAN, Nimrud II 520, $526 \mathrm{f}$ und Abb.436f. 


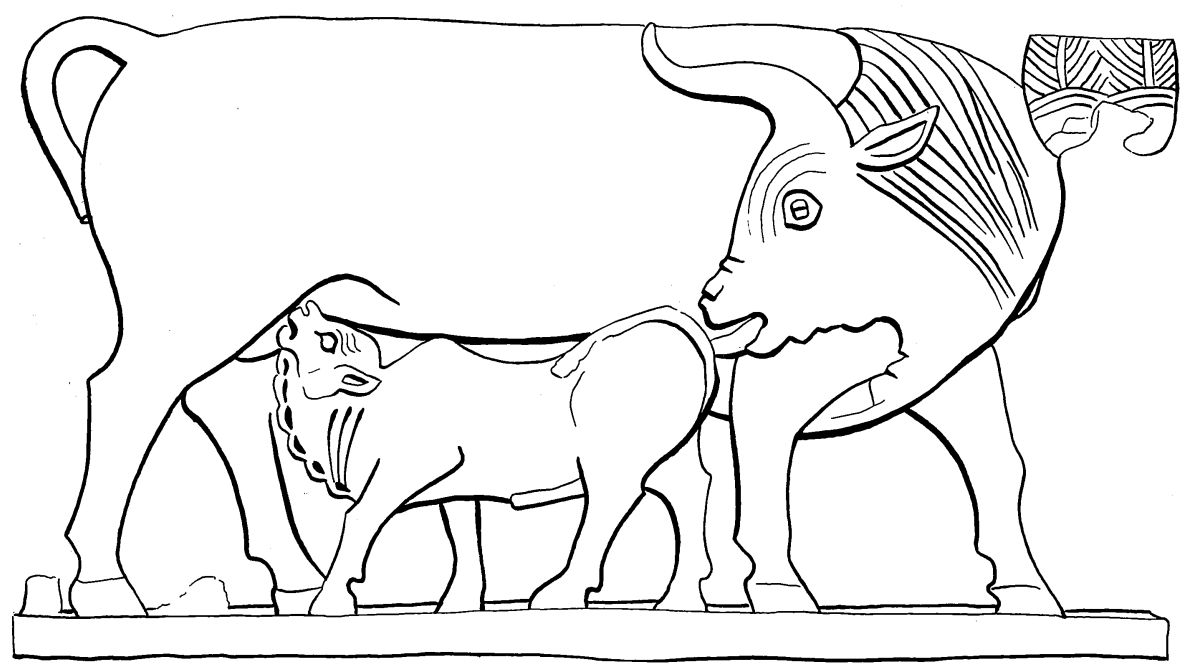

Abb.114 Elfenbeinschnitzerei aus Arslan Tasch; jetzt im Louvre in Paris; 9.Jh.V.Chr.; THUREAU-DANGIN/BARROIS/DOSSIN/DUNAND, Arslan Tash Pl.XXXVII Nr.63; teilweise ergänzt vgl. FRANKFORT, Art and Architecture Pl.169 B.

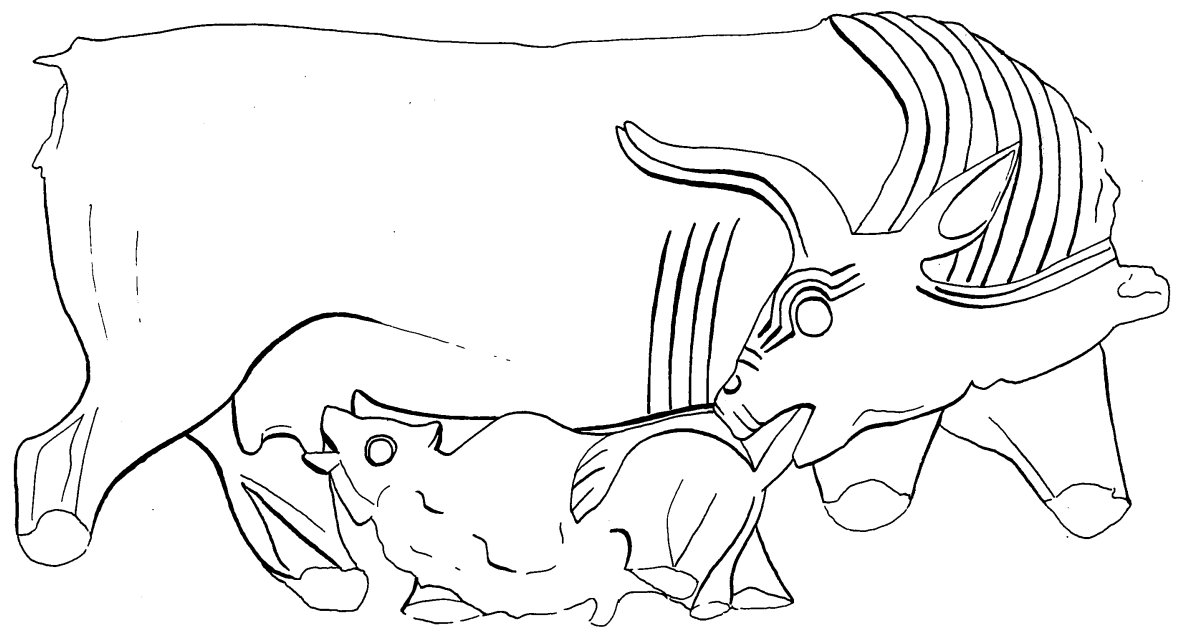

Abb.115 Elfenbeinschnitzerei aus Arslan Tasch; jetzt in Karlsruhe; 9.Jh. v.Chr.; THIMME, Phönizische Elfenbeine Taf.28. 


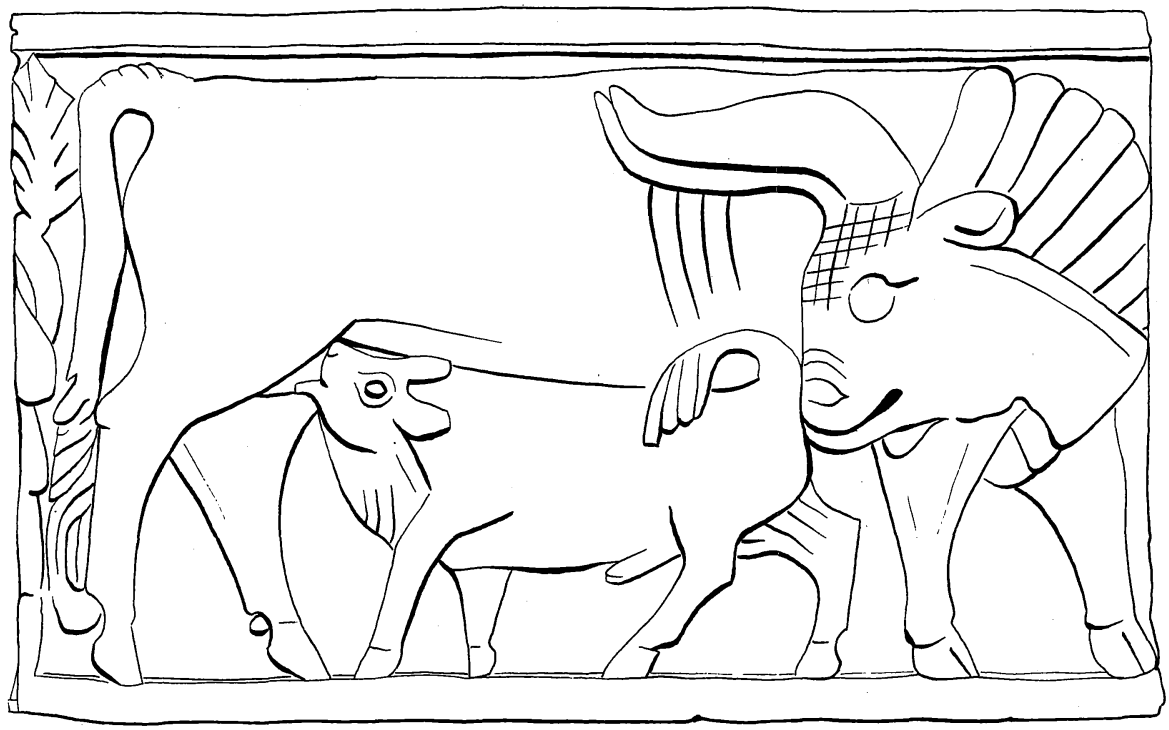

Abb.116 Elfenbeintäfelchen aus Arslan Tasch; jetzt in Karlsruhe; 9.Jh.v. Chr.; THIMME, Phönizische Elfenbeine Taf.24.

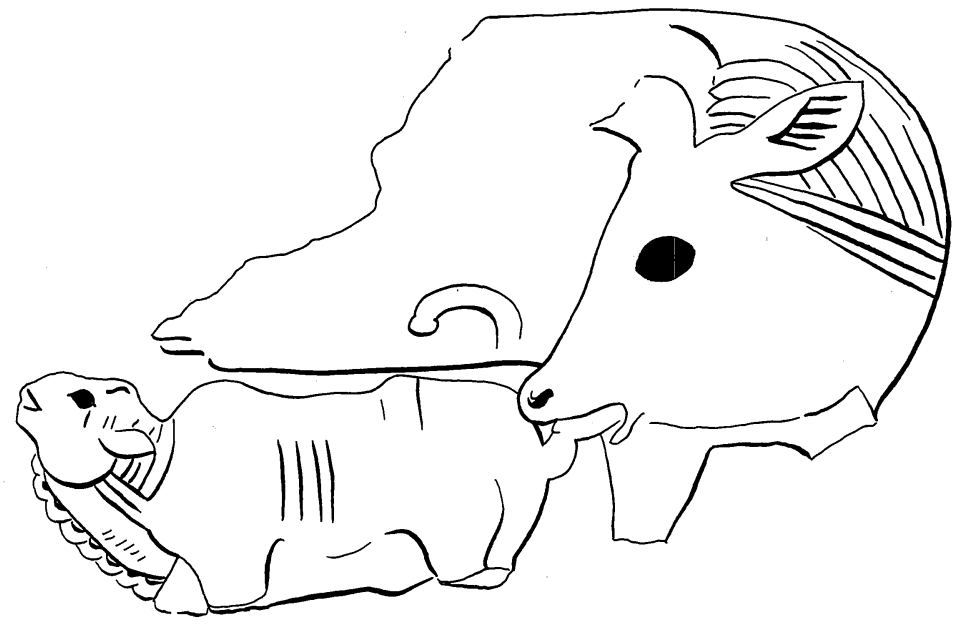

Abb.117 Fragmente einer Elfenbeinschnitzerei aus Nimrud; 8.Jh.v.Chr.; BARNETT, Catalogue P1.V C 22,34. 


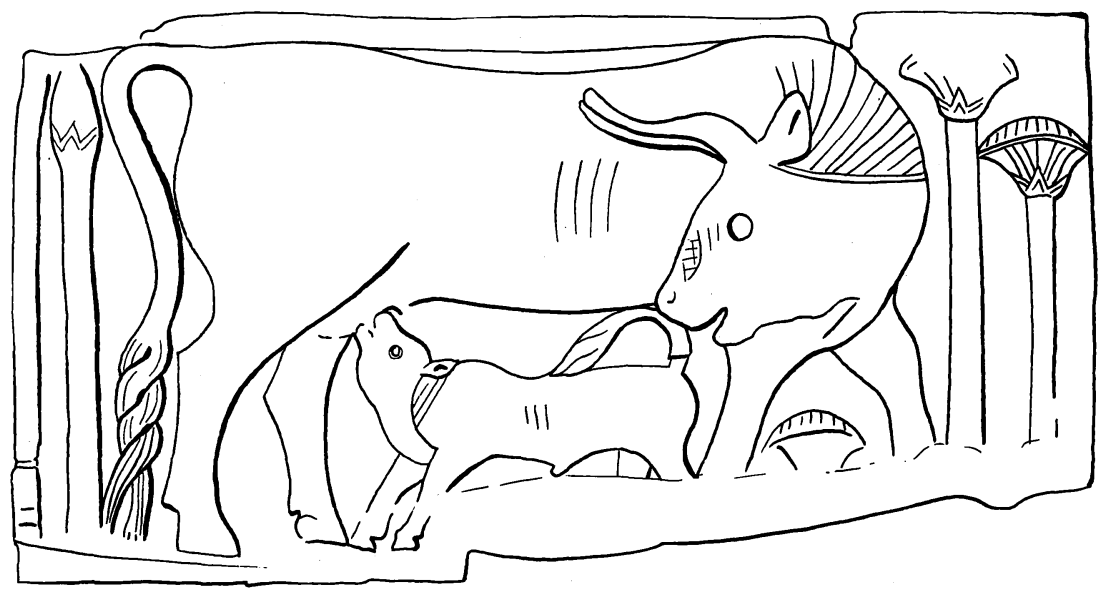

Abb.118 Elfenbeintäfelchen aus Fort Shalmaneser in Nimrud; jetzt im Ashmolean Museum in Oxford 1962. 602; 8.Jh.v.Chr.; nach Postkarte des Museums.

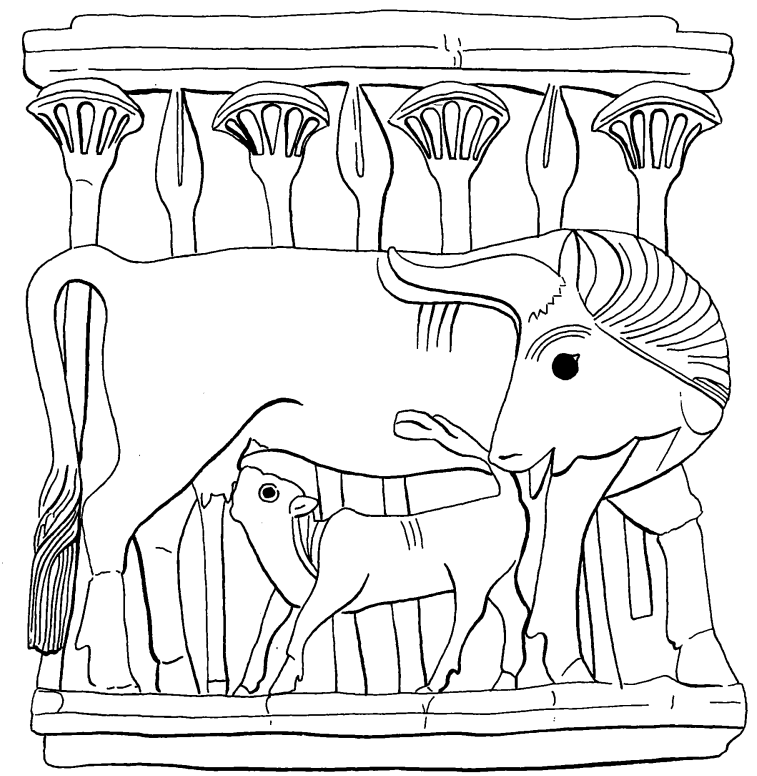

Abb.119 Elfenbeinschnitzerei aus Fort Shalmaneser in Nimrud; 8.Jh.v.Chr.; MALLOWAN, Nimrud II PI.VI gegenüber von S.52O. 
weckt einmal mehr Reminiszenzen an die Hathorkuh. Solche scheinen bei der anscheinend älteren Gruppe von Arslan Tasch noch zu fehlen.

Wenn die jüngeren stücke dank dem Papyrus (Chemmis)-Motiv einer interpretatio aegyptiaca zugänglich sind, so scheinen die älteren noch von einem syrischen Hintergrund her gedeutet werden $\mathrm{zu}$ müssen. Wie verschiedene ägyptische und mesopotamische, so werden auch syrische Göttinnen im Verhältnis zu ihrem göttlichen Kind gelegentlich als werfende und säugende kühe vorgestellt. Es ist $\mathrm{zu}$ beachten, dass die Elfenbeine stets ein neugeborenes männliches Kalb zeigen, das eben von seiner Mutter trocken geleckt wird.

In einem ägyptischen Zauberspruch des Neuen Reiches spricht der Beschwörer zum Samana-Dämon : "Siehe, an den Zitzen der Anat habe ich gesaugt, der grossen $\operatorname{Kuh}\left(\boldsymbol{c}_{m r y}, t\right)$ des Set (=Bacal)!"211. In einem meisterhaften Aufsatz hat E.LIPINSKI 1965 eine Anzahl ugaritischer Texte bearbeitet, in denen mehrmals davon die Rede ist, dass Anat als Kuh begattet wird und ein Stierkalb wirft 212 . Als Kuh mit Stierkalb wird Anat u.a. an jener Stelle im BacalsMythos vorgestellt, wo $\mathrm{Ba}^{\mathrm{C}} \mathrm{al}$, ehe er in die Unterwelt hinabsteigt, eine Kuh begattet, die ein Stierkalb wirft :

"Er liebt ein Rind auf der Weide eine Kuh im Uferfeld des Aufenthalts der Toten, er legt sich zu ihr $77 \mathrm{mal}$, sie lässt ihn (sich) $88 \mathrm{mal}$ besteigen. Sie empfängt und wirft ein Männliches...".

211 Papyrus Leiden I 343 recto VI 10-11; BORGHOUTS, Magical Texts 20; zum ägyptischen Text siehe GRDSELOFF, Rechef 27.

212 Syria 42 (1965) 45-73, besonders 67-69. Vgl. jetzt auch CAQUOT, UF 11 (1979) 101-104. 


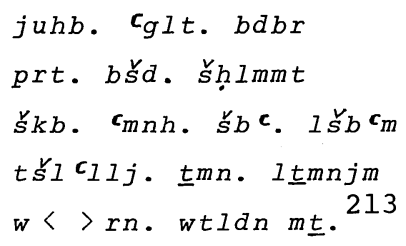

Im BaCals-Mythos findet sich auch zweimal die offensichtlich fest geprägte Wendung :

"Wie das Herz der Kuh auf ihr Kalb,

wie das Herz des Mutterschafs auf sein Lamm

so (war) das Herz Anats auf Bacal (gerichtet)".

$k I b . \operatorname{arh} .1 c_{g l h}$

klb. tat. Iimrh

lb. $c_{n t}$ attr. b $c_{1} \cdot 214$

Ob Anat als Kuh mit Kalb vorgestellt oder nur mit einer solchen bzw. mit einem Mutterschaf (vgl. Abb.87) verglichen wird, jedenfalls besass die Kuh mit dem Kalb dadurch eine Transparenz aufs Göttliche hin, und ein elementarer Schutz der Kuh-Kalb-Beziehung, ihre - mindestens rudimentäre - Tabuisierung war von daher naheliegend.

Die säugende Capride mit dem Skorpion auf Siegeln ist zwar die wichtigste, aber nicht die einzige Form des säugenden Muttertiers, die im Israel der Königszeit Beachtung fand. Auch das Bild der säugenden Kuh hat hier Eingang gefunden. Wahrscheinlich ist sie für Israel als Elfenbeinschnitzerei belegt ${ }^{215}$. Im israelitischen

213 VIROLLEAUD, Syria 15 (1934) 326; HERLiNER, Corpus $36 \mathrm{Nr} .5$ V 18-22; DIETRICH/LORETZ/SANMARTIN, Keilalphabethische Texte $23 \mathrm{Nr}$. $1.5 \mathrm{~V}$ 18-22; zur Uebersetzung vgl. neben LIPINSKI auch CAQUOT/SZNYCER/HERDNER, Textes ougaritiques I 248f. Ebd. 273-289 auch Ausgaben und Uebersetzung des Textes IV $A B$ "Ba $C_{a l}$ und das Rind".

214 VIROLLEAUD, Syria 12 (1931) 205f IAB II 6-9 und 28-30; HERDNER, Corpus $39 \mathrm{f} \mathrm{Nr}$. 6 II 6-9. 28-30; DIETRICH/LORETZ/ SANMARTIN, Keilalphabethische Texte $25 \mathrm{f} \mathrm{Nr}$. 1.6 II 6-9. 28-30.

215 Vgl. Anm. 207. 
Heiligtum von Kuntillet $\mathbf{c}_{\mathrm{Aj}}$ rud (ca. $50 \mathrm{~km}$ südlich von Qadesch) aus dem 9./8.Jh.v.Chr. ist die phönizische Version der Kuh, die ihr Kalb säugt, als Scherbenzeichnung aufgetaucht (Abb.120). Nebst Möbelverzierungen aus Elfenbein und Zeichnungen auf Ostraka haben auch reliefierte Gefässe als Bildträger für unser Motiv gedient, wie ein Fragment aus Buseirah in Transjordanien aus dem 7./6.Jh.v.Chr. zeigt (Abb.121) .

Vor allem aber wurde die phönizische Version der säugenden Kuh auf Stempelsiegeln als Bildträger im ganzen Mittelmeerraum verbreitet. Dieser phönizisch-punischen Serie geht ein Siegel mit einem aramäischen Namen $\left(I c_{z j}\right)$ voraus (Abb.122). K. GALLING datiert es ins $8 . \mathrm{Jh} . \mathrm{v} . \mathrm{Chr}{ }^{216}$. Das Ursprungsland der ebenso schematisch wie kräftig geschnittenen Gruppe dürfte eher Nordsyrien als Phönizien sein. Ein anderes stück hat seine Heimat westlich vom alten Phönizien in zypern (Abb.123), wie die zyprische Beischrift verrät. Es dürfte in die Frühzeit der phönizisch-punischen Serie, ins 6./5. Jh.v.Chr., zu datieren sein. Hingegen ist das schon von A.FURTWAENGLER publizierte Siegel aus Arwad an der syrischen Küste, auf dem die säugende Kuh vor einem Papyrusdickicht steht, als phönizisch anzusprechen (Abb.124). Aehnlich wie auf den wahrscheinlich zeitgenössischen ägyptischen Amuletten $\underline{A b b} .47$ und $\underline{48}$ stellen Kuh und Kalb hier Isis und Horus dar, die in der Spätzeit im ganzen Mittelmeerraum ungeheure Popularität erlangten. Im ganzen römischen Reich war der Ruf $z u$ hören : "Heil dir, du Stier, Sohn eines Stiers, den die göttliche Kuh geboren hat. Heil dir Horus, der aus Osiris hervorkam, den die Göttin Isis geboren hat" 217 .

Drei Belege aus der Gegerd von Karthago (Utica, Kerkuan) gehören ins 5.-3., höchstwahrscheinlich in die erste Hälfte des 4 . Jhs.

216 ZDPV 64 (1941) 141.

217 BORGHOUTS, Magical Texts 83. 


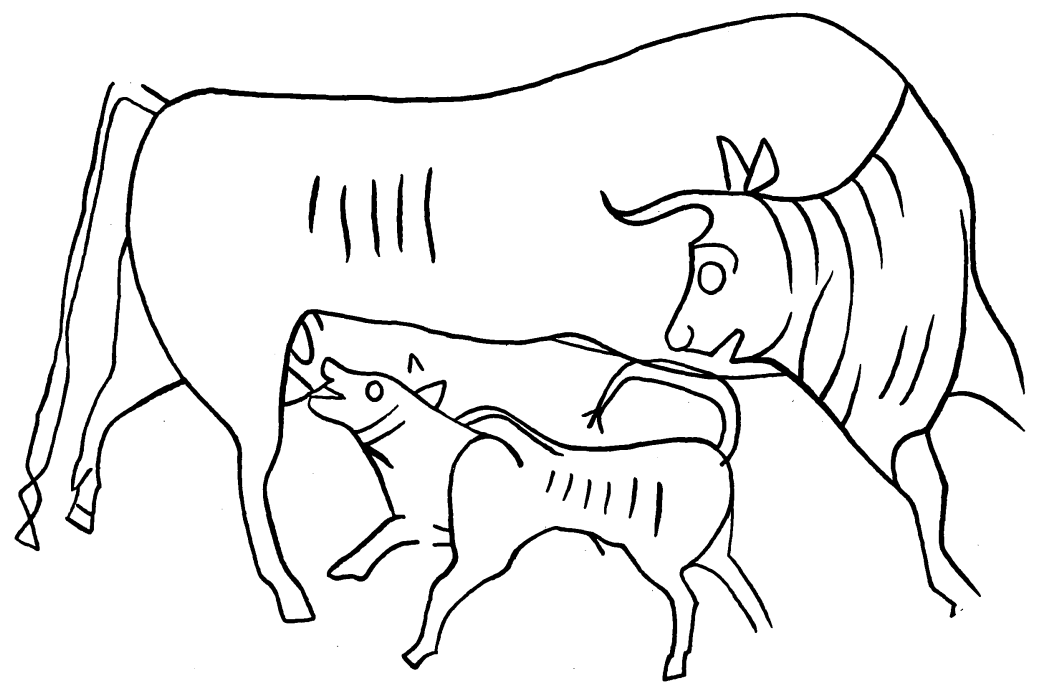

Abb.120 Zeichnung auf einer Scherbe aus Kuntillet CAjrud; um 800 V.Chr.; MESHEL, Qadmoniot 9 (1976) Pl.III unten.

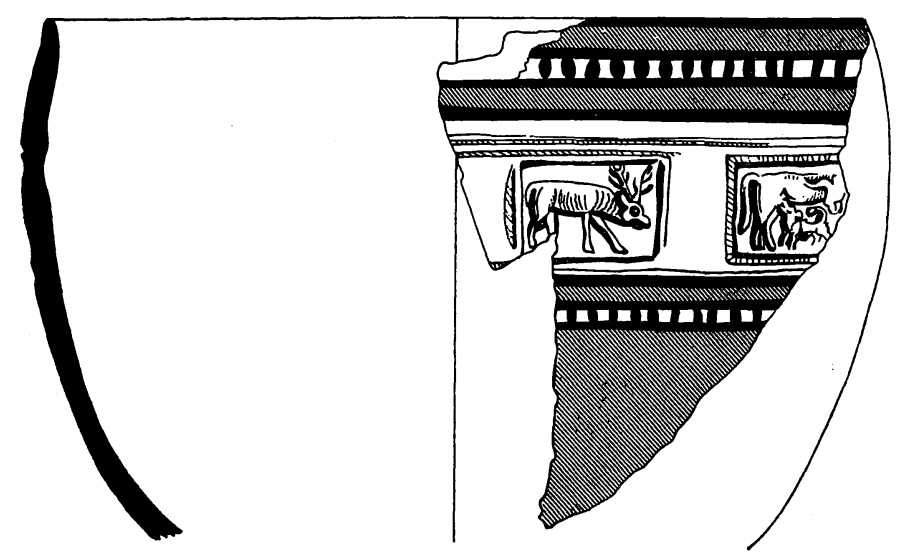

Abb.121 Fragment eines reliefierten Gefässes aus Buseirah; 7./6.Jh.v.Chr.; BENNETT, Levant 7 (1975) $14 f$ Fig. 8,10. 
v.Chr. (Abb.125) ${ }^{218}$. In die gleiche Zeit sind zwei Exemplare aus Nora in Sardinien zu datieren. Interessant ist, dass auf dem einen Stück die Kuh den Kopf nicht gesenkt hat, sondern übe: den Rücken nach rückwärts wendet $\left(\underline{\text { Abb.126) }}{ }^{219}\right.$. Von den zwei Stücken aus Tharros (ebenfalls Sardinien) hat die Kuh auf dem einen den Kopf überhaupt nicht zurückgewandt, sondern schaut erhobenen Hauptes nach vorn $($ Abb.127) 220 . Es ist fraglich, ob wir hier noch einen Beleg rein phönizischer Tradition vor uns haben. Denn es ist ja stets zu bedenken, dass es neben der ägyptischen und der vorderasiatischen auch eine Tradition gab, die sich von der minoisch-mykenischen herkommend bis in die hellenistische zeit durchgehalten hat ${ }^{21}$.

Aber nicht nur im Westen, sondern auch im Osten hat sich das Motiv bis zur griechischen zeit erhalten. Zwei achämenidische Rollsiegel zeigen ein Buckelrind mit nach vorn gerichtetem Kopf, das ein Kalb säugt (Abb.128) ${ }^{222}$.

218 VERCOUTTER, Objets égyptiens $241 \mathrm{Nr} .660 ; 248 \mathrm{Nr} .692$, Pl.XVIII Nr. 660 und XIX Nr. 690. Vgl, auch $216 \mathrm{Nr}$. 562; $217 \mathrm{Nr}$. 563, Pl.XV Nr. 562 und XVI Nr.563, auf denen die Kuh den Kopf geradeaus gerichtet hat.

219 Vgl. auch CHIERA, Testimonianze su Nora 99f, 102f, Tav. VI,4, bei dem die Kuh den gesenkten Kopf nach rückwärts gewendet hat.

220 Zum anderen siehe ACQUARO, Anecdota tharrica $65 \mathrm{Nr}$. B 10; Tav. XXIV Nr. B 10.

221 EVANS, Palace of Minos IV, 2 552-559; WATZINGER, Adonisfest $264 \mathrm{f}$.

222 Vgl. LAYARD, Niniveh and Babylon II 604 unten rechts. 

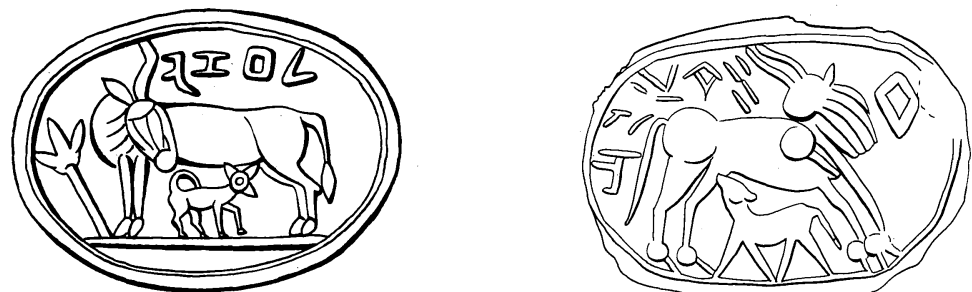

Abb.122 Skaraboid; 8.Jh.V.Chr.; GALLING, Biblisches Reallexikon 301 Abb.78, 14.

Abb.123 Skaraboid, angeblich aus Kurion; jetzt im Metropolitan Museum, New York; 6./5.Jh.v.Chr.; BOSSERT, Altsyrien lOl Abb.34l.
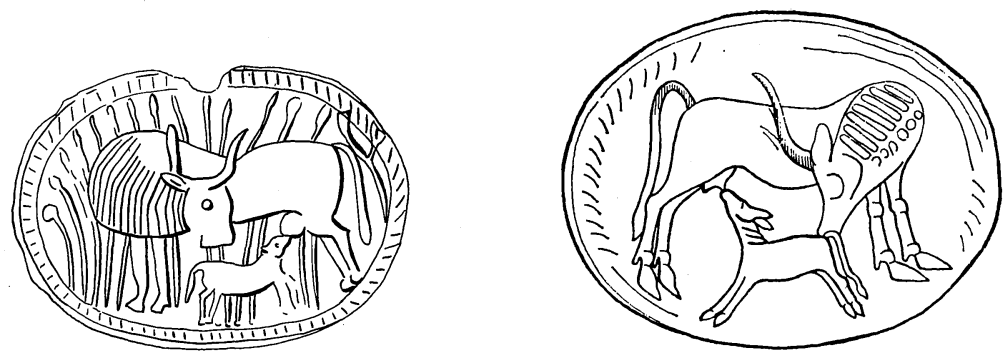

Abb.124 Skarabäus aus Arvad; 6./5. Jh.v.Chr.; FURTWAENGLER, Die antiken Gemmen II $35 \mathrm{Nr} .35$; III Taf.VII Nr.35.

Abb.125 Skarabäus aus Utica, Tunesien; im Museum Bardo in Tunis; 1. Hälfte des 4.Jh.s v.Chr.; LECLANT, Archéologie vivante I,2 (1968) $97 \mathrm{Nr} . X X I I=$ VERCOUTTER, Objets égyptiens $248 \mathrm{Nr}$. 691, Pl.XIX Nr.691.
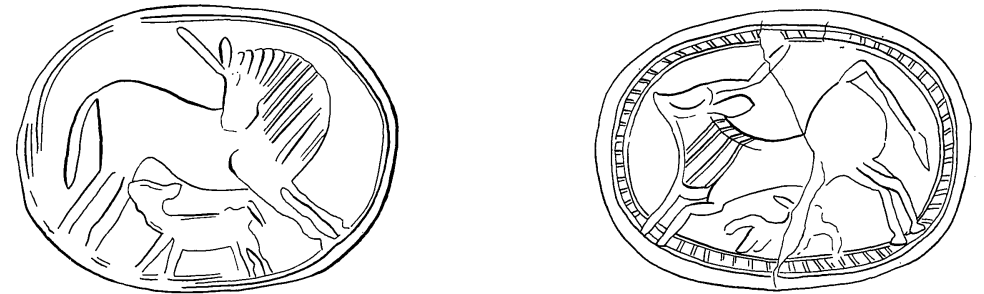

Abb.126 Skarabäus aus Nora (Sardinien); 5./4. Jh.v.Chr.; CHIERA, Testimonianze su Nora 99f. 102 Tav. VI, 5.

Abb.127 Skarabäus aus Tharros (Sardinien); 5./4. Jh.v.Chr.; ACQUARO, Anecdota Tharrica 59, $65 \mathrm{Nr}$. B 9, $70 \mathrm{Fig.1} \mathrm{Nr.} \mathrm{B} \mathrm{9;} \mathrm{Tav.XXIV} \mathrm{Nr.} \mathrm{B} 9$.

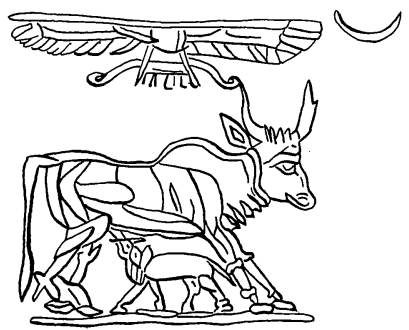

Abb.128 Achämenidisches Rollsiegel; 5.Jh.v.Chr.; WARD, Seal Cylinders 334 Fig. 1098 . 
ZUSAMMENFASSUNG

Wenn wir die lange und facettenreiche Geschichte des Bildmotivs des säugenden Muttertiers überblicken, die hier nur kurz skizziert wurde, dann fällt auf, dass es anscheinend an verschiedenen Orten und $\mathrm{zu}$ verschiedenen Zeiten spontan entstanden und wieder entstanden ist und dass wir in allen wichtigen Kulturräumen des alten Orients Göttinnen haben, die in Kuhgestalt vorgestellt werden (Hathor, Isis, Ninhursag, Ischtar, Anat), dass es aber oft schwierig ist, das Bild einer säugenden Kuh mit einer bestimmten Göttin zu identifizieren. Obwohl die Ikone des säugenden Muttertiers, wie auf den altsyrischen und altbabylonischen Siegeln (Abb.66-71 und 73-77), mit einer bestimmten Gottheit assoziiert ist, ist die genaue Art der Beziehung zwischen beiden oft schwer zu bestimmen.

Wichtige Beleggruppen, wie die mit der säugenden Capride (plus Skorpion) aus Israel (Abb.89-94) oder die neuassyrische mit der säugenden Kuh, die gleichzeitig besprungen wird (Abb. 101-105), legen nahe, das säugende Muttertier verkörpere als solches eine numinose Macht, ohne streng auf eine bestimmte Göttin bezogen und als deren Manifestation verstanden worden zu sein.

Endlich demonstrieren jene Bilder, bei denen das säugende Muttertier ein Element grösserer landwirtschaftlicher szenen oder der wildlebenden Tierwelt bildet, dass dieses auch ganz einfach Hinweis auf ein gesegnetes Gedeihen sein kann.

Ob man im säugenden Muttertier direkt die Erscheinungsgestalt einer Gottheit oder nur eine Manifestation göttlichen Segens gesehen hat, jedenfalls war es eine Gestalt, die in besonderem Masse das Gewahrwerden göttlicher Lebensmacht und Lebenslust erlaubte und gleichsam den Blick auf die freudige Zärtlichkeit und Liebe freigab, die den Fluss des Lebens in Gang hält. 
Gerade weil das säugende Muttertier im syro-palästinischen Raum nicht sehr fest mit einer bestimmten Gottheit verbunden war, konnte Israel bestimmte Opfertabus und Speisevorschriften in bezug auf das säugende Muttertier übernehmen, ohne seine exklusive Orientierung an Jahwe aufzugeben, und die Vorschriften konnten später, etwa bei PHILO, ohne Schwierigkeit als Ausdruck des Respekts vor der Weisheit einer allgemeinen Schöpfungsordnung, die den Fluss des Lebens in Gang hält, interpretiert werden. Diese Deutung liegt übrigens durchaus in der Linie des Alten Orients und des AT, die, ohne sentimental zu sein, einen wachen Sinn für die Bindung des Muttertiers an sein Junges (vgl. Abb.3-8; 1 Sam 6,7-12) und für die geheimen Mächte des Lebens hatten.

Der literarische Kontext, der ausser dem Wortlaut der konkreten, Bestimmungen (S. 11-12) unsere nächste Verstehenshilfe darstellt, legt denn auch nahe, in ihnen - ähnlich wie in den Erntefesten und Vorschriften über Erstlingsopfer, in deren Rahmen sie genannt werden - ein kanaanäisches Erbe zu sehen.

Die kultpolemische Deutung, die unsere Vorschriften gegen kanaanäische Fruchtbarkeitsriten gerichtet sehen will, ist aus sachlichen Gründen wenig wahrscheinlich. Wenn das Muttertier und sein Junges Manifestation und Symbol von Gottheiten sind, die für die Fruchtbarkeit verantwortlich waren, hat man kaum gerade sie diesen geopfert, denn wir haben zahlreiche Hinweise aus Aegypten und Syrien, dass die Symboltiere einer Gottheit als Opfertiere verboten waren (vgl. z.B. HERODOT, Historien II 4lf; LUKIAN, De Dea Syria 54). Die kultpolemische Deutung konnte denn auch keinen einzigen Beleg für die von ihr vermuteten Fruchtbarkeitsriten beibringen. Ihre älteren Belege sind nichts anderes als eine zur "Tatsache" ausgebaute Vermutung des MAIMONIDES (Führer der Unschlüssigen III, 48), und der neueste Beleg aus Ugarit hält einer genaueren Ueberprüfung auch nicht stand. 
Die hier vorgeschlagene Deutung erfolgt aufgrund einer kritischen Prüfung der verschiedenen Interpretationsmöglichkeiten, unter Beachtung des literarischen Kontexts und des bisher etwas vernachlässigten zeitgenössischen Verstehenshorizontes. Sie will vorerst den ursprünglichen Sinn der Verbote eruieren.

Nachdem dies geschehen ist, darf aber auch gesehen werden, dass wir der Impulse, die von diesen Gesetzen ausgehen können, wie eh und je bedürfen. Sie stellen einen Versuch dar, das Tier nicht nur als Nahrungslieferant, sondern wenigstens momentweise in seinem Eigenwert und vor allem als Sinnträger zu begreifen und $z u$ schützen. Sie lehren konkret, das säugende Muttertier als Manifestation göttlichen Wohlwollens und der daraus resultierenden zärtlichkeit und Lebenslust $\mathrm{zu}$ verstehen und $\mathrm{zu}$ respektieren und damit auch $\mathrm{zu}$ begreifen, dass de Mensch nicht nur von Kalbschnitzeln und Entrecôtes lebt, sondern auch von den emotionalen und geistigen Werten, die ihm das Tier vermitteln kann. Dass in diesem Bereich alles Kompromiss bleibt, muss keinem sehenden Menschen gesagt werden. Aber der Herausforderung, wenigstens einen Kompromiss anzustreben, dürfen wir uns nicht entziehen, wenn wir nicht verkümmern wollen.

Nebst den Impulsen, die die Uebernahme der Opfertabus, die das Muttertier und sein Junges betreffen, der Beziehung Mensch-Tier vermitteln kann, hatte und hat sie auch Implikationen für das Gottesbild. Sie verleiht dem in manchen stücken sehr kriegerischen und patriarchalischen Jahwe züge mütterlicher wärme und Sorge. Die eingangs zitierten Rabbinen und nach ihnen manche primär um die Unbegreiflichkeit und den absoluten Herrschaftsanspruch Gottes besorgte Theologen haben diesen Schluss zwar abgelehnt. Das hier vorgelegte Material und seine Aufarbeitung scheinen mir aber doch zu zeigen, dass jene anderen jüdischen und später auch christlichen Kreise im Recht sind, die aus unseren Geboten den Schluss gezogen haben : "Bis auf ein Vogelnest reicht Dein Erbarmen" (Mischna Berakot V 3a). 
Taf. $I, I=A b b .35, S .77$.
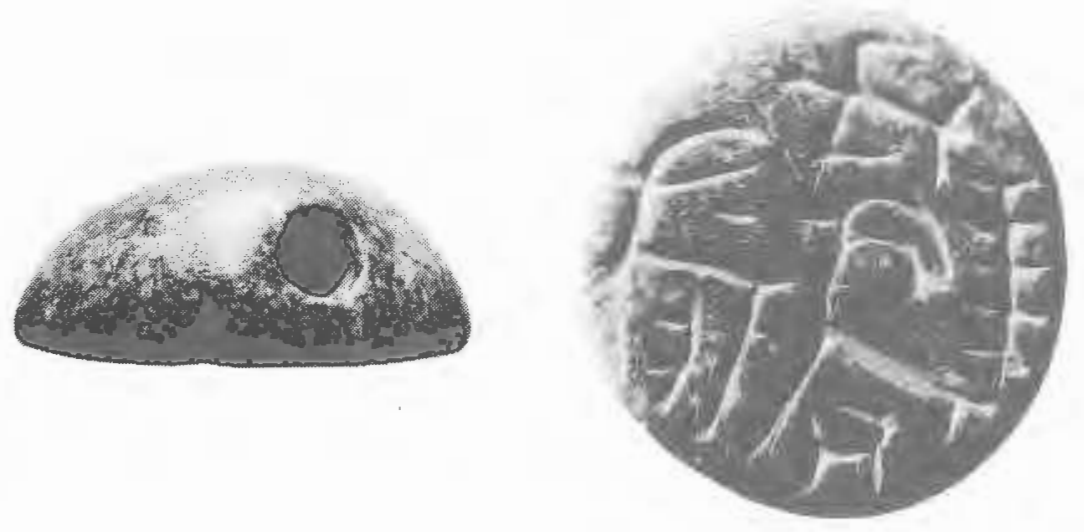

Taf. $I, 2=A b b .54, S .90$. 

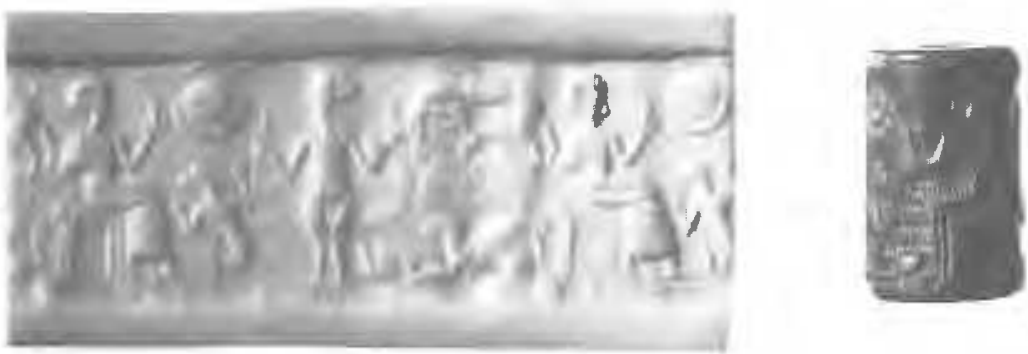

Taf.II, I $=A b b .66$, S.101.
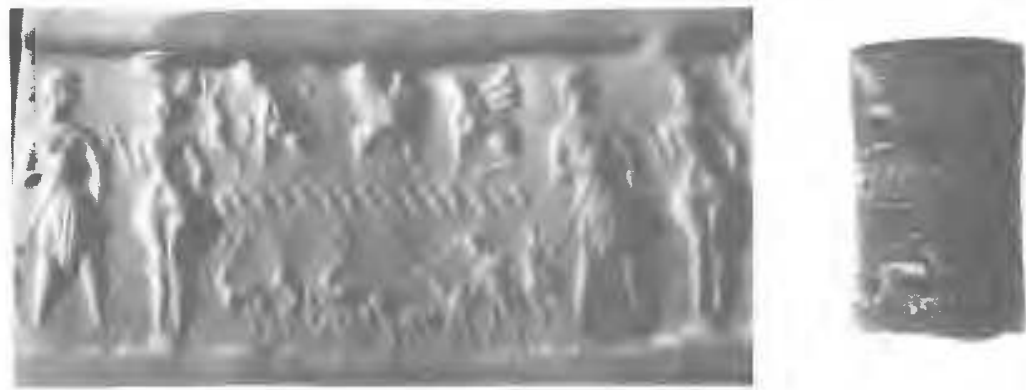

Taf.II, $2=A b b .68$, S.101.

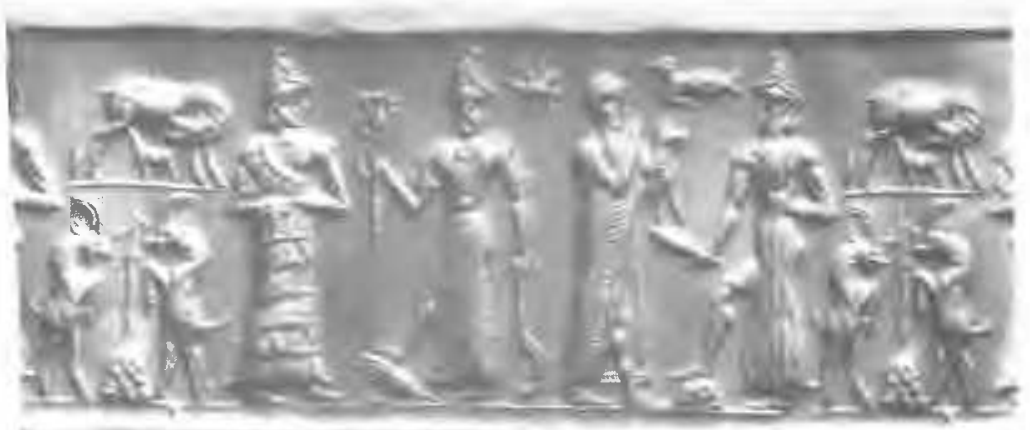

Taf.II, $3=A b b .74$, S. 104 . 


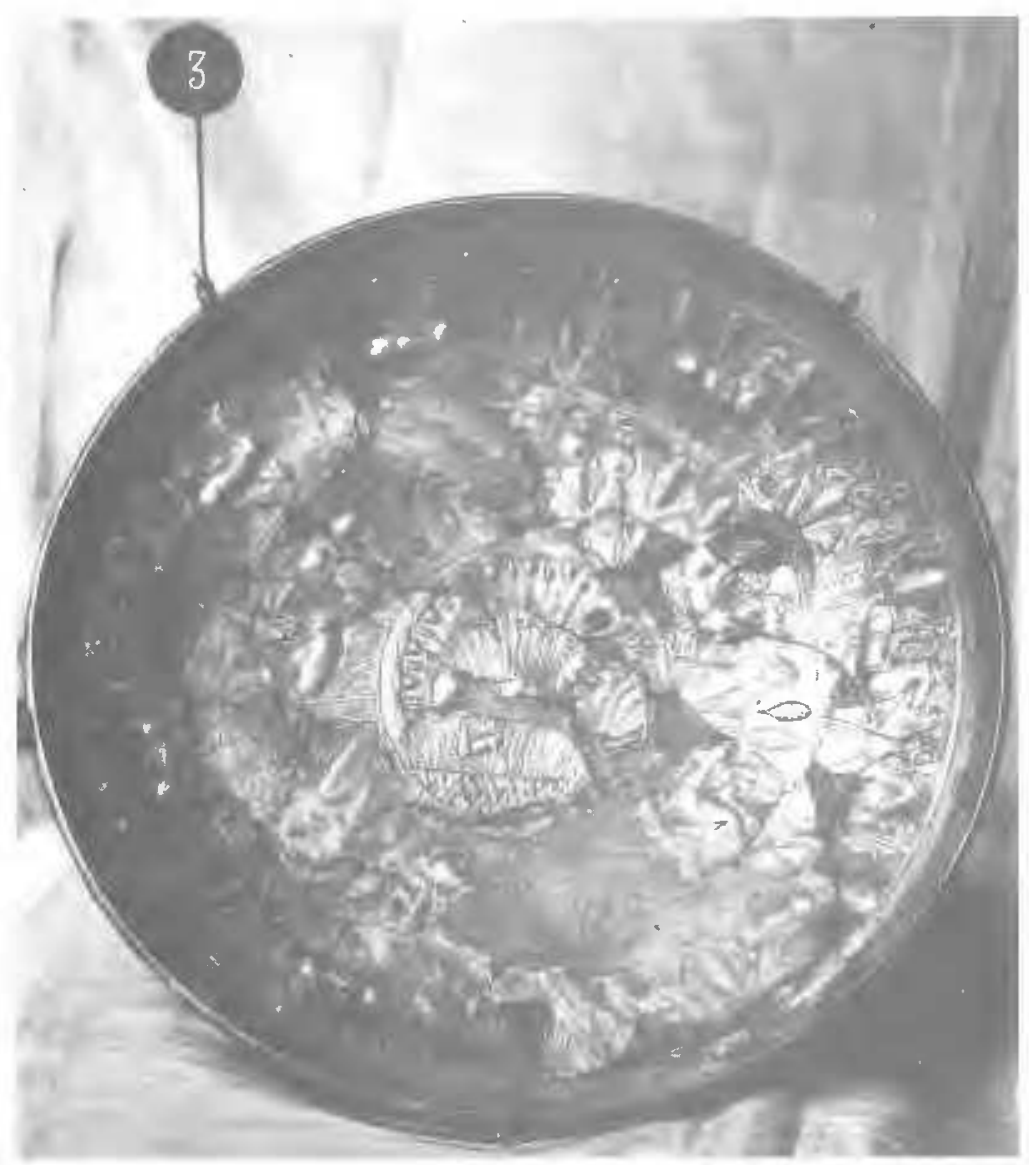

Taf.III $=A b b .113, S .131$. 
QUELLEN zu den Abbildungen

Die Abb.2, 14, 16, 18-20, 25, 26, 28, 29, 35, 38-40, 42, 45, 45a, $48 a-b, 49,49 b, 49 d, 50,54,57,58,61-63,65,66,68,70-72$, 74-77, 79-82, 84-93, 95, 99 , 101-107, 109, 110, 114-120, 122-124, 126 und 127 wurden von Hildi Keel-Leu; Abb.67 wurde von Zita Rüegg gezeichnet.

Die übrigen Abbildungen sind den in den Bildlegenden genannten Werken entnommen.

QUELLEN zu den Tafeln

Taf.I, 1 Photo The Metropolitan Museum of Art, Gift of Miss Helen Miller Gould, 1910, New York.

Taf.I,2 Photo H. Hauser, Kehrsatz b.Bern.

Taf.II,l Photo Musées Royaux du Cinquantenaire, Bruxelles.

Taf.II, 2 Photo O. Keel, Fribourg.

Taf.II, 3 Photo, Oriental Institute, Chicago.

Taf.III Photo, Vatikan-Museum, Rom. 
ABRABANEL D.I., פירוש על התררה, ed. anonyma, Jerusalem 1964. ACQUARO E., MOSCATI S., UBERTI M.-L., Anecdota tharrica (Collezione di studi fenici 5) Rom 1975.

Amuleti egiziani ed egittizzanti del Museo nazionale di Cagliari (Collezione di studi fenici 10) Rom 1977.

AELIAN Cl., Varia historia, ed. R. Hercher, Leipzig 1887.

AISTLEITNER J., Wörterbuch der ugaritischen Sprache, Berlin 1963.

ALLAM S., Beiträge zum Hathorkult bis zum Ende des Mittleren Reichs (Münchner Aegyptologische Studien 4) Berlin 1963.

AMIET P., Notes sur le répertoire iconographique de Mari à l'époque du Palais, Syria 37 (1960) 215-232.

- La Glyptique de Mari à l'époque du Palais. Note additionnelle, Syria 38 (1961) 1-6.

- Glyptique Susienne, 2 Bde (MDAI 43) Paris 1972.

AMIRAN R.B.K., A Seal from Brak : Expression of Consecutive Movements in Late Minoan Glyptik, Iraq 18 (1956) 57-59.

ARISTOTELES, Opera, 5 Bde, ed. I. Bekker, Berlin, Nachdruck 1960.

BAENTSCH B., Exodus - Leviticus - Numeri (Handkommentar zum Alten Testament I,2) Göttingen 1903.

BARNETT R.D., Three Antiquities from Syria, British Museum Quarterly 8 (1933/34) l4lf.

- The Nimrud Ivories and the Art of the Phoenicians, Iraq 2 (1935) 179-210.

- A Catalogue of Nimrud Ivories, London 1957, 21975.

BARTELS K./HUBER L., Lexikon der Alten Welt, Zürich/Stuttgart 1965.

BENNETT C.-M., Excavations at Buseirah, Southern Jordan, 1973, Levant 7 (1975) 1-19.

BEN-TOR A., Cylinder Seals of third-Millenium Palestine (AASOR, Suppl.Series No 22) Cambridge MA 1978. 
BERAN T., Assyrische Giyptik des 14.Jahrhunderts, ZA 52 (1957) $141-215$.

von BISSING F.W., Eine Bronzeschale mykenischer Zeit, Jahrbuch des Kaiserlichen Deutschen Archäologischen Instituts 13 (1898) 28-56.

BLACKMAN A.M./APTED M.R., The Rock Tombs of Meir, 6 Bde, London 1914-1953.

BOCHARTUS S., Hierozoicon sive bipartitum opus de animalibus Sacrae Scripturae, Frankfurt 21675.

BOECKER H.J., Recht und Gesetz im Alten Testament und im Alten Orient, Neukirchen 1976.

BOISSIER A., Nin Huarsag et Hâthor, OLZ 11 (1908) 234-236.

BONNET H., Reallexikon der ägyptischen Religionsgeschichte, Berlin 1952.

BORGER R., Handbuch der Keilschriftliteratur, 3 Bde, Berlin 1967-1975.

BORGHOUTS J.F., Ancient Egyptian Magical Texts (Religious Texts Translation Series. Nisaba 9) Leiden 1978.

BOSSERT H.Th., Altsyrien. Kunst und Handwerk in Cypern, Syrien, Palästina, Transjordanien und Arabien von den Anfängen bis zum völligen Aufgehen in der griechisch-römischen Kultur, Tübingen 1951.

BOTTA P.E., Monuments de Ninive, 5 Bde, Paris 1849-1850.

BRIEND J./HUMBERT J.B., Tell Keisan (1971-1976) une cité phénicienne en Galilée (ОBO Series Archaeologica 1) Fribourg/Göttingen/Paris 1980.

BRUNNER H., Die Geburt des Gottkönigs. Studien zur Ueberlieferung eines altägyptischen Mythos, Wiesbaden 1964.

BRUNTON G., Qau and Badari II und III (British School of Egypt 45 und 50) London 1928 und 1930.

BUCHANAN B., Further observations on the Syrian Glyptic style, JCS 11 (1957) 74-76.

BUCHANAN B., Catalogue of Ancient Near Eastern Seals in the Ashmolean Museum I. Cylinder Seals, Oxford 1966.

BUCHHOLZ H.G./KARAGEORGHIS V., Altägäis und Altkypros, Tübingen 1971 . 
van BUREN E.D., A Clay Relief in the Iraq Museum, Afo 9 (1933/ 34) 165-171.

The Scorpion in Mesopotamian Art and Religion, Afo 12 (1937/39) 1-28.

- Symbols of the Gods in Mesopotamian Art (Analecta Orientalia 23) Rom 1945.

CAQUOT A./SZNYCER M./HERDNER A., Textes Ougaritiques, Tome I : Mythes et Légendes, Paris 1974.

CAQUOT A., Un épisode peu connu du mythe de Baal et de la Génisse $(19.54=\mathrm{PRU} V, 124=\mathrm{KTU} 1.93)$, UF 11 (1979) 101-104.

CAZELles H., Etudes sur le Code de l'Alliance, Paris 1946.

CHASSINAT E., Le temple de Dendara, 8 Bde, Le Caire 1934-1978.

- Le Mammisi d'Edfou (Mémoires de l'Institut Français d'Archéologie Orientale XVI) Le Caire 1939.

CHEHAB M., Un trésor d'orfèvrerie syro-égyptien, Bulletin du Musée de Beyrouth 1 (1937) 7-21.

CHIERA G., Testimonianze su Nora (Collezione di studi fenizi 11) Rom 1978 .

CHWOLsON D., Die Ssabier und Ssabismus, 2 Bde, St.Petersburg 1856, Nachdruck Amsterdam 1965.

CLEMEN C., Lukians Schrift über die syrische Göttin (AO 37, 3/4) Leipzig 1938.

CRELIER H.J., L'Exode (La Sainte Bible 2), Paris 1886.

CROWFOOT J.W./CROWFOOT G.M., Early Ivories from Samaria, (Samaria-Sebaste II) London 1938.

DARESSY G., Rapport sur la trouvaille de Hatiay, ASAE 2 (1901) $1-13$.

DAUBE D., A Note on a Jewish Dietary Law, JThS 37 (1936) 289291.

DAVIES N.de G., The Mastaba of Ptahhetep and Akhethetep at Saqqareh, 2 Bde (Archaeological Survey of Egypt 8-9) London 1900/01.

- The Egyptian Expedition 1931/32. The Work of the Graphic Branch of the Expedition, Bulletin of the Metropolitan Museum of Art 27 (1933) $28 f$. 
DECAMPS DE MERTZENFELD C., Inventaire commenté des ivoires phéniciens et apparentés découverts dans le ProcheOrient, Paris 1954.

DEIMEL A., Pantheon babylonicum. Nomina deorum e textibus cuneiformibus excerpta et ordine alphabetico distributa, Rom 1914 .

DELAPORTE L., Catalogue du Musée Guimet. Cylindres Orientaux (Annales du Musée Guimet 33) Paris 1909.

- Catalogue des Cylindres Orientaux et des cachets de la Bibliothèque Nationale, 2 Bde , Paris 1910.

- Catalogue des Cylindres Orientaux, Musée du Louvre, 2 Bde, Paris 1920-1923.

DELOUGAZ P., A Site rich in early Mesopotamian Painted Pottery Illustrated London News Nr. 5198 (3. Dez. 1938) 1027.

DHORME E., Les religions de Babylonie et d'Assyrie, Paris 1949.

DIETRICH M./LORETZ O./SANMARTIN J., Die Keilalphabetischen Texte aus Ugarit. Teil 1 : Transkription (AOAT 24;1) Kevelaer/Neukirchen-Vluyn 1976.

DILLMANN A., Die Bücher Exodus und Leviticus (Kurzgefasstes Exegetisches Handbuch zum Alten Testament) Leipzig 1880 .

DIODOR SICULUS, Bibliotheca Historica, 6 Bde, ed. F.Vogel/Th. Fischer, Leipzig/Stuttgart 1888-1969.

DONADONI S., Great Museums of the World. Egyptian Museum Cairo, London 1969.

DONDELINGER E., Papyrus d'Ani, Paris 1979.

DUSSAUD R., The British Museum Quarterly VIII,4, Londres 1934, Syria 15 (1934) 392 .

- Les origines cananéennes du sacrifice israélite, Paris 21941 .

EGGEBRECHT A., Schlachtungsbräuche im alten Aegypten und ihre Wiedergabe im Flachbild bis zum Ende des Mittleren Reiches, München 1973.

EISEN G.A., Ancient Oriental Cylinder and Other Seals with a Description of the Collection of Mrs. W.H.Moore, Chicago 1940.

ELLIGER K., Leviticus (HAT I,4) Tübingen 1966. 
ERLENMEYER M.-L./ERLENMEYER H., Ueber Philister und Kreter III, Or 30 (1961) 269-293.

ERMAN A./GRAPOW H., Wörterbuch der ägyptischen Sprache, 13 Bde, Berlin 21971.

EURIPIDES, Bakkchen, ed. E.R.Dodds, Oxford 1944 .

EUSEBIUS, Werke VIII. Die Praeparatio evangelica, 2 Bde, ed. K.MRAS, Berlin 1954-1956.

EVANS A., The Palace of Minos. A comparative Account of the successive Stages of the early Cretan Civilization as illustrated by the Discoveries at Knossos, 4 Bde, London 1921-1935, Nachdruck New York 1964.

- On a Minoan Bronze Group of a galloping Bull and acrobatic Figure from Crete, Journal of Hellenic Studies 41 (1921) 247-259.

FALKENSTEIN A./von SODEN W., Sumerische und Akkadische Hymnen und Gebete, Zürich/stuttgart 1953.

FIELD H./MARTIN R.A., Painted Pottery from Jemdet Nasr, Iraq, AJA 39 (1935) 312-320.

FISCHER H.G., "Milk in everything cooked" (Sinuhe B 91-92), in : Ders., Varia-Egyptian Studies I, New York 1976, 97-99.

FISHER L.R., Ras Shamra Parallels I (Analecta Orientalia 49) Roma 1972 .

FRANKFORT H., Allard Pierson Museum, Cylinder-Zegels, JEOL 3 (1935) 153-157.

- The Oldest Stone Statuette ever found in Western Asia and other Relics of ancient Sumerian Culture, Illustrated London News Nr. 5084 (26.Sept.1936) 43.

- Cylinder Seals, London 1939.

- The Art and Architecture of the Ancient Orient, Harmondsworth 1954 (Paperback 41970).

- Stratified Cylinder Seals from the Dijala-Region (OIP 72) Chicago $1955,21964$.

FRAZER J.G., Folklore in the Old Testament. Studies in Comparative Religion, Legend and Law III, London 1918.

FURLANI G., Il sacrificio nella religione dei Semiti di Babilonia e Assiria, Rom 1932. 
FURTWAENGLER A., Die antiken Gemmen. Geschichte der Steinschneidekunst im klassischen Altertum, 3 Bde, München 1900 (Nachdruck Amsterdam/Osnabrück 1965).

GALLING K., Biblisches Reallexikon, Tübingen 1937, ${ }^{2} 1977$.

- Beschriftete Bildsiegel des 1. Jahrtausends v.Chr., vornehmlich aus Syrien und Palästina, ZDPV 64 (1941) 121-202.

- Das Salben der Mutterbrust (Sfire I A 2lf), ZDPV 83 (1967) $134 \mathrm{f}$.

GAMER-WALLERT I., Fische und Fischkulte im alten Aegypten (Aegyptologische Abhandlungen 21) Wiesbaden 1970.

GINSBERG H.L., Notes on "The Birth of the Gracious and Beautiful Gods", Journal of the Royal Asiatic Society 67 (1935) 45-72.

- The Ugaritic Texts (hebr.), Jerusalem 1936.

GOFF B.L., Symbols of Prehistoric Mesopotamia, New Haven/London 1963.

GOLDSCHMIDT L. (Hg.), Der babylonische Talmud mit Einschluss der vollständigen Mišnah, 9 Bde, Leipzig, Berlin u.a., 1897-1935.

GRANT E., Rumeileh being Ain Shems Excavations (Palestine) III, Haverford 1934 .

GRDSELOFF B., Les débuts du culte de Rechef en Egypte, Le Caire 1942 .

HALBE J., Das Privilegrecht Jahwes Ex 34,10-26 (FRLANT 114) Göttingen 1975.

HARAN M., Seething a Kid in its Mothers Milk, JJS 30 (1979) 23-35.

HAUSSIG H.W., Wörterbuch der Mythologie Bd.1, Götter und Mythen im Vorderen Orient, Stuttgart 1965.

HAYES W.C., The Scepter of Egypt. A Background for the Study of the Egyptian Antiquities in the Metropolitan Museum of Art I. From the Earliest Times to the End of the Middle Kingdom, New York 1953.

HEHN J., Die biblische und die babylonische Gottesidee. Die israelitische Gottesauffassung im Lichte der altorientalischen Religionsgeschichte, Leipzig 1913. 
HENNINGER J., Les Fêtes des Printemps chez les Sémites et la Pâque Israélite (Etudes Bibliques) Paris 1975.

HERDNER A., Corpus des tablettes en cunéiformes alphabétiques découvertes à Ras Shamra-Ugarit de 1929 à 1939 (Mission de Ras Shamra X) Paris 1963.

HERMANN A., Altägyptische Liebesdichtung, Wiesbaden 1959.

HERODOT, Historien, 2 Bde, ed. C.HUDE, Oxford 1908, Nachdruck $1966 / 67$.

HERZFELD E., Aufsätze zur altorientalischen Archäologie II. Stempelsiegel, Archäologische. Mitteilungen aus Iran 5 (1933) 49-103.

HESS J.J., ראם, ZAW 35 (1915) 121-123.

HOGARTH D.G., Hittite Seals, Oxford 1926.

HOLZINGER H., Exodus (Kurzer Hand-Commentar zum Alten Testament 2) Tübingen 1900.

HOMER, Ilias, 2 Bde, ed.D.B.MONRO/Th.W. ALLEN, Oxford 1946-1951.

HORNUNG E./STAEHELIN E., Skarabäen und andere Siegelamulette aus Basler Sammlungen (Aegyptische Denkmäler in der Schweiz, Bd 1) Mainz 1976.

HORNUNG E., Das Totenbuch der Aegypter, Zürich/München 1979.

von HUMMELAUER F., Commentarius in Exodum et Leviticum (Cursus Scripturae Sacrae I,2) Paris 1897.

IBN ESRA A.b.M., באור על ספר שמרת נקרא הקצר ,ed. Reggio, Prag 1840 .

- ed. A.WEISER, Jerusalem 1977.

JACOBSEN T., The Treasures of Darkness. A History of Mesopotamian Religion, New Haven/London 1976.

JIDEJIAN N., Byblos through the Ages, Beirut 1971.

JOSEFUS FLAVIUS, Opera, 6 Bde, ed. B. Niese, Berlin 1955.

JUNKER H., Gîza III, Wien/Leipzig 1938.

JUNKER H./WINTER E., Das Geburtshaus des Tempels der Isis in Philae (Oesterreichische Akademie der Wissenschaften. Phil.-Hist. Kl. Denkschriften Sonderband. Philae Publikation II) Wien 1965. 
KAYSER H., Die ägyptischen Altertümer im Roemer-PelizaeusMuseum in Hildesheim, Hildesheim 1973.

KEIL C.F., Biblischer Commentar über die Bücher Mose's I. Genesis und Exodus (Biblischer Commentar über das Alte Testament $I, 1)$ Leipzig 1861.

KEEL O., Vögel als Boten. Studien zu Ps 68,12-14, Gen 8,6-12, Koh 10,20 und zum Aussenden von Botenvögeln in Aegypten. Mit einem Beitrag von U.Winter zur Ikonographie der vorderasiatischen Göttin mit der Taube, OBO 14, Freiburg (CH), Göttingen 1977.

- Die Welt der altorientalischen Bildsymbolik und das Alte Testament. Am Beispiel der Psalmen, Zürich-Neukirchen 1972,31980 .

- Jahwes Entgegnung an Ijob. Eine Deutung von Ijob 38-41 vor dem Hintergrund der zeitgenössischen Bildkunst (FRLANT 121) Göttingen 1978.

- Hg. , Monotheismus im Alten Israel und seiner Umwelt. Mit Beiträgen von B.HARTMANN, E.HORNUNG, G.PETTINATO und F.STOLZ (Biblische Beiträge 14) Freiburg (CH) 1980.

KENNA V.E.G., Ancient Crete and the Use of the Cylinder Seal, American Journal of Archaeology 72 (1968) 321-336.

- A Late Bronze Stamp Seal from Jordan, ADAJ 18 (1973) 79 .

KLEBS L., Die Reliefs des Alten Reiches (2980-2475 v.Chr.), Material zur ägyptischen Kulturgeschichte, Heidelberg 1915.

- Die Reliefs und Malereien des Mittleren Reiches (7.17. Dynastie, ca. 2475-1580 v.Chr.), Heidelberg 1922.

- Die Reliefs und Malereien des Neuen Reiches (18.-20. Dynastie, ca. 1580-1100 v.Chr.), Heidelberg 1934.

KORNFELD W., Das Buch Leviticus (Die Welt der Bibel. Kleinkommentare zur Heiligen Schrift) Düsseldorf 1972.

KOSMALA H., The so called ritual Decalogue, ASTI 1 (1962) 50-56.

KUECHLER M., Frühjüdische Weisheitstraditionen. Zum Fortgang weisheitlichen Denkens im Bereich des frühjüdischen Jahweglaubens (OBO 26) Freiburg/Göttingen 1979.

KUEHNE H., Das Rollsiegel in Syrien. Zur Steinschneidekunst in Syrien zwischen 3300 und $330 \mathrm{v} . \mathrm{Chr}$. (Ausstellungskataloge der Universität Tübingen No. 11) Tübingen 1980. 
LAMBERT W.G., A Middle Assyrian Medical Text, Iraq 31 (1965) 28-39.

LAMON R.S./SHIPTON G.M., Megiddo I. Seasons of 1925 - 1934. Strata I-V (Oriental Institute Publications 42) Chicago 1939.

LANGE K./HIRMER M., Aegypten, Architektur, Plastik, Malerei in drei Jahrtausenden, München 41967.

LANZONE R.V., Dizionario di Mitologia Egizia II, Torino 1882.

LAPP P.W., The 1966 Excavations of Tell Ta'annek, BASOR 185 (1967) 2-39.

LAYARD A.H., Discoveries in the Ruins of Niniveh and Babylon II, London 1853.

LECLANT J., Les talismans egyptiens dans les Necropoles, Archéologie vivante I,2 (1969) 95-113.

LEFEBVRE G., Le tombeau de Petosiris, Le Caire 1924.

LEPSIUS R., Denkmäler aus Aegypten und Aethiopien, 12 Bde , Berlin 1849-1858 (Neudruck Osnabrück 1969).

- Denkmäler aus Aegypten und Aethiopien. Ergänzungsband, herausgegeben von E.Naville unter Mitwirkung von L. Borchardt bearbeitet von K. Sethe, Leipzig 1913.

de LIAGRE BOEHL F.M.Th., Oud-babylonische Mythen, JEOL 4 (1936) 194-204.

LIPIŃSKI E., Les Conceptions et Couches merveilleuses de CAnath, Syria 42 (1965) 45-73.

LOEWENSTAMM S.E., Lexicographical Notes on 1. țbhi 2. hlny, Ugarit-Forschungen 5 (1973) 209-211.

de LONGPERIER A., Oeuvres réunies et mises en ordre par G. Schlumberger I. Archéologie orientale. Monuments arabes, Paris 1883.

LUCKENBILL D.D., Ancient Records of Assyria and Babylonia, 2 Bde, Chicago 1926 (Nachdruck New York 1968).

LUKIAN VON SAMOSATA, Opera, 4 Bde, ed. C.IACOBITZ, Leipzig 1836-1841, Nachdruck 1966. 
MACALISTER R.A.S., The Excavation of Gezer, 3 Bde, London 1912.

MAIMONIDES (Maimon) M.B., More nebukim, ed. S.MUNK, 3 Bde , Paris 1956-66.

MALLOWAN M.E.L., Excavations at Brak and Chagar Bazar, Iraq 9 (1947) 1-259.

- Nimrud and its Remains I-II, London 1966.

MASPERO G., Le Musée Egyptien. Recueil de monuments et de notices sur les fouilles d'Egypte II, Le Caire 1907.

MATOUK F.S., Corpus du scarabée égyptien. Tome II : Analyse Thématique, Beirut 1977.

MATTHIAE P., Il motivo della vacca che allata nell'iconografia del Vicino Oriente antico, Rivista degli Studi Orientali (RSO) 36 (1961) 1-31.

McCOWN C.C., Tell en Naṣbeh I, Berkeley/New Haven 1947.

MENANT J., Collection de Clerq. Catalogue méthodique et raisonné I. Cylindres Orientaux, Paris 1888.

MESHEL Z., Kuntillet Ajrud - An Israelite Site on the Sinai Border (hebr.), Qadmoniot 9 (1976) 119-124.

de MOOR J.C., Murices in Ugaritic Mythology, Or 37 (1968) 212215 .

- New Year with Canaanites and Israelites. Part 1 : Description, Part 2 : The Canaanite Sources (Kamper Cahiers No. 21/22), Kampen 1972.

MOORTGAT A., Vorderasiatische Rollsiegel. Ein Beitrag zur Geschichte des Steinschneidekunst, Berlin 1940.

- Assyrische Glyptik des 12. Jahrhunderts, ZA 14 (48) (1944) 22-44.

DE MORGAN J., BOURIANT U., LEGRAIN G., JEQUIER G., BARSANTI A., Catalogue des monuments de l'Egypte antique I. Haute Egypte. De la frontière de Nubie a Kom Ombos, Vienne 1894.

MOUSSA A.M./ALTENMUELLER H., Old Kingdom Tombs at the Causeway of King Unas et Saqqara. The Tomb of Nefer and Ka-hay (Deutsches Archäologisches Institut, Abtl. Kairo. Archäolog. Veröffentlichungen 5) Mainz 1971. 
NAGEL W., Djamdat Nasr-Kulturen und frühdynastische Buntkeramik (Berliner Beiträge zur Vor- und Frühgeschichte 8) Berlin 1964.

NAVILLE E., The Temple of Deir el Bahari, 6 Bde (Memoirs of the Egypt Exploration Society No. $13,14,16,19,27,29$ ) London 1895-1908.

- The XIth Dynasty Temple at Deir el-Bahari I (Memoirs of the Egypt Exploration Fund 28) London 1907.

NAVILLE E./SETHE K. (Hg.) R. Lepsius, Denkmäler aus Aegypten und Aethiopien. Ergänzungsband, Leipzig 1913.

NEWBERRY P.E., Beni Hasan I-II (Archaeological Suvey of Egypt 12) London 1893-94.

- The Tim(m)ins Collection of Ancient Egyptian Scarabs and Cylinder Seals, London 1907.

NIMS Ch.F./SWAAN W., Thebes of the Pharaos. Pattern for every City, New York 1965.

NOTH M., Das dritte Buch Mose, Leviticus (ATD 6) Göttingen 1962.

- Das zweite Buch Mose, Exodus (ATD 5) Göttingen 1965.

OPIFICIUS R., Syrisch aegyptischer Einfluss auf die Kunst des Zweistromlandes in altbabylonischer Zeit, MOORTGATFestschrift, Berlin 1964, 216-220.

- Geschnittene Steine der Antike, Katalog der Münzen und Medaillen AG, Basel 1968.

OPPENHEIM A.L., The Assyrian Dictionary, Chicago/Glückstadt 1956f. von der OSTEN H.H., Ancient Oriental Seals in the Collection of Mr.E.T.Newell, Chicago 1934.

PARROT A., Le "Bon Pasteur". A propos d'une statue de Mari, in : Mélanges Syriens offerts à M. René Dussaud I, Paris 1939, 171-182.

- Mission archéologique de Mari II. Le Palais III. Documents et Monuments, Paris 1959.

PERROT G./CHIPIEZ C., Histoire de l'art dans l'Antiquité, Vol. III (Phénicie-Cypre) Paris 1885.

PETRIE W.M.F., Illahun, Kahun and Gurob, London 1891, Warminster 21974 . 
- Deshashe (Memoirs of the Egypt Exploration Fund 15) London 1898.

PHILO, Opera quae supersunt, 7 Bde, ed. L.COHN/P.WENDLAND, Berlin 1896-1930, Nachdruck 1962.

PLATON N., Corpus der minoischen und mykenischen Siegel. II. Iraklion. Archäologisches Museum. 1. Die Siegel der Vorpalastzeit, Berlin 1969.

PLUTARCH, Moralia, 7 Bde., ed. G.N.BERNARDAKIS, Leipzig 18881896.

PORADA E., Corpus of Ancient Near Eastern Seals in North American Collections I. The Collection of the Pierpont Morgan Library, 2 Bde, Washington 1948.

- Critical Review (ihres eigenen Werks über die Siegel der Pierpont Morgan Library), Journal of Cuneiform Studies 4 (1950) 155-162.

PORTER B./MOSS R.L.B., Topographical Bibliography of Ancient Egyptian Hieroglyphic Texts, Reliefs and Paintings, 7 Bde, Oxford 1927-52, 2 1960ff.

POULSEN F., Der Orient und die frühgriechische Kunst, Leipzig/ Berlin 1912 .

PSEUDOPHOKYLIDES, In : Theognis, Pseuao-Pythagoras, PseudoPhokylides, Chares, Anonymi Aulodia, ed. D.YOUNG, Leipzig 1961, 21971.

von RAD G., Das fünfte Buch Mose, Deuteronomium (ATD 8) Göttingen 1964 .

RADIN M., The Kid and its Mother's Milk, AJSL 40 (1923/24) 209218 .

RICHTER W., Recht und Ethos. Versuch einer Ortung des weisheitlichen Mahnspruches (Studien zum Alten und Neuen Testament 15) München 1966.

RIESSLER P., Altjüdisches Schrifttum ausserhalb der Bibel, übersetzt und erklärt, Augsburg 1928 (Nachdruck Heidelberg 1966).

ROBERT A./TOURNAY R./FEUILLET A., Le Cantique des Cantiques. Traduction et Commentaire (Etudes Bibliques) Paris 1963.

SAFADI H., Die Entstehung der Glyptik und ihre Entwicklung in der Zeit von Zimrilim bis Ammitaqumma, UF 6 (1974) 313-352. 
SCAMMUZI E., Egyptian Art in the Egyptian Museum of Turin, Torino 1964.

SCHEIL V., IŠtar sous le symbole de la vache, RT 20 (1898) 62.

SCHMOEKEL H., Ur, Assur und Babylon (Grosse Kulturen der Frühzeit) Zürich ${ }^{6} 1962$.

SETHE K., Urgeschichte und älteste Religion der Aegypter (Abhandlungen für die Kunde des Morgenlandes 18,4$)$ Leipzig 1930.

SEYRIG H., Scène de hiérogamie, Syria 32 (1955) 38-41.

SINUHE-Text sieh : A.M.BLACKMPN, Middle-Egyptian Stories (Bibliotheca Aegyptiaca II) Bruxelles 1972, 1-41.

SMITH S., An early painted Vase from Khafaji, British Museum Quarterly 8 (1933/34) 38-4l.

SMITH W.R., Die Religion der Semiten, Tübingen 1899; Nachdruck : Darmstadt 1967.

SMITH W.S., A History of Egyptian Sculpture and Painting in the old Kingdom, London 1946.

von SODEN W., Akkadisches Handwörterbuch, Wiesbaden $1965 f$.

SPELEERS L., Catalogue des Intailles et Empreintes Orientales des Musées Royaux du Cinquantenaire, Bruxelles 1917.

STRACK H.L./BILLERBECK P., Kommentar zum Neuen Testament aus Talmud und Midrasch 4 Bde, München 1926-1928, ${ }^{3} 1961$.

STEINDORFF G., Die Kunst der Aegypter. Bauten, Plastik, Kunstgewerbe, Leipzig 1928.

STROMMENGER E., Der Garten in Eden. 7 Jahrtausende Kunst und Kultur an Euphrat und Tigris, Berlin 1978.

TALLQVIST K., Akkadische Götterepitheta (Societas Orientalis Fennicae. Studia Orientalia 7) Helsinki 1938.

THIMME J., Phönizische Elfenbeine. Bildhefte des Badischen Landesmuseums Karlsruhe, Karlsruhe 1973.

THOMAS VON AQUIN, Summa Theologiae, ed. P.CARAMELlO, 3 Bde, Turin/Rom 1952-1956.

THUREAU DANGIN F./BARROIS A./DOSSIN G./DUNAND M., Arslan-Tash, 2 Bde, Paris 1931. 
VANDIER J., Manuel d'Archéologie égyptienne V, Paris 1969.

de VAUX R., Les fouilles de Tell el-Far'ah près Naplouse. Cinquième Campagne, RB 62 (1955) 541-589.

- Les sacrifices de l'Ancien Testament, Paris 1964.

VERCOUTTER J., Les objets égyptiens et égyptisants du mobilier funéraire carthaginois (Bibliothèque archéologique et historique 40) Paris 1945.

VIROLLEAUD Ch., Un poème phénicien de Ras-Shamra. La lutte de Môt, fils des dieux, et d'Aleĩn, fils de Baal, Syria 12 (1931) 193-224.

- "La naissance des dieux gracieux et beaux", Syria 14 (1933) 128-154.

- La mort de Baal, Poème de Ras Shamra ( $\left.I^{*} A B\right)$, Syria 15 (1934) 305-336.

WARD W.H., The Seal Cylinders of Western Asia (Publication Nr. 100 of the Carnegie Institution of Washington) Washington 1910.

WATZINGER C., Adonisfest, in : Antike Plastik. Walter Amelung zum 60. Geburtstag, Berlin und Leipzig 1928, 261-266.

WEIGALL A.E.P.B., An ancient Egyptian Funeral Ceremony, JEA 2 (1915) 10-12.

WILMS F.E., Das jahwistische Bundesbuch in Ex 34 (STANT 32) München 1973.

WINKLER H.A., Aegyptische Volkskunde, Stuttgart 1936.

WOLDERING I., Bildkataloge des Kestner-Museums Hannover I. Ausgewählte Werke der ägyptischen Sammlung, Hannover 1955.

WOLF W., Die Kunst Aegyptens. Gestalt und Geschichte, Stuttgart 1957.

WRESZINSKI W., Atlas der altägyptischen Kulturgeschichte, 3 Bde, Leipzig 1923-1938.

WRIGHT G.E., Selected Seals from the Excavations at Balâtah (Shechem), BASOR 167 (1962) 5-13. 
Reihen, Zeitschriften und Standardwerke sind im allgemeinen nach S.SCHWERTNER, Internationales Abkürzungsverzeichnis für Theologie une Grenzgebiete, Berlin, New York 1974 abgekürzt. Zusätzlich wurden folgende Abkürzungen verwendet :

AOB PS KEEL, Die Welt der altorientalischen Bildsymbolik und das Alte Testament. Am Beispiel der Psalmen (siehe Literaturverzeichnis)

KTU DIETRICH/LORETZ/SANMARTIN, Die keilalphabetischen Texte aus Ugarit (siehe Literaturverzeichnis)

MDAI Mémoires de la Délégation Archéologique en Iran

ово Orbis Biblicus et Orientalis

RT Recueil de Travaux Relatifs à la Philologie et à l'Archéologie Egyptiennes et Assyriennes

STANT Studien zum Alten und Neuen Testament

WAM HAUSSIG, Wörterbuch der Mythologie (sieh Literaturverzeichnis) 

Bd. 1 OTTO RICKENBACHER: Weisheitsperikopen bei Ben Sira. X-214-15* Seiten. 1973.

Bd. 2 FRANZ SCHNIDER: Jesus der Prophet. 298 Seiten. 1973. Vergriffen.

Bd. 3 PAUL ZINGG: Das Wachsen der Kirche. Beiträge zur Frage der lukanischen Redaktion und Theologie. 345 Seiten. 1974. Vergriffen.

Bd. 4 KARL JAROS : Die Stellung des Elohisten zur kanaanäischen Religion. 496 Seiten. 1974. Vergriffen. Ncuauflage in Vorbereitung.

Bd. 5 OTHMAR KEEL: Wirkmächtige Siegeszeichen im Alten Testament. Ikonographische Studien zu Jos 8, 18-26; Ex 17, 8-13; 2 Kön 13, 14-19 und 1 Kön 22, 11. 232 Seiten, 78 Abbildungen. 1974.

Bd. 6 VITUS HUONDER: Israel Sobn Gottes. Zur Deutung eines alttestamentlichen Themas in der jüdischen Exegese des Mittelalters. 231 Seiten. 1975.

Bd. 7 RAINER SCHMITT: Exodus und Passab. Ibr Zusammenhang im Alten Testament. 112 Seiten. 1975. Vergriffen. Neuauflage in Vorbereitung.

Bd. 8 ADRIAN SCHENKER: Hexaplarische Psalmenbruchstücke. Die hexaplarischen Psalmenfragmente der Handschriften Vaticanus graecus 752 und Canonicianus graecus 62. Einleitung, Ausgabe, Erläuterung. XXVIII - 446 Seiten. 1975.

Bd. 9 BEAT ZUBER: Vier Studien zu den Ursprüngen Israels. Die Sinaifrage und Probleme der Volks- und Traditionsbildung. 152 Seiten. 1976. Vergriffen.

Bd. 10 EDUARDO ARENS: The $H A \Theta O N$-Sayings in the Synoptic Tradition. A Historico-critical Investigation. 370 Seiten. 1976.

Bd. 11 KARL JAROŠ: Sichem. Eine archäologische und religionsgeschichtliche Studie, mit besonderer Berücksichtigung von Jos 24. 280 Seiten, 193 Abbildungen. 1976.

Bd. 11a KARL JAROŠ / BRIGITTE DECKERT: Studien zur Sichem-Area. 81 Seiten, 23 Abbildungen. 1977.

Bd. 12 WALTER BUHLMANN: Vom rechten Reden und Scbweigen. Studien zu Proverbien 10-31. 371 Seiten. 1976.

Bd. 13 IVO MEYER: Jeremia und die falschen Propheten. 155 Seiten. 1977.

Bd. 14 OTHMAR KEEL: Vögel als Boten. Studien zu Ps 68, 12-14, Gen 8, 6-12, Koh 10, 20 und dem Aussenden von Botenvögeln in Agypten. - Mit einem Beitrag von Urs Winter zu Ps 56, 1 und zur Ikonographie der Göttin mit der Taube. 164 Seiten, 44 Abbildungen. 1977.

Bd. 15 MARIE-LOUISE GUBLER: Die frübesten Deutungen des Todes Jesu. Eine motivgeschichtliche Darstellung aufgrund der neueren exegetischen Forschung. XVI - 424 Seiten. 1977.

Bd. 16 JEAN ZUMSTEIN. La condition du croyant dans l'Evangile selon Matthieu. 467 pages. 1977.

Bd.17 FRANZ SCHNIDER: Die verlorenen Söbne. Strukturanalytische und historisch-kritische Untersuchungen zu Lk 15. 105 Seiten. 1977.

Bd. 18 HEINRICH VALENTIN: Aaron. Eine Studie zur vor-priesterschriftlichen Aaron-Überlieferung. VIII - 441 Seiten. 1978. 
Bd. 19 MASSÉO CALOZ: Etude sur la LXX origénienne du Psautier. Les relations entre les leçons des Psaumes du Manuscrit Coislin 44, les Fragments des Hexaples et le texte du Psautier Gallican. 480 pages. 1978.

Bd. 20 RAPHAEL GIVEON: The Impact of Egypt on Canaan. Iconographical and Related Studies. 156 Seiten, 73 Abbildungen. 1978.

Bd. 21 DOMINIQUE BARTHELEMY: Etudes d'bistoire du texte de l'Ancien Testament. XXV - 419 pages. 1978.

Bd. 22/1 CESLAS SPICQ: Notes de Lexicograpbie néo-testamentaire. Tome I: p. 1-524. 1978.

Bd. 22/2 CESLAS SPICQ: Notes de Lexicograpbie néo-testamentaire. Tome II: p. 525980. 1978.

Bd. 23 BRIAN M. NOLAN: The royal Son of God. The Christology of Matthew 1-2 in the Setting of the Gospel. 282 Seiten. 1979.

Bd. 24 KLAUS KIESOW: Exodustexte im Jesajabuch. Literarkritische und motivgeschichtliche Analysen. 221 Seiten. 1979.

Bd. 25/1 MICHAEL LATTKE: Die Oden Salomos in ibrer Bedeutung für Neues Testament und Gnosis. Band I. Ausführliche Handschriftenbeschreibung. Edition mit deutscher Parallel-Ubbersetzung. Hermeneutischer Anhang zur gnostischen Interpretation der Oden Salomos in der Pistis Sophia. XI - 237 Seiten. 1979.

Bd. 25/1a MICHAEL LATTKE: Die Oden Salomos in ibrer Bedeutung für Neues Testament und Gnosis. Band Ia. Der syrische Text der Edition in Estrangela Faksimile des griechischen Papyrus Bodmer XI. 68 Seiten. 1980.

Bd. 25/2 MICHAEL LATTKE: Die Oden Salomos in ibrer Bedeutung für Neues Testament und Gnosis. Band II. Vollständige Wortkonkordanz zur handschriftlichen, griechischen, koptischen, lateinischen und syrischen Überlieferung der Oden Salomos. Mit einem Faksimile des Kodex N. XVI - 201 Seiten. 1979.

Bd. 26 MAX KUCHLER: Frübjüdische Weisheitstraditionen. Zum Fortgang weisheitlichen Denkens im Bereich des frühjüdischen Jahweglaubens. 703 Seiten. 1979.

Bd. 27 JOSEF M. OESCH: Petucha und Setuma. Untersuchungen zu einer überlieferten Gliederung im hebräischen Text des Alten Testaments. XX - $394-37^{*}$ Seiten. 1979.

Bd. 28 ERIK HORNUNG / OTHMAR KEEL (Herausgeber): Studien zu altägyptischen Lebenslebren. 394 Seiten. 1979.

Bd. 29 HERMANN ALEXANDER SCHLOGL: Der Gott Tatenen. Nach Texten und Bildern des Neuen Reiches. 216 Seiten, 14 Abbildungen. 1980.

Bd. 30 JOHANN JAKOB STAMM: Beiträge zur Hebräischen und Altorientalischen Namenkunde. XVI - 264 Seiten. 1980.

Bd. 31 HELMUT UTZSCHNEIDER: Hosea - Prophet vor dem Ende. Zum Verhältnis von Geschichte und Institution in der alttestamentlichen Prophetie. 260 Seiten. 1980.

Bd. 32 PETER WEIMAR: Die Berufung des Mose. Literaturwissenschaftliche Analyse von Exodus 2,23-5,5. 402 Seiten. 1980.

Bd. 33 OTHMAR KEEL: Das Böcklein in der Milch seiner Mutter und Verwandtes. Im Lichte eines altorientalischen Bildmotivs. 163 Seiten, 141 Abbildungen. 1980. 